\title{
BIOLOGICAI CHEMISTR
}

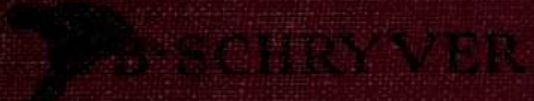




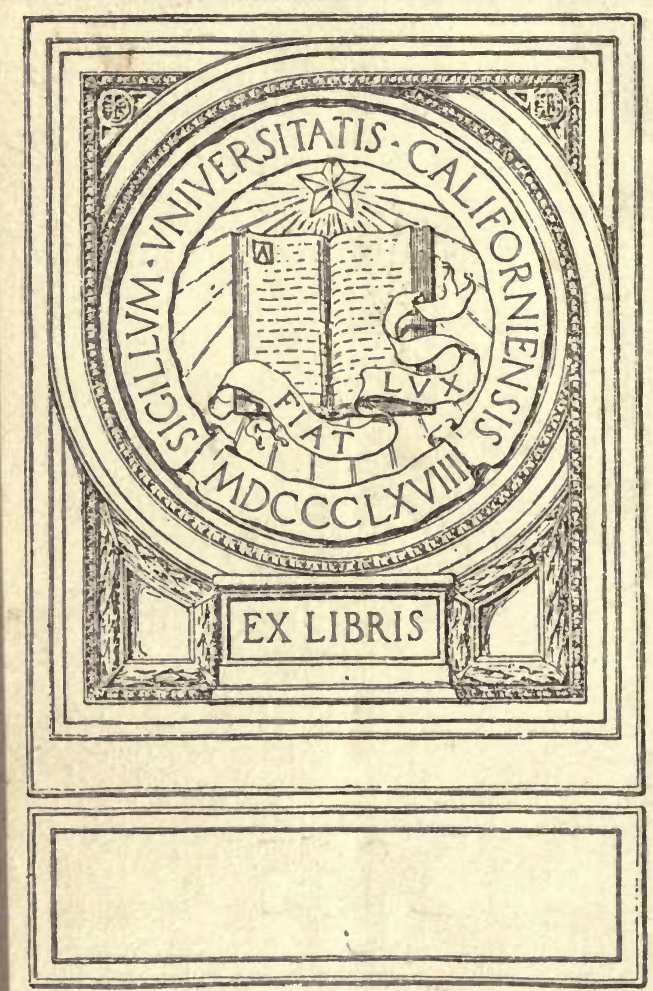




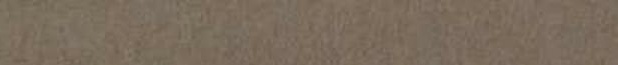

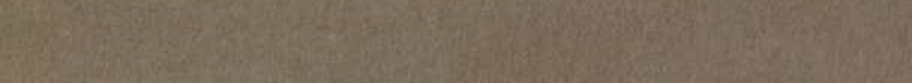
(9) Nis 3. S A

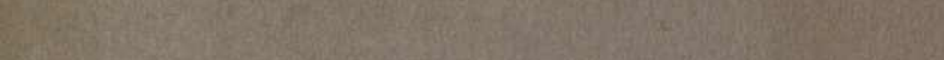

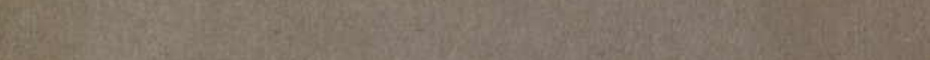

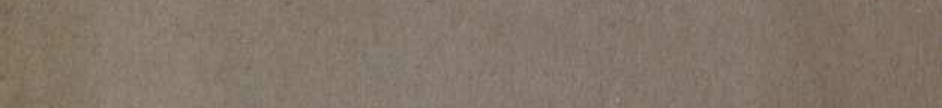

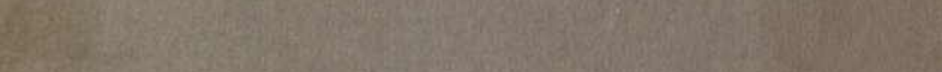

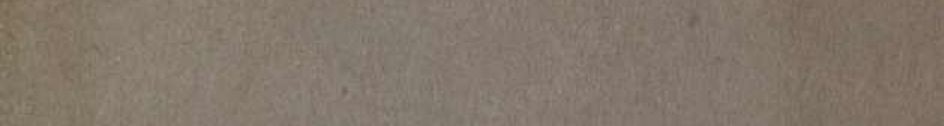

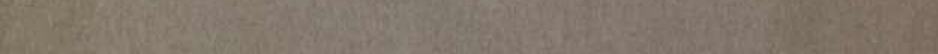
(2) -

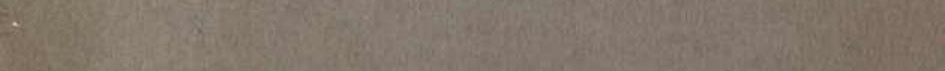

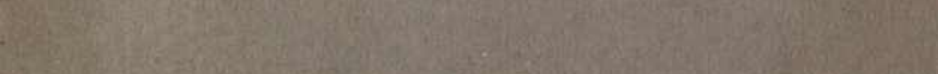

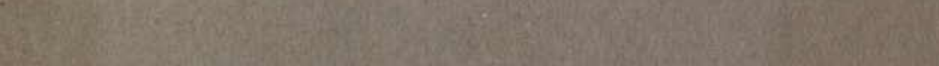

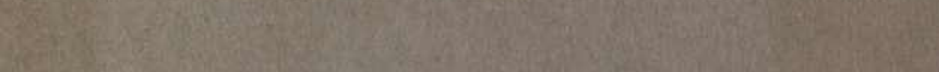

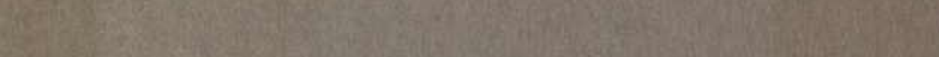

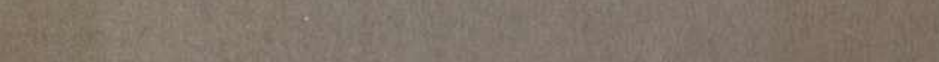

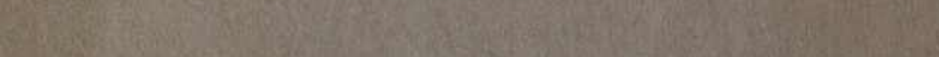
Then

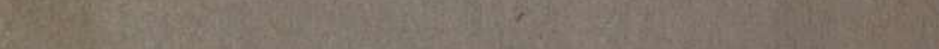
W. thit 20.7.

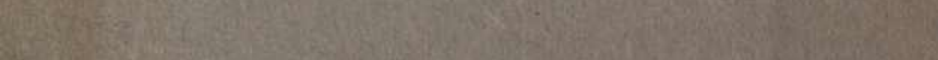
Ne a. if Q6.

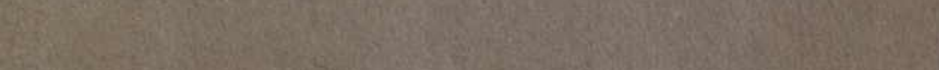

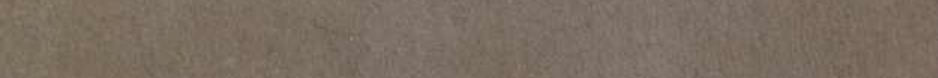

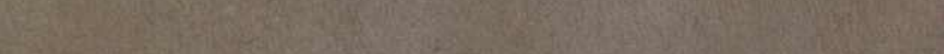

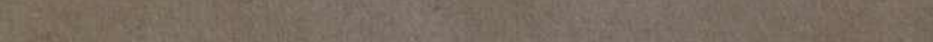

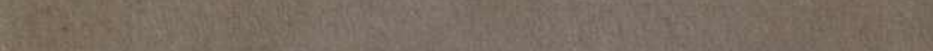

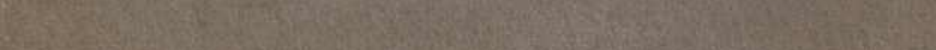
Fing 
48

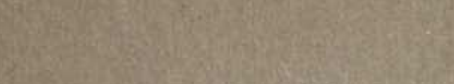

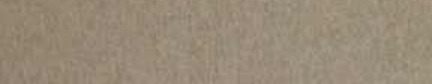

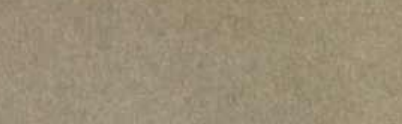

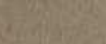

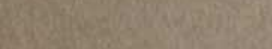

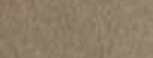

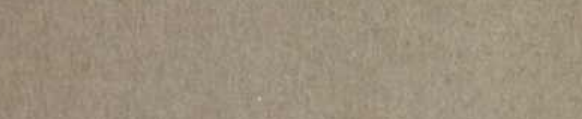

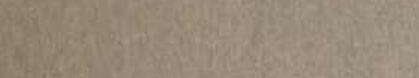

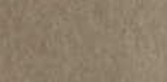

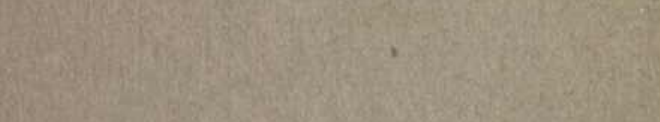

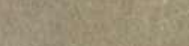
203

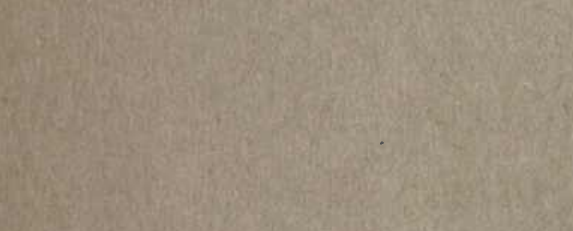

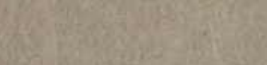

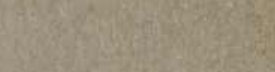

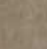

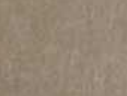

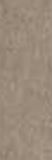
ines

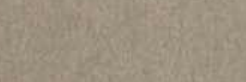
2fing

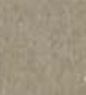
$y_{10} x^{2}=2$ $\sin ^{2} \sin ^{2}$ antert X.5 6390 tox

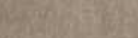 \\ fit in}

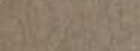

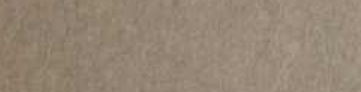

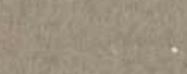

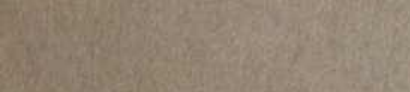




\section{BIOLOGICAL CHEMISTRY}





\section{AN INTRODUCTION TO THE STUDY OF \\ B I O LOG I CA L \\ CHE M I ST.R Y}

BY

S. B. SCHRYVER, D.Sc. (LoNd.)

ASSISTANT PROFESSOR IN THE IMPERIAL COLLEGE OF SCIENCE AND TECHNOLOGY

LONDON: T. C. \& E. C. JACK, LtD. 35 PATERNOSTER ROW, E.C. AND EDINBURGH 


$$
\begin{gathered}
\text { QD } 415 \\
\text { S4 }
\end{gathered}
$$




\section{P R E F A C E}

In the following pages no attempt has been made to deal with more than one part of the study of biological chemistry-namely, that concerned with the structure of materials of which the bodies of living objects are composed. In many parts this book does not differ markedly from an elementary text-book on organic chemistry. Certain subjects, however-such as, for example, the aromatic derivatives-have been dealt with very briefly, whereas the treatment of other subjects-such as the carbohydrates and proteins, which are of great importance to the physiologist-has been expanded beyond the limits which are usual in an elementary text-book. Furthermore, an attempt has been made to indicate the methods by means of which the branch of chemical science known as organic chemistry may be applied to biological research.

It is hoped that a book in this form may, when the study of it is supplemented by practical exercises carried out in the laboratory, prove of use to students of medicine and of biology generally.

Other branches of biochemical investigation can only be studied satisfactorily by those who possess a good fundamental knowledge of physical chemistry; the discussion of them has been entirely omitted from this book. 


\section{O N T E N TS}

CHAP.

I. THE GENERAL SCOPE OF BIOCHEMICAL STUDY • • 7

II. THE IDENTIFICATION AND ANALYSIS OF ORGANIC

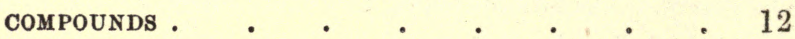

III. THE "CONSTITUTION," OR "STRUCTURE," OF SOME OF THE SIMPLER ORGANIC COMPOUNDS . . . 46

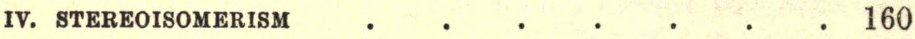

v. THE CHIEF CHEMICAL CONSTITUENTS OF THE ANIMAL

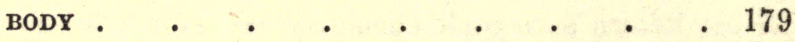

VI. THE METHODS EMPLOYED FOR INVESTIGATION OF CHEMICAL CHANGES WITHIN THE ANIMAL ORGANISM 266

vil. THE CHEMICAL PROCESSES TAKING PLACE IN PLANTS • 319

Many of the engravings of apparatus are taken by permission from the catalogue of Messrs. Tatlock \& Baird (London), Ltd., 14 Cross Street, Hatton Garden, E.C. 


\section{AN INTRODUCTION TO THE STUDY OF BIOLOGICAL CHEMISTRY}

\section{CHAPTER I.}

THE GENERAL SCOPE OF BIOCHEMICAL STUDY.

TTHE study of biological chemistry, which comprises the 1 systematic investigation of the chemical processes which take place within living objects, is of comparatively recent origin. Up to nearly the end of the eighteenth century, the standard text-book of chemistry most usually referred to was one by Nicolas Léméry, entitled " Cours de Chymie,". originally published in 1675 . In this book the subject of chemistry is subdivided into three parts, dealing respectively with the composition of animal, vegetable, and mineral substances. During the last quarter of the eighteenth century chemical studies received a considerable stimulus from important researches published by a number of distinguished investigators, who succeeded in isolating in a pure state several substances from both plants and animals. Products of this character were shown by Lavoisier (1743-1794) to contain carbon, hydrogen, and generally oxygen, and to possess the property of charring when heated and giving rise to volatile products of decomposition, in which respect they differed markedly from substances of mineral origin. From this time 
onwarde the bidder division of chemistry into the three branches ceased; substances were thereafter divided into two groups, according to whether they were of mineral or "inorganic" origin or of "organic" origin. This subdivision of substances was reflected in the science of chemistry itself, which came to be divided into two main branches, namely, mineralogical or inorganic chemistry and organic chemistry; or, as the latter was defined by Gerhardt in 1844, the chemistry of carbon compounds. This dual subdivision has been further justified by the fact that many organic substances can be derived from both animals and plants, and that where a substance exists only in one kingdom, it generally has a chemical analogue existing in the other.

It is not possible within the limits of this book to follow in any detail the history of the study of organic chemistry during the early years of its development. Its main function came to be recognized as the determination of the "structure" of the various carbon compounds-that is, the relative arrangement in space to one another of the various atoms of which the molecule is composed. Students of organic chemistry concentrated their attention on the various compounds themselves without any reference to their mode of formation in nature; in fact, it was at first generally held that products derived from animals or vegetables owed their formation to some peculiar "vital" process and could not be artificially produced by any laboratory process, and in this respect they were supposed to differ from the inorganic or mineral compounds of which many "syntheses" had been accomplished. The lines of demarcation between vital and non-vital and organic and inorganic compounds were broken down in 1828, when Wöhler published his synthesis of urea, a substance which had been obtained hitherto only from the 


\section{General Scope of Biochemical Study.}

urine of animals (by Fourcroy and Vauquelin in 1799), and was regarded as a typical product of vital origin; this was actually obtained from materials which had been hitherto regarded as inorganic. The discovery of Wöhler was not immediately followed up by many other artificial constructions of organic substances, but in the later developments of organic chemistry the "synthetical" method has proved the most useful one in the determination of the structure or constitution of organic compounds.

It can be readily understood that a knowledge of the structure of plant and animal products was necessary before any real advance could be made in the study of the methods by means of which such substances could be formed or utilized by living objects. A great pioneer in this branch of investigation was Liebig, who, by the publication of three great works, created an epoch in the study of biological chemistry. The three works in question were entitled, "Chemistry in its Application to Agriculture and Physiology," 1840 ; "Animal or Organic Chemistry in its Application to Physiology and Pathology," 184.2 ; and "The Chemical Processes in the Nutrition of Vegetables and the Natural Laws of Tillage," 1862.*

From the foregoing remarks it will be observed that there are three stages in the biochemical study of any given substance. In the first place, it is necessary to isolate it in a state of purity and unmixed with other substances from the animal or plant in which it has been produced; in the second place, its chemical structure or "constitution" must be determined; and in the third place, the method by means of which it is built up or broken down in the organism must be investigated. The process of change of chemical substances in the organism

* English translations are given of the original German titles. 
is known as metabolism, the building-up process, or formation of a complex from simpler substances, being described as one of anabolism, and the reverse or degrading process as one of katabolism. Where these proceed in a normal manner, the organism is stated to be acting physiologically; but where deviations from the norm occur, a pathological condition results, which may lead to a well-marked disease or even the death of the organism. A knowledge of biological chemistry is therefore essential for a satisfactory study of the functions of the organism, and the modern physiologist has endeavoured not only to elucidate the chemical changes produced on living objects as a whole, but also to ascertain the particular organs which are concerned in any given chemical change.

In addition to the carbon (organic) compounds, animal or vegetable bodies contain also certain amounts of mineral matter, the presence of which can be demonstrated when the organisms are burnt. When the combustion is complete, the carbon is oxidized to carbon dioxide, and the hydrogen to water, and the presence of the inorganic matter is then revealed by the fact that a residue of incombustible mineral matter (" ash") always remains. Part of this forms an essential constituent of certain tissues; thus, bones contain calcium phosphate, the red-blood corpuscles of animals contain iron, and the green chloroplasts of plants contain magnesium, and the iron and magnesium in the two latter cases are found in a state of stable combination with carbon compounds, and both elements are essential for the normal development of the organisms which contain them.

Apart, however, from the mineral matter which forms an essential constituent of the tissues, the bodies of plants and animals contain certain quantities of salts, which do not appear to enter into any form of combination with 


\section{General Scope of Biochemical Study. II}

organic substance. The elements of which these salts are composed appear to be indispensable for the life of the organism, and must be administered with the food. Their exact functions have not yet been ascertained, but they appear markedly to influence the physical characters of the tissues. The latter are composed of biological units, or " cells," which function normally only when they possess a certain physical structure and maintain a definite state of aggregation, and there is no doubt that the inorganic salts play an important rôle in the preservation of this state. The study of problems dealing with factors of this kind is, however, still in its infancy, and it is not possible to discuss them in an elementary treatise of this character, except in a very cursory manner. It must not be forgotten, however, that such problems exist, and that their study forms an important branch of biological chemistry, which is bound, in the near future, to lead to important practical results.

As bodies of living objects are made up chiefly of organic substances, the main part of this book will be devoted to their consideration. It is proposed, in the first place, to devote a certain number of chapters to the methods of examining these substances and determining their structure. A short account will follow of some typical methods for the investigation of metabolism, and of ascertaining the normal chemical functions of individual organs. 


\section{CHAPTER II.}

\section{THE IDENTIFICATION AND ANALYSIS OF ORGANIC COMPOUNDS.}

THE bodies of plants and animals are composed for the most part of highly complex substances, the structures of which, even after several decades of investigations, have not yet been elucidated in a perfectly satisfactory manner. The chief reason for the delay in acquiring a more complete knowledge of such complex substances lies, apart from the fact of their complexity, in the circumstance that no definite criteria of their purity exists, and the investigator is often at a loss to know whether the product in his hands is a chemical entity or a mixture of different substances. As the first stage in the investigation of an organic substance is the determination of its exact chemical composition, it follows that the product submitted to chemical analysis should be perfectly pure and free from all contaminating admixtures. Now although it is often impossible to attain such a standard of purity in the case of very complex substances, it is generally possible, by means of some chemical process, to degrade them into simpler products, which can be readily obtained in a pure state, and of which the chemical constitution, or structure, can be determined. By a knowledge, then, of the nature of the chemical process by means of which the degradation has been brought about, and by a knowledge, furthermore, 


\section{Identification of Organic Compounds. I 3}

of the constitution of its degradation products, it is often possible to obtain an approximately correct idea of the chemical architecture of a complex substance. With such an approximation, in the present state of development of chemical technique, the investigator must often remain content.

From the foregoing remarks it is obvious that it is essential to study, in the first instance, the methods by means of which the simpler organic compounds can be isolated in a state of purity and their chemical composition and constitution determined.

\section{The Preparation of Pure Products and the Criteria of Purity.}

\section{(a) SOLID SUBSTANCES.}

The more complex substances which are found in living objects are, for the most part, amorphous - that is to say, they possess no definite crystalline structures. They can also be heated until they char and decompose without showing any definite "melting point." In these respects they differ markedly from the simpler derived products. The latter can generally be dissolved in some liquid heated to its boiling point, from which, on cooling, they will separate in a crystalline form, provided that the degree of saturation in the hot liquid is sufficiently great. This process of "crystallization" is very often employed for the purpose of purification, for if the substance originally dissolved in the hot solvent is not perfectly pure, the contaminating substances will often remain in the "mother liquors" on cooling, and the chief product will separate out in a purer state in crystalline form when the hot solution is cooled. Even after this process the crystals may not be those of a perfectly pure substance; in this case a second recrystallization will result in the production 


\section{Biological Chemistry.}

of a purer product, and the process must be repeated until a sample is obtained which exhibits all the properties of a homogeneous substance. By a process of fractional crystallization it is often possible to separate two substances which are soluble in the same solvent. The less soluble substance will separate first, whilst the more soluble will remain in the mother liquors; these on evaporation will yield a further crop of crystals, which again, on recrystallization, can be either partially or wholly separated into two products. By systematically carrying out a process of "fractional crystallization" it is often possible to separate a mixture into its various components. Such a separation is, however, seldom complete and quantitative, although it is often possible to obtain by this method samples of the substances sufficiently pure for analysis and complete identification. A more satisfactory method of separation of pure substances from a mixture consists in treating the latter with a solvent in which only one of the constituents is soluble. Thus, for example, if a mixture of common salt and malonic acid is treated with ether, only the acid will dissolve. On evaporating off the ether, the malonic acid will be obtained free from admixture with the salt. By such means a quantitative separation can be accomplished.

The process of separating one substance from another by the employment of a liquid in which only one is soluble, can also be applied to a solution of a mixture. Thus, if the above mixture of sodium chloride and malonic acid is dissolved in water, and the aqueous solution is shaken with ether, the aqueous and ethereal layers will, on standing, separate into two phases, the upper one consisting of moist ether and the lower one of water in which a small amount of ether is dissolved. If, now, these layers be separated in a "separating funnel" (see illustration, 


\section{Identification of Organic Compounds. I 5}

Fig. 1), the ethereal layer will be found to have dissolved a large part of the malonic acid, from which it will separate on evaporation, whilst the sodium chloride will remain in the aqueous layer. By repeating the extraction of the aqueous layer with fresh quantities of ether, practically the whole of the malonic acid can be removed. On evaporation of the aqueous solution after repeated extraction with ether, the salt can be obtained practically free from malonic acid. The malonic acid and salt separated in the above manner can be finally purified by the process of recrystallization.

The next question which arises is, How can it be definitely ascertained whether a given product obtained by any of the processes de-

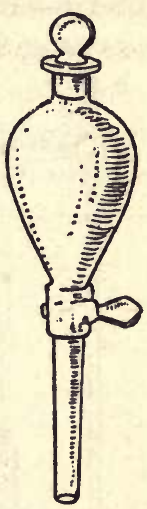

Fig. 1. scribed above is a chemical entity free from any admixture? Now it has already been stated that the majority of the simpler organic compounds melt when heated, and this melting takes place at a certain definite temperature, known as the "melting point." A small admixture of a foreign organic substance will tend to alter very appreciably (generally to lower) this melting point. Furthermore, with a pure substance, the melting point must be sudden; at a given temperature the whole sample melts to a homogeneous mass, and if on raising the temperature after the greater part has melted, unmolten crystals can still be observed, this will indicate that a mixture is present. When a substance is perfectly pure and homogeneous, it should not only melt sharply at a given point, but the melting point should show no alteration after the substance has been recrystallized from a suitable solvent. The melting point is usually determined by placing a small amount of the sample in the lower end 
of a capillary tube (which may be sealed at either one or both ends). The capillary tube is then fastened to a thermometer by means of an india-rubber band, and the lower ends of the two are then immersed in a liquid such

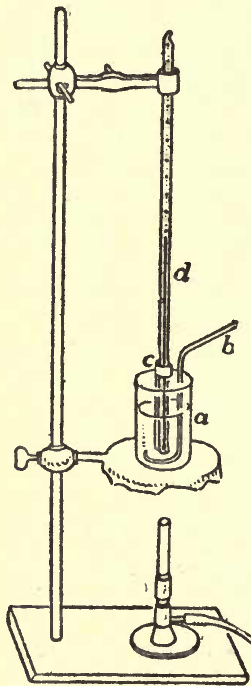

Fig. 2. as a high boiling paraffin or sulphuric acid contained in a beaker or small bulb of about 50 c.c. capacity (see illustration, Fig. 2). The liquid is then slowly warmed and stirred, whilst the substance in the capillary tube, which should be close to the mercury reservoir of the thermometer, is care-. fully watched. As soon as it melts, the temperature indicated by the thermometer is noted. If the liquid is not too rapidly heated, a pure substance should melt within the interval indicated by one degree of the thermometer.

Although the majority of the simpler organic substances possess a definite melting point, there are some which do not melt, or of which the melting point is not a very characteristic constant. In these cases, it is usually possible to prepare by a simple process a derivative which can be more readily characterized.

\section{(b) LIQUid SUBSTANCES.}

Just as the melting point is the chief criterion of purity employed for solid substances, the boiling point is the constant which usually serves to characterize liquids.

To determine this a liquid is placed in a flask (see illustration, Fig. 3) with a side tube ("fractionating" flask), and 
a thermometer is inserted in the neck so that the reservoir is just level with the side tube, which is then connected with one end of a condensing tube, placed at such an angle that the liquid, after vaporizing and condensing, readily flows out at the other. In the case of liquids of low boiling point, it is necessary to surround the condensing tube with an outer tube, through which a stream of cold water continuously circulates; * but with less volatile

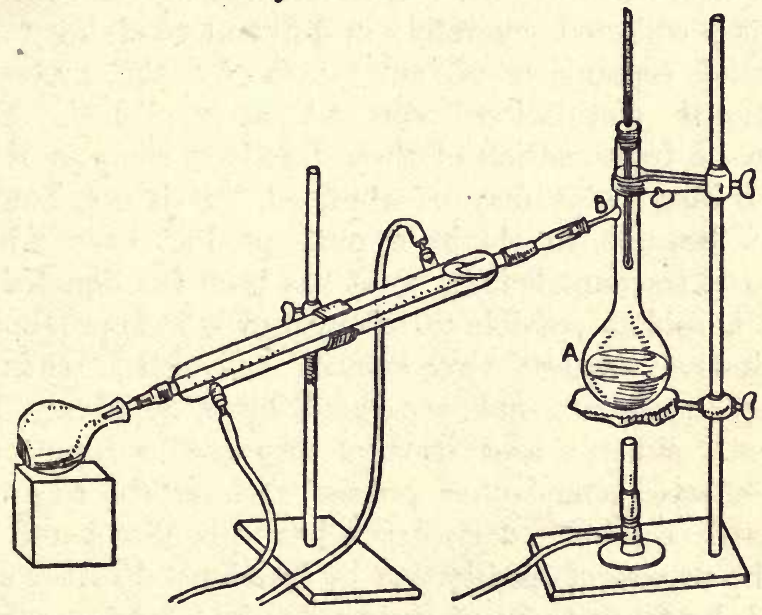

Fig. 3.

substances (substances with higher boiling points) this is unnecessary, and a simple "air condenser" is sufficient. If, now, the liquid in the fractionating flask is heated, a point may be reached at which it will boil, and the vapour will condense and flow out through the lower end of the condensing tube, and may be collected in a suitable vessel used as a receiver. When a pure liquid is being distilled in this way, the thermometer will indicate a constant

*Various forms of condensers, some with "double surface" condensing systems, will be found in the catalogues of apparatus manufacturers. 
temperature throughout the whole process of distillation. The temperature indicated will be the boiling point of the substance at the particular atmospheric pressure under which the liquid is distilled. When, however, the liquid consists of a mixture of substances of different boiling points, this constancy of temperature will not be maintained. If the fractions of the liquid which come over within the different intervals indicated by the thermometer are collected separately in different receiving vessels, a partial separation of substances by the process of "fractional distillation" can be accomplished. By a systematic fractionation of these fractions, samples of constant boiling point may be obtained. It is not, however, always possible to obtain a pure product even when a sample of constant boiling point has been fractionated out; and it is seldom possible to separate, even in approximately quantitative manner, two volatile substances when the boiling points are not separated by a relatively large interval. When a separation of two such substances has to be effected, some other process, such as the conversion into easily separable derivatives, has to be discovered.

The process of purification by fractional distillation has proved, however, to be of great value in a large number of cases, especially when a given substance has only small amounts of admixed impurities, such as the brown colouring matters which are so often formed during chemical operations.

It is, of course, essential, when the process of fractional distillation is employed for purification of a substance, that the latter should distil without decomposition. Many substances, however, which decompose on distillation under ordinary atmospheric pressure, can be distilled at lower temperatures and without change under diminished pressure. The process of distillation in vacuo is often 


\section{Identification of Organic Compounds. 19}

employed, and the adjoined figure (Fig. 4) illustrates an apparatus employed for this purpose. This particular form was employed by Professor Emil Fischer for separating derivatives of protein degradation products, to which more detailed reference will be made later. In this case it was found necessary to distil under very low pressures $(0.5 \mathrm{~mm}$. of mercury or even less) to avoid decomposition. The liquid to be distilled is placed in the flask $a$, with a special form of side tube containing the thermometer, and the various fractions are connected in receivers, one of

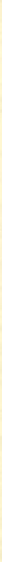

which, $d$, is illustrated. The triangular glass-piece with taps, $c$, is so devised that the receiver $d$ can be opened to the air and disconnected from the remainder of the apparatus without interrupting appreciably the course of the distillation; a new receiver for collecting a different fraction can then be put in its place. The lower vacuum required is maintained by a power-driven double Geryk pump, between which and the distillation apparatus a receiver, $e$, cooled with liquid air, $g$, in a Dewar flask, $f$, is interposed to prevent any vapours entering the pump. 
The pressure in the apparatus is indicated by a manometer, $m$, and the very low pressures (under $1 \mathrm{~mm}$.) by a MacLeod gauge $(p, o, n)$. $^{*}$ It is not, of course, always necessary to fractionate under such low pressures. Ordinarily, fractionation under $10-12 \mathrm{~mm}$. pressure is sufficient, and in this case the usual laboratory Bunsen water-pump can be employed. The apparatus can then be simplified, in that the pressure can be determined by the ordinary manometer, and a vapour-trap cooled with liquid air is unnecessary. The boiling point of a liquid will vary with the pressure under which distillation takes place; this constant, therefore, should never be cited unless the pressure is given at the same time. When a substance is distilled under ordinary atmospheric pressure, the height of the barometer, as read at the time, should also be noted.

Certain substances, which are solid at ordinary temperatures, can also be purified by distillation, and these generally melt before boiling. Other solid substances can be vaporized without melting (such as iodine), and purified in this way. This is known as the process of sublimation; in this process the vapours are allowed to come into contact with a cooled surface, and the substance is condensed in a crystalline form.

A more complete separation can often be effected by distilling through a long column or still head, examples of which are illustrated (Fig. 5). When this is used the vapour of the less volatile substance is being continually condensed and falling back into the distillation flask, whilst the more volatile product passes over.

Certain substances will not distil without decomposition even under the lowest pressures. Various resinous products come under this category, and they are often not to

* For description of this gauge reference should be made to text-books on Physics. 


\section{Identification of Organic Compounds. 2 I}

be obtained in a state of chemical purity, and their chemical nature can only be approximately ascertained by the examination of their degradation products.

Other substances, on the other hand, are gaseous at ordinary atmospheric temperatures. Under high pressures, and with low temperatures, these substances can now all be

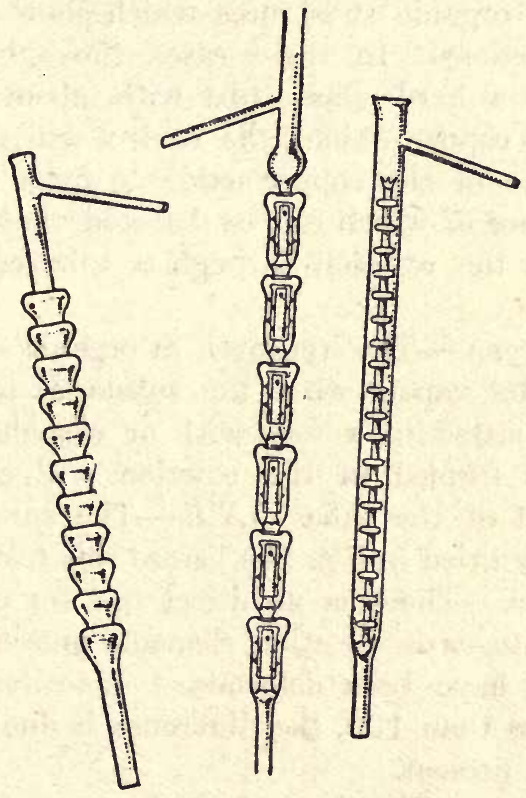

Fig. 5.

obtained in a liquid state, and by means of special apparatus fractionally distilled. As, however, it is seldom necessary in biochemical investigation to effect a separation and purification of substances which are under ordinary condition gases, the methods need not be referred to in greater detail in this place. 


\section{Qualitative Analysis of Organic Compounds.}

Carbon.-This is a constituent of all organic com. pounds, and its existence is readily revealed by the fact that the majority of organic substances blacken on heating, or when treated with concentrated sulphuric acid. There are a few organic substances which show neither of the above reactions. In these cases, the substance may be heated in a hard glass tube with about ten times its weight of copper oxide; the carbon will then unite with the oxygen of the copper oxide to form carbon dioxide, the presence of which can be detected by leading the gas formed in the reaction through a tube containing limewater.

Hydrogen.-The hydrogen in organic substances gives rise to water vapour when the substance is burnt; if the latter is heated in a tube with or without copper oxide, the steam formed in the reaction will condense in the upper part of the tube. (N.B.-The substance must be thoroughly dried (see p. 25) before this test is applied.)

Oxygen.-There is no direct test for oxygen. When the percentages of the other elements present in an organic compound have been determined quantitatively, and the total is less than 100, the difference is due to the amount of oxygen present.

Nitrogen.-This is an important constituent of plant and animal bodies; in most cases its presence can be detected by heating the substance with soda-lime (about ten times its weight), when ammonia is evolved, and can be recognized by the smell. This test is not, however, always decisive. In such a case, a small amount of the substance is gently warmed with a clean piece of sodium or potassium in a test-tube; the metal first melts and is thus brought into intimate contact with the organic substance. The 


\section{Identification of Organic Compounds.}

mixture is then heated to a higher temperature. Whilst the test-tube is still hot, the lower end is plunged under cold water and thus splintered; the water then acts on the excess of metal. The alkaline solution is then filtered off from the excess of carbonaceous matter, and a few drops of ferrous sulphate are added; after warming for a few moments, the liquid is acidified, and a drop of ferric chloride is added. The formation of a bluish-green colour, or of a Prussian blue precipitate, indicates the presence of nitrogen. This test depends on the formation, in the first instance, of sodium cyanide, which reacts with the ferrous salt in alkaline solution to form a ferrocyanide, which with ferric salts gives the well-known Prussian blue reaction.

The Halogens.-These substances cannot be detected directly in the majority of cases by silver nitrate. The simplest test is to heat the substance with a little sodium, as in the case of the nitrogen reaction given above, and after getting rid of the excess of metal by water, to acidify the liquid with nitric acid and to add silver nitrate. In this reaction the halogens combine with sodium to form the sodium halide salt. Cyanides also give the same reaction.

Sulphur.-The substance is mixed with several times its weight of a mixture of potassium nitrate and sodium carbonate $\left(2 \mathrm{KNO}_{3}+\mathrm{Na}_{2} \mathrm{CO}_{3}\right)$ in a crucible. The heating should be very gentle at first, but the temperature is afterwards raised until the mixture fuses. The sulphur is thereby oxidized to sulphate, which can be detected by extracting the fused mass with water, acidifying with nitric acid, and adding barium chloride.

Phosphorus. - The substance is heated in a small flask with a mixture of equal volumes of concentrated sulphuric and nitric acids (in a fume cupboard). The heat is applied 
gently at first, but the temperature is afterwards raised, and the mixture is warmed until it is colourless; water is then added, and the mixture is boiled for a few minutes until nitrous fumes cease to be evolved. A few drops of fifty per cent. ammonium nitrate solution are then added to the cooled solution, and then a few drops of ten per cent. ammonium molybdate solution. In the event of the presence of phosphorus in the substance a yellow precipitate of ammonium phosphomolybdate will form, especially if the mixture is gently warmed.

Metals.-Attention has already been called (p. 10) to the fact that certain plant and animal products contain metals in a state of chemical combination. Such substances on ignition are not entirely destroyed, but an "ash" is always left, which may be investigated by the ordinary methods of qualitative inorganic analysis.

\section{Quantitative Organic Analysis.}

To Lavoisier must be ascribed the merit of having recognized that organic substances on burning give rise to carbon dioxide and water, the carbon being, on complete oxidation, converted into the former substance, and the hydrogen into the latter; by estimating the amounts of these products formed from a given weight of a substance, the amount of carbon and hydrogen can be calculated. The technique as employed by Lavoisier was, however, cumbersome, and it was not until Liebig, in 1830, published his methods of analysis that the composition of organic compounds could be determined as an ordinary routine process of research. These methods, with certain not very essential modifications of detail, have remained in vogue up to the present day; and the method described below, which is due to Dennstedt, is founded on the process 
Identification of Organic Compounds. 25

first employed by Liebig. With the certainty of being able to ascertain with accuracy and readiness the composition of a compound, the progress of organic chemistry made rapid advances.

\section{NECESSARY PRELIMINARY PRECAUTIONS.}

It cannot be too often reiterated that it is generally useless to submit a product to quantitative analysis until the investigator has satisfied himself as to its purity and freedom from admixture with other substances. Two criteria of purity, namely, melting and boiling points, have already been discussed in some detail. It happens, however, that solid substances, even when they exhibit a sharp melting point, often contain appreciable quantities of the solvent from which they have been recrystallized, which is sometimes combined with them in molecular proportions in the form of solvent of crystallization. It is usual to eliminate this before submitting a substance to analysis, or determining finally its melting point. The solvent-free substance will usually have a different melting point to that containing solvent of crystallization (which is often quite a definite one, and does not alter on recrystallization from that solvent), and the fact as to whether the latter is absent or present should always be stated when a melting point is given.

The adhering solvent can be eliminated in various ways. Often a substance can be obtained quite solvent free on keeping in air; more often it is necessary to eliminate the solvent by heating (to volatilize it) the substance, or by keeping it in vacuo (especially when the substance decomposes readily) over some material, such as concentrated sulphuric acid, which readily combines with the vapour. In other cases, when the solvent is 
held firmly bound to the substance, the latter must be heated in vacuo in the presence of absorbing material to effect complete elimination of the solvent. Whatever

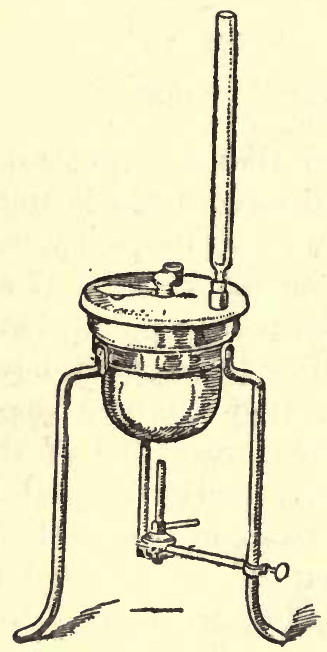

Fig. 6. treatment is adopted, it is necessary that it should be continued until the substance no longer loses weight.

Illustrations are appended of three types of apparatus which are usually employed for eliminating the solvent. The first of these (Fig. 6) is the so-called Victor Meyer bath, a double-walled vessel, containing in the outer jacket a liquid of known boiling point, which is kept in a state of constant ebullition, and is condensed in a tube (either jacketed with water or not, according to the boiling point of the liquid used and the length of the tube) fitting into the outer jacket. The inside of the vessel is thereby kept at constant temperature. For eliminating water from a substance, toluene (boiling point about $110^{\circ}$ ) is usually employed.

The second form of apparatus (Fig. 7) is the ordinary vacuum "desiccator," which is generally evacuated by connecting with a Bunsen water pump and manometer to ascertain the pressure. The lower part of the apparatus is filled with a liquid to absorb the vapour of the solvent.

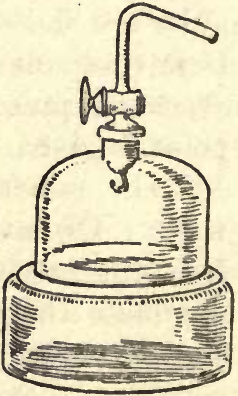

Fig. 7.

The third form of apparatus (Fig. 8) is devised for elimi- 


\section{Identification of Organic Compounds.}

nating a solvent in vacuo at higher temperatures. The flask $a$ contains a liquid of constant boiling point, which maintains the interior of the apparatus at constant temperature $\left(100^{\circ}\right.$ with water, $110^{\circ}$ with toluene, etc.). The vapour of the boiling solvent circulates round an inner tube $b$, and is continually condensed in the condenser $c$, and flows back into $a$. Into $b$ is inserted, by means of a cork fitting into a prolongation of the outer tube, a third tube connected with a retortshaped vessel, $d$, by means of a ground-glass joint. This is provided with a side piece and a stop-cock, through which it can be connected with a vacuum pump and manometer, and

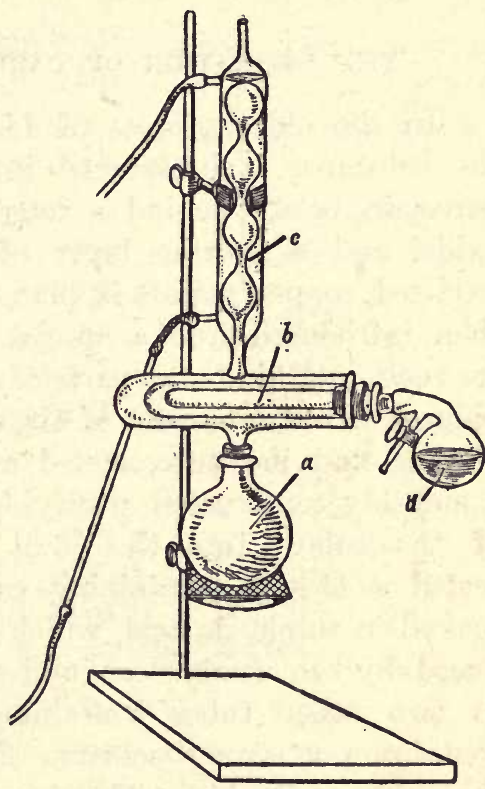

Fig. 8. when the innermost part of the apparatus has been sufficiently evacuated (as determined by the manometer) the stop-cock can be closed. The vessel $d$ contains the absorbing substance, which, when water is to be eliminated from the substance under examination, is usually phosphorus pentoxide. Other substances, such as sulphuric acid, can be used when organic solvents are to be absorbed. The method of employing this apparatus should be obvious from the above description.

The substance, in whichever form of apparatus it is dried, is kept during the operation in tubes or small 
flasks with ground stoppers made to fit tightly, which are inserted during the weighings.

\section{THE ESTIMATION OF CARBON AND HYDROGEN.}

In the older process of Liebig, a weighed amount of the substance is introduced into a long glass tube in a porcelain boat,* behind a long layer of granular copper oxide, and a shorter layer of the oxide (generally an oxidized copper spiral) is placed behind it. The tube is then introduced into a special form of furnace, and the foremost and hindmost parts of the tube are heated to dull redness, whilst a current of air, carefully freed from carbon dioxide and moisture, is led at a uniform rate through a suitably constructed purifying apparatus into the back of the tube. Into the front part of the tube is inserted a $U$ tube containing calcium chloride or pumice soaked in sulphuric acid, which absorbs the moisture produced by the combustion, and this is joined on in series to two other tubes containing soda-lime, or to bulbs containing a strong solution of caustic potash to absorb the carbon dioxide. These various tubes or bulbs are weighed both before and after the combustion, and their gain in weight indicates the amount of water and carbon dioxide formed by the oxidation of the substance. As soon as the copper oxide before and behind the substance has attained a dull red heat, the substance itself may be heated; it then gradually decomposes and chars. The temperature is then gradually raised, and the final stages of the combustion are now usually completed in a current of oxygen instead of air. Air is finally led through the tube until all the pure oxygen is displaced, and all the products of combustion have been passed through the

* Or in a small glass bulb if the substance is a liquid. 


\section{Identification of Organic Compounds. 29}

drying tube. During the process the copper oxide is partially reduced to copper, which is reoxidized during the passage of oxygen.

This process consists essentially in the oxidation of all the carbon to carbon dioxide, and of all the hydrogen to water, and the amounts of these products formed from a given weight of substance are weighed.

In the more modern method due to Dennstedt, the copper oxide is dispensed with, but the substance is burnt in a current of oxygen instead of air, and the combustion is promoted by the presence of a "contact substance"* made from platinized quartz, or from platinum itself, which promotes the oxidation of the volatile substances produced when the organic substance is charred (see Fig. 9). A form of furnace simpler than the older Liebig

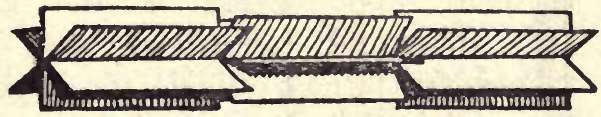

Fig. 9.

apparatus can be employed when this process is used. The method is illustrated by the accompanying figures. The oxygen is passed from the gasholder B (Fig. 10) by displacement of water contained in the bottle $\mathrm{A}$, both of which have a content of about five litres, through a purifying tower, containing in the bottom concentrated sulphuric acid, and in the upper part of the tower, first, a layer of soda-lime, and above this a layer of calcium chloride. In this way it can be completely freed from moisture and carbon dioxide. Three special burners are employed, one for heating the substance; a second, for the platinum star; and a third, consisting of a number of small jets, for the front part of the tube. The weighed

* The action of substances which act catalytically will be discussed later. 


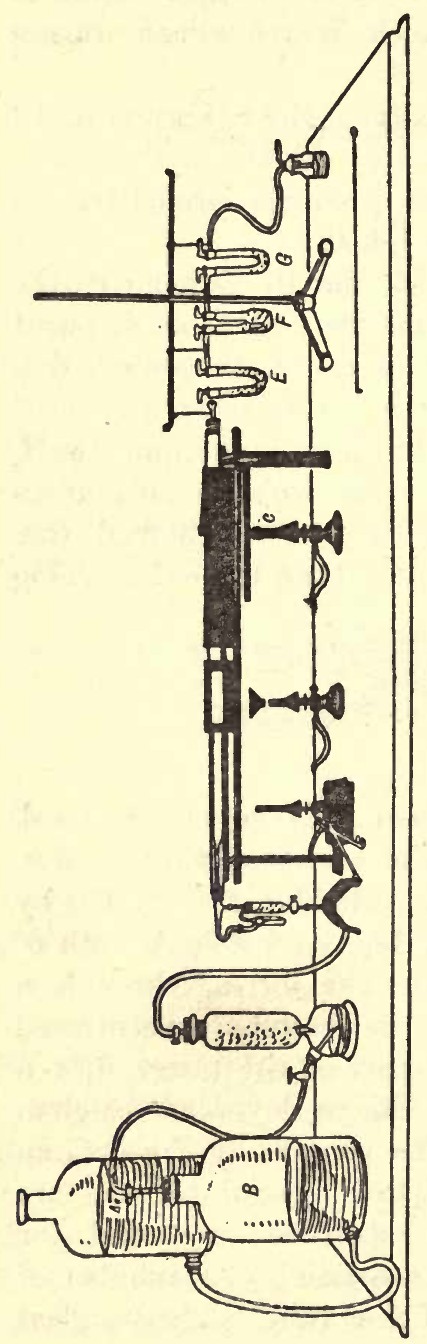

amount of substance to be combusted (usually about 0.2 grm.) is introduced into the long tube behind the platinum star in a porcelain boat, or (in the case of a liquid) in a glass bulb, which is introduced into a tube, one end of which is drawn out into a capillary which fits into a wider tube which passes through the cork (see Fig. 11). The last-named tube is connected with a specially constructed apparatus, interpolated between it and the drying tower, the object of which is $\stackrel{0}{*}$ to divide the oxygen current into two streams. The smaller stream passes through the capillary, and comes into direct contact with the substance, whereas the greater stream passes on the outside of the tube into which the substance has been inserted, and mixes with the products of combustion. The water formed is collected in the $U$ tube $E$, and the carbon dioxide in the vessels $\mathrm{F}$, containing sodalime, and $\mathrm{G}$, containing in the first limb soda-lime and in the second calcium chloride 


\section{Identification of Organic Compounds. 3 I}

These various tubes are weighed both before and after the combustion, and from their gains in weight the hydrogen and carbon content of the substance are determined.

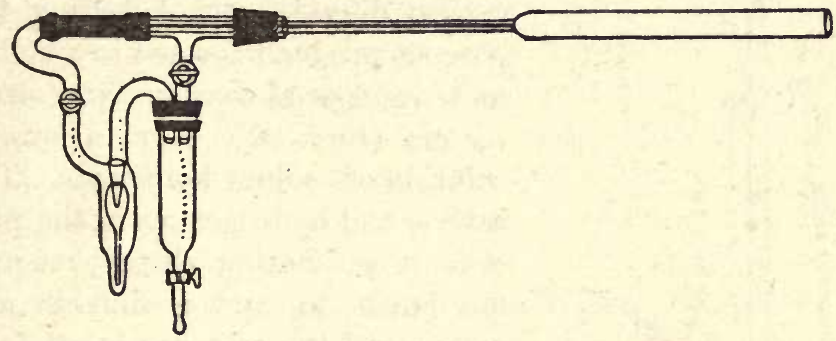

Fig. 11.

There are various modifications of the above method; and several precautions must be taken, such as the complete expulsion of all moisture and carbon dioxide from the tube before analysis, to obtain correct results. These can, however, only be learnt by direct experience, and it is not possible in this place to give more than a general outline of the method.

When the substance contains nitrogen, oxides of nitrogen will be formed, which will be retained by the soda-lime, and lead thus to an incorrect result in the carbon determination. To avoid this, it is usual to insert a boat containing lead peroxide in the front part of the tube (over burner $c$ ), to decompose the oxides. This substance will also retain sulphur and the halogens, which may be quantitatively estimated afterwards. The nitrogen will be retained in the form of lead nitrate, and the sulphur as lead sulphate.

\section{ESTIMATION OF NITROGEN.}

Two methods can be employed for the estimation of this element. 
(a) The Method of Dumas.-The principle of this method consists in burning the substance in contact with

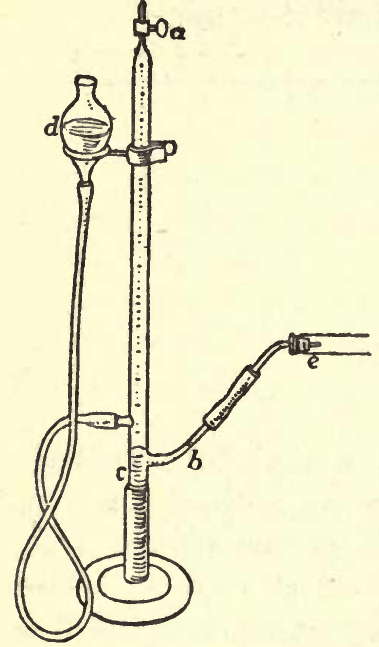

Fig. 12. copper oxide in a stream of dry carbon dioxide, and collecting the gaseous products formed in a eudiometer of special construction (nitrometer) (Fig. 12) over a strong solution of sodium hydroxide. The carbon and hydrogen, as in the process of estimating these elements, are burnt to carbon dioxide and water, and the nitrogen is set free, or oxidized to oxides, which latter can be decomposed by hot copper; the nitrogen thus formed is carried forward with the stream of carbon dioxide into the nitrometer, and there measured, the latter gas being absorbed by the alkali.

The form of combustion tube and furnace is similar to that employed for the estimation * of carbon and hydrogen. Into the front part of the combustion tube is introduced a spiral of bright copper to decompose the oxides of nitrogen; behind this follows a long layer of granular copper oxide, and behind this is the weighed amount of substance mixed with copper oxide, $c$ (again about $0.2 \mathrm{grm}$. is generally employed), and behind this again is a roll of oxidized copper,

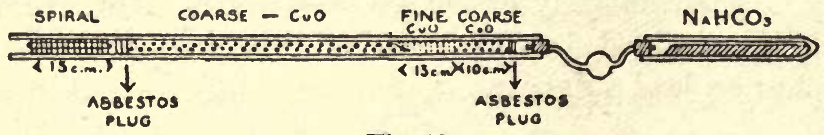

Fig. 13.

or coarse copper oxide (see Fig. 13). The carbon dioxide is

* The Dennstedt furnace may also be employed, in which case copper oxide is not used. The older method is here described. 


\section{Identification of Organic Compounds.}

prepared in a hard glass tube by heating sodium hydrogen carbonate. The front part of the combustion tube is connected with the nitrometer. All parts of the combustion tube, except that in the immediate neighbourhood of the substance mixed with copper oxide, are heated whilst a stream of carbon dioxide is led through. The nitrometer is previously filled with the solution of caustic soda which absorbs the carbon dioxide which passes through. When all the gas which collects in the nitrometer is absorbed, a fact which indicates that no more air is left in the apparatus, the nitrometer is filled up with alkaline solution by raising the funnel $d$, the slight excess of alkali being driven through the $\operatorname{tap} a$, which is then closed. In this way the air which has collected is expelled from the nitrometer. If, now, the copper oxide is sufficiently hot (a dull red heat), the actual combustion of the substance may be commenced by lighting the burner under that part of the tube in which it is contained. The burning is complete when the volume of gas in the nitrometer no longer shows any increase. After it has stood for some time to attain the atmospheric temperature, the level of the alkaline liquid in the reservoir is brought to that of the liquid in the graduated measuring tube, and the volume is read. The height of the barometer and temperature are noted, and the volume is then corrected for normal pressure and temperature $(760 \mathrm{~mm}$. and $0^{\circ} \mathrm{C}$.).

(b) The Method of Kjeldahl.-This method has not such a wide application as the previous one, as in the case of a few substances incorrect results are obtained. It is, however, of considerable value in biological chemistry, as the nitrogen of that important class of compounds, the proteins, is readily determined by this process. Owing to its simplicity, and the small amount of labour involved in the analyses, it is to be preferred to the Dumas method 
wherever it is applicable. It has the further advantage in that several analyses can be carried out at the same time. It depends upon the principle that when a nitrogenous organic substance is incinerated with concentrated sulphuric acid, the nitrogen is reduced to ammonia, which combines with the acid to form ammonium sulphate. On adding excess of alkali to the incineration mixture, the ammonia is set free, and the amount formed can be estimated by distilling it off into an excess of standard acid, which excess can afterwards be determined by titration with standard alkali.

The amount of substance to be taken for analysis will vary with its nitrogen content. When this is small, relatively large amounts should be incinerated to obtain correct results, but usually not more than 1 gramme is necessary even for nitrogen-poor products. The weighed amount is introduced into a round-bottomed flask with some water and about 10 c.c. of concentrated sulphuric acid. The mixture is heated, gently at first, but afterwards more vigorously, and the operation is continued until, at a high temperature, the contents of the flask are colourless (that is, contain no more organic matter). Care must be taken not to allow the liquid completely to evaporate; if too much of the liquid has disappeared before incineration is complete, more acid (another 10 c.c.) must be added after the contents of the flask have been allowed partially to cool. At the completion of the destruction of the organic matter, the contents of the flask are diluted with about 200 c.c. water, and then 40 per cent. sodium hydroxide solution (600 c.c. for each 10 c.c. sulphuric acid used) is added. The ammonia set free is then distilled off into standard acid. The apparatus employed for this purpose (when six analyses are carried out at once) is illustrated (Fig. 14), the standard acid being 


\section{Identification of Organic Compounds. 35}

introduced into the conical (Erlenmeyer) flasks. Generally 50 c.c. of tenth-normal sulphuric acid should be used, and the excess not neutralized by ammonia is estimated after the completion of the distillation by titration with tenth-

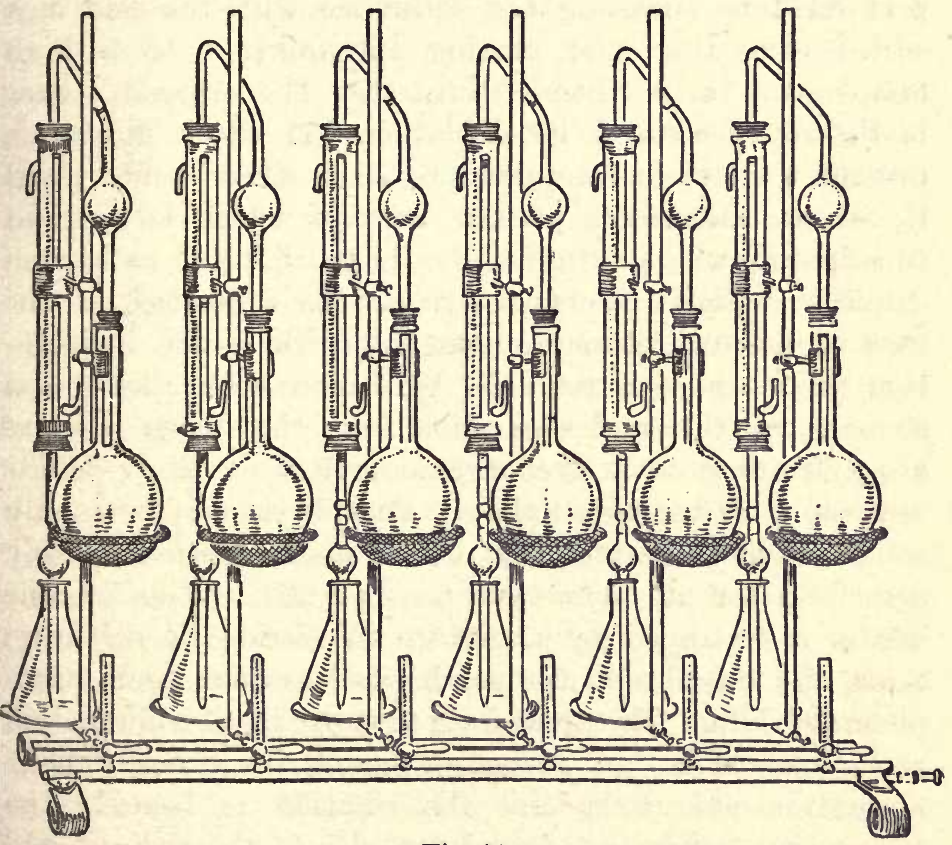

Fig. 14.

normal sodium hydroxide with the use of sodium alizarine sulphate or dialyzed litmus or any other convenient indicator. Each c.c. of decinormal acid neutralized by the ammonia is equivalent to $1.4 \mathrm{mg}$. of nitrogen.

ESTIMATION OF OTHER ELEMENTS IN ORGANIC COMPOUNDS.

There are various methods of estimating chlorine, bromine, iodine, phosphorus, and sulphur in organic com- 
pounds which need not be considered here in any very great detail. The most general method consists in treating the substance with nitric acid at high temperatures with excess of the acid. This operation is generally performed by enclosing the substance with the acid in a sealed glass tube and heating the mixture to a high temperature in a "bomb" furnace. The organic matter is thereby destroyed by oxidation. If silver nitrate is present, the halogens are precipitated as silver halides; and if barium chloride is present, sulphur which is oxidized to sulphuric acid in the reaction is precipitated as barium sulphate. These elements can also be estimated, in the case of non-volatile substances, by various dry incineration processes-for example, by fusion with alkalis and sodium peroxide and separation from the fusion mixture after destruction of the organic matter as silver halide compounds or barium sulphate. Phosphorus may be readily estimated quantitatively by the use of the method already described for its detection (see p. 23). The organic matter is destroyed by a mixture of nitric and sulphuric acids, and the phosphorus precipitated as ammonium phosphomolybdate. The precipitate thus produced is filtered off and dissolved in an excess of standard (generally halfnormal) caustic soda and the solution is heated; the ammonium salt is thereby converted into the sodium salt, and the ammonia is volatilized. The excess of standard alkali is then determined by titration with standard acid (1 c.c. $\mathrm{N} / 2$ sodium hydroxide used up is equivalent to $1.268 \mathrm{mg}$. phosphorus). This method is known as Neumann's wet-ashing process.*

* This method does not always yield correct results. It is better to dissolve the yellow phosphomolybdate precipitate in ammonia, and then to reprecipitate the phosphate by magnesia mixture and continue the estimation in the ordinary manner. 


\section{The Molecular Weight of Compounds.}

In the earlier stages of the development of organic chemistry it was considered an axiom that substances of the same composition should possess the same chemical properties. In 1825, however, Faraday discovered a hydrocarbon in oil gas, which contained the same percentage of carbon and hydrogen as ethylene gas. It was therefore obvious that the mere determination of the relative proportions of the various elements present in a compound was not sufficient for its complete characterization. By means of analysis the relative but not the absolute number of atoms present in a compound can be ascertained. Thus, for example, a substance of the formula $\mathrm{C}_{2} \mathrm{H}_{4}$ would contain the same percentage of carbon and hydrogen as a compound of the formula $\mathrm{C}_{5} \mathrm{H}_{10}$ or $\mathrm{C}_{6} \mathrm{H}_{12}$. It was not, however, until about 1840-1845 that the true significance of molecular weight was recognized and an older generalization of Avogadro was revived by Gerhardt and Laurent and applied to organic compounds. According to Avogadro, all volumes of gases under the same conditions of temperature and pressure contain the same number of molecules; the vapour of a substance of the formula $\mathrm{C}_{5} \mathrm{H}_{10}$ will, therefore, be heavier than that of a substance $\mathrm{C}_{2} \mathrm{H}_{4}$. It is possible, then, directly to determine the molecular weight of any substance which can be obtained in a volatile form without decomposition, by determining the density of its vapour.

Determination of the Molecular Weight of Volatile Substances. - Various forms of apparatus can be employed for this purpose, but the one most commonly used is that suggested by Victor Meyer, which is figured in the adjoining sketch (Fig. 14a). A long narrow tube $a$, with a reservoir at the bottom of the general form of a 
barometer tube, but widened at the top and provided with a side tube $d$, and a stopper $f$, is immersed in an outer jacket $b$, to which at the bottom a bulb $c$ is blown. "Into

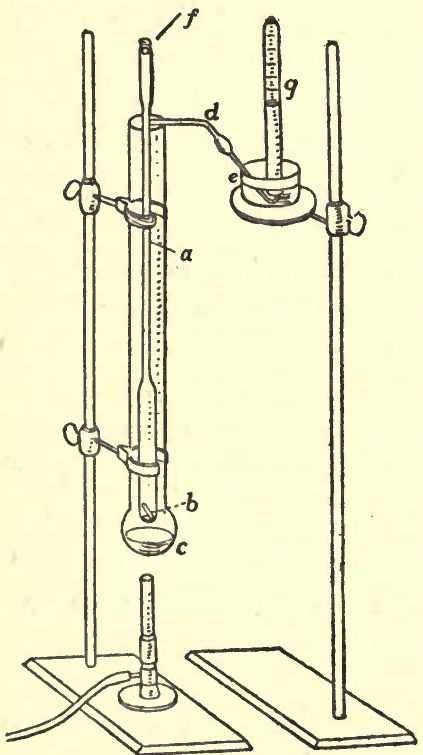

Fig. 14a. this is introduced a liquid which boils at a higher temperature than the liquid the molecular weight of which is to be determined. (The boiling point should not be less than about $25^{\circ}$ higher.) The side tube $d$ is connected with a eudiometer tube $g$ standing over water. The liquid in $c$ is boiled and heats the air contained in the inner tube $a$. As soon as the volume is constant, a fact which is indicated by the constancy of volume of air in the eudiometer tube $g$, the latter is filled with water. The stopper is then momentarily removed from the inner tube $a$, into which is rapidly introduced a weighed quantity of the liquid under investigation (about 0.05 gramme), contained in a small bottle or bulb which it completely fills. This falls to the bottom of $a$, which contains at the bottom some glass or cotton wool to break the fall, and the liquid immediately vaporizes. In doing so it displaces a certain amount of air in $a$, which enters the eudiomete tube $g$. The volume of air collected in this tube corresponds with the volume of the vapour measured at the temperature of the air in tube $g$, and under the barometric pressure prevailing at the time of the experiment. The volume to which this amount would correspond at $0^{\circ}$ and 


\section{Identification of Organic Compounds.}

$760^{\circ}$ must then be calculated. If $t^{\circ}$ is the temperature of the air, and $\beta$ the barometric pressure, and $\mathrm{T}$ the vapour tension of aqueous vapour at $t^{\circ}$, then if $v$ is the volume read directly in the eudiometer tube, $v_{0}$ the corrected volume $=v \cdot \frac{273}{273+t^{\circ}} \times \frac{\beta-T}{760}$. Now the weight of the corresponding volume of hydrogen is known (22.4 litres weigh 2 grammes). If the weight of substance taken is divided by this amount, the vapour density of the substance (taking that of hydrogen as $=1$ ) is obtained. From Avogadro's hypothesis the molecular weight should be twice the vapour density.

The Molecular Weight of Substances which cannot be volatilized without Decomposition.-When a substance is dissolved in any liquid the freezing points of the latter are lowered and the boiling points raised, and it has been found that the amount of change thus produced is a function of the molecular weight of the dissolved substance. By the determinations, therefore, of these changes produced by solution of a known weight of a given substance in a liquid, the molecular weight of the former can be calculated. It is not possible to enter into the theory of the phenomena (which was worked out fully by van't Hoff); it must be noted, however, that according to this theory, correct molecular weight determinations are only to be expected when the depressions in freezing points and raising of boiling points produced by dissolving relatively small amounts of substance in the liquid are measured. In carrying out the measurement of the depression of freezing points, which was first applied to molecular weight determinations by Raoult, and known as the cryoscopic method, an apparatus devised by Beckmann is generally employed. As the actual depression to be measured is, in practice, small, a special form of thermo- 
meter must be employed, which is graduated in hundredths of a degree centigrade. The interval of a degree indicated on the thermometer scale must therefore be a long one. By means of this thermometer, which is perhaps the most essential feature of the Beckmann apparatus, the freezing point of a given weight of a pure solvent, and of the same after solution of a known weight of a solvent, can be determined. The difference between the two determinations gives the depression of the freezing point. The same form of thermometer is used and similar principles are applied in the determination of the elevation of the boiling point.

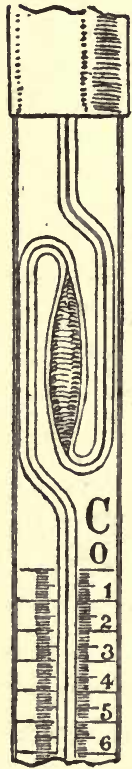

Fig. 15.

The Beckmann thermometer is devised not for the measurement of actual temperatures, but rather for the measurement of differences. Although the instrument is a long one, the whole range indicated on the scale is not more than $6^{\circ}$. In order to use such an instrument over a large range of temperatures, the thermometer is constructed in a special manner. The mercury is contained in a large bulb which terminates in a very fine capillary tube attached to the scale. At the upper end of the scale, this capillary is widened out into a reservoir (see illustration, Fig. 15). If the bulb of the thermometer is warmed, the mercury can be made to rise through the capillary in a continuous column until it reaches the reservoir. By giving the instrument a sharp tap, the column of mercury in the reservoir can be broken and part of the metal will fall to the bottom and thus be separated from the remainder. In this way the amount of mercury in the continuous column from the bulb to capillary can be diminished. It is also possible to increase the amount of 


\section{Identification of Organic Compounds. 4I}

mercury in the continuous column, namely, by warming until the column again reaches the reservoir, and then inverting the instrument, so that part of the mercury contained in the lower part of the reservoir can be made to join the continuous column. By altering the amount of mercury in this, it is possible, therefore, to so adjust the instrument that the top of the column occupies a convenient position on the scale over the range of temperatures at which any particular series of measurements are to be made. It is possible to construct an instrument which can be employed for determinations of both boiling and freezing points (ranging from below zero to above $106^{\circ}$ ), although the range indicated on the scale does not much exceed $6^{\circ}$. It is generally, however, advisable to use a single thermometer over a relatively small range of temperature.

The actual apparatus for measurement of freezing points is illustrated in the accompanying illustration (Fig. 16). A weighed amount of the liquid is introduced into a widemouthed test-tube $\mathrm{A}$, with a side tube $\mathrm{A}^{\prime}$. Into this is introduced the

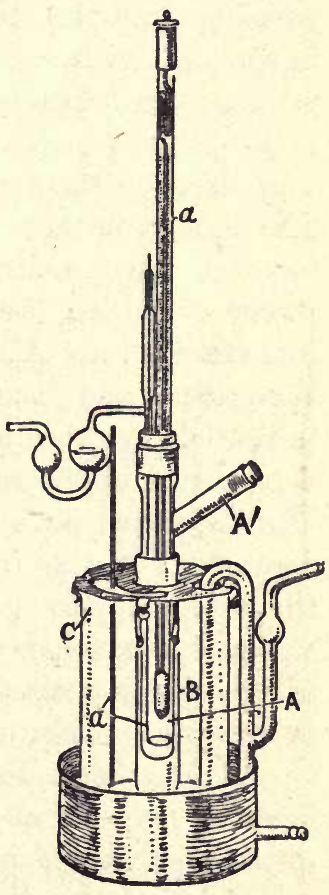

Fig. 16.

Beckmann thermometer $a$, and a small stirrer $a^{\prime}$ (the bottom of which is usually made from a fairly stout piece of platinum wire bent into a loop), both of which are inserted into a cork. The vessel A is itself inserted, by means of a cork at a point below the junction of its side tube, into a wide tube $B$, which serves as an 
air chamber. This again is contained in a thick glass vessel C, which is provided with a stout stirrer (generally of aluminium) and a metal top. A freezing mixture (ice and salt) is introduced into this outer vessel, which is well stirred. The liquid in A can then be supercooled without freezing, and its temperature will sink. If, now, it is inoculated with a crystal (in the case of water, a crystal of ice), the supercooled liquid will freeze, and the thermometer will rise to a given point and remain constant. The point on the scale at which this happens is then noted. The tube $\mathrm{A}$ is then removed from the apparatus and the liquid is then melted, and a weighed amount of the substance of which the molecular weight is required is then introduced into $\mathrm{A}^{\prime}$. The tube is then replaced in the apparatus, and the melting point of the solution as indicated on the arbitrary thermometric scale is then determined in the same way as that of the pure solvent. The difference between the two measured points gives the depression of the freezing point due to a given weight of the solvent. To get accurate results with this method, various precautions must be taken, and a certain amount of practice is necessary. The principle only of the method is indicated in the above description.

It has been found now that the depression of the freezing point of any given solvent produced by dissolving another substance in it is proportional to the number of molecules of the dissolved substance (solute). Equimolecular proportions of different substances will, therefore, always produce the same amount of depression of freezing point for a given solvent. This amount will vary with different solvents. It is possible now to calculate what this depression should (theoretically) be, when one gramme molecule of a substance (that is to say, the same number of grammes as the molecular weight of the substance) is 


\section{Identification of Organic Compounds.}

dissolved in 100 grammes of a liquid, from the determination of the depression of the freezing point of any given solution of a substance of known molecular weight. Suppose the solute taken is glucose, which has the formula $\mathrm{C}_{6} \mathrm{H}_{12} \mathrm{O}_{6}$, and the solvent is water. Now the molecular weight of glucose is 342 (that is, $6 \times 12+12 \times 1+6 \times 16$ ). Suppose, furthermore, that 0.6 gramme of the substance when dissolved in 100 c.c. produces a depression of $0.035^{\circ}$. Then the depression produced by dissolving 342 grammes in 100 c.c. should (theoretically) be $0.035 \times \frac{342}{0.6}, 19.9^{\circ}$. This number is the so-called "molecular depression" of a substance; it is a constant for every given solvent which can always be determined experimentally by ascertaining the depression of freezing point of that solvent produced by dissolving in it a given (not too large) amount of a substance of known molecular weight. When the molecular depression, $k$, of a solvent has once been determined, it can be used for the estimation of molecular weights of other substances which dissolve in it.* The method of calculation is very simple, for if $d^{\circ}$ be the depression produced when $w$ grammes of a solute are dissolved in $W$ grammes of the solvent, and $m=$ the molecular weight of the solute, then $m=k \frac{w}{d W} \times 100$.

The method employed for measuring the elevation of a boiling point of a solvent by a dissolved substance is very similar. Many forms of apparatus have been employed, one of which is illustrated in the accompanying figure (Fig. 17). The solvent in weighed amount $(w)$ is introduced into a tube A, with a side tube carrying a condenser. The Beckmann thermometer is inserted into the mouth of the tube A,

* There are certain exceptions, especially when water is employed. Salts give anomalous molecular depressions when dissolved in water. 
and glass beads are introduced through the side tube till the bulb of the thermometer is nearly covered. Tube A is then inserted into a jacket of special form (B, see illustration), which also carries a side tube for the insertion of a condenser; into this jacket some of the solvent is introduced. The whole is then placed on an asbestos place

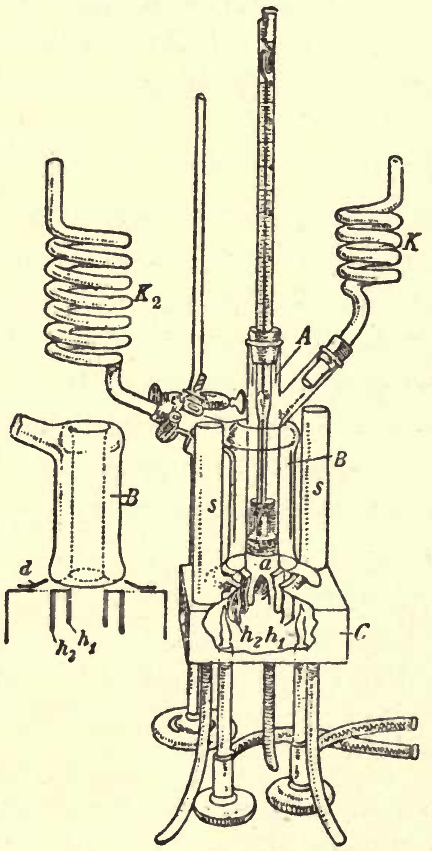

Fig. 17.

carrying funnels, and is gradually heated by Bunsen burners, which are not placed directly below the glass apparatus. The object of the glass beads and jacket $B$ is to ensure regular ebullition and to prevent loss of heat by radiation. After the liquid has been in a state of regular ebullition for about five minutes, the position of the 


\section{Identification of Organic Compounds. 45}

mercury on the thermometer scale is noted. The condenser of the tube $\mathrm{A}$ is then removed, a weighed amount of the substance $(w)$ under investigation (compressed, when a solid, into a pastille) is added through the side tube, and the condenser is then rapidly replaced. The solution of this substance will raise the boiling point of the solvent (after a momentary fall), and the mercury in the column will finally rise. As soon as its position has become constant, it is noted. The difference between this and that of the pure solvent will give the elevation of the boiling point $e$ produced by dissolving $W$ grammes of the substance under investigation in $w$ grammes of solvent. If $k$ is the molecular elevation of the solvent (that is, the theoretical rise produced when a gramme molecular equivalent of a substance is dissolved in 100 grammes of the solvent, as calculated by measuring the rise produced by the solution of a given weight of a solute of known molecular weight in a given weight of the solvent), then $m$, the molecular weight, can be calculated from the formula-

$$
m=k \cdot \frac{w}{e \cdot W} \times 100
$$




\section{CHAPTER III.}

THE “ COnstitution," OR "STRUCture," of some of the SIMPLER ORGANIC COMPOUNDS.

\section{Introduction.}

IN the foregoing chapter the methods of ascertaining the composition of a given organic compound have been discussed, and it has been shown that analytical results alone are not sufficient for the determination of its correct formula, for different substances may contain the same relative proportions of constituent elements and yet differ from one another in their molecular complexity. The axiom that substances of the same composition should possess the same chemical propcrties was completely overthrown, and methods of fixing with certainty the true formulæ of organic substances were gradually established. It was found, finally, that by the determination of molecular weights, in addition to that of the composition of a substance, its correct formula could be definitely fixed.

The question which next arises is the following: Are all substances with the same chemical composition and of the same molecular complexity identical? Experience has shown that this question must be answered in the negative. As long ago as 1823 Liebig found that a substance, silver fulminate, prepared by him, was identical in chemical composition with, although totally different 
Structure of Simpler Organic Compounds.

in its properties from, a substance, silver cyanate, which had been described by Wöhler a year before. Somewhat later (in 1828), Wöhler himself succeeded in converting ammonium cyanate into urea, a substance with identical chemical composition, although widely differing in its properties. At the date at which these discoveries were made, it was not possible to determine the molecular complexity; but later researches have shown that substances in which this constant is the same, may differ widely from one another in chemical and physical properties. Thus, for example, three different substances are known to possess the simple formula $\mathrm{C}_{5} \mathrm{H}_{12}$, all of which have not only the same chemical composition, but also the same vapour density, and consequently the same molecular weight. Such substances are said to be isomeric with one another, and the individual members of the group are designated isomerides. It is now known that the differences between isomerides is due to differences in the relative arrangement of the atoms to one another, and the determination of this arrangement constitutes the chief problem of organic chemistry. It is one also of fundamental importance to the physiologist, for isomerides exhibit, as a rule, totally different reactions in the bodies of living organisms.

In the present chapter the relative arrangements of the atoms to one another in some of the simpler organic compounds will be discussed. Such an arrangement constitutes what is known as the "structure" of a compound, and is represented by a graphical method. It is not possible in this place to trace out the history of the evolution of this modern method of representing the structure (or "constitution") of organic substances; it will suffice to state that, although now firmly established, it was only reached after several decades of controversy, which was often 
bitter and personal in character, and in which several of the most distinguished chemists of the nineteenth century took a very prominent part.

\section{Part I. - The Chemistry of the Hydrocarbons.}

The simplest type, perhaps, of any organic compound is the gas known as methane, or marsh gas, which is found, as the name indicates, in marshes and other places where decay of vegetable matter is taking place. It is also an important constituent of the gases which issue from petroleum wells. It can be readily prepared also in the laboratory by heating together sodium or potassium acetate with (four times the weight of) soda-lime. The composition of the gas and its vapour density correspond with the formula $\mathrm{CH}_{4}$.

Now one of the fundamental conceptions upon which the principles of the chemistry of the carbon compounds have been built up is, that carbon is a tetrad or quadrivalent element-that is to say, it is an element which combines normally with four univalent elements, or two bivalent elements, or one bivalent element and two univalent elements, or with one trivalent and one univalent element, etc. If hydrogen is taken as a type of a univalent element, the conception of the valencies of elements may be illustrated by the formula of the following typical compounds :

$\mathrm{HCl}$

$$
\mathrm{H}_{2} \mathrm{O}
$$

$\mathrm{H}_{8} \mathrm{~N}$

Hydrochloric acid. Water. Ammonia. Marsh gas.

Hydrochloric acid. Water. Ammonia. Marsh gas.

$\mathrm{H}_{4} \mathrm{C}$

In these formulæo one, two, three, and four atoms respectively of hydrogen are combined with one atom of other elements ; these are typical uni-, bi-, ter- and quadri-valent elements. If these valencies are accepted as correct, it should be possible to form various carbon compounds con- 
Structure of Simpler Organic Compounds.

taining a single carbon atom united with these elements having such formulæ as the following:-
(1) $\mathrm{CH}_{3} \mathrm{Cl}$
(2) $\mathrm{CH}_{2} \mathrm{Cl}_{2}$
(3) $\mathrm{CHCl}_{3}$
(4) $\mathrm{CCl}_{4}$
(5) $\mathrm{CO}_{2}$
(6) $\mathrm{H}_{2} \mathrm{CO}$
(7) $\mathrm{HCN}$

Such substances are in fact known, and are designated (1) monochlormethane or methyl chloride, (2) dichlormethane, (3) trichlormethane or chloroform, (4) tetrachlormethane or carbon tetrachloride, (5) carbon dioxide, (6) formaldehyde, (7) hydrogen cyanide or prussic acid. In the first four compounds carbon is united to four univalent atoms (which need not all be of the same element); in the fifth, to two bivalent elements; in the sixth, to two univalent elements and one divalent element; and in the seventh, to one tervalent element and one univalent element. In all cases the sum of the valencies of the elements united with carbon is four, and the valencies themselves are deduced from the formulæ of simple compounds of the various elements with hydrogen.

These conceptions are usually indicated by a graphical method. A single line is used to indicate each unit of valency. Methane would thus be represented by the formula-

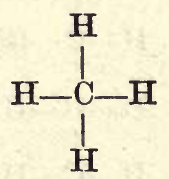

Carbon dioxide by the formula-

$$
\mathrm{O}=\mathrm{C}=\mathrm{O}
$$

(the bivalent element oxygen having its valency represented by two lines), and hydrogen cyanide by the formula-

$$
\mathrm{H}-\mathrm{C} \equiv \mathrm{N}
$$

In the above three cases, the hydrogen, oxygen, and $(1,997)$ 
nitrogen are represented as being "directly" united to a carbon atom. The other typical compounds containing only a single carbon atom, which have been mentioned above, can be graphically represented by the following formulæ-<smiles>O=CCC(Cl)(Cl)Cl</smiles>

The bonds or linkings, as the single lines in the above formulæ are called, may be conveniently replaced by dots, thus $\mathrm{O}: \mathrm{C}: \mathrm{O}, \mathrm{H} \cdot \mathrm{C}: \mathrm{N}$.

All the above examples are compounds containing only one carbon atom; but the conception of the quadrivalency of the carbon atom can also be applied to the representation of compounds containing more than one carbon atom.

Thus, if the following formulæ represent substances with respectively two, three or four carbon atoms, the quadrivalency of the carbon is still maintained.
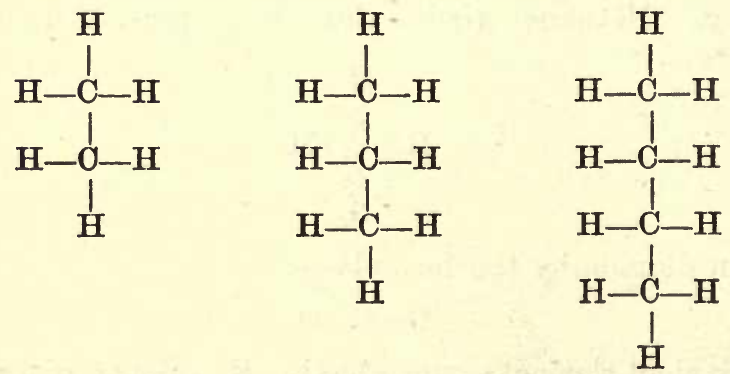

In formulæ such as these the carbon atoms are represented as being "directly united" to one another. Now it is possible to lengthen the "chain" of carbon atoms indefinitely and to represent structurally a series of com- 


\section{Structure of Simpler Organic Compounds. $5^{\text {I }}$}

pounds of this type containing one up to an infinite number of carbon atoms. All substances with structures of this type can be represented by the general formula $\mathrm{C}_{n} \mathrm{H}_{2 n+2}$. A large series of such substances is actually known; they are designated paraffins, and their chemical and physical properties will be considered in some detail later.

Now, in the formulæ of the hydrocarbons given above, it will be noticed that no carbon atom is directly bound to less than two hydrogen atoms, and all the carbon atoms are united to one another in a "straight" chain. When, however, compounds of this series contain four or more carbon atoms, it is possible to construct the formulæ in another way and to maintain still the quadrivalency of the carbon atom. Thus, it is possible to represent a hydrocarbon with four carbon atoms by the formula-

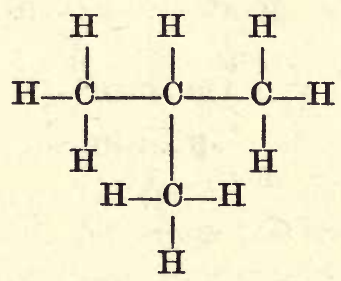

Both this formula and the one given above of a hydrocarbon with four carbon atoms represent a substance with the empirical formula $\mathrm{C}_{4} \mathrm{H}_{10}$. Now it has been found that two substances differing from one another in their properties actually exist, and are examples of what has been designated "isomerism" (see p. 47). The physical properties of the two "isomerides" are not identical, and the derivatives which can be obtained from them by various chemical reactions are different. The first formula given (that is, the "straight-chain" formula) represents the substance which is known as butane, and the second (or 
"branched-chain" formula) represents isobutane. There is a simpler way of representing the formula which still indicates the differences of structure in these compounds. Butane may be represented by the formula $\mathrm{CH}_{3} \cdot \mathrm{CH}_{2} \cdot \mathrm{CH}_{2} \cdot \mathrm{CH}_{3}$, or more simply still by the formula $\mathrm{CH}_{3}\left(\mathrm{CH}_{2}\right)_{2} \mathrm{CH}_{3}$, and the "iso"-compound by the formula $\mathrm{CH}\left(\mathrm{CH}_{3}\right)_{3}$. This latter formula is taken to represent the fact that one carbon atom is "united directly" to three other carbon atoms. It will be seen later that it is possible to determine experimentally the correct structural formula for each of these compounds.

The structural formulæ representing paraffin hydrocarbons with five carbon atoms of the empirical formula $\mathrm{C}_{5} \mathrm{H}_{12}$ (pentanes) are the following:-

(I.)<smiles>CCCC</smiles>

$\mathrm{CH}_{3} \cdot \mathrm{CH}_{2} \cdot \stackrel{\text { or }}{\mathrm{CH}_{2}} \cdot \mathrm{CH}_{2} \cdot \mathrm{CH}_{3} \quad \mathrm{CH}_{3} \geq \mathrm{CH} \cdot \mathrm{CH}_{2} \cdot \mathrm{CH}_{3}$

(II.)

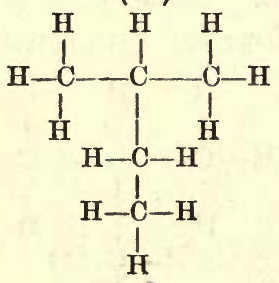

I. is called pentane, II. is called isopentane, and III. tetramethyl methane, which may be considered as a methane in which each hydrogen atom is replaced by four $\mathrm{CH}_{3}$ 's (or what are called, as will be explained later, methyl groups).

It is quite easy to see from the above examples, that the more complex it is, and the greater the number of carbon atoms a substance contains, the greater is the pos- 
sible number of isomerides. In the case of the paraffins with four carbon atoms, two isomerides exist, whereas in the case of these with five carbon atoms, three exist. When the formula reaches the complexity $\mathrm{C}_{13} \mathrm{H}_{23}$, it has been calculated that no less than 802 isomerides can exist.

\section{THE PARAFFIN HYDROCARBONS.}

A whole series of compounds is known, the composition of which may be represented by the general formula $\mathrm{C}_{n} \mathrm{H}_{2 n+2}$. These substances are found in large quantities in nature in petroleum or mineral naphtha. The lower members of the series are gaseous under ordinary atmospheric conditions of temperature and pressure, and can only be liquefied under high pressures and at low temperatures. The boiling points rise as the molecular complexity increases, and the highest members of the series are solid at ordinary temperatures (paraffin wax and ozokerite). It is difficult to separate the pure chemical individuals from the various natural oils which consist of a mixture of a large number of them. By a process of fractional distillation the crude oils can be separated into fractions to which various trade names are assigned. The gases can be collected separately as they issue from the earth and used for burning; the lower boiling liquid fractions are used for motor spirit, and are largely employed as solvents in the laboratory under the names of "light petroleum," "ligroin," " petroleum ether," etc.; a higher boiling liquid fraction is known as "kerosene," the fraction which is partly solid at ordinary temperature is known as "vaseline," whereas the fractions containing the highest hydrocarbons constitute the paraffin waxes, from which products of varying melting points can be obtained. 
The following is a list of some of the chief members of the series :-

\begin{tabular}{|c|c|c|c|}
\hline Methane, & $\mathrm{CH}_{4}$ & b.p. $-11^{\circ}$ & under 180 atmospheres. \\
\hline Ethane, & $\mathrm{C}_{2} \mathrm{H}_{6}$ & $",+4^{\circ}$ & " $46 \quad "$ \\
\hline Propane, & $\mathrm{C}_{3} \mathrm{H}_{8}$ &,$\quad-45^{\circ}$ & \\
\hline Butane, & $\mathrm{C}_{4} \mathrm{H}_{10}$ & $\Rightarrow \quad 0^{\circ}$ & \\
\hline Pentane, & $\mathrm{C}_{5} \mathrm{H}_{12}$ & $"+37^{\circ}$ & \\
\hline Hexane, & $\mathrm{C}_{6} \mathrm{H}_{14}$ & $\Rightarrow \quad 69^{\circ}$ & under ordinary atmospheric \\
\hline Heptane, & $\mathrm{C}_{7} \mathrm{H}_{16}$ & $98^{\circ}$ & pressure $(760 \mathrm{~mm})$. \\
\hline Octane, & $\mathrm{C}_{8} \mathrm{H}_{18}$ & $125 \cdot 5^{\circ}$ & \\
\hline Nonane, & $\mathrm{C}_{9} \mathrm{H}_{20}$ & $149 \cdot 5^{\circ}$ & \\
\hline Decane, & $\mathrm{C}_{10} \mathrm{H}_{22}$ & 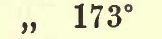 & \\
\hline
\end{tabular}

The above numbers refer to the "normal" or "straightchained" compounds.

The Preparation and Properties of the Paraffin Hydrocarbons.-It has already been stated that it is very difficult to isolate paraffin hydrocarbons in a pure condition from the complex mixture in which they are found native. They can, however, be readily prepared from the sodium salts of certain acids which are obtainable in a pure condition, either by synthesis or from natural sources, when these substances are distilled with soda-lime. The acids in question are known as the "fatty acids," and possess the general formula $\mathrm{C}_{n} \mathrm{H}_{2 n} \mathrm{O}_{2}$. As an example of this reaction, the preparation of methane from sodium acetate, the sodium salt of acetic acid, may be cited-

$$
\mathrm{C}_{2} \mathrm{H}_{3} \mathrm{O}_{2} \mathrm{Na}+\mathrm{NaOH}=\mathrm{CH}_{4}+\mathrm{Na}_{2} \mathrm{CO}_{3}
$$

In general, a hydrocarbon of the formula $\mathrm{C}_{n} \mathrm{H}_{2 n+2}$ may be obtained from acids of the formula $\mathrm{C}_{n+1} \mathrm{H}_{2 n+2} \mathrm{O}_{2}$, of which the sodium salt has the formula $\mathrm{C}_{n+1} \mathrm{H}_{2 n+1} \mathrm{O}_{2} \mathrm{Na}$. They can also be obtained synthetically by the treatment of the halogen derivatives with sodium or zinc. This synthetical method, which is of great historical importance, is due to Würtz. It may be illustrated by the 


\section{Structure of Simpler Organic Compounds. 55}

following examples. From methane it is possible to obtain a derivative, methyl bromide, by "substituting" * a hydrogen atom by bromine. If methyl bromide is treated with sodium, two molecules will react according to the equation-

$$
\mathrm{CH}_{3} \mathrm{Br}+\mathrm{CH}_{3} \mathrm{Br}+2 \mathrm{Na}=2 \mathrm{NaBr}+\mathrm{CH}_{3} \cdot \mathrm{CH}_{3}
$$

In this reaction, the halogen derivative of only one hydrocarbon is employed. It is possible to carry out the reaction, however, with mixtures of halogen derivatives of hydrocarbons; thus by treatment of bromo-derivatives of methane and ethane with sodium the following reaction is possible :

$$
\mathrm{CH}_{3} \mathrm{Br}+\mathrm{C}_{2} \mathrm{H}_{5} \mathrm{Br}+2 \mathrm{Na}=2 \mathrm{NaBr}+\mathrm{CH}_{3} \cdot \mathrm{C}_{2} \mathrm{H}_{5}
$$

In actual practice mixtures of $\mathrm{CH}_{3} \cdot \mathrm{CH}_{3}$ and $\mathrm{C}_{2} \mathrm{H}_{5} \cdot \mathrm{C}_{2} \mathrm{H}_{5}$ would be obtained. The method has only a limited practical application to chemical synthesis, as mixtures of hydrocarbons would be obtained when mixtures of halogen derivatives are employed. Nevertheless, it is of great theoretical importance, as it affords one of the simplest illustrations of building up or synthesis of more complex from less complex substances. The general equation representing the reaction may be given as follows:-

$$
\mathrm{C}_{n} \mathrm{H}_{2 n+1} \mathrm{X}+\mathrm{C}_{m} \mathrm{H}_{2 m+1} \mathrm{X}+2 \mathrm{Na}=2 \mathrm{NaX}+\mathrm{C}_{n} \mathrm{H}_{2 n+1} \cdot \mathrm{C}_{m} \mathrm{H}_{2 m+1} \dagger
$$

There are various other synthetical methods which need not be considered here.

The paraffins are generally very stable substances which are not readily destroyed, and withstand the action of powerful oxidizing reagents. One of their most characteristic reactions is the formation of "substitution"

* The meaning of this term will be explained in detail in the sequel.

† Remember also the following reactions can take place at the same time:-

$$
2 \mathrm{C}_{n} \mathrm{H}_{2 n+1} \mathrm{X}+2 \mathrm{Na}=2 \mathrm{NaX}+\mathrm{C}_{n} \mathrm{H}_{2 n+1} \cdot \mathrm{C}_{n} \mathrm{H}_{2 n+1}
$$

and

$$
2 \mathrm{C}_{m} \mathrm{H}_{2 m+1} \mathrm{X}+2 \mathrm{Na}=2 \mathrm{NaX}+\mathrm{C}_{m} \mathrm{H}_{2 m+1} \cdot \mathrm{C}_{m} \mathrm{H}_{2 m+1}
$$


products when treated with certain of the halogens. When a paraffin is allowed to stand in the presence of chlorine or bromine in sunlight, reaction takes place: very readily in the case of chlorine, but less so in the case of bromine. A hydrogen atom in the carbon compound is "substituted" by one atom of halogen and removed in combination with another atom.

Thus

$\mathrm{CH}_{4}+\mathrm{Cl}_{2}=\mathrm{CH}_{3} \mathrm{Cl}+\mathrm{HCl}$

or

$\mathrm{CH}_{4}+\mathrm{Br}_{2}=\mathrm{CH}_{3} \mathrm{Br}+\mathrm{HBr}$

In this way one or more atoms of the hydrogen of the hydrocarbon can be "substituted" by a halogen. From methane itself, the following chlorine derivatives are obtainable by the gradual substitution of the hydrogen atoms- $\mathrm{CH}_{3} \mathrm{Cl}$, or methyl chloride or monochlormethane; $\mathrm{CH}_{2} \mathrm{Cl}_{2}$, methylene dichloride or dichlormethane; $\mathrm{CHCl}_{3}$, chloroform or trichlormethane; and $\mathrm{CCl}_{4}$, carbon tetrachloride or tetrachlormethane. In view of the fact that mixtures are obtained when a hydrocarbon is treated with a halogen, the method of preparation by direct substitution is not the most convenient one for obtaining the halogen derivatives of the hydrocarbons. Other methods will be discussed later. It is important to remember, however, that halogens act upon hydrocarbons by substitution, and that the hydrogen compound of the halogen is formed at the same time. Iodine does not act readily in the same way as chlorine or bromine, and the iodine substitution products are generally prepared by other methods.

THE OLEFINES OR ETHYLENE HYDROCARBONS.

In addition to compounds containing only hydrogen and carbon of the general formula $\mathrm{C}_{n} \mathrm{H}_{2 n+2}$, a series of the formula $\mathrm{C}_{n} \mathrm{H}_{2 n}$ is also known. The typical member of this group of substances is the gas which is formed when alcohol $\mathrm{C}_{2} \mathrm{H}_{6} \mathrm{O}$ is treated under certain conditions with a 
Structure of Simpler Organic Compounds.

dehydrating agent such as concentrated sulphuric acid or phosphoric acid. This gas is known as ethylene, and possesses the formula $\mathrm{C}_{2} \mathrm{H}_{4}$. It can also be obtained from a monohalogen substitution product of ethane when it is treated with a caustic alkali in alcoholic solution. These two reactions may be represented by the following equations:-

$$
\begin{gathered}
\mathrm{C}_{2} \mathrm{H}_{6} \mathrm{O}-\mathrm{H}_{2} \mathrm{O} \text { (combines with dehydrating agent) }=\mathrm{C}_{2} \mathrm{H}_{4} \\
\mathrm{C}_{2} \mathrm{H}_{5} \mathrm{Br}+\mathrm{KOH}=\mathrm{KBr}+\mathrm{H}_{2} \mathrm{O}+\mathrm{C}_{2} \mathrm{H}_{4}
\end{gathered}
$$

Ethylene is a gas which liquefies at $10^{\circ}$ under a pressure of 60 atmospheres. Other members of the series are prepared by an analogous method, higher "alcohols" (see p. 65 and seq.) or halogen derivatives yielding hydrocarbons with large numbers of carbon atoms.

Now there is a marked chemical distinction between the hydrocarbons of this series and those of the paraffin group. They are, in the first place, far more readily attacked by chemical reagents such as oxidizing mixtures, and there is, in the second place, a very marked difference in their behaviour towards the halogens. Whereas the paraffins react with these substances to form "substitution" products, the substances of the ethylene group react with the formation of "addition" products. When, for example, ethylene is treated with bromine, it reacts to form ethylene dibromide or "Dutch liquid," a colourless crystalline substance with melting point $9.5^{\circ}$ and boiling point $131^{\circ}$, and high specific gravity. The reaction may be represented by the equation-

$$
\mathrm{C}_{2} \mathrm{H}_{5}+\mathrm{Br}_{2}=\mathrm{C}_{2} \mathrm{H}_{4} \mathrm{Br}_{2}
$$

It is to be noticed that no hydrogen bromide is evolved during this reaction. In view of the fact that an "addition" and not a "substitution" product is formed in reactions of this type, ethylene is stated to be an "unsaturated" compound in contradistinction to "saturated" 
substances like the paraffins when a halogen cannot enter into combination with the carbon compound without replacing another element. The formula of ethylene is generally represented in the following way:-

$$
{ }_{\mathrm{CH}_{2}}^{\mathrm{CH}_{2}} \text {, or } \mathrm{CH}_{2}: \mathrm{CH}_{2}
$$

The two carbon atoms are said to be united together by means of a double bond. It is not necessary to enter into any discussion here as to the physical meaning to be attached to this expression, or the kind of combination between two carbon atoms which are united in this way; this point is still a subject of some controversy. It will be sufficient for the present to remember that the double bond is used as a graphical method to represent certain facts. When a compound is represented as containing a double bond, it will usually be more unstable than those substances in which it is absent, and will readily form certain addition products. If the double bond is regarded as representing two valencies, the carbon atom will still appear as quadrivalent. When the addition product has been formed (in the case when only one double bond exists) the unsaturated character of the compound disappears. Thus, in the case of ethylene, the addition of bromine may be represented graphically-

$$
\|_{\mathrm{CH}_{2}}^{\mathrm{CH}_{2}}+\mathrm{Br}_{2}={\stackrel{1}{\mathrm{CH}_{2} \mathrm{Br}}}_{\mathrm{CH}_{2} \mathrm{Br}}^{\mathrm{CH}_{2}}
$$

Further action of bromine can only take place by substitution to form such compounds as $\mathrm{CHBr}_{2} \cdot \mathrm{CH}_{2} \mathrm{Br}$, $\mathrm{CBr}_{3} \cdot \mathrm{CH}_{2} \mathrm{Br}$, etc. It is to be noticed in the above equations that the bromine atoms are represented as being attached to two different carbon atoms, and the substance obtained thus from ethylene is different from the sub- 


\section{Structure of Simpler Organic Compounds.}

stance $\mathrm{CH}_{3} \cdot \mathrm{CHBr}_{2}$ when both bromine atoms are united to the same carbon atoms, and which is obtained by an entirely different method (see p. 80).*

Addition products can also be formed with halogen acids, thus-

$$
\mathrm{C}_{2} \mathrm{H}_{4}+\mathrm{HBr}=\mathrm{C}_{2} \mathrm{H}_{5} \mathrm{Br}
$$

The following are the names of the lower members of the olefine or ethylene series:-

\begin{tabular}{l|l} 
Ethylene, $\mathrm{C}_{2} \mathrm{H}_{4}$ & Amylene, $\mathrm{C}_{5} \mathrm{H}_{10}$ \\
Propylene, $\mathrm{C}_{3} \mathrm{H}_{6}$ & Hexylene, $\mathrm{C}_{6} \mathrm{H}_{12}$, etc. \\
Butylene, $\mathrm{C}_{4} \mathrm{H}_{9}$ &
\end{tabular}

The names of the members of this series are characterized by the termination ene in contrast with those of the paraffin series, all of which end in the syllable ane. The substances of the group do not possess the same technological importance as those of the paraffin group, but they have been employed extensively in the chemical laboratory to effect various syntheses. As in the case of the paraffin series, the boiling points increase with increasing molecular complexity of the substances. Large numbers of isomerides are possible, and isomerism is influenced not only by the relative arrangements of the carbon atoms, but by the position of the double bonds. Thus $\mathrm{CH}_{3} \cdot \mathrm{CH}_{2} \cdot \mathrm{CH}: \mathrm{CH}_{2}$ is isomeric, but not identical with $\mathrm{CH}_{3} \cdot \mathrm{CH}: \mathrm{CH} \cdot \mathrm{CH}_{3}$. The former is known as $\alpha-$ and the latter as $\beta$-butylene, the use of the Greek letters being employed to indicate the degree of proximity of the double bond to the terminal carbon atoms.

\section{THE ACETYLENE SERIES.}

A "homologous" series of hydrocarbons is also known, which can be represented by the general formula $\mathrm{C}_{n} \mathrm{H}_{2 n-2}$.

* The bromine compounds are produced in the same manner as the chlorine compounds described on page 80 , only $\mathrm{PBr}_{5}$ is substituted for $\mathrm{PCl}_{5}$. 
If ethylene dibromide is treated with caustic alkalis in alcoholic solution, all the bromine can be removed, and the reaction can be represented by the equation-

$$
\mathrm{C}_{2} \mathrm{H}_{4} \mathrm{Br}_{2}+2 \mathrm{KOH}=\mathrm{C}_{2} \mathrm{H}_{2}+2 \mathrm{KBr}+2 \mathrm{H}_{2} \mathrm{O}
$$

The gas acetylene is thereby obtained, which is also unsaturated, and which is capable of uniting with no less than four bromine atoms before a fully saturated compound is obtained. This fact is graphically represented by the use of the "triple" bond, thus-

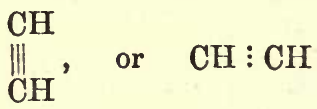

The saturation by bromine can take place in stages$\underset{\mathrm{CH}}{\mathrm{CH}}+\mathrm{Br}_{2}=\underset{\mathrm{CHBr}}{\mathrm{CHBr}}$ and $\underset{\mathrm{CHBr}}{\mathrm{CHBr}}+\mathrm{Br}_{2}=\underset{\mathrm{CHBr}}{\stackrel{\mathrm{CHBr}_{2}}{I}}$

(1) may be regarded as a "substitution " product of an olefine; (2) is a tetra-substitution product of a paraffin.

Acetylene, the chief member of the series, can be obtained, in addition to the method already described, by a variety of processes. Theoretical interest attaches to its direct synthesis from the elements, for it was shown by Berthelot that the gas is produced when hydrogen is led through a globe in which an electric arc is passing between carbon poles. It is also formed by the incomplete combustion of methane, coal-gas, alcohol, and other organic substances. It is most readily obtained, however, by the action of water on calcium carbide.

$$
\mathrm{CaC}_{2}+2 \mathrm{H}_{2} \mathrm{O}=\mathrm{Ca}(\mathrm{OH})_{2}+\mathrm{C}_{2} \mathrm{H}_{2}
$$

The carbide is obtained by heating together a mixture of coke and calcium carbonate to a very high temperature in the electric furnace. This product is made commer- 
Structure of Simpler Organic Compounds. 6 I

cially, and is decomposed by water in specially constructed apparatus. Acetylene prepared in this manner is largely used as an illuminant. It is a colourless gas, which can be liquefied at $1^{\circ}$ under 48 atmospheres pressure. It readily forms addition products with the halogens (see above) by virtue of its unsaturated character, and it can also be reduced by nascent hydrogen into two stages, forming first ethylene, and then ethane.

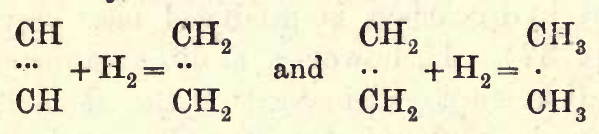

Its most characteristic property is, perhaps, its power of forming so-called acetylides when passed into solutions of certain salts of metals. Thus, when the gas is passed into an ammoniacal solution of cupreous chloride, a red precipitate of copper acetylide, $\mathrm{C}_{2} \mathrm{Cu}_{2}$, is produced, from which acetylene is generated on treatment with hydrochloric acid. The copper compound readily explodes on percussion, or on heating to $120^{\circ}$.

Isomerism in the Acetylene Series.-In addition to compounds containing a triple bond, there also exist in the series of the hydrocarbons of the general formula $\mathrm{C}_{n} \mathrm{H}_{2 n-2}$, compounds containing two double bonds. The former compounds form saturated derivatives by the addition of four halogen atoms to two contiguous carbon atoms, whereas the latter form similar derivatives by addition to more than two carbon atoms. The most interesting member of the series is isoprene, which has the formula $\mathrm{CH}_{2}: \mathrm{C}\left(\mathrm{CH}_{3}\right) \cdot \mathrm{CH}: \mathrm{CH}_{2}$, which, on a treatment with acids, polymerizes to give a product very similar in its properties to india-rubber. The formula of its tetrabrom-derivative is $\mathrm{CH}_{2} \mathrm{Br} \cdot \mathrm{CBr}\left(\mathrm{CH}_{3}\right) \cdot \mathrm{CHBr} \cdot \mathrm{CH}_{2} \mathrm{Br}$-that is, the addition of bromine has taken place to no less than four carbon atoms. 


\section{Part II.-The Halogen Derivatives of the Hydrocarbons.}

These substances have already been repeatedly referred to in the discussion of the hydrocarbons, and can be produced from the latter by "substitution" in the case of the saturated members of the class, and by "addition" from the unsaturated. When these halogen derivatives are treated with an alcoholic solution of sodium hydroxide an unsaturated hydrocarbon is produced (see preparation of ethylene, p. 57). If, however, a dilute aqueous solution of the alkali is employed instead of the alcoholic solution, the halogen is replaced by the elements oxygen and hydrogen, and a characteristic substance belonging to the class known as alcohols is produced. These reactions may be illustrated by the following reactions of monobromethane :

$$
\prod_{\mathrm{CH}_{2} \mathrm{Br}}^{\mathrm{CH}_{2} \mathrm{Br}}+\mathrm{KOH} \text { (alcoholic) }=\mathrm{KBr}+\underset{\mathrm{H}_{2} \mathrm{O}}{\mathrm{CH}_{3}}+\stackrel{\mathrm{CH}_{2}}{\mathrm{CH}_{2}}
$$

In the latter case, the halogen is replaced by a "hydroxyl" group, the properties of which will be discussed later. Conversely, if an alcohol is treated with a halogenating reagent, the hydroxyl group can be replaced by a halogen. Thus, if ethyl alcohol is treated with phosphorus pentachloride, or with dry hydrogen chloride in the presence of a dehydrating agent, such as zinc chloride, it yields monochlorethane.

$$
\begin{aligned}
& \mathrm{CH}_{3} \cdot \mathrm{CH}_{2} \mathrm{OH}+\mathrm{PCl}_{5}=\mathrm{CH}_{3} \mathrm{CH}_{2} \mathrm{Cl}+\mathrm{POCl}_{3}+\mathrm{HCl} \\
& \mathrm{CH}_{3} \cdot \mathrm{CH}_{2} \mathrm{OH}+\mathrm{HCl} \rightleftarrows \mathrm{CH}_{3} \cdot \mathrm{CH}_{2} \mathrm{Cl}+\mathrm{H}_{2} \mathrm{O}
\end{aligned}
$$

If a dehydrating agent is not used in the latter case, and the water formed is not removed from the sphere of action, the reverse action may take place, and this is indicated in 
Structure of Simpler Organic Compounds.

the above equation by the two arrows pointing in opposite directions.

From substances containing two hydroxyl groups, such as that known as ethylene glycol, $\mathrm{CH}_{2} \mathrm{OH} \cdot \mathrm{CH}_{2} \cdot \mathrm{OH}$, a dichlor-derivative can be obtained in a similar manner. Halogen derivatives containing two halogen atoms attached to the same carbon atom can be obtained by the action of phosphorus pentachloride on a class of substances known as the aldehydes, the character of which will be discussed later.

To summarize, the chief methods of preparing the halogen derivatives of hydrocarbons are (a) by the substituting action of halogens (chlorine and bromine) on saturated hydrocarbons, (b) by addition of halogens to unsaturated hydrocarbons, $(c)$ by the action of halogenating agents such as the phosphorus halogen compounds on alcohols and aldehydes.

The following is a list of some of the chief monohalogen derivatives:

Methyl chloride, $\mathrm{CH}_{3} \mathrm{Cl}$ Ethyl chloride, $\mathrm{C}_{2} \mathrm{H}_{5} \mathrm{Cl}$ Propyl chloride, $\mathrm{C}_{3} \mathrm{H}_{7} \mathrm{Cl}$ Butyl chloride, $\mathrm{C}_{4} \mathrm{H}_{9} \mathrm{Cl}$ Amyl chloride, $\mathrm{C}_{5} \mathrm{H}_{11} \mathrm{Cl}$
Methyl bromide, $\mathrm{CH}_{3} \mathrm{Br}$ Ethyl bromide, $\mathrm{C}_{2} \mathrm{H}_{5} \mathrm{Br}$ Propyl bromide, $\mathrm{C}_{3} \mathrm{H}_{7} \mathrm{Br}$ Butyl bromide, $\mathrm{C}_{4} \mathrm{H}_{9} \mathrm{Br}$ Amyl bromide, $\mathrm{C}_{5} \mathrm{H}_{11} \mathrm{Br}$
Methyl iodide, $\mathrm{CH}_{3} \mathrm{I}$ Ethyl iodide, $\mathrm{C}_{2} \mathrm{H}_{5} \mathrm{I}$ Propyl iodide, $\mathrm{C}_{3} \mathrm{H}_{7} \mathrm{I}$ Butyl iodide, $\mathrm{C}_{4} \mathrm{H}_{9} \mathrm{I}$ Amyl iodide, $\mathrm{C}_{5} \mathrm{H}_{11} \mathrm{I}$

These substances can all be derived from the corresponding alcohols. In the higher members of the series isomerides can exist; the isomerism depending upon the configuration of the hydrocarbon from which they are derived, and the position in these hydrocarbons in which a hydrogen atom is replaced by a halogen. A word is here necessary as to the nomenclature employed. The alcohols from which they are obtained are methyl alcohol, $\mathrm{CH}_{3}(\mathrm{OH})$, ethyl alcohol, $\mathrm{C}_{2} \mathrm{H}_{5}(\mathrm{OH})$, propyl alcohol, $\mathrm{C}_{3} \mathrm{H}_{7}(\mathrm{OH})$, butyl alcohol, $\mathrm{C}_{4} \mathrm{H}_{9}(\mathrm{OH})$, and amyl alcohol, $\mathrm{C}_{5} \mathrm{H}_{11}(\mathrm{OH})$. These alcohols 
may be considered as derivatives of the hydrocarbons methane, ethane, propane, butane, and pentane (see p. 54), in which one hydrogen atom is replaced by a "hydroxyl" group; and it will be seen later that there is a justification in giving the above formulæ to these compounds, in that one hydrogen atom (that is, the hydrogen of the hydroxyl group) behaves differently to the other hydrogen atoms in the molecule. These, with the carbon atoms, form groups which are designated "alkyl" or alcohol radicles. These radicles, methyl, ethyl, propyl, etc., will be repeatedly referred to in the succeeding pages, and it will be seen that the grouping of atoms which they designate can remain intact through many series of operations. The monohalogen derivatives mentioned above are liquids, of which the boiling points show progressive rises with increasing molecular weights. The bromides have higher boiling points than the corresponding chlorides, and the iodides boil at higher temperatures than the bromides. Certain of the halogen derivatives are of technological interest.

Methyl chloride, or monochlormethane, which boils at $-24^{\circ}$ under the pressure of 1 atmosphere, is used for the production of low temperatures, being supplied in the form of a compressed gas which absorbs heat on evaporation. It is also largely employed as a reagent in various manufacturing processes. It is manufactured by heating crude trimethylamine hydrochloride (see p. 124).

Methyl, ethyl, and, other iodides are prepared generally by the action of red phosphorus and iodine on the corresponding alcohols.

Chloroform or trichlormethane, which is largely used as an anæsthetic, is prepared commercially by the action of bleaching powder on alcohol, methylated spirit, or acetone. It can also be readily obtained by this method 


\section{Structure of Simpler Organic Compounds. 65}

in the laboratory, but the product so prepared is generally not very pure. A purer product can be obtained by warming chloral or chloral hydrate (see p. 86) with sodium hydroxide. The reaction between bleaching powder and alcohol, or acetone, is a somewhat complex one. Chloroform is a heavy liquid with boiling point $61^{\circ}$.

Iodoform or tri-iodomethane is the corresponding iodine compound. It is formed by a somewhat complex reaction, when ethyl alcohol, acetone, aldehyde, and other organic substances are warmed with iodine in the presence of an alisali hydroxide or carbonate. It is a substance of characteristic smell, which crystallizes in six-sided lustrous plates, which melt at $120^{\circ}$. It is largely used as an antiseptic.

\section{Part III.-The Alcohols.}

It has been already mentioned that this series of compounds can be derived from the halogen derivatives of the hydrocarbons when the latter are warmed with dilute aqueous solutions of caustic alkalis. It was stated above that in this reaction the halogen is replaced by a hydroxyl radicle. The chief member of the group is ethyl alcohol, or "spirits of wine," which has been known from very early times as a product of fermentation, produced when yeast and other micro-organisms are allowed to grow in solutions containing sugar. The corresponding methyl derivative, methyl alcohol, is one of the products of the destructive distillation of wood.

The constitution of this substance can be represented by the formula-

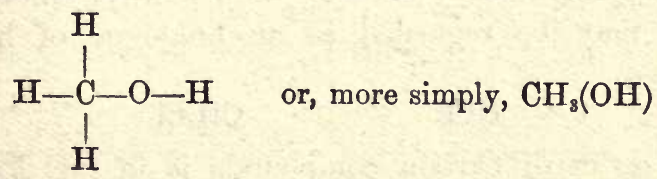


The chief reason for assigning this constitution is the fact that one of the hydrogen atoms behaves differently to the three others. If an alcohol is treated with metallic sodium or potassium, one and only one atom is replaced by the metal forming, with evolution of hydrogen, a compound with the formula $\mathrm{CH}_{3} \mathrm{ONa}$, which can be decomposed by water according to the equation-

$$
\mathrm{CH}_{3} \mathrm{ONa}+\mathrm{H}_{2} \mathrm{O}=\mathrm{CH}_{3} \mathrm{OH}+\mathrm{NaOH}
$$

This reaction is analogous to the action of sodium on water, which leads to the formation of sodium hydroxide, or caustic soda, $\mathrm{NaOH}$. The sodium derivative of methyl alcohol may be considered as analogous to sodium hydroxide, the hydrogen of the latter substance being regarded as replaced by the methyl group. It is known as sodium methoxide. The analogy will be clear from the following formulæ:-

\section{$\mathrm{NaOH}$}

\section{$\mathrm{NaOCH}_{3}$}

Methyl alcohol, if such conceptions are correct, can then be regarded as an analogue of water, in which one hydrogen is replaced by a methyl group-
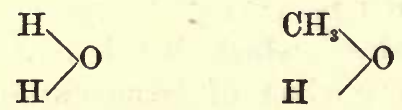

Furthermore, the fact that such a group as the methy] exists in the molecule is indicated by its preparation from methyl chloride (monochlormethane); in this compounc three hydrogen atoms are directly united to a carbor atom. Again, the oxygen and one hydrogen atom are together replaceable by chlorine, and methyl chloride thus obtained may be regarded as an analogue of hydroger chloride-

$\mathrm{HCl}$ $\mathrm{CH}_{8} \mathrm{Cl}$

A whole series of carbon compounds is in fact known, $o$ : 
which the members may be regarded as substances derived from inorganic compounds by the replacement of a hydrogen by an "alkyl" radicle (see p. 64). Thus, by the replacement* of the hydrogen atoms of water by methyl, the compounds-
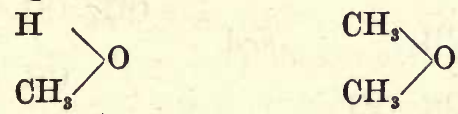

methyl alcohol and methyl ether, may be derived.

In the same way, from the acids-

$$
\mathrm{HCl} \quad \mathrm{H}_{2} \mathrm{SO}_{4} \quad \mathrm{H}_{3} \mathrm{PO} \text {, }
$$

substances with the formulæ-

$\mathrm{CH}_{3} \mathrm{Cl} \quad \begin{aligned} & \mathrm{CH}_{3} \mathrm{HSO}_{4} \\ & \left(\mathrm{CH}_{3}\right)_{2} \mathrm{SO}_{4}\end{aligned} \quad\left(\mathrm{CH}_{3}\right)_{3} \mathrm{PO}_{4}$, etc.,

can be derived, and are actually known.

It is not, therefore, unreasonable to regard methyl alcohol as an analogue of water, and to assign to it the formula $\mathrm{CH}_{3}(\mathrm{OH})$ (or $\mathrm{CH}_{3} \cdot \mathrm{OH}$ ), and to assume that it contains two groups, namely, a methyl group of a carbon atom united to three hydrogen atoms, which group can remain intact through whole series of operations, and a hydroxyl group, the main characteristics of which are that it is replaceable by a halogen, and that the hydrogen is replaceable by an alkali metal, which acts upon the alcohol with evolution of hydrogen. The oxygen of the hydroxyl group must in this case be assumed to be directly united to a carbon atom and one hydrogen atom, which latter differs in its reactions from the other three hydrogen atoms, which are directly combined with the carbon. A large series of homologues of methyl and ethyl alcohol are known, some of which, like ethyl alcohol, are products

* "Replacement" here does not mean that the reaction can be accomplished by a direct experimental method. The term is applied only to the graphical formulæ, the main object of which is to indicate the relative arrangement of the atoms to one another. 
of fermentation produced by micro-organisms. In the members of the series higher than ethyl alcohol isomerides exist. Thus two alcohols with three carbon atoms, namely-

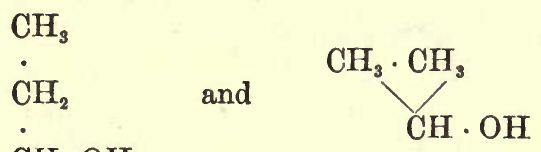

$\mathrm{CH}_{2} \cdot \mathrm{OH}$

are known, the former being known as propyl, and the latter as isopropyl alcohol. The former contains the propyl and the latter the isopropyl radicle. There are four butyl alcohols, or alcohols with four carbon atoms. These have the formulæ-

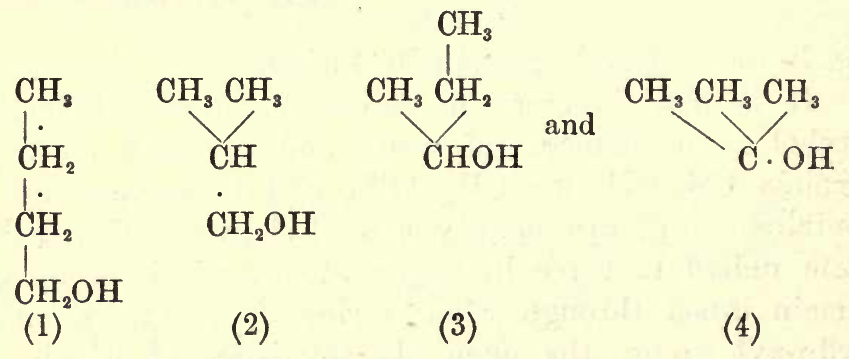

The first of these is normal butyl alcohol, the second isobutyl alcohol, the third secondary butyl alcohol, and the fourth tertiary butyl alcohol. The term "primary alcohol " is applied to those alcohols in which the hydroxyl group is attached to a carbon atom to which two other hydrogen atoms are also attached $\left(\cdot \mathrm{CH}_{2} \cdot \mathrm{OH}\right)$. Both (1) and (2) would, therefore, be called primary alcohols. Where the hydroxyl group is united to a carbon atom attached to only one hydrogen atom (and to two alkyl radicles, that is, through carbon atoms), the alcohol is said to be "secondary" ( $>\mathrm{CHOH}$, as in No. 3); and where it is united to a carbon atom which is attached to no hydrogen atom but 


\section{Structure of Simpler Organic Compounds. 69}

to three alkyl groups ( $=\mathrm{C} \cdot \mathrm{OH}$, as in No. 4), the alcohol is said to be "tertiary."

From the general conceptions advanced as to the nature of isomerism in the carbon compounds the existence of all these isomerides might be predicted; they have, in fact, all been isolated, and the correct constitution of each individual member has been determined by means of various synthetical and other reactions to which reference will be made later. Their constitution may also be regarded in another light. They may be considered as derived from methyl alcohol, $\mathrm{CH}_{3} \cdot \mathrm{OH}$, by the replacement of the hydrogens in the methyl radicle by an alkyl radicle. Thus, normal butyl alcohol (formula 1) may be regarded as methyl alcohol in which one hydrogen is replaced by the propyl radicle $\left(\mathrm{C}_{3} \mathrm{H}_{7}\right)$, and written $\mathrm{C}_{3} \mathrm{H}_{7} \cdot \mathrm{CH}_{2} \mathrm{OH}$. The group $\equiv \mathrm{C}-\mathrm{OH}$ is in this connection designated "carbinol," and normal butyl alcohol is, therefore, also called propyl carbinol. Similarly isobutyl alcohol (formula 2) is called isopropyl carbinol, secondary butyl alcohol (formula 3) is methyl ethyl carbinol, and tertiary butyl alcohol (formula 4) is trimethyl carbinol. The general formulæ of the three classes of alcohols may be thus represented-

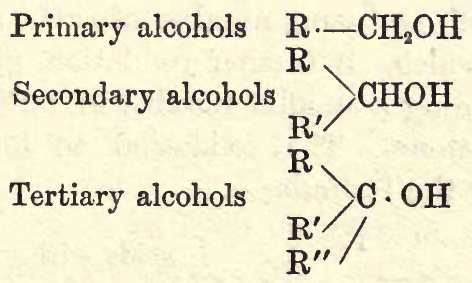

when $R=$ alkyl radicle and $R_{1}, R^{\prime}, R^{\prime \prime}$ may be the same or different radicles.

Now, if a certain substance has been obtained, and its empirical formula has been determined, it is always pos- 
sible to ascertain whether it is an alcohol. The essential point is that it should contain the alcoholic hydroxyl group. This should be replaceable by chlorine or bromine when the substance is treated with the pentachloride or pentabromide of phosphorus ; one hydrogen atom, furthermore, should be replaceable by sodium, when the substance is treated with this metal. It is also possible to ascertain whether an alcohol is primary, secondary, or tertiary. When a primary alcohol is oxidized under certain conditions it yields a substance known as an aldehyde, which, on further oxidation, gives an acid containing the same number of carbon atoms. If the general formula given above is employed, the formula of the substances produced may be represented thus-

$\begin{array}{ccc}\mathrm{R} \cdot \mathrm{CH}_{2} \mathrm{OH} & \mathrm{R} \cdot \mathrm{CHO} & \mathrm{R} \cdot \mathrm{CO}_{2} \mathrm{H} \\ \text { Alcohol. } & \text { Aldehyde. } & \text { Acid. }\end{array}$

Or, taking a concrete instance-
$\mathrm{CH}_{2} \cdot \mathrm{CH}_{2} \mathrm{OH}$
$\mathrm{CH}_{3} \cdot \mathrm{CHO}$
Ethyl alcohol.
Acetaldehydo.
$\mathrm{CH}_{3} \cdot \mathrm{CO}_{2} \mathrm{H}$
Acetic acid.

This series of reactions always takes place when a substance contains the group $-\mathrm{CH}_{2} \mathrm{OH}$, whatever $\mathrm{R}$ may be. Secondary alcohols, on the other hand, yield on oxidation a substance with the same number of carbon atoms known as a ketone, which, on further oxidation, gives a mixture of acids containing a smaller number of carbon atoms than the alcohol ketone. The oxidation to ketones may be represented by the formula-

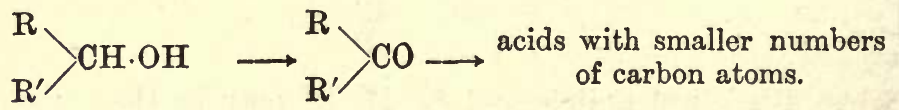

Conversely, aldehydes and ketones can be converted by nascent hydrogen into primary and secondary alcohols. The chemistry of these important classes of compounds, 
Structure of Simpler Organic Compounds. 7 I

namely, aldehydes, ketones, and the so-called fatty acids, will be considered in detail later. The tertiary alcohols give on oxidation a mixture of products, generally ketones and acids, but the ketones obtained in this case contain a smaller number of carbon atoms than the alcohol from which they are derived. Thus, tertiary butyl alcohol, or trimethyl carbinol, yields on oxidation a mixture of acetone, $\mathrm{CH}_{3} \cdot \mathrm{CO} \cdot \mathrm{CH}$, acetic acid, $\mathrm{CH}_{3} \cdot \mathrm{CO}_{2} \mathrm{H}$, or carbon dioxide and other products.

The above reactions are sufficient to determine only whether any particular substance belongs to one of the three classes-that is, primary, secondary, or tertiary alcohols. In the case of the butyl alcohols, which contain only four carbon atoms, two isomerides which are primary alcohols, and one secondary and one tertiary alcohol exist. If the above-described oxidations were carried out on a butyl alcohol of the formula $\mathrm{C}_{5} \mathrm{H}_{10} \mathrm{O}$, it would be possible to determine only whether such a substance were a primary, secondary, or tertiary alcohol. If the result of these experimental investigations indicated, for example, that the substance was a primary alcohol, the question as to whether it was butyl or isobutyl alcohol (formula (1) and (2)) would still remain undetermined.

In the case of alcohols higher than butyl alcohol, a still larger number of isomerides is capable of existence, and the problem of the determination of the constitution becomes still more complex. Thus, no less than eight amyl alcohols of the formula $\mathrm{C}_{5} \mathrm{H}_{12} \mathrm{O}$ can exist.

The constitution of such substances can be finally settled by a method which has rendered almost incalculable service to organic chemistry, namely, the method of "synthesis," or the building up of complex from simpler substances.

A very good example of such a method is afforded by 
what is known as Grignard's reaction, which has been largely employed for the synthesis of alcohols. Many other synthetical methods will be mentioned in the following pages.

Grignard's Method.-When an alkyl bromide or iodide (see p. 64) is treated with magnesium powder in the presence of pure ether, a derivative of the type $\mathrm{MgBrR}$ or $\mathrm{MgIR}$ is formed ( $\mathrm{R}=$ alkyl radicle). The derivative from ethyl iodide would thus have the formula $\mathrm{MgC}_{2} \mathrm{H}_{5} \mathrm{I}$. Such substances readily react with a variety of other organic compounds. Thus, if treated with an aldehyde of the general formula $\mathrm{R}^{\prime} \mathrm{CHO}$ they react in the following manner:-

$$
\mathrm{R}^{\prime} \mathrm{CHO}+\mathrm{RMgI}=\mathrm{R}^{\prime} \mathrm{CH} \overbrace{R}^{\mathrm{O} M g B r}
$$

This addition product is readily decomposed by dilute hydrochloric acid, according to the equation--

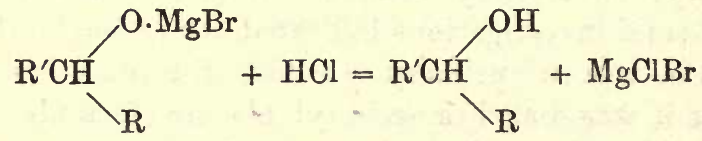

The product of reaction obtained in this case is a secondary alcohol. It will be seen that the product obtained contains two alkyl groups. The reaction may be illustrated by the following example. It has been already stated that when ethyl alcohol, $\mathrm{CH}_{3} \cdot \mathrm{CH}_{2} \mathrm{OH}$, is oxidized under certain conditions it yields aldehyde, $\mathrm{CH}_{3} \cdot \mathrm{CHO}$. If, now, the magnesium derivative of isopropyl iodide (which has the formula $\underset{\mathrm{CH}_{3}}{\mathrm{CH}_{3}}>\mathrm{CHI}$ ) is treated with the aldehyde, and the reaction product is then decomposed with hydrochloric acid, a secondary alcohol will be obtained which can only have the constitution- 
Structure of Simpler Organic Compounds. 73

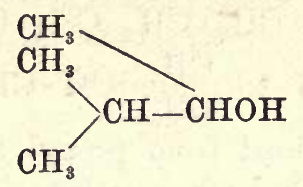

that is, it is a secondary alcohol with methyl and isopropyl groups, and is, according to the nomenclature adopted, methyl isopropyl carbinol.

Again, if a magnesium halogen derivative is treated with a ketone (see p. 70) it reacts according to the equation-

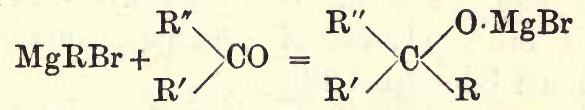

and the addition product on treatment with hydrochloric acid decomposes-

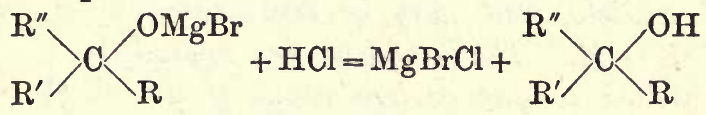

In this way a tertiary alcohol is obtained. In the above formula $R, R^{\prime}, R^{\prime \prime}$ may be the same or different alkyl radicle.

The above Grignard's reactions will be more readily understood when the chemical characters of the aldehydes and ketones have been more fully discussed (pp. 79 and 83). It is important, however, to grasp the full significance of the synthetic method in the early stages of the study of organic chemistry. It has played, and will play, an important part in all biological investigations which are concerned with the chemical processes taking place in the living organism.

Many other synthetic methods for the preparation of alcohols have been employed. Thus, reactions are known by means of which it is possible to "lengthen the chain"-for example, to pass from the alcohol $\mathrm{CH}_{3} \cdot \mathrm{OH}$ to the alcohol $\mathrm{CH}_{3} \cdot \mathrm{CH}_{2} \mathrm{OH}$, and thence to the alcohol $\mathrm{CH}_{3} \cdot \mathrm{CH}_{2} \cdot \mathrm{CH}_{2} \mathrm{OH}$, etc., or from the alcohols (propyl) 
$\mathrm{CH}_{3} \mathrm{CH}_{2} \cdot \mathrm{CH}_{2} \mathrm{OH}$ to $\mathrm{CH}_{3} \cdot \mathrm{CH}_{2} \cdot \mathrm{CH}_{2} \cdot \mathrm{CH}_{2} \mathrm{OH}$, and (isopropyl) $\left.\begin{array}{l}\mathrm{CH}_{3} \\ \mathrm{CH}_{3}\end{array}\right\rangle \mathrm{CHOH}$ to $\mathrm{CH}_{3} \mathrm{CH}_{3}>\mathrm{CH} \cdot \mathrm{CH}_{2} \mathrm{OH}$. Butyl alcohol would be obtained from propyl and isobutyl from isopropyl alcohol. By such reactions it would be, therefore, possible to assign the correct formulæ to the two primary butyl alcohols, as the two propyl alcohols from which they are derived can be readily distinguished from one another in that one is a primary and the other a secondary alcohol. As the reactions involved entail a knowledge of other classes of organic compounds, they will be discussed later (p. 128).

To summarize, the simplest members of the alcohol group are substances containing an alkyl radicle and a hydroxyl radicle, and may be represented by a general formula $R \cdot \mathrm{OH}$. The oxygen is regarded as being directly united to one carbon atom of the alkyl radicle and to one hydrogen which differs from all the other hydrogen atoms. They yield as first products of oxidation classes of compounds known as aldehydes or ketones, the oxidation products obtained varying according to whether the alcohols are of primary, secondary, or tertiary character.

The following are some of the more important members of the series:-

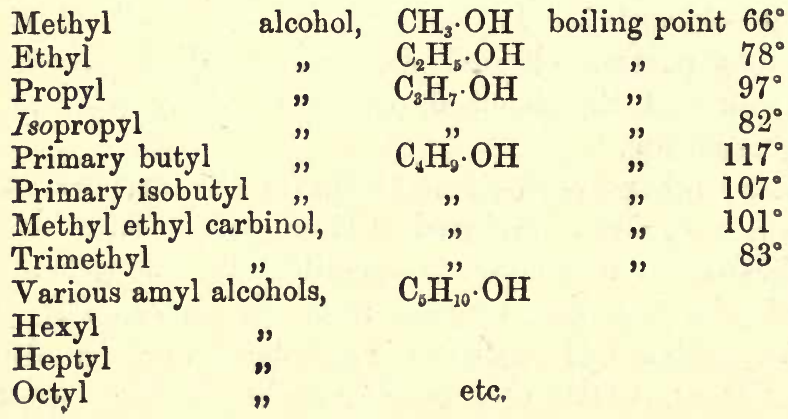


Methyl alcohol, as already stated, is one of the products of the destructive distillation of wood. It is largely employed both in the laboratory and in manufacturing processes as a solvent.

Ethyl alcohol, or more simply, alcohol, is the typical substance which has given its name to the whole class. It is produced, together with carbon dioxide, from sugar by the action of various micro-organisms, such as the yeasts. The action, which was first definitely shown to be due to the presence of living organisms by Pasteur, is known as "fermentation," and is due to the presence in these organisms of substances known as "enzymes" or "ferments," the action of which will have to be discussed in detail later. The chemical reaction when a simple sugar, such as glucose (dextrose), is employed may be represented by the equation-

$$
\mathrm{C}_{6} \mathrm{H}_{12} \mathrm{O}_{6}=2 \mathrm{C}_{2} \mathrm{H}_{6} \mathrm{O}+\mathrm{CO}_{2}
$$

Alcohol can also be obtained from more complex "carbohydrates" (see p. 214 and seq.) such as starch, sucrose (canesugar), etc., which first undergo hydrolysis to yield the simpler carbohydrates. The actual mechanism of fermentation processes may be best discussed when dealing with the chemistry of the carbohydrates. For the manufacture of alcohol on a large scale starch from potatoes and other cheap raw materials is employed. The alcohol contained in beer and wines is derived from the carbohydrates contained in the malt or grapes.

Propyl Alcohol.-In alcoholic fermentation there is produced, in addition to alcohol, small quantities of other products with higher boiling points, which can be separated by a process of fractional distillation. The higher boiling portion of the volatile fermentation products is known as fusel oil. The separation from the "raw spirit," as the crude fermentation product is called, is accomplished 
in distilleries by various forms of stills. The fusel oil is a mixture which can, by fractional distillation, be separated into various components, amongst which is propyl alcohol.

Amyl Alcohols $\left(\mathrm{C}_{5} \mathrm{H}_{12} \mathrm{O}\right)$. - Of the eight isomerides which are capable of existence, two occur in fusel oil. These are known to be isobutyl carbinol, $\mathrm{CH}_{3}>\mathrm{CH} \cdot \mathrm{CH}_{2} \cdot \mathrm{CH}_{2} \mathrm{OH}$, and the so-called active amyl alcohol, which has the constitution $\underset{\mathrm{CH}_{3} \cdot \mathrm{CH}_{2}}{\mathrm{CH}_{2}}>\mathrm{CH} \cdot \mathrm{CH}_{2} \cdot \mathrm{OH}$. The ordinary commercial amyl alcohol, which is largely employed as solvent, possesses a characteristic pungent smell.

\section{THE POLYHYDROXY ALCOHOLS.}

In addition to those substances containing one hydroxyl group, others are known which contain two or more such groups, which may be regarded as derived from hydrocarbons by the substitution of two or more hydrogen atoms. Just as from a mono-halogen substitution product of a hydrocarbon, by the treatment with aqueous solutions of caustic alkalis, a monohydroxy alcohol can be obtained, so from the poly-substituted halogen derivatives, polyhydroxy alcohols can be produced. Thus from ethylene $\mathrm{CH}_{2} \mathrm{Br}$ dibromide

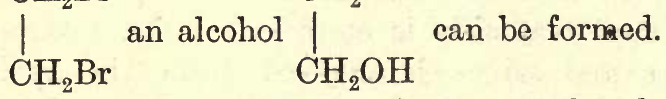

The dihydroxy derivatives are known as the glycols.

$\mathrm{CH}_{2} \mathrm{OH}$

Ethylene glycol, or simply glycol, $\mathrm{CH}_{2} \mathrm{OH}$ 
can be obtained. The glycols have the general formula $\mathrm{C}_{n} \mathrm{H}_{2 n}(\mathrm{OH})_{2}$. They are named after the members of the olefine series to which they belong, being designated ethylene, propylene, butylene glycols, etc. The isomerism will depend not only on the hydrocarbons from which they are derived, but also on the position in which the hydroxyl groups are substituted. Thus, from normal propane, two propylene glycols can be derived, namely, $\mathrm{CH}_{2}(\mathrm{OH}) \cdot \mathrm{CH}_{2} \cdot \mathrm{CH}_{2}(\mathrm{OH})$ and $\mathrm{CH}_{3} \cdot \mathrm{CH}(\mathrm{OH}) \mathrm{CH}_{2}(\mathrm{OH})$. The former is known as $\alpha-\gamma$ and the latter as $\alpha-\beta$ propylene glycol, the letters $\alpha, \beta, \gamma$, etc., being employed to indicate the position of the carbon atom to which the hydroxyl group is attached-the terminal carbon atom being indicated by $\alpha$, the contiguous carbon atom by $\beta$, and so on. The glycols are neutral thick liquids, similar in properties to glycol.

Glycerol, which is more generally called glycerine,* is the most important of the polyhydroxy alcohols. It is trihydroxy propane, $\mathrm{CH}_{2}(\mathrm{OH}) \mathrm{CH}(\mathrm{OH}) \mathrm{CH}_{2}(\mathrm{OH})$, and is prepared on a large scale by the hydrolysis of fats and oils. When such substances are heated with water under high pressure, they undergo decomposition, yielding glycerol and fatty acids. The latter are insoluble in the water, and can be filtered off. The aqueous solution on concentration yields glycerol, which can be purified by fractional distillation under reduced pressure. As ordinarily prepared, it is a thick syrup of sp. gr. 1·26, but by careful purification it can be obtained in the form of crystals which have a melting point of $17^{\circ}$. These are very hygroscopic, and readily take up moisture from the atmosphere to form a syrup. Glycerol is readily soluble in water and alcohol, but not in ether-a property which it shares

* The termination $o^{?}$ is employed to indicate the presence in the substance of a hydroxyl group. 
generally with substances containing several hydroxyl groups. Its constitution is known from the fact that it can be obtained by a series of reactions from tribrompropane of the formula $\mathrm{CH}_{2} \mathrm{Br} \cdot \mathrm{CHBr} \cdot \mathrm{CH}_{2} \mathrm{Br}$. This bromine derivative can be got from propylene, $\mathrm{CH}_{2}: \mathrm{CH} \cdot \mathrm{CH}_{3}$, which with bromine gives first propylene dibromide, $\mathrm{CH}_{2} \mathrm{Br} \cdot \mathrm{CHBr} \cdot \mathrm{CH}_{3}$, from which by further action of bromine in the presence of iron the compound $\mathrm{CH}_{2} \mathrm{BrCHBrCH}{ }_{2} \mathrm{Br}$ can be obtained. It is known that the bromine atoms in this compound are all attached to different carbon atoms, for if more than two were attached to the same carbon atom, a substance having aldehydic or ketonic properties would be obtained by the replacement of the halogen by a hydroxyl group.

One or more of the hydroxyl groups of glycerol can be replaced by chlorine, giving rise to substances known as the "chlorhydrins."

Alcohols with a still larger number of hydroxyl groups are known, of which may be mentioned erythritol,

\section{$\mathrm{CH}_{2}(\mathrm{OH}) \mathrm{CH}(\mathrm{OH}) \mathrm{CH}(\mathrm{OH}) \mathrm{CH}_{2}(\mathrm{OH})$,}

which is found native in certain lichens and sea-weeds, and certain hexahydroxy alcohols,

$\mathrm{CH}_{2}(\mathrm{OH}) \cdot \mathrm{CH}(\mathrm{OH}) \mathrm{CH}(\mathrm{OH}) \mathrm{CH}(\mathrm{OH}) \mathrm{CH}(\mathrm{OH}) \cdot \mathrm{CH}_{2}(\mathrm{OH})$,

of which mannitol (mannite), dulcitol (dulcite), and sorbitol (sorbite) occur native, and which are closely related to the sugars (see p. 191 and seq.).

\section{OTHER ALCOHOLS.}

Alcohols are also known which may be considered as derived from unsaturated hydrocarbons by the substitution of a hydrogen atom by a hydroxyl group. As an example of substances of this character may be cited allyl 
Structure of Simpler Organic Compounds. 79

alcohol, $\mathrm{CH}_{2}: \mathrm{CH} \cdot \mathrm{CH}_{2} \mathrm{OH}$, which can be prepared by the distillation of glycerol with oxalic acid. (The reaction is somewhat complex.). It has the properties both of an unsaturated substance (for example, can give addition products) and of an alcohol (can give sodium derivatives, etc.).

\section{Part IV.-The Aldehydes.}

When a primary alcohol is submitted to oxidation under certain conditions, it gives rise to a product known as an aldehyde (see p. 70)-

$$
\mathrm{RCH}_{2} \mathrm{OH}+\mathrm{O}=\mathrm{H}_{2} \mathrm{O}+\mathrm{R} \cdot \mathrm{CHO}
$$

Ethyl alcohol under these conditions gives rise to the typical substance of this class, which is generally known as acetaldehyde-

$$
2 \mathrm{CH}_{3} \cdot \mathrm{CH}_{2} \mathrm{OH}+\mathrm{O}_{2}=2 \mathrm{CH}_{3} \cdot \mathrm{CHO}+2 \mathrm{H}_{2} \mathrm{O}
$$

The oxidizing reagent generally employed for this purpose is a mixture of potassium dichromate and sulphuric acid. The product of the reaction is a volatile liquid, boiling point $20 \cdot 8^{\circ}$, which possesses a characteristic pungent odour and is miscible with water, alcohol, and ether in all proportions.

The lower member of the series, which is prepared by the oxidation of methyl alcohol, is known as formaldehyde, which, in 4.0 per cent. solution, is sold as a disinfectant under the name of formalin. This substance is usually prepared by passing the vapour of methyl alcohol mixed with air through a tube containing a copper spiral, or platinized asbestos, heated to dull redness.

$$
2 \mathrm{CH}_{3} \mathrm{OH}+\mathrm{O}_{2}=2 \mathrm{H} \cdot \mathrm{CHO}+2 \mathrm{H}_{2} \mathrm{O}
$$

Formic aldehyde is also a substance of intense penetrating odour, which is gaseous at ordinary temperatures, but can be condensed to a liquid at $-21^{\circ}$. It readily 
polymerizes to form a solid substance trioxymethylamine, $\left(\mathrm{CH}_{2} \mathrm{O}\right)_{3}$, which, on heating, "depolymerizes" to yield formaldehyde again. This is one of the best methods for obtaining the pure aldehyde. Another polymer of formaldehyde, namely, paraformaldehyde, $\left(\mathrm{CH}_{2} \mathrm{O}\right)_{2}$, is known, and is formed when an aqueous solution of the aldehyde is evaporated.

Acetaldehyde also readily forms a series of polymers. Paraldehyde, $\left(\mathrm{C}_{2} \mathrm{H}_{4} \mathrm{O}\right)_{3}$, is produced when a drop of concentrated sulphuric acid is added to acetaldehyde. This is a liquid, but slightly soluble in water, of boiling point $124^{\circ}$, which has distinct narcotic action, and is often employed for producing complete anæsthesia in physiological experiments. Another, a solid polymer, is produced when acetaldehyde is treated with acids at low temperatures.

The constitutional formula assigned to aldehyde is-

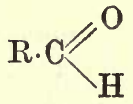

and to form- and acet- aldehydes-

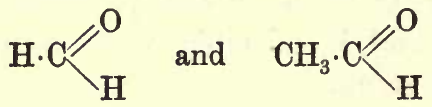

It will be noticed that in this formula the hydrogen is not directly united to the oxygen atom as it is in the alcohols, and is not directly replaceable by metals. Furthermore, when acetaldehyde is treated with phosphorus pentachloride, the oxygen alone is replaced by chlorine, two univalent chlorine atoms replacing the bivalent oxygen thus-

$$
\mathrm{CH}_{3} \cdot \mathrm{C}_{\mathrm{H}}^{\mathrm{O}}+\mathrm{PCl}_{5}=\mathrm{POCl}_{3}+\mathrm{CH}_{3} \cdot \mathrm{C}_{\mathrm{H}}^{\mathrm{Cl}_{2}}
$$

A dichlorethane is thus produced, which differs from the symmetrical ethylene dichloride, $\mathrm{CH}_{2} \mathrm{Cl} \cdot \mathrm{CH}_{2} \mathrm{Cl}$ (see 
Structure of Simpler Organic Compounds. 8I

p. 58), in that the two chlorine atoms are united to the same carbon atom.

Furthermore, aldehydes readily form addition products, the production of which can be readily explained on the basis of the above formula.

Thus when aldehyde is treated with sodium hydrogen sulphite (bisulphite) it forms a crystalline compound of the formula $\mathrm{CH}_{3} \mathrm{CHO} \cdot \mathrm{NaHSO}_{3}$; with ammonia it forms the compound $\mathrm{CH}_{3} \mathrm{CHO} \cdot \mathrm{NH}_{3}$; with hydrocyanic acid it forms a cyanhydrin, $\mathrm{CH}_{3} \mathrm{CHO} \cdot \mathrm{HCN}$; and with alcohol at $100^{\circ}$ it forms acetal. To these addition products the following constitutional formulæ may be assigned:-

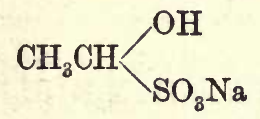

and

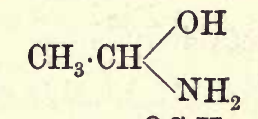

$\mathrm{CH}_{3} \mathrm{CH}\left\langle\mathrm{OC}_{2} \mathrm{H}_{5}\right.$

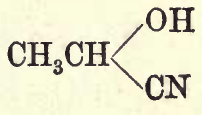

The aldehydes generally are very reactive substances. As they can be produced from primary alcohols by oxidation, so conversely, by treatment with nascent hydrogen, they can be reduced again to alcohols-

$$
\text { R. } \mathrm{CHO}+\mathrm{H}_{2}=\mathrm{R} \cdot \mathrm{CH}_{2} \mathrm{OH}
$$

Furthermore, on oxidation they give rise to a "fatty" acid, containing the same number of carbon atoms-

$$
\mathrm{R} \cdot \mathrm{CHO}+\mathrm{O}=\mathrm{R} \cdot \mathrm{CO}_{2} \mathrm{H}
$$

This oxidation is best accomplished by means of silver oxide, $\mathrm{Ag}_{2} \mathrm{O}$, which is thereby reduced to metallic silver-

$$
\mathrm{CH}_{8} \mathrm{CHO}+\mathrm{Ag}_{2} \mathrm{O}=\mathrm{Ag}_{2}+\mathrm{CH}_{3} \mathrm{CO}_{2} \mathrm{H}
$$

By virtue of the readiness with which the aldehydes are oxidized, they readily act as "reducing agents." Thus an alkaline solution of cupric salts is reduced to cuprous oxide (Fehling's solution, see p. 195), and a silver mirror 
is readily produced when an aldehyde is warmed with an ammoniacal solution of a silver salt.

Aldehydes undergo, furthermore, certain characteristic reactions.

The chief of those reactions, to which repeated reference will be made later, is that with phenylhydrazine, a derivative of benzene (see p. 150), a reagent which is employed for the detection of aldehydes. A product known as a phenylhydrazone or hydrazone is thereby produced. The reaction may be represented by the following equation:-

$$
\text { R. } \mathrm{CH} O \mathrm{O}+\mathrm{H}_{2} \mathrm{~N} \cdot \mathrm{NHC}_{6} \mathrm{H}_{5}=\mathrm{H}_{2} \mathrm{O}+\mathrm{R} \cdot \mathrm{CH}: \mathrm{N} \cdot \mathrm{NHC}_{6} \mathrm{H}_{5}
$$

or, in the case of acetaldehydes-

$$
\mathrm{CH}_{3} \cdot \mathrm{CHO}+\mathrm{H}_{2} \mathrm{~N} \cdot \mathrm{NHC}_{6} \mathrm{H}_{5}{ }^{*}=\mathrm{H}_{2} \mathrm{O}+\mathrm{CH}_{3} \cdot \mathrm{CH}: \mathrm{N} \cdot \mathrm{NHC}_{6} \mathrm{H}_{5}
$$

The phenylhydrazones are crystalline products which can be readily purified by recrystallization from suitable solvents, and are therefore well adapted for the identification of various aldehydes.

A second reagent, which acts in a similar way to phenylhydrazine, is hydroxylamine, which forms with aldehydes a series of compounds known as the oximes. The character of the reaction is indicated by the equation-

$$
\mathrm{R} \cdot \mathrm{CHO}+\mathrm{H}_{2} \mathrm{~N} \cdot \mathrm{OH}=\mathrm{R} \cdot \mathrm{C}: \mathrm{N} \cdot \mathrm{OH}+\mathrm{H}_{2} \mathrm{O}
$$

These substances are also usually crystalline, and like the hydrazones can be employed for the identification of aldehydes.

A third reagent with similar action is semicarbazide, $\mathrm{NH}_{2} \cdot \mathrm{NH} \cdot \mathrm{CO} \cdot \mathrm{NH}_{2}$. The general reaction takes place according to the equation-

$$
\mathrm{R} \cdot \mathrm{CHO}+\mathrm{H}_{2} \mathrm{~N} \cdot \mathrm{NH} \cdot \mathrm{CO} \cdot \mathrm{NH}_{2}=\mathrm{H}_{2} \mathrm{O}+\mathrm{R} \cdot \mathrm{CH}: \mathrm{N} \cdot \mathrm{NH} \cdot \mathrm{CO} \cdot \mathrm{NH}_{2}
$$

* The reason for assigning this constitution to phenylhydrazine will be given later. 


\section{Structure of Simpler Organic Compounds. 83}

The general properties of the aldehydes may be summarized as follows:-

They are obtained by the oxidation of primary alcohols to which they stand in a definite genetic relationship. Into these substances they can be reconverted by treatment with nascent hydrogen. They are readily oxidized, and therefore act as "reducing agents," yielding, with suitable reagents, "fatty" acids containing the same number of carbon atoms. On treatment with phosphorus pentachloride they yield dichloro derivatives, with two chlorine atoms attached to the same carbon atom. They yield characteristic addition products with sodium bisulphite, ammonia, and hydrocyanic acid, and with alcohol a series of products known as the acetals. Finally, they enter into characteristic reactions with the substances phenylhydrazine, hydroxylamine, and semicarbazide to form products which serve to characterize them. Their constitution is represented by the general formula $R \cdot C=O$.

\section{Part V.-The Ketones.}

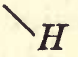

The ketones are produced from the secondary alcohols by oxidation in a way similar to that in which the aldehydes are produced from primary alcohols. The formation can be represented by the general equation-

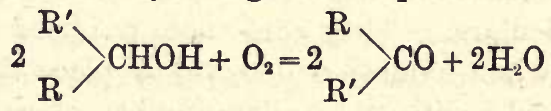

where $R$ or $R^{\prime}$ may be the same or different alkyl radicles. As an example of this reaction, the production of the simplest member of the class, namely, acetone, from isopropyl alcohol, may be quoted-

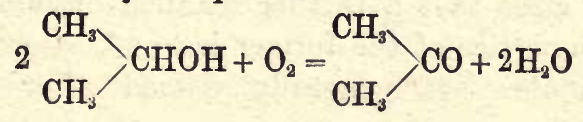


Conversely, when a ketone is treated with nascent hydrogen, a secondary alcohol is regenerated-

$$
{ }_{\mathrm{R}^{\prime}}^{\mathrm{R}}>\mathrm{CO}+\mathrm{H}_{2}={ }_{\mathrm{R}^{\prime}}^{\mathrm{R}}>\mathrm{CH} \cdot \mathrm{OH}
$$

From these reactions a considerable analogy between the ketones and aldehydes may be predicted. Their relationship may be expressed by the following formulæ:-
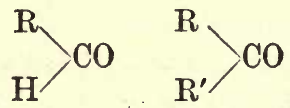

Their reactions are in many respects similar. Thus, they react with phosphorus pentachloride to yield dichloro derivatives, in which both chlorine atoms are attached to the same carbon atom of the general formula-

$$
\text { R. } \mathrm{CCl}_{2} \mathrm{R}^{\prime} \text { or }\left({ }_{\mathrm{R}}^{\mathrm{R}}, \mathrm{C} \cdot \mathrm{Cl}_{2}\right)
$$

They also form similar addition products with sodium (bi) hydrogen sulphite and hydrocyanic acid (but not with ammonia), and they form similar "condensation" products with phenylhydrazine, hydroxylamine, and semicarbazide. The constitution of the products thus formed can be readily derived by substituting $\mathrm{R}^{\prime}$ for $\mathrm{H}$ in the aldehyde group in the equations given above.

The ketones differ from the aldehydes, however, in certain particulars. They are not oxidized nearly so readily, and when oxidation does takes place they yield a mixture of acids with a smaller number of carbon atoms than the ketone. Thus acetone, $\mathrm{CH}_{3} \cdot \mathrm{CO} \cdot \mathrm{CH}_{3}$, on oxidation yields a mixture of acetic $\left(\mathrm{C}_{2} \mathrm{H}_{4} \mathrm{O}_{2}\right)$ and carbonic acids. The chemical analogy between the ketones and the aldehydes is so close that a further detailed discussion of the chemical properties of the former is unnecessary.

The ketones are generally named after the alkyl 


\section{Structure of Simpler Organic Compounds. 85}

groups which they contain. Thus, $\mathrm{CH}_{3} \cdot \mathrm{CO} \cdot \mathrm{CH}_{3}$, generally known as acetone, can be designated dimethyl ketone; $\mathrm{CH}_{3} \cdot \mathrm{CO} \cdot \mathrm{C}_{2} \mathrm{H}_{5}$, methylethyl ketone; $\mathrm{C}_{2} \mathrm{H}_{5} \cdot \mathrm{CO} \cdot \mathrm{C}_{2} \mathrm{H}_{6}$, diethyl ketone. Acetone was originally obtained by the dry distillation of the calcium salt of acetic acid thus-

$$
\left(\mathrm{C}_{2} \mathrm{H}_{4} \mathrm{O}\right)_{2} \mathrm{Ca}=\mathrm{CaCO}_{3}+\mathrm{CH}_{3} \mathrm{COCH}_{3}
$$

Hence the name-acetone. Calcium propionate (see p. 90) in a similar way yields diethyl ketone, and is sometimes called propionone.

Of the simple ketones, only one needs any detailed consideration.

Acetone.-This substance occurs in small quantities in normal urine and in larger quantities in the urine of patients suffering from diabetes mellitus, to which it imparts its characteristic odour. It is a product of the destructive distillation of wood. It is prepared on a large scale by the distillation of calcium acetate, and can be readily separated from the crude distillate by shaking it with sodium bisulphite, with which it forms a crystalline addition product (see above). This product can be decomposed by distilling with sodium carbonate. An aqueous solution of acetone then distils over, from which the water can be removed when it is redistilled over calcium chloride. Acetone is a colourless liquid, boiling point $56.5^{\circ}$, with a characteristic odour, and is miscible with water, alcohol, and ether in all proportions. It is largely used as a solvent.

The general properties of the ketones may be summarized as follows:

Their constitution is indicated by their formation by the oxidation of secondary alcohols, with which they can be reconverted by nascent hydrogen. Their properties are similar to those of the aldehydes, from which they differ in that they are not so readily oxidized; and when oxidation does tuke place they yield, in contra- 
distinction to the aldehydes, acids with a smaller number. of carbon atoms. They can be represented by the general formula $\begin{aligned} & R \\ & R^{\prime}\end{aligned}>C O$, where $R$ and $R^{\prime}$ may be the same or different alkyl radicles.

\section{ADDENDUM TO PARTS IV. AND V.-SUBSTITUTED} ALDEHYDES AND KETONES.

Aldehydes and ketones are also known in which the hydrogen of the alkyl radicle is substituted by a halogen atom. Certain of these compounds are of technological importance by virtue of their powerful narcotic action.

Chloral.-The chief of these is chloral, $\mathrm{CCl}_{3} \cdot \mathrm{CHO}$, which may be regarded as acetaldehyde in which three of the hydrogen atoms of the methyl group are substituted by chlorine. It is formed by the action of chlorine on alcohol by a series of somewhat complex reactions, and was originally isolated by Liebig. It is an oily liquid, boiling point $20^{\circ}$, which readily forms a crystalline addition product with water, to which the formula $\mathrm{CCl}_{3} \mathrm{CH} \angle \mathrm{OH}$ may be assigned. The crystals, which melt at $57^{\circ}$, are soluble in water; it is in the form of the hydrate that it is generally employed as a drug. Chloral hydrate exhibits most of the characteristic aldehyde reactions, and is readily oxidized to trichloracetic acid-that is, acetic acid in which three of the hydrogen atoms are replaced by chlorine (see p. 90 ).

$$
2 \mathrm{CCl}_{3} \mathrm{CHO}+\mathrm{O}_{2}=2 \mathrm{CCl}_{3} \cdot \mathrm{CO}_{2} \mathrm{H}
$$

Other analogous more complex substances are known, such as butyl chloral, which find a limited application in medicine as narcotics or hypnotics. 
Structure of Simpler Organic Compounds. 87

\section{Part VI.-The Fatty Acids.}

On the oxidation of aldehydes with suitable oxidizing reagents a series of products, to which reference has been repeatedly made, is formed. These form the important class of organic compounds known as the fatty acids, as the higher members of the series are obtained from the natural fats. Formic aldehyde and acetic aldehyde yield in this way the two lowest members of the series, namely, formic and acetic acid, $\mathrm{H} \cdot \mathrm{CO}_{2} \mathrm{H}$ and $\mathrm{CH}_{3} \cdot \mathrm{CO}_{2} \mathrm{H}$.

The general formula assigned to these substances is-

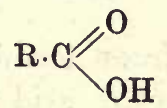

Formic and acetic acids would consequently have the formulæ-

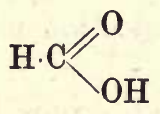

They all contain the group - $\mathrm{C} / \mathrm{OH}$, which is known as the carboxyl group, and is characteristic of most of the organic acids. Substances containing such a group (except those which contain also a basic or alkaline group-as, for example, certain amino-acids, see p. 219) have definite acidic properties. Their solutions turn red litmus paper blue, and they can be neutralized by alkalis and other bases, and give rise to a well-defined series of salts. Thus, with sodium hydroxide-

$$
\mathrm{R} \cdot \mathrm{CO}_{2} \mathrm{H}+\mathrm{NaOH}=\mathrm{R} \cdot \mathrm{CO}_{2} \mathrm{Na}+\mathrm{H}_{2} \mathrm{O}
$$

This fact alone might indicate the presence of a hydroxyl group such as exists in the alcohols. There is, however, a marked difference between the action of alkali metals in the case of the alcohols and acids; for whereas the metallic 
derivatives of the former can be obtained only by the direct action of the metal itself, with evolution of hydrogen-

$$
2 \mathrm{R} \cdot \mathrm{OH}+2 \mathrm{Na}=2 \mathrm{RONa}+\mathrm{H}_{2}
$$

and the products thus obtained are decomposable by water-

$$
\mathrm{R} \cdot \mathrm{ONa}+\mathrm{H}_{2} \mathrm{O}=\mathrm{R} \cdot \mathrm{OH}+\mathrm{NaOH}
$$

the metallic derivatives of the acids can be obtained by the action of the caustic alkalis and other bases, and are stable in the presence of water (or undergo decomposition only to a minor extent, especially when an excess of alkali is absent).

The salts derived from formic acid are known as formates, and those of acetic acid are known as acetates. The free acids themselves can be designated as hydrogen formate or hydrogen acetate respectively, and the termination ate is used generally in connection with salts of these acids.

If they contain a hydroxyl group it might also be surmised that this should be replaceable by a halogen. As a matter of fact, when these acids are treated with phosphorus halogen compounds the expected reaction takes place, and a series of well-defined products of the general formula $\mathrm{R} \cdot \mathrm{COCl}, \mathrm{R} \cdot \mathrm{COBr}$ are obtained when the acids are treated with phosphorus pentachloride or bromide.

These reactions should indicate, therefore, the existence of a hydroxyl group, and the formulæ of the acids can therefore be expanded from R. $\mathrm{CO}_{2} \mathrm{H}$ into R.CO.OH. The formulæ of the salts of the monad metals would be R.CO.OM.

In addition to the method of preparation of the acids by the oxidation of aldehydes, there is also another very important one which indicates their genetic relationship to other substances. Cyanides (or nitriles, as they are some- 


\section{Structure of Simpler Organic Compounds. 89}

times called), on boiling with dilute mineral acids, undergo hydrolysis to yield acids -

$$
\text { R. } \mathrm{CN}+2 \mathrm{H}_{2} \mathrm{O}=\mathrm{R} \cdot \mathrm{CO}_{2} \mathrm{H}+2 \mathrm{NH}_{3}
$$

(the ammonia will, of course, combine with the acids).

This reaction is of practically universal application, and is repeatedly employed in the synthesis of acids. By means of it formic acid can be obtained from hydrocyanic acid (HCN), and acetic acid from acetonitrile. Now the nitriles themselves are readily obtained from halogen derivatives when the latter are treated with potassium cyanide. Thus, methyl iodide when treated with potassium cyanide reacts thus-

$$
\mathrm{CH}_{3} \mathrm{I}+\mathrm{KCN}=\mathrm{CH}_{3} \mathrm{CN} \cdot+\mathrm{KI}
$$

The cyanide on hydrolysis yields acetic acid-

$$
\mathrm{CH}_{3} \mathrm{CN}+2 \mathrm{H}_{2} \mathrm{O}=\mathrm{CH}_{3} \cdot \mathrm{CO}_{2} \mathrm{H}+2 \mathrm{NH}_{3}
$$

This synthesis indicates that in acetic acid there is a methyl group. A similar conclusion can be drawn from the fact that acetic acid can be derived from the oxidation of ethyl alcohol (through aldehyde) -

$$
\mathrm{CH}_{3} \cdot \mathrm{CH}_{2} \cdot \mathrm{OH} \longrightarrow \mathrm{CH}_{3} \cdot \mathrm{CHO} \longrightarrow \mathrm{CH}_{3} \cdot \mathrm{CO}_{2} \mathrm{H}
$$

The constitution of the acids can be further exemplified by certain reactions of acetic acid itself. Of the four hydrogen atoms contained in the formula $\mathrm{C}_{2} \mathrm{H}_{4} \mathrm{O}_{2}$, one and one only is replaceable by a metal. Furthermore, this hydrogen atom, together with $\mathrm{O}$ (combined together in a hydroxyl group), is replaceable by a halogen. Now when acetic acid is treated with chlorine, a series of products can be obtained, in which consecutively one, two, or three hydrogen atoms are replaced by the halogen. It might be expected, from what has been already learnt of the formation of substitution products, that this substitution should take place in the alkyl (methyl) group. If this is 
really the case, the following should be the formulæ assignable to the chlorine substitution products of acetic acid:-

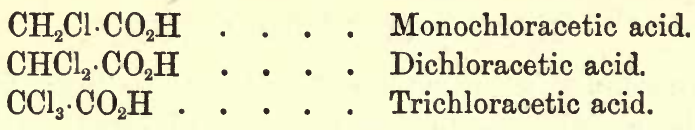

If, now, the carboxyl group has remained intact throughout these operations, these substitution products should still have a hydrogen replaceable by a metal and give salts with the formulæ $\mathrm{CH}_{2} \mathrm{Cl} \cdot \mathrm{CO}_{2} M, \mathrm{CHCl}_{2} \cdot \mathrm{CO}_{2} M, \mathrm{CCl}_{3} \cdot \mathrm{CO}_{2} M$ (when $M=\mathrm{Na}, \mathrm{K}$, or any univalent metal). The hydroxyl group should, furthermore, be replaceable by chlorine, and it should be possible to obtain substances of the formulæ $\mathrm{CH}_{2} \mathrm{Cl} \cdot \mathrm{COCl}, \mathrm{CHCl}_{2} \cdot \mathrm{COCl}, \mathrm{CCl}_{3} \cdot \mathrm{COCl}$, on treatment of the above chlorine derivatives with phosphorus pentachloride. As a matter of fact, all these reactions can be accomplished. There seems, therefore, no other possible constitutional formula for acetic acid than that which has been proposed, which may be expanded into the following:-

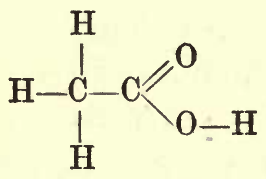

This indicates the presence of a methyl group and a hydroxyl group, and the oxygen atom other than that in the carboxyl group is directly united to a carbon atom as it is in the aldehyde from which the acid is derived by oxidation.

The following are some of the chief fatty acids, with their physical properties:-

$\begin{array}{lllll} & & & & \\ \text { Formic } & \text { acid } & \mathrm{H} \cdot \mathrm{CO}_{2} \mathrm{H} & 8 \cdot 3^{\circ} & \text { point. } \\ \text { Acetic } & \Rightarrow & \mathrm{CH}_{3} \cdot \mathrm{CO}_{2} \mathrm{H} & 161^{\circ} & 118^{\circ} \\ \text { Propionic } & \quad & \mathrm{C}_{2} \mathrm{H}_{6} \cdot \mathrm{CO}_{2} \mathrm{H} & 36^{\circ} & 141^{\circ}\end{array}$


Structure of Simpler Organic Compounds. 91

\begin{tabular}{|c|c|c|c|c|}
\hline & & & $\begin{array}{c}\text { Melting } \\
\text { point. }\end{array}$ & $\begin{array}{l}\text { Boiling } \\
\text { point. }\end{array}$ \\
\hline Normal butyric & acid & $\mathrm{C}_{3} \mathrm{H}_{7} \cdot \mathrm{CO}_{2} \mathrm{H}$ & $-4^{\circ}$ & $163^{\circ}$ \\
\hline Iso butyric & ", & " & $-79^{\circ}$ & $155^{\circ}$ \\
\hline Normal valeric & , & $\mathrm{C}_{4} \mathrm{H}_{9} \cdot \mathrm{CO}_{2} \mathrm{H}$ & $-59^{\circ}$ & $186^{\circ}$ \\
\hline Iso valeric & $"$ & & $-51^{\circ}$ & $174^{\circ}$ \\
\hline Normal heptylic & , & $\mathrm{C}_{6} \mathrm{H}_{13} \cdot \mathrm{CO}_{2} \mathrm{H}$ & $-10.5^{\circ}$ & $223^{\circ}$ \\
\hline " lauric & " & $\mathrm{C}_{11} \mathrm{H}_{23} \cdot \mathrm{CO}_{2} \mathrm{H}$ & $+43 \cdot 6^{\circ}$ & \\
\hline " myristic & $"$ & $\mathrm{C}_{13} \mathrm{H}_{27} \cdot \mathrm{CO}_{2} \mathrm{H}$ & $+54^{\circ}$ & \\
\hline " palmitic & 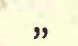 & $\mathrm{C}_{15} \mathrm{H}_{31} \cdot \mathrm{CO}_{2} \mathrm{H}$ & $+62^{\circ}$ & \\
\hline " stearic & $"$ & $\mathrm{C}_{17} \mathrm{H}_{35} \cdot \mathrm{CO}_{2} \mathrm{H}$ & $+69^{\circ}$ & \\
\hline
\end{tabular}

The general formula of all these acids is $\mathrm{C}_{n} \mathrm{H}_{2 n} \mathrm{O}_{2}$. The higher ones, which are all "long-chained" derivatives (that is, $\left.\mathrm{CH}_{3} \cdot \mathrm{CH}_{2} \cdot \mathrm{CH}_{2} \ldots \mathrm{CH}_{2} \cdot \mathrm{COOH}\right)$, ${ }^{*}$ are derived by the "saponification" of fats and oils (see p. 181). In the higher members of the series a large number of isomerides can be obtained, and, as in the case of other homologous series, the larger the number of carbon atoms, the greater the number capable of existence. There is, however, a general synthetical method for preparing these higher acids which will be discussed later. There are, however, apart from the acids derived from fats and oils, few of them which are of any direct interest in connection with this subject.

Formic acid, $\mathrm{H} \cdot \mathrm{CO}_{2} \mathrm{H}$, occurs in nature in ants, stinging nettles, and other organisms, and is usually prepared by heating glycerol (glycerine) with anhydrous oxalic acid (see p. 106). The reaction is a somewhat complex one, but the ultimate result may be expressed by the equation-

$$
\mathrm{H}_{2} \mathrm{C}_{2} \mathrm{O}_{4}=\mathrm{CO}_{2}+\mathrm{H} \cdot \mathrm{CO}_{2} \mathrm{H}
$$

The formic acid is separated from the crude product thus obtained in the form of its lead salt by warming the aqueous distillate produced in the reaction with litharge. The salt $(\mathrm{H} \cdot \mathrm{COO})_{2} \mathrm{~Pb}$ is then produced, from which pure

\footnotetext{
"For the meaning of "long-chained," see p. 50.
} 
formic acid can be obtained by treatment with hydrogen sulphide gas.*

Formic acid when obtained anhydrous is a hygroscopic liquid with a characteristic pungent odour. It differs from the higher fatty acids of the series in the fact that it is somewhat readily oxidized. Like the aldehydes, it reduces ammoniacal silver solutions thus-

$$
\mathrm{H} \cdot \mathrm{COOH}+\mathrm{Ag}_{2} \mathrm{O}=2 \mathrm{Ag}+\mathrm{CO}_{2}+\mathrm{H}_{2} \mathrm{O}
$$

It forms a well-defined series of salts known as the formates. Formic acid is now largely used as a solvent in the laboratory.

Acetic Acid, $\mathrm{CH}_{3} \cdot \mathrm{COOH}$.-This important acid can be obtained on a large scale by the destructive distillation of wood, and also from crude alcoholic liquors which have been left exposed to air and allowed to become sour. The reaction which takes place in the conversion of alcohol into acetic acid may be represented by the equation-

$$
\mathrm{C}_{2} \mathrm{H}_{6} \mathrm{O}+\mathrm{O}_{2}=\mathrm{C}_{2} \mathrm{H}_{4} \mathrm{O}_{2}+\mathrm{CO}_{2}
$$

It was found out by Pasteur that this reaction is not one of simple oxidation, but is a fermentation + process brought about by the action of a living organism, the mycoderma aceti.

Vinegar thus produced is a dilute solution of acetic acid, containing colouring matter and other substances which give to the different preparations their characteristic odours. Vinegars contain from 4 per cent. to 10 per cent. of acetic acid.

"Glacial," or anhydrous, acetic acid is made by treating the anhydrous sodium salt with concentrated sulphuric acid. The sodium salt can be obtained by neutralizing dilute acetic acid preparations obtained in various com-

- For details, refer to a text-book on practical organic chemistry.

+ The action of ferments is discussed in greater detail in Chapter VI. 


\section{Structure of Simpler Organic Compounds.}

mercial processes with sodium carbonate; on concentration of the solutions thus produced, the hydrated salt separates out in crystals. The anhydrous salt can be obtained by fusing these crystals.

Glacial acetic acid has a sharp pungent taste, and exerts a corroding action on animal tissues. It is miscible with water, alcohol, and ether in all proportions. It is largely used in the preparation of various drugs, dyes, and other chemicals, and also as a solvent in the laboratory. Some of the salts are of importance.

Sodium acetate, $\mathrm{C}_{2} \mathrm{H}_{3} \mathrm{O}_{2} \mathrm{Na} \cdot 3 \mathrm{H}_{2} \mathrm{O}$, is largely used as a laboratory reagent.

Lead acetate, $\left(\mathrm{C}_{2} \mathrm{H}_{3} \mathrm{O}_{2}\right)_{2} \mathrm{~Pb} \cdot 3 \mathrm{H}_{2} \mathrm{O}$, and basic lead acetate are both largely used as precipitants; the former is prepared by dissolving litharge in acetic acid solutions and concentrating the product; the basic salt is obtained by dissolving litharge in solutions of the ordinary acetate.

Various copper acetates are known, of which one of the basic ones is known as verdigris.

Of the other fatty acids, propionic acid occurs amongst the products of destructive distillation of wood; normal butyric acid occurs in butter (as a glyceride), and is produced as a product of various fermentation processes. The valeric acids occur in various plants. The higher fatty acids will be referred to in detail later in the discussion of the chemistry of fats.

The chemistry of the fatty acids may be summarized as follows: They can be represented by the general formula $R-\mathrm{COOH}$, the residue $-\mathrm{CO} \cdot \mathrm{OH}$ being known as the carboxyl group, and contained in the majority of organic acids. It contains one hydrogen replaceable by a metal, and a hydroxyl group replaceable by chlorine when the acid is treated with phosphorus pentachloride. The genetic relationship of the acids to the substances already discussed 
is indicated by the fact that they can be produced from the primary alcohols by oxidation, the acids thus obtained containing the same number of carbon atoms as the alcohol, and they can be synthesized from hydrocarbons through the intermediation, first, of halogen derivatives, then of nitriles or cyanides, which latter substances, on hydrolysis with mineral acids, yield the organic (carboxylic) acids.

\section{Part VII.-The Esters.}

Attention has been already called to the fact (p. 67) that a series of substances can be derived from inorganic acids by the replacement of a hydrogen atom by an alkyl radicle. The following are typical examples of such derivatives :

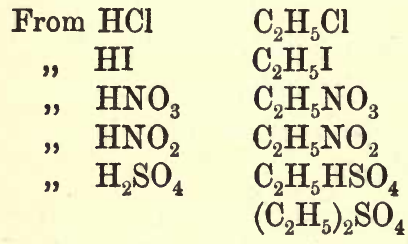

General formula, R.Cl

$\begin{array}{ll}" & \mathrm{RI} \\ " & \mathrm{R} \cdot \mathrm{NO}_{3} \\ " & \mathrm{R} \cdot \mathrm{NO}_{2} \\ " & \mathrm{RHSO} \\ & \mathrm{R}_{2} \cdot \mathrm{SO}_{4}\end{array}$

In the same way from organic acids of the formula $\mathrm{R} \cdot \mathrm{CO} \cdot \mathrm{OH}$ a series of compounds can be derived in which the (acid) hydrogen of the carboxyl group is replaced by an alkyl radicle, and which can be represented by the general formula $\mathrm{R} \cdot \mathrm{CO} \cdot \mathrm{OR}^{\prime}$. Such compounds may be regarded as analogous to salts of organic acids, in which the hydrogen of the carboxyl group, instead of being replaced by a metal, is replaced by an alkyl radicle. They are, therefore, sometimes called alkyl salts of acids. The substance, $\mathrm{CH}_{3} \cdot \mathrm{CO} \cdot \mathrm{OC}_{2} \mathrm{H}_{5}$, if this latter method of regarding these substances is adopted, may be called ethyl acetate-that is to say, it is a derivative of acetic acid, in which the hydrogen atom is replaced by the alkyl group ethyl. Substances derived from acids by the re- 


\section{Structure of Simpler Organic Compounds. 95}

placement of the hydrogen atom by an alkyl group are known generally as esters.

The derivatives of the halogen acids have been already discussed (p. 62 and seq.). These have been regarded as halogen substitution products of hydrocarbons, and some of them can be produced by the method of direct substitution. The product, $\mathrm{C}_{2} \mathrm{H}_{5} \mathrm{Br}$, for example, may therefore be designated as monobrom ethane or ethyl bromide. According to the first title it would be regarded as a substitution product of ethane; and according to the second an ethyl ester of hydrobromic acid. The esters are more generally produced from the alcohols by treatment of these substances with the acids in the presence of a dehydrating agent to remove the water-

$$
\begin{array}{lll}
\mathrm{R} \cdot \mathrm{OH}+\mathrm{HCl} & \rightleftarrows \mathrm{RCl}+\mathrm{H}_{2} \mathrm{O} \\
\mathrm{R} \cdot \mathrm{OH}+\mathrm{R}^{\prime} \cdot \mathrm{CO} \cdot \mathrm{OH} & \rightleftarrows \mathrm{R}^{\prime} \cdot \mathrm{CO} \cdot \mathrm{OR}+\mathrm{H}_{2} \mathrm{O}
\end{array}
$$

The dehydrating agent is employed to remove the water formed in the reaction. When acids and alcohols are mixed, a reaction takes place. The change is a reversible one, and the final composition of a mixture of an alcohol and acid will depend upon the relative proportions of the various substances in the mixture. When large amounts of water are present, the principal reaction is in the direction of the arrow pointing to the left-that is, the water tends to decompose the ester formed. If, however, a dehydrating agent is present (such as concentrated sulphuric acid), the water is removed from the sphere of action, and the formation of the ester tends to proceed towards completion - that is, in the direction of the arrow pointing to the right. This is, perhaps, the most general method of preparing esters. The phenomenon of ester formation, or "esterification," is governed by the general laws of mass action, and need not be further discussed in this place. 
Ethyl nitrate is formed when alcohol is treated with nitric acid-

$$
\mathrm{C}_{2} \mathrm{H}_{5} \mathrm{OH}+\mathrm{HNO}_{3}=\mathrm{H}_{2} \mathrm{O}+\mathrm{C}_{2} \mathrm{H}_{5} \cdot \mathrm{NO}_{3}
$$

This reaction is carried out in the presence of urea (carbamide), which decomposes nitrous acid and moderates the reaction-

$$
2 \mathrm{HO} \cdot \mathrm{NO}+\mathrm{CO}\left(\mathrm{NH}_{2}\right)_{2}=\mathrm{CO}_{2}+\mathrm{H}_{3} \mathrm{O}+\mathrm{N}_{2}
$$

If urea is not present, the reaction is apt to take place with explosive violence.

Ethyl nitrate is a colourless liquid, boiling point $87^{\circ}$, with a pleasant fruity odour, and but slightly soluble in water.

Ethyl nitrite, prepared by treatment of alcohol with nitrous acid (a mixture of sulphuric acid and potassium nitrite), is a colourless liquid, boiling point $17^{\circ}$. It is a constituent of the pharmacopœeal preparation of sweet spirit of nitre.

Ethyl nitrite can also be prepared by treatment of silver nitrite with ethyl iodide-

$$
\mathrm{AgNO}_{2}+\mathrm{C}_{2} \mathrm{H}_{5} \mathrm{I}=\mathrm{AgI}+\mathrm{C}_{2} \mathrm{H}_{5} \mathrm{NO}_{2}
$$

By this method, however, a mixture of two isomerides is obtained-the one ethyl nitrite, boiling point $17^{\circ}$, and the other the so-called nitroethane, boiling point $114^{\circ}$. The constitution of the former may be represented by the formula-

$$
\mathrm{O}=\mathrm{N}-\mathrm{OC}_{2} \mathrm{H}_{5}
$$

-that is, a true derivative of nitrous acid, in which a hydrogen is replaced by an ethyl radicle, whereas the constitution of nitroethane is represented by the formula-

$$
\mathrm{C}_{2} \mathrm{H}_{5}-\mathrm{N} / 0
$$

- that is, the nitrogen is directly united to a carbon of the alkyl radicle. The reason for assigning this constitution 


\section{Structure of Simpler Organic Compounds.}

is, that on treatment with nascent hydrogen it is reduced to ethylamine-

$$
\mathrm{C}_{2} \mathrm{H}_{5} \mathrm{NO}_{2}+3 \mathrm{H}_{2}=\mathrm{C}_{2} \mathrm{H}_{5} \cdot \mathrm{NH}_{2}+3 \mathrm{H}_{2} \mathrm{O}
$$

This latter substance, the chemistry of which will be discussed later, is known, from other methods of preparation, to have a nitrogen directly united to a carbon atom.

Amyl nitrite, boiling point $96^{\circ}$, is used in medicine on account of its characteristic action on the heart.

Ethyl hydrogen sulphate, $\mathrm{C}_{2} \mathrm{H}_{5} \cdot \mathrm{HSO}_{4}$, is formed by the treatment of alcohol with sulphuric acid. On treating this mixture, after warming, with barium carbonate, the excess of sulphuric acid is precipitated as barium sulphate, and barium ethyl sulphate, $\left(\mathrm{C}_{2} \mathrm{H}_{5} \mathrm{SO}_{4}\right)_{2} \mathrm{Ba}$, remains in solution and crystallizes out on concentration of the liquid. The free acid is a very strong acid which readily decomposes; it is used chiefly in the form of its salts.

Diethyl sulphate, $\left(\mathrm{C}_{2} \mathrm{H}_{5}\right)_{2} \mathrm{SO}_{4}$, can be obtained by the action of ethyl iodide on silver sulphate-

$$
2 \mathrm{C}_{2} \mathrm{H}_{5} \mathrm{I}+\mathrm{Ag}_{2} \mathrm{SO}_{4}=\left(\mathrm{C}_{2} \mathrm{H}_{5}\right)_{2} \mathrm{SO}_{4}+\mathrm{AgI}
$$

Ethyl acetate, $\mathrm{CH}_{3} \cdot \mathrm{CO} \cdot \mathrm{OC}_{2} \mathrm{H}_{5}$, may be taken as a type of an important series of organic compounds, namely, the esters of the organic acids. It can be prepared by a variety of methods, the chief of which consists in the treatment of a mixture of alcohol and acetic acid with a dehydrating agent such as sulphuric acid-

$$
\mathrm{CH}_{3} \mathrm{COOH}+\mathrm{C}_{2} \mathrm{H}_{5} \mathrm{OH}=\mathrm{H}_{2} \mathrm{O}+\mathrm{CH}_{3} \mathrm{CO} \cdot \mathrm{OC}_{2} \mathrm{H}_{5}
$$

It can also be prepared, like some of the other esters above mentioned, by double decomposition between the silver salt of the acid and an alkyl iodide-

$$
\mathrm{CH}_{3} \mathrm{COOAg}+\mathrm{C}_{2} \mathrm{H}_{5} \mathrm{I}=\mathrm{AgI}+\mathrm{CH}_{3} \cdot \mathrm{COOC}_{2} \mathrm{H}_{5}
$$

These two methods illustrate sufficiently the chemical constitution of the substance. 
Ethyl acetate, like most other esters of organic acids, is a liquid with pleasant fruity odour and boiling point $77^{\circ}$. It is only slightly soluble in water, but miscible with organic solvents, such as alcohol, ether, etc. It is like other esters, readily hydrolyzed on boiling with solutions of alkalis and acids, yielding a mixture of the alcohol and acid (or a salt of the same) from which it has been prepared-

$$
\mathrm{CH}_{3} \cdot \mathrm{CO} \cdot \mathrm{OC}_{2} \mathrm{H}_{5}+\mathrm{NaOH}=\mathrm{C}_{2} \mathrm{H}_{5} \mathrm{OH}+\mathrm{CH}_{3} \cdot \mathrm{CO} \cdot \mathrm{ONa}
$$

This process of hydrolysis is known as "saponification," as the sodium salts of the higher fatty acids produced in the process yield soaps (see below).

In addition to the esters of the alcohols containing only one hydroxyl group, esters can also be obtained from the polyhydroxy alcohols - as, for example, glycol and glycerol. In these substances, one or more hydroxyl groups can enter into reaction, in the case of the organic acids, with one or two carboxyl groups. Thus, from glycol two esters can be obtained by reaction with an acid of the formula $\mathrm{R} \cdot \mathrm{COOH}$, namely-

$$
\begin{aligned}
& \mathrm{R} \cdot \mathrm{CO} \cdot \mathrm{O} \cdot \mathrm{H}_{2} \mathrm{C} \\
& \mathrm{R} \cdot \mathrm{CO} \cdot \mathrm{O} \cdot \mathrm{H}_{2} \mathrm{C}
\end{aligned} \text { and } \begin{array}{r}
\mathrm{R} \cdot \mathrm{CO} \cdot \mathrm{OCH}_{2} \\
\mathrm{HO} \cdot \mathrm{CH}_{2}
\end{array}
$$

Glycerol, which contains three hydroxyl groups, can yield esters of the general formula-

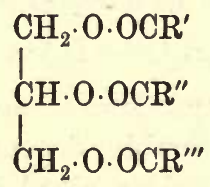

and it can also yield esters in which only one or two of the hydroxyl groups have undergone condensation with a carboxylic acid. The esters in which all the hydroxyl groups have undergone condensation, which are repre- 


\section{Structure of Simpler Organic Compounds.}

sented by the above formulæ, form a very important class of compounds. Where $R_{1} R^{\prime \prime}$ and $R^{\prime \prime \prime}$ represent complex radicles-that is, when glycerol has undergone condensation with acids of high molecular weights, such as palmitic, stearic acids, etc. - the substances known as the fats and fatty oils are produced. The chemistry of these substances will be discussed in detail later.

To summarize, the esters are substances produced by the condensation of alcohol with acids, of which the most important class, as far as the subject of this book is concerned, are those formed by condensation of the alcohols with the organic (carboxylic) acids. In this case the effect of mixing alcohols and acids may be represented by the general equation-

\section{$\mathrm{R} \cdot \mathrm{OH}+\mathrm{R}^{\prime} \cdot \mathrm{COOH} \rightleftarrows \mathrm{H}_{2} \mathrm{O}+\mathrm{R} \cdot \mathrm{O} \cdot \mathrm{CO} \cdot \mathrm{R}^{\prime}$}

The process, known as esterification, is a reversible one, and only proceeds to completion (or towards completion) in the presence of a reagent which withdraws water from the sphere of action. The esters are neutral substances, which are readily hydrolyzed by alkalis in accordance with the equation-

\section{$\mathrm{R} \cdot \mathrm{O} \cdot \mathrm{CO} \cdot \mathrm{R}^{\prime}+\mathrm{NaOH}=\mathrm{R}^{\prime} \cdot \mathrm{CO} \cdot \mathrm{ONa}+\mathrm{R} \cdot \mathrm{OH}$}

This process is generally known as "saponification." In the case of alcohols containing more than one hydroxyl group, one or more of such groups can take part in ester formation. In the case of glycerol, when ester formation has taken place between the three hydroxyl groups and higher fatty acids, the fats and fatty oils are obtained, which on hydrolysis with caustic alkalis give rise to glycerol and alkali salts of the fatty acids, which are generally known as the soaps. 


\section{Part VIII.-Some Derivatives of Fatty Acids.}

(a) ACID CHLORIDES.

It has been already stated that carboxylic acids, when treated with phosphorus pentachloride, react according to the equation-

$$
\mathrm{R} \cdot \mathrm{CO} \cdot \mathrm{OH}+\mathrm{PCl}_{5}=\mathrm{POCl}_{3}+\mathrm{R} \cdot \mathrm{CO} \cdot \mathrm{Cl}+\mathrm{HCl}
$$

Phosphorus trichloride can also be employed, the reaction being represented by the equation-

$$
3 \mathrm{R} \cdot \mathrm{CO} \cdot \mathrm{OH}+\mathrm{PCl}_{3}=3 \mathrm{R} \cdot \mathrm{CO} \cdot \mathrm{Cl}+\mathrm{P}_{2} \mathrm{O}_{3}+3 \mathrm{HCl}
$$

The substance obtained from acetic acid, $\mathrm{CH}_{3} \cdot \mathrm{COCl}$, is known as acetyl chloride; that from propionic acid, propionyl chloride, the termination $y l$ being generally employed in designating substance of this class. The group $\left(\mathrm{CH}_{3} \cdot \mathrm{CO}\right)$ is known as the acetyl group.

These acid chlorides readily react with other substances containing a hydroxyl group, as, for example, water or alcohols, the chlorine being removed from the molecule in the form of hydrochloric acid. The reactions may be illustrated by the two following equations-

$$
\begin{aligned}
& \mathrm{CH}_{3} \cdot \mathrm{COCl}+\mathrm{H}_{2} \mathrm{O}=\mathrm{CH}_{3} \cdot \mathrm{CO} \cdot \mathrm{OH}+\mathrm{HCl} \\
& \mathrm{CH}_{3} \cdot \mathrm{COCl}+\mathrm{C}_{2} \mathrm{H}_{5} \mathrm{OH}=\mathrm{CH}_{3} \cdot \mathrm{COOC}_{2} \mathrm{H}_{5}+\mathrm{HCl}
\end{aligned}
$$

In the former case, the original acid is regenerated, and in the latter, an ester is formed. Both of these reactions are types of general ones, and the second is often employed for the preparation of esters.

Acetyl chloride is a liquid which boils at $55^{\circ}$, and has, like other members of the series, a very pungent odour. It forms fumes when exposed to moist air.

\section{(b) ACID ANHYDRIDES.}

The carboxylic acids are capable of forming anhydrides of the general formula- 
Structure of Simpler Organic Compoinds 101

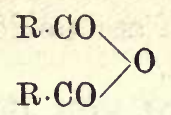

These can be prepared by treating an alkali salt of the acid with its acid chloride, for example-

$$
\mathrm{CH}_{3} \cdot \mathrm{COOK}+\mathrm{CH}_{3} \mathrm{COCl}=\mathrm{KCl}+\mathrm{CH}_{3} \cdot \mathrm{CO} \cdot 0 \cdot \mathrm{CO} \cdot \mathrm{CH}_{3}
$$

When the alkali salt is treated with phosphorus oxychloride, the salt yields acetyl chloride, which then reacts with more salt. This is the more general method of preparation, the formation of the anhydride being represented by the equation-

$$
4 \mathrm{CH}_{3} \cdot \mathrm{COONa}+\mathrm{POCl}_{3}=2\left(\mathrm{CH}_{3} \mathrm{CO}\right)_{2} \mathrm{O}+\mathrm{NaPO}_{3}+3 \mathrm{NaCl}
$$

The anhydrides, like the acid chlorides, readily react with substances containing a hydroxyl group; thus, with water-

$$
\left(\mathrm{CH}_{3} \cdot \mathrm{CO}\right)_{2} \mathrm{O}+\mathrm{H}_{2} \mathrm{O}=2 \mathrm{CH}_{3} \cdot \mathrm{CO} \cdot \mathrm{OH}
$$

the anhydride being reconverted into its acid. With alcohol-

$$
\left(\mathrm{CH}_{3} \mathrm{CO}\right)_{2} \mathrm{O}+\mathrm{C}_{2} \mathrm{H}_{5} \mathrm{OH}=\mathrm{CH}_{3} \cdot \mathrm{COOC}_{2} \mathrm{H}_{5}+\mathrm{CH}_{3} \mathrm{CO} \cdot \mathrm{OH}
$$

In this case a mixture of acid and ester is obtained.

Acetic anhydride, $\left(\mathrm{CH}_{3} \mathrm{CO}\right)_{2} \mathrm{O}$, is a liquid with irritant, unpleasant odour, of boiling point $137^{\circ}$.

\section{(c) AMIDES.}

When an ester, an anhydride, or acid chloride of an acid is treated with ammonia a product is obtained which may be regarded as derived from a carboxylic acid by the replacement of its hydroxyl group by another group containing the elements $-\mathrm{NH}_{2}$, and known as the amido group.

These reactions, in the case of the acetic acid derivatives, may be represented by the equations-

$$
\begin{gathered}
\mathrm{CH}_{3} \mathrm{COOC}_{2} \mathrm{H}_{5}+\mathrm{NH}_{3}=\mathrm{CH}_{3} \cdot \mathrm{CO} \cdot \mathrm{NH}_{2}+\mathrm{C}_{2} \mathrm{H}_{5} \mathrm{OH} \\
\left(\mathrm{CH}_{3} \mathrm{CO}\right)_{2} \mathrm{O}+2 \mathrm{NH}_{3}=\mathrm{CH}_{3} \mathrm{CO} \cdot \mathrm{NH}_{2}+\mathrm{CH}_{3} \cdot \mathrm{CO} \cdot \mathrm{ONH}_{4}
\end{gathered}
$$


(In this case a mixture of acetamide and ammonium acetate is obtained.)

$$
\mathrm{CH}_{3} \cdot \mathrm{CO} \cdot \mathrm{Cl}+2 \mathrm{NH}_{3}=\mathrm{CH}_{3} \cdot \mathrm{CO} \cdot \mathrm{NH}_{2}+\mathrm{NH}_{4} \mathrm{Cl}
$$

The substance obtained in these reactions is known as acetamide, and may be regarded as a derivative of ammonia, $\mathrm{NH}_{3}$, in which one hydrogen is replaced by the acetyl group, $\mathrm{CH}_{3} \mathrm{CO}$ (see p. 100). Acetamide can also be obtained by the distillation of ammonium acetate-

$$
\mathrm{CH}_{3} \cdot \mathrm{COONH} \mathrm{NH}_{4}=\mathrm{CH}_{3} \cdot \mathrm{CO} \cdot \mathrm{NH}_{2}
$$

The acid amides, of which acetamide is the type, are decomposed on heating with mineral acids and alkalis, with evolution of ammonia (which, when an acid has been employed for hydrolysis, combines with it to form an ammonium salt) yielding the acid from which they are derived-

$$
\text { R. } \mathrm{CO} \cdot \mathrm{NH}_{2}+\mathrm{H}_{2} \mathrm{O}=\mathrm{NH}_{3} \cdot+\mathrm{R} \cdot \mathrm{CO} \cdot \mathrm{OH}
$$

Acetamide, $\mathrm{CH}_{3} \cdot \mathrm{CO} \cdot \mathrm{NH}_{2}$, forms colourless crystals, melting point $82^{\circ}$, boiling point $222^{\circ}$, with a characteristic mouse-like odour. It is readily soluble in water and alcohol. The amides of the higher acids are not so readily soluble in water.

\section{ADDENDUM TO PART VIII.-UREA.}

Closely allied to the acid amides is a substance of great importance in physiology, namely, urea or carbamide. In this form mammals excrete the greater part of their waste nitrogen in the urine. It is also a substance of considerable interest in the history of chemistry, for its synthesis by Wöhler in 1828 forms the first example of the artificial preparation of an animal product.

Wöhler found that when an aqueous solution of ammonium cyanate, $\mathrm{NH}_{4} \cdot \mathrm{CNO}$, was evaporated, the atoms in the molecule underwent a rearrangement, and 


\section{Structure of Simpler Organic Compounds. I03}

instead of the original cyanate, an isomeride separated. This reaction affords also a classical example of the phenomenon of isomerism. Ammonium cyanate is obtained by the double decomposition of ammonium sulphate and potassium cyanate. Potassium cyanate can be obtained by the oxidation of potassium cyanide with lead oxide-

$$
\mathrm{KCN}+\mathrm{PbO}=\mathrm{KCNO}+\mathrm{Pb}
$$

It is of interest to note that all these substances were regarded as of inorganic nature, and for this reason the synthesis of urea, a typical animal product, by the above method aroused at the time of its discovery considerable interest in the scientific world.

The change from ammonium cyanate to urea may be represented by the equation-

$$
\mathrm{NH}_{4} \mathrm{O} \cdot \mathrm{C}: \mathrm{N} \longrightarrow \mathrm{OC}<_{\mathrm{NH}_{2}}^{\mathrm{NH}_{2}}
$$

In ammonium cyanate only one nitrogen is directly united to a carbon atom, whereas in urea two nitrogen atoms are so united. The urea is generally synthesized by mixing solutions of potassium cyanate with ammonium sulphate, and evaporating the mixture to dryness. The intermediate product, ammonium cyanate, is not isolated, but the urea is extracted directly from the dried mass by alcohol. Now the constitution of urea is known from various facts. Acid chlorides and esters on treatment with ammonia give rise, as stated above, to acid amides. Urea can be prepared from similar derivatives of carbonic acid. If this latter acid be represented by the formula-

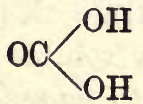

it should form an ester and acid chloride (by the substitution of two hydroxyl groups) of the formulæ- 


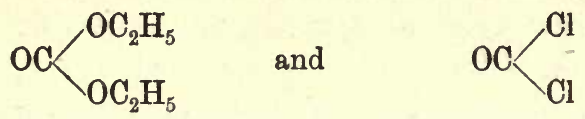

(Note.-These substances are not quite analogous in their formulæ to esters and acid chlorides of simple carboxylic acids, in that carbonic acid can be regarded as a substance with two hydroxyl groups attached to the same carbon atom; the simple carboxylic group, on the other hand, contains only one hydroxyl group.)

The equations representing the formation of urea from the above substances, ethyl carbonate and carbonyl chloride, are the following:-

$$
\begin{array}{ll}
\mathrm{CO}\left(\mathrm{OC}_{2} \mathrm{H}_{5}\right)_{2}+2 \mathrm{NH}_{3} & =\mathrm{CO}\left(\mathrm{NH}_{2}\right)_{2}+2 \mathrm{C}_{2} \mathrm{H}_{5} \mathrm{OH} \\
\mathrm{COCl}_{2}+4 \mathrm{NH}_{3} & =\mathrm{CO}\left(\mathrm{NH}_{2}\right)_{2}+2 \mathrm{NH}_{4} \mathrm{Cl}
\end{array}
$$

Urea is a crystalline substance, melting point $132^{\circ}$, which is soluble in alcohol and water, but almost insoluble in ether. On heating to a high temperature with water under pressure, it decomposes into ammonia and carbon dioxide-

$$
\mathrm{CO}\left(\mathrm{NH}_{2}\right)_{2}+2 \mathrm{H}_{2} \mathrm{O}=\mathrm{CO}_{2}+2 \mathrm{NH}_{3}
$$

It also decomposes when treated with sodium hypobromite-

$$
\mathrm{CO}\left(\mathrm{NH}_{2}\right)_{2}+3 \mathrm{NaOBr}=\mathrm{CO}_{2}+\mathrm{N}_{2}+3 \mathrm{H}_{2} \mathrm{O}+3 \mathrm{NaCl}
$$

This reaction is employed for estimating the urea in a sample of urine; a given volume is treated with a solution of the hypobromite, and the nitrogen evolved in the reaction is measured. This process gives, however, only approximately accurate results.

Urea acts as a base, and forms with acids a series of well-defined salts. The nitrate, $\mathrm{CO}\left(\mathrm{NH}_{2}\right)_{2} \mathrm{HNO}_{3}$, crystallizes well, and is only sparingly soluble in nitric acid. Advantage is taken of this fact to separate urea from urine; the latter fluid is concentrated and treated with strong nitric acid, when urea nitrate separates out. 
Structure of Simpler Organic Compounds. 105

\section{Part IX.-The Dibasic Acids.}

A large number of organic acids are known which contain more than one carboxyl group (see p. 87): As each of such groups contains a hydrogen replaceable by a metal, these acids will be polybasic; those containing two carboxyl groups will have two hydrogens replaceable, and are therefore dibasic; those containing three carboxyl groups are tribasic; and those with still more carboxyl groups will have still higher basicities.

The simplest dibasic acid is oxalic acid, which can be represented by the formula-

\section{$\mathrm{COOH}$ \\ $\mathrm{COOH}$}

-that is, it is a substance consisting of two carboxylic groups only.

The formula of this substance, which is found in a large number of plants, is readily demonstrated by two methods of synthesis. In the first place, it can be obtained from cyanogen by hydrolysis; if an aqueous solution of this gas is kept for some time it forms, amongst other products, ammonium oxalate-

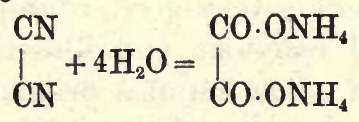

It will be remembered that the (CN) nitrile group always undergoes hydrolysis according to the equation-

$$
-\mathrm{CN}+2 \mathrm{H}_{2} \mathrm{O}=-\mathrm{COOH}+\mathrm{NH}_{3}
$$

(In the absence of a mineral acid the ammonia will form an ammonium salt with the carboxylic acid thus produced, as in the above equation representing the decomposition of cyanogen.)

The second synthesis is an example of the oxidation 


\section{ro6 Biological Chemistry.}

of the primary alcohol group, $-\mathrm{CH}_{2} \mathrm{OH}$, to a carboxyl group (compare p. 70). Oxalic acid can be produced by the oxidation of ethylene glycol, which contains two primary alcoholic groups-

$$
{ }_{\mathrm{CH}_{2} \mathrm{OH}}^{\mathrm{CH}_{2} \mathrm{OH}}+2 \mathrm{O}_{2}=\frac{\mathrm{CO} \cdot \mathrm{OH}}{\mathrm{CO} \cdot \mathrm{OH}}
$$

In this reaction aldehydes can be formed as intermediate products, as might be expected, and one or both of the alcoholic groups can undergo oxidation; in fact, a whole series of intermediate oxidation products might be expected to be formed (and, as a matter of fact, are formed) in the process, the formulæ of which are here given-

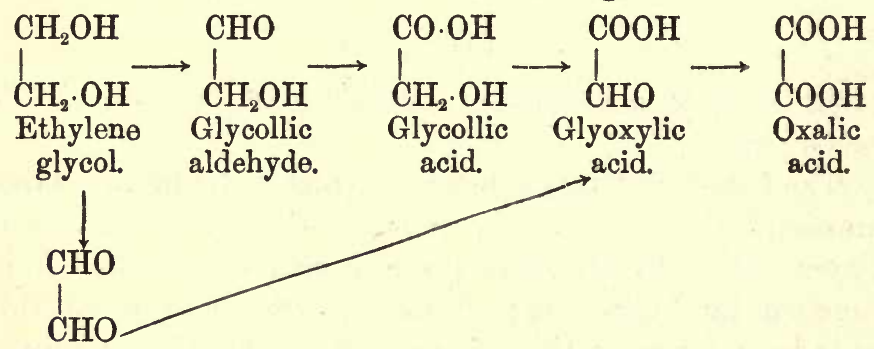

Glyoxal.

The above offers a very good example of the general nature of chemical reactions, and illustrates in a striking way the method of oxidation of a primary alcoholic group.

The following are some of the chief acids of the oxalic acid series :-

Oxalic acid, $\mathrm{COOH}$<smiles>CC(=O)O</smiles>

melting point of the hydrated form

Malonic acid, $\mathrm{CO} \cdot \mathrm{OH}$ melting point, $132^{\circ}$

\section{$\mathrm{COOH}$}

$2 \mathrm{H}_{2} \mathrm{O}, 100^{\circ}$

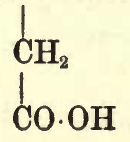


Structure of Simpler Organic Compounds. 107

Succinic acid, CO.OH melting point, $185^{\circ}$

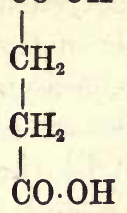

Glutaric acid, $\mathrm{CO} \cdot \mathrm{OH}$ or, more shortly, $\mathrm{COOH}\left(\mathrm{CH}_{2}\right)_{3} \cdot \mathrm{COOH}$

$!$
$\mathrm{CH}_{2}$
1
$\mathrm{CH}_{2}$
$!$
$\mathrm{CH}_{2}$
$\mathrm{COOH}$

Adipic acid, $\mathrm{CO} \cdot \mathrm{OH}\left(\mathrm{CH}_{2}\right)_{4} \cdot \mathrm{COOH}$ melting point, $148^{\circ}$

Various isomerides of these substances exist, but the longchain substances are of more importance. The isomeride of succinic acid is-

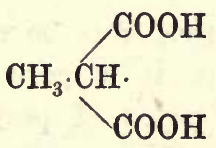

or methyl malonic acid.

These substances can form acid and neutral salts, according to whether the hydrogen of one or both carboxyl groups is replaced by a metal. The two sodium oxalates $\mathrm{COONa}$

would have the formulæ |

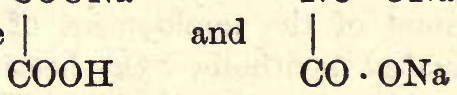

In the same way acid and neutral esters can be obtained, such as the acid and neutral ethyl oxalates-

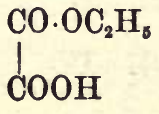

$\mathrm{CO} \cdot \mathrm{OC}_{2} \mathrm{H}_{5}$
$\mathrm{CO} \cdot \mathrm{OC}_{2} \mathrm{H}_{6}$ 
Amides can also be prepared-in fact, each carboxyl group exhibits the properties characteristic of that group.

Oxalic acid, which separates from aqueous solutions in crystalline form with two molecules of water of crystallization $\left(\mathrm{CO}_{2} \mathrm{H}\right)_{2} 2 \mathrm{H}_{2} \mathrm{O}_{1}$, is produced by the oxidation of a large number of organic substances, and is prepared on a large scale by heating sawdust with a concentrated solution of sodium hydroxide to $240^{\circ}$ in iron pans. From the extract of the melt it can be precipitated by calcium salts, as calcium oxalate, $\mathrm{C}_{2} \mathrm{O}_{4} \mathrm{Ca} \cdot \mathrm{H}_{2} \mathrm{O}$ (one molecule of water of crystallization), is practically insoluble in water. Oxalic acid is readily oxidized, and is used extensively on this account in analytical chemistry; thus, in the presence of warm potassium permanganate, it is oxidized to carbon dioxide and water-

$\mathrm{CO} . \mathrm{OH}$

$$
\mathrm{CO}_{\mathrm{CH}}+\mathrm{OH}=2 \mathrm{CO}_{2}+\mathrm{H}_{2} \mathrm{O}
$$

As the crystalline substance can be readily obtained in a state of great purity, it is a convenient substance to employ for the standardization of permanganate solutions. Oxalic acid is largely used for various technological purposes.

\section{Malonic Acid, $\mathrm{CH}_{2}$, is an important substance $\mathrm{COOH}$}

on account of the employment of some of its derivatives in chemical synthesis. On heating, it decomposes into acetic acid and carbon dioxide. This reaction is typical of substances in which two carboxyl groups are attached to the same carbon atom-

$$
\overbrace{\mathrm{COOH}}^{\mathrm{COOH}}=\mathrm{CH}_{3} \cdot \mathrm{CO} \cdot \mathrm{OH}+\mathrm{CO}_{2}
$$


Structure of Simpler Organic Compounds. 109

This reaction is sufficient to indicate its constitution. Its constitution is also indicated by the following synthesis. When acetic acid is treated with chlorine, it yields a series of chlorine substitution products (see p. 90). The monochlor derivative is $\mathrm{CH}_{2} \mathrm{Cl} \cdot \mathrm{CO} \cdot \mathrm{OH}$. The potassium salt of this acid on treatment with potassium cyanide yields the potassium salt of cyanacetic acid-

$$
\mathrm{ClCH}_{2} \cdot \mathrm{COOK}+\mathrm{KCN}=\mathrm{KCl}+(\mathrm{CN}) \cdot \mathrm{CH}_{2} \cdot \mathrm{COOH}
$$

This latter substance on hydrolysis undergoes the general reaction of substances containing the (CN) group, which is converted into the carboxyl group-

(CN) $\mathrm{CH}_{2} \cdot \mathrm{COOH}+2 \mathrm{H}_{2} \mathrm{O}=\mathrm{NH}_{3}+\mathrm{COOH} \cdot \mathrm{CH}_{2} \cdot \mathrm{COOH}$ and yields malonic acid.

If the potassium cyanacetate is treated with hydrochloric acid gas in the presence of alcohol, it yields, instead of malonic acid, its ethyl ester$(\mathrm{CN}) \mathrm{CH}_{2} \cdot \mathrm{COOK}+2 \mathrm{HCl}+2 \mathrm{C}_{2} \mathrm{H}_{5} \cdot \mathrm{OH}$

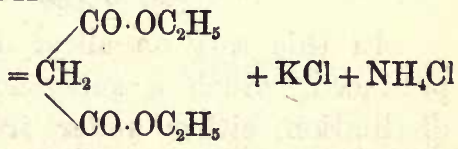

In this way ethyl malonate is produced, which, on account of certain characteristic reactions, has been largely employed for the purpose of organic synthesis.

SYNTHESIS BY MEANS OF ETHYL MALONATE.

By virtue of a special property which it possesses, ethyl malonate forms a basis from which a large number of more complex substances can be built up. It has been found that when the group of elements $-\mathrm{CH}_{2}$ - is placed between two carbonyl (- $\mathrm{CO}-$ ) groups, as is the case in ethyl malonate, the two hydrogens of the former group can be replaced by an alkali metal such as sodium. This reaction is carried out in the following way. One atomic 
equivalent of sodium is dissolved in alcohol, with the formation sodium ethoxide, $\mathrm{C}_{2} \mathrm{H}_{5} \cdot \mathrm{ONa}$, and evolution of hydrogen. If to the solution of sodium ethoxide thus produced, one molecular equivalent of ethyl malonate is added, the two substances enter into double decomposition-

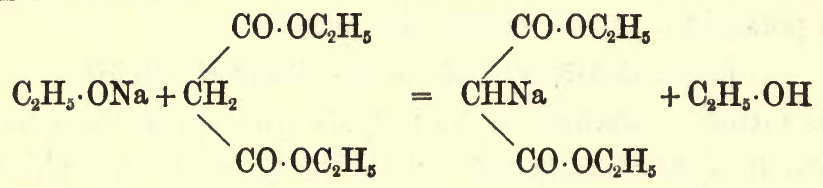

The sodium derivative (which need not be isolated) readily enters into reaction with alkyl iodides according to the following equation:-

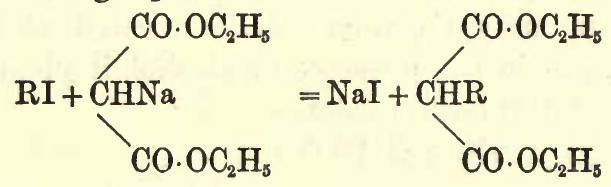

In this way an alkyl derivative of malonic acid is produced. Such a substance can be readily purified by distillation, either under ordinary pressure or in vacuo, according to its complexity; the more complex the substance and the higher its molecular weight, the greater the probability that it cannot be distilled under ordinary pressure without decomposition. If the malonic ester derivative is now saponified with sodium hydroxide, it yields the sodium salt of corresponding substituted malonic acid-

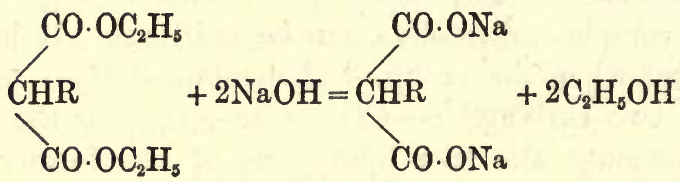

From the sodium salt the free acid can be obtained by the addition of a mineral acid. The acids thus produced 


\section{Structure of Simpler Organic Compounds. I I I}

can be extracted with ether, and as they are generally crystalline substances, they can usually be readily purified by crystallization. Furthermore, they contain two carboxyl groups attached to the same carbon atom, and therefore (see above), like malonic acid, they decompose when heated above their melting point, with evolution of carbon dioxide-

\section{$\int_{\mathrm{COOH}}^{\mathrm{COOH}}=\mathrm{CO}_{2}+\mathrm{CH}_{2} \mathrm{R} \cdot \mathrm{COOH}$}

In this way an alkyl derivative of acetic acid is obtained. If methyl iodide had been employed for condensation with sodio-malonic ester, the final product would be $\mathrm{CH}_{2}\left(\mathrm{CH}_{3}\right) \cdot \mathrm{COOH}$-that is, propionic acid; if ethyl iodide had been employed, the final product would be $\mathrm{CH}_{2}\left(\mathrm{C}_{2} \mathrm{H}_{5}\right) \mathrm{COOH}$-that is, normal butyric acid. In this way a large number of complex fatty acids can be built up.

But this synthetical method can be still further extended. If the alkyl derivative of ethyl malonate is isolated, and instead of being hydrolyzed, is treated with one molecular equivalent of sodium ethoxide in alcohol, a second hydrogen can be replaced with sodium-

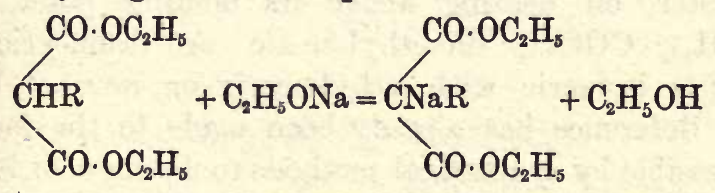

This sodio derivative can also react with alkyl halogen derivatives-

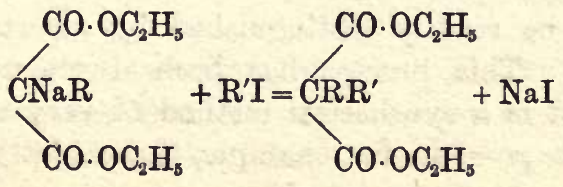


From this ester the free acid can be obtained by hydrolysis, namely :

\section{$\mathrm{CRR}^{\mathrm{COOH}}$ \\ $\mathrm{COOH}$}

which on heating above its melting point decomposes-

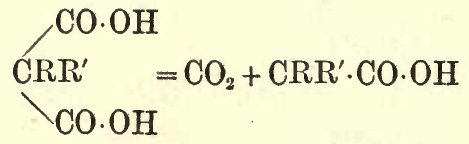

yielding a dialkyl substitution product of acetic acid. The value of this process for the determination of the constitution of fatty acids is evident. To take only one concrete example:

If sodio ethyl malonate is treated with ethyl iodide, and the ester thus produced is hydrolyzed, and the acid so obtained heated above its melting point, the final product, as already mentioned, is $\mathrm{CH}_{2}\left(\mathrm{C}_{2} \mathrm{H}_{5}\right) \mathrm{CO} \cdot \mathrm{OH}$-that is, normal butyric acid. If the sodio-malonic ester is, however, treated with methyl iodide, and the methyl derivative of malonic ester thus produced is treated with sodium ethoxide, and the sodium salt is then treated with methyl iodide, the dimethyl-malonic ester is obtained; the free acid of this ester, on heating above its melting point, yields $\mathrm{CH}\left(\mathrm{CH}_{3}\right)_{2} \cdot \mathrm{COOH}$, dimethyl-acetic or isobutyric acid, which is isomeric with ethyl-acetic or normal butyric acid. Reference has already been made to the fact that it is possible by synthetical methods to distinguish between the various fatty acids. These two acids will themselves differ in their properties, as will those of their salts, and they can be readily distinguished by ascertaining these properties. This process has been dwelt upon in some detail, as it is a synthetical method of very wide application. It is possible, for example, that a fatty acid of the 
Structure of Simpler Organic Compounds. I I 3

composition $\mathrm{C}_{3} \mathrm{H}_{8} \mathrm{O}_{2}$ has been isolated as the result of some fermentation process; this acid will be found to form salts, esters, acid chlorides, etc., and have therefore all the properties of a substance containing a carboxyl group. None of these reactions would serve, however, to distinguish between the formulæ $\mathrm{CH}_{2}\left(\mathrm{C}_{2} \mathrm{H}_{5}\right) \mathrm{CO} \cdot \mathrm{OH}$ and $\mathrm{CH}\left(\mathrm{CH}_{3}\right)_{2} \mathrm{CO} \cdot \mathrm{OH}$. The synthetic method just described would, however, settle this question finally, as the two acids with different properties can both be obtained, and the method of synthesis leaves no doubt as to their respective constitutions.

Another example of the value of this and similar synthetical methods. When leucine (see p. 318) is added to a yeast fermentation of sugar, an amyl alcohol, $\mathrm{C}_{5} \mathrm{H}_{11} \cdot \mathrm{OH}$, is produced. Eight isomerides of this formula are capable of existence. The alcohol in question can be oxidized to $\mathrm{C}_{5} \mathrm{H}_{10} \mathrm{O}_{2}$, and is therefore a primary alcohol. Now, from ethyl malonate, the various acids of this formula can be obtained synthetically; it will be found that the acid from the anyl alcohol in question is got when the sodium derivative of ethyl malonate is treated with isopropyl iodide-
$\left(\mathrm{CH}_{3}\right)_{2} \mathrm{CHI}+\underbrace{\mathrm{CO} \cdot \mathrm{OC}_{2} \mathrm{H}_{5}}_{\mathrm{CO} \cdot \mathrm{OC}_{2} \mathrm{H}_{5}}=\mathrm{NaI}+\left(\mathrm{CH}_{3}\right)_{2} \mathrm{CH} \cdot \underbrace{\mathrm{CO} \cdot \mathrm{OC}_{2} \mathrm{H}_{3}}_{\mathrm{CH}}$

From this, on saponification, is obtained-

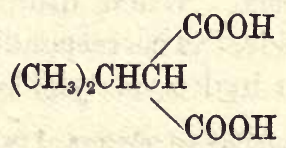

which, on heating, yields $\left(\mathrm{CH}_{3}\right)_{2} \mathrm{CH} \cdot \mathrm{CH}_{2} \mathrm{COOH}$. It is obvious, therefore, that the constitution of the alcohol derived from leucine is- 


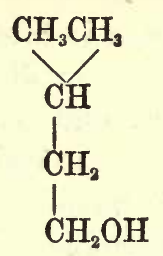

the ordinary fermentation amyl alcohol.

Thus, by a comparatively simple laboratory process, the constitution of an important biological product can be ascertained.

Besides ethyl malonate, other substances can be employed for the purpose of analogous synthetical reaction. The most important of these is perhaps the substance known as acetoacetic ether, or ethyl acetoacetate-

$$
\mathrm{CH}_{3} \cdot \mathrm{CO} \cdot \mathrm{CH}_{2} \cdot \mathrm{CO} \cdot \mathrm{OC}_{2} \mathrm{H}_{5} *
$$

This again contains a $-\mathrm{CH}_{2}-$ group between two carbonyl groups, and has consequently two hydrogen atoms replaceable by sodium. The syntheses of this substance are more complex and need not be considered in greater detail in this place.

Succinic acid-

\section{$\mathrm{CH}_{2} \cdot \mathrm{COOH}$ $\mathrm{CH}_{2} \cdot \mathrm{COOH}$}

This acid occurs in many plants, in certain animal secretions, and in amber. It is also a by-product of the alcoholic fermentation of sugar. Its constitution is readily determined by a simple synthesis. When dibromethane is treated with potassium cyanide, the corresponding cyano derivative is obtained, which on hydrolysis yields succinic acid-

* This substance is an equilibrated mixture of two isomerides$\mathrm{CH}_{3} \cdot \mathrm{CO} \cdot \mathrm{CH}_{2} \cdot \mathrm{COOC}_{2} \mathrm{H}_{5} \rightleftarrows \mathrm{CH}_{3} \cdot \mathrm{C}(\mathrm{OH})=\mathrm{CH} \cdot \mathrm{COOC}_{2} \mathrm{H}_{5}$

The former is called the ketonic and the latter the enolic form. Such isomerides which readily pass from one into another are said to be tautomeric or desmotropic forms. 


\section{Structure of Simpler Organic Compounds. I I 5}

$$
\begin{aligned}
& \int_{\mathrm{CH}_{2} \mathrm{Br}}^{\mathrm{CH}_{2} \mathrm{Br}}+2 \mathrm{KCN}=\underset{\mathrm{CH}_{2} \mathrm{CN}}{\stackrel{\mathrm{CH}_{2} \mathrm{CN}}{1}}
\end{aligned}
$$

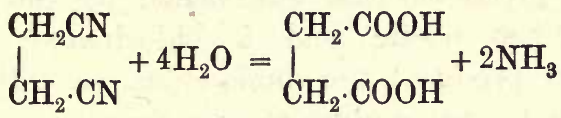

It yields an anhydride of the formula-

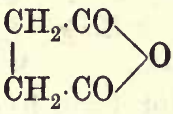

Adipic acid, $\mathrm{COOH} \cdot\left(\mathrm{CH}_{2}\right)_{4} \cdot \mathrm{COOH}$, is obtained by heating fats with nitric acid (hence the name).

Summary.-The dicarboxylic acids contain two carboxyl groups, and act as dibasic acids. The chief members of the series of interest are oxalic, malonic, and succinic acids. The ester of malonic acid, $\mathrm{CH}_{2}\left(\mathrm{COOC}_{2} \mathrm{H}_{5}\right)_{2}$, yields a sodium compound, $\mathrm{CHNa}\left(\mathrm{CO} \cdot \mathrm{OC}_{2} \mathrm{H}_{5}\right)_{2}$, which reacts with alkyl halogen compounds to form alkyl substituted malonic esters, $\mathrm{CHR}\left(\mathrm{CO} \cdot \mathrm{OC}_{2} \mathrm{H}_{5}\right)_{2}$, from which, by a series of reactions, alkyl substituted acetic acids can be formed of the general formula $\mathrm{CH}_{2} \mathrm{R} \cdot \mathrm{COOH}$. From the alkyl malonic esters, sodium compounds, $\mathrm{CNaR}\left(\mathrm{CO} \cdot \mathrm{OC}_{2} \mathrm{H}_{5}\right)_{2}$, can be obtained, which with alkyl iodides yield derivatives of the type $\mathrm{CRR}\left(\mathrm{CO} \cdot \mathrm{OC}_{2} \mathrm{H}_{5}\right)_{2}$, from which dialkyl substituted acetic acid derivatives, $\mathrm{CHRR^{ \prime }} \cdot \mathrm{CO} \cdot \mathrm{OH}$, can be formed.

Each of the carboxyl groups in the dibasic acids can undergo the ordinary reactions characteristic of this group.

\section{Part X.-The Hydroxy Acids.}

Amongst the oxidation products of ethylene glycol, mention has been already made of glycollic acid-

$\mathrm{CH}_{2} \cdot \mathrm{OH}$

$\mathrm{COOH}_{\mathrm{CO}}$ 
This substance contains both an alcoholic hydroxy and a carboxyl group, and its constitution, apart from its formation from glycol, is also established by the following synthesis. When acetic acid is chlorinated, it yields, amongst other products, the mono-chlor derivative. This on warming with water gives rise to glycollic acid-

$$
\left.\right|_{\mathrm{COOH}} ^{\mathrm{CH}_{2} \mathrm{Cl}}+\mathrm{H}_{2} \mathrm{O}=\stackrel{\mathrm{CO} \cdot \mathrm{OH}}{\mathrm{CH}_{2} \mathrm{OH}}
$$

Glycollic acid is, therefore, hydroxy acetic acid. It is a monobasic acid, containing as it does only one carboxyl group, and it gives rise to esters of the general formula-

$$
\begin{aligned}
& \mathrm{CH}_{2} \cdot \mathrm{OH} \\
& \mathrm{CO} . \mathrm{OR}
\end{aligned}
$$

The acid itself is a hygroscopic crystalline product, melting point $82^{\circ}$.

Lactic acid, $\mathrm{CH}_{3} \cdot \mathrm{CH}(\mathrm{OH}) \cdot \mathrm{CO} \cdot \mathrm{OH}$, is a more important product, which is constantly met with in biological research. It is a product of fermentation of sugars, starches, etc., and is known to occur in various isomeric forms, some of which exhibit optical activity. The nature of this isomerism, which is different to any so far discussed, will be considered in detail later (Chapter IV.). The sarcolactic acid of muscle is one of these forms.

The ordinary lactic acid, as prepared synthetically in the laboratory, is, however, optically inactive. Amongst the synthetical methods for its preparation two may be mentioned:-(a) When propionic acid is treated with bromine under certain conditions, the substance

\section{$\mathrm{CH}_{2} \cdot \mathrm{CHBr} \cdot \mathrm{CO} \cdot \mathrm{OH}$}

is obtained. This on treatment with water yields lactic acid-

$$
\mathrm{CH}_{3} \cdot \mathrm{CHBr} \cdot \mathrm{CO} \cdot \mathrm{OH}+\mathrm{H}_{2} \mathrm{O}=\mathrm{CH}_{0} \cdot \mathrm{CH}(\mathrm{OH}) \cdot \mathrm{CO} \cdot \mathrm{OH}+\mathrm{HBr}
$$




\section{Structure of Simpler Organic Compounds. I I 7}

This reaction would not prove the constitution of lactic acid unless the constitution of the bromine derivative were also established, for the compound, $\mathrm{CH}_{2} \mathrm{Br} \cdot \mathrm{CH}_{2} \cdot \mathrm{COOH}$, is also capable of existence. (b) The following synthesis, however, places the constitution beyond doubt. Acetaldehyde forms, as already stated (p. 81), an addition product with hydrocyanic acid-

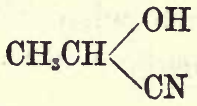

On hydrolysis the (CN) group undergoes the usual change, the product being lactic acid-

$$
\left.\mathrm{CH}_{3} \mathrm{CH}\right\rangle_{\mathrm{CN}}^{\mathrm{OH}}+2 \mathrm{H}_{2} \mathrm{O}=\mathrm{CH}_{3} \cdot \mathrm{CH}\left\langle\mathrm{CO} \cdot \mathrm{OH}+\mathrm{NH}_{3}\right.
$$

The constitution of lactic acid can also be well established by other synthetical methods. An isomeride of the constitution $\mathrm{CH}_{2}(\mathrm{OH}) \cdot \mathrm{CH}_{2} \cdot \mathrm{COOH}$, or $\beta$ * hydroxy propionic acid (lactic acid is $\alpha$ - hydroxy propionic acid), is also known, but is of little importance.

Lactic acid is a thick syrupy liquid, which is miscible with water, alcohol, and ether in all proportions. It cannot be distilled, and as it has no definite boiling or melting point, it is best identified by means of its salts. Of these the most suitable are the calcium and the zinc salts-

$$
\left(\mathrm{C}_{3} \mathrm{H}_{6} \mathrm{O}_{3}\right)_{2} \mathrm{Ca} \cdot 5 \mathrm{H}_{2} \mathrm{O} \text { and }\left(\mathrm{C}_{3} \mathrm{H}_{6} \mathrm{O}_{3}\right)_{2} \mathrm{Zn} \cdot 3 \mathrm{H}_{2} \mathrm{O}
$$

Some hydroxyl derivatives of polybasic acids are of interest.

Malic acid-

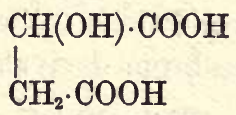

which is found native in apples and other fruits, is a

* For the significance of the symbols $\alpha$ and $\beta$, ree p. 77 . 
hydroxy derivative of succinic acid. It can be obtained synthetically from the latter acid, which is first treated under certain conditions with bromine. The bromo derivative-

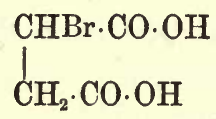

is thereby obtained, which when warmed with water and silver hydroxide gives malic acid-

$$
\begin{aligned}
& \mathrm{CHBr} \cdot \mathrm{CO} \cdot \mathrm{OH} \quad \mathrm{CH}(\mathrm{OH}) \cdot \mathrm{CO} \cdot \mathrm{OH} \\
& { }_{\mathrm{CH}_{2}} \cdot \mathrm{CO} \cdot \mathrm{OH}+\mathrm{Ag}(\mathrm{OH})=\mathrm{AgBr}+{\underset{\mathrm{CH}}{2}}_{2} \cdot \mathrm{CO} \cdot \mathrm{OH}
\end{aligned}
$$

Malic acid is a crystalline acid, melting point $100^{\circ}$, which is easily soluble in water.

Tartaric acid-

$$
\begin{aligned}
& \mathrm{CH}(\mathrm{OH}) \cdot \mathrm{COOH} \\
& \mathrm{CH}(\mathrm{OH}) \cdot \mathrm{COOH}
\end{aligned}
$$

is dihydroxy tartaric acid. This is also an acid which is widely distributed in plants. In the later stages of grape fermentation, the so-called "argol" is deposited, which is the acid potassium salt of tartaric acid; and this is the principal commercial source of the acid. Like lactic acid it also occurs in optically active isomeric forms (see Chap. IV.), and certain aspects of its chemistry will be considered in a later chapter. It can be prepared from succinic acid, through the intermediation of its dibromo derivative.

When succinic acid is treated with bromine under certain experimental conditions (different to those required for obtaining the mono-brom derivative) a substance-

$\mathrm{CHBr} \cdot \mathrm{CO} \cdot \mathrm{OH}$

$\mathrm{CHBr} \cdot \mathrm{CO} \cdot \mathrm{OH}$ 
Structure of Simpler Organic Compounds. I I 9

is obtained which, on treatment with silver hydroxide, yields tartaric acid-

$$
\int_{\mathrm{CHBr} \cdot \mathrm{CO} \cdot \mathrm{OH}}^{\mathrm{CHBr} \cdot \mathrm{CO} \cdot \mathrm{OH}}+2 \mathrm{AgOH}=2 \mathrm{AgBr}+{\underset{\mathrm{CH}}{\mathrm{CH}}(\mathrm{OH}) \cdot \mathrm{CO} \cdot \mathrm{OH}}^{\mathrm{CH}(\mathrm{OH} \cdot \mathrm{OH}}
$$

It can also be obtained synthetically from glyoxal (see p. 106), when this substance is treated with hydrocyanic acid-

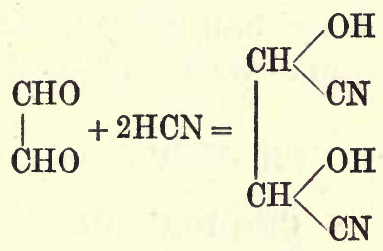

The dihydroxy nitrile so produced undergoes the usual reaction on hydrolysis-

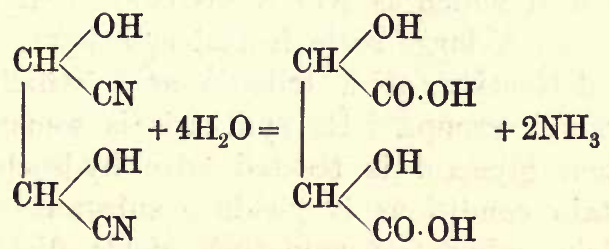

yielding tartaric acid. This reaction leaves no doubt as to the chemical constitution of tartaric acid.

Tartaric acid, furthermore, can be converted into succinic acid by reduction. The reagent generally used for replacing the hydroxyl group in hydroxy acids by hydrogen is hydriodic acid-

$$
{\underset{\mathrm{CH}}{\mathrm{CH}}(\mathrm{OH}) \cdot \mathrm{CO} \cdot \mathrm{OH}}_{2 \mathrm{HI}}^{\mathrm{CH}}=\underset{\mathrm{CH}_{2} \cdot \mathrm{CO} \cdot \mathrm{OH}}{\mathrm{CH}_{2} \cdot \mathrm{CO} \cdot \mathrm{OH}}+\mathrm{I}_{2}+2 \mathrm{H}_{2} \mathrm{O}
$$

This is a general reaction, and by the same means lactic acid can be reduced to propionic acid, and malic to succinic acid. 
Tartaric acid is a crystalline substance soluble in water and alcohol, but insoluble in ether. The isomeride obtained from argol melts at $167^{\circ}$. It forms both normal and acid salts as it is a dibasic acid. An interesting salt is the potassium antimonyl tartrate-

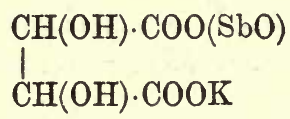

which is obtained by heating potassium tartrate with antimonous oxide and water, and is known as "tartar" emetic."

Citric acid-

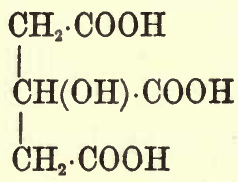

is also an acid which is widely distributed in fruits, and is prepared on a large scale from lemon juice. This is a hydroxyl derivative of a tribasic acid, which contains three carboxyl groups. Its synthesis is somewhat complex. When glycerol is treated with hydrochloric acid, under certain conditions, it yields a substance called $\alpha \cdot \alpha$ dichlorhydrin, which on oxidation yields dichloracetone. The relationship of these substances to one another is shown in the following formulæ:-
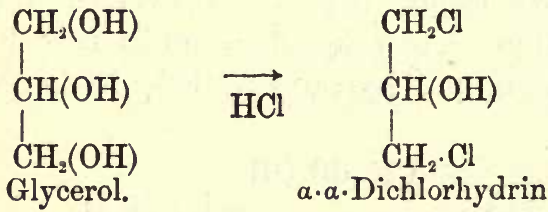

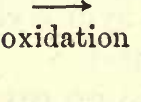

$\mathrm{CH}_{2} \mathrm{Cl}$

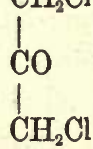

Dichloracetone.

Dichloracetone on treatment with hydrocyanic acid yields, in the usual way, a hydroxy nitrile, in which, by hydrolysis, the $\mathrm{CN}$ group can be replaced by the carboxyl group, thus- 
Structure of Simpler Organic Compounds. I 2 I

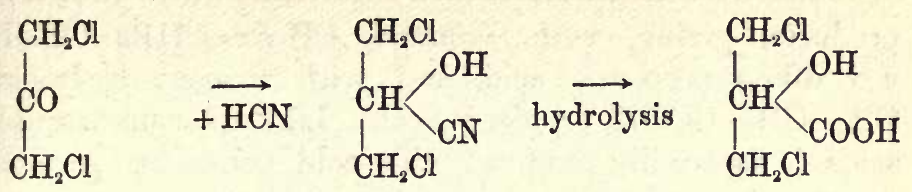

By treating this last chlorine acid with potassium cyanide, and then hydrolyzing the derivative thus obtained, citric acid is produced-
$\mathrm{CH}_{2} \mathrm{Cl}$
$\mathrm{CH}_{2} \mathrm{CN}$
$\mathrm{CH}_{2} \cdot \mathrm{CO} \cdot \mathrm{OH}$
${ }_{\mathrm{CH}}^{\mathrm{CH}}<\mathrm{COOH}$
$\mathrm{CH}_{2} \mathrm{Cl}$

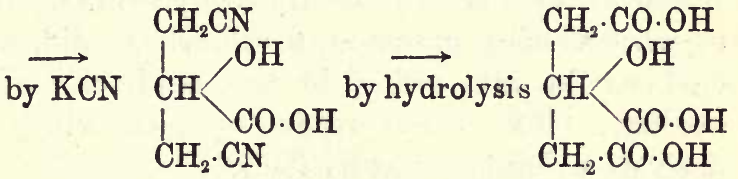

Thus, a fairly complex synthesis has been accomplished by a series of simple reactions, which have been repeatedly mentioned in the foregoing pages.

Citric acid crystallizes with one molecule of water; these crystals, which are readily soluble in water, but insoluble in ether, melt at $100^{\circ}$. As it is a tribasic acid, citric acid forms three series of salts-for example, with potassium, $\mathrm{C}_{6} \mathrm{H}_{6} \mathrm{O}_{7} \mathrm{~K}_{3}, \mathrm{C}_{6} \mathrm{H}_{6} \mathrm{O}_{7} \mathrm{~K}_{2}$, and the most acid salt, $\mathrm{C}_{6} \mathrm{H}_{7} \mathrm{O}_{7} \mathrm{~K}$.

\section{Part XI.-The Unsaturated Acids.}

A type of this class of acids is acrylic acid, $\mathrm{CH}_{2}: \mathrm{CH} \cdot \mathrm{COOH}$, which can be obtained by treatment of $\beta$-brompropionic acid with an alcoholic solution of potassium hydroxide-

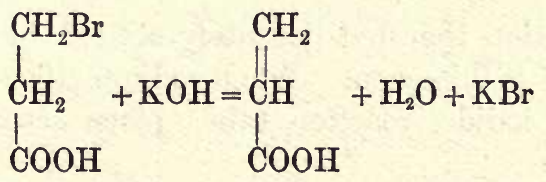

This is a liquid, smelling like acetic acid, which boils at $139^{\circ}-140^{\circ}$, and is miscible with water. Like unsaturated derivatives generally, it readily forms addition 
products, giving, with bromine, $\mathrm{CH}_{2} \mathrm{Br} \cdot \mathrm{CHBr} \cdot \mathrm{COOH}$, $\alpha \beta$ dibrompropionic acid, and with nascent hydrogen, $\mathrm{CH}_{3} \cdot \mathrm{CH}_{2} \cdot \mathrm{COOH}$, propionic acid. Like other unsaturated acids, it is readily oxidized with cold potassium permanganate.

Another important member of the series is oleic acid, $\mathrm{C}_{18} \mathrm{H}_{34} \mathrm{O}_{2}$, which is obtained by the hydrolysis of olive oil, which consists chiefly of the triglyceride of this acid. It is, when freshly prepared, a colourless acid, which rapidly darkens in air owing to the readiness with which it oxidizes. (Note the readiness with which unsaturated derivatives undergo oxidation.)

Other complex fatty acids are derived from the hydrolysis of fats and oils, some of which contain more than one double bond. These will be discussed later (Chap. V.).

\section{Part XII.-The Ethers.}

The general character of the ethers has been already mentioned (p. 67). Just as ethyl alcohol may be regarded as derived from water by the replacement of one hydrogen by the ethyl radicle, so ethyl ether may be regarded as derived from the same substance by replacement of both hydrogens by the same radicle-
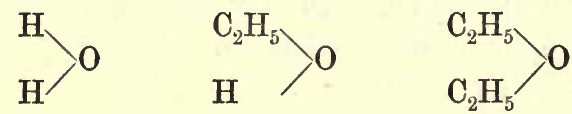

Its constitution was first definitely settled by the classical synthesis of Williamson. When sodium ethoxide is treated with ethyl iodide, reaction takes place according to the equation-

$$
\mathrm{C}_{2} \mathrm{H}_{5} \mathrm{ONa}+\mathrm{C}_{2} \mathrm{H}_{5} \mathrm{I}=\mathrm{NaI}+\mathrm{C}_{2} \mathrm{H}_{5}-\mathrm{O} \cdot \mathrm{C}_{2} \mathrm{H}_{5}
$$

The ethers, of which ethyl ether (generally known simply as ether) is the typical representative, have the 


\section{Structure of Simpler Organic Compounds. 1 23}

general formulæ $\mathrm{R}-\mathrm{O}-\mathrm{R}^{\prime}$. They can be prepared in the same way as ethyl ether, by the action of an alkyl iodide on the sodium derivative of an alcohol-

$$
\mathrm{R} \cdot \mathrm{ONa}+\mathrm{R}^{\prime} \mathrm{I}=\mathrm{NaI}+\mathrm{R}-\mathrm{O}-\mathrm{R}^{\prime}
$$

Ethyl ether is generally prepared by warming a mixture of alcohol (five parts) with concentrated sulphuric acid (nine parts), which is contained in a flask connected with a condenser, to $140^{\circ}$. As soon as ether commences to distil over, more alcohol is added to the mixture from a tap-funnel, the additional alcohol being added at about the same rate that the ether distils over. This process of preparation is what is known as a "continuous" one, a small amount of sulphuric acid being sufficient to convert a large amount of alcohol into ether. The actual reaction is not one of simple dehydration such as might be represented by the equation-

$$
2 \mathrm{C}_{2} \mathrm{H}_{5} \mathrm{OH}-\mathrm{H}_{2} \mathrm{O}=\left(\mathrm{C}_{2} \mathrm{H}_{5}\right)_{2} \mathrm{O}
$$

In reality the first reaction between ethyl alcohol and sulphuric acid is to form the acid ethyl ester of sulphuric acid (see p. 97)-

$$
\mathrm{C}_{2} \mathrm{H}_{5} \mathrm{OH}+\mathrm{H}_{2} \mathrm{SO}_{4}=\mathrm{C}_{2} \mathrm{H}_{5} \cdot \mathrm{HSO}_{4}+\mathrm{H}_{2} \mathrm{O}
$$

The hydrogen ethyl sulphate can then react with alcohol according to the equation-

$$
\mathrm{C}_{2} \mathrm{H}_{5} \mathrm{HSO}_{4}+\mathrm{C}_{2} \mathrm{H}_{5} \mathrm{OH}=\left(\mathrm{C}_{2} \mathrm{H}_{5}\right)_{2} \mathrm{O}+\mathrm{H}_{2} \mathrm{SO}_{4}
$$

The sulphuric acid is thus regenerated, and the ether as it is formed distils over, fresh alcohol being added from time to time to replace that which has been converted into ether according to the above equations. It might be thought that a small amount of sulphuric acid would convert an unlimited amount of alcohol into ether. In actual practice this is not, however, the case, as in the course of the reaction the acid becomes dilute, and the 
first stage (the formation of the ethyl sulphate) will not then take place. A part of the sulphuric acid, furthermore, is reduced to sulphur dioxide, and a certain amount of charring takes place during the reaction.

The ether which is prepared by this process is contaminated by water and alcohol. These can, for the most part, be removed by distillation over calcium chloride. The last traces of alcohol can be removed by treatment of the distillate with metallic sodium; the alcohol forms sodium ethoxide and remains behind as a residue when the ether is again distilled.

Ethers are somewhat inert chemical substances and enter into comparatively few chemical reactions. For this reason they are of great value as solvents in various chemical processes.

The only member of the series of any importance is ethyl ether, boiling point $35^{\circ}$, which is largely used as an anæsthetic. It is soluble in about ten times its own volume of water and in most organic solvents. It has a characteristic smell, and is highly inflammable.

\section{Part XIII.-The Alkyl Derivatives of Nitrogen.}

An important series of organic compounds is known, which may be considered as derived from ammonia by the substitution of a hydrogen atom by alkyl group. Such substances may be represented by the general formulæ-

\section{$\mathrm{NH}_{2} \mathrm{R}, \mathrm{NHR}_{2}, \mathrm{NHR}_{3}$}

Where one hydrogen only is substituted by an alkyl radicle, the substance is known as a "primary amine," where substituted by two as a "secondary amine," and where by three alkyl radicles as a "tertiary amine."

Like ammonia, all these substances are strongly basic, giving solutions alkaline to litmus, and forming salts of 


\section{Structure of Simpler Organic Compounds. I 25}

the type $\mathrm{NH}_{2} \mathrm{R} \cdot \mathrm{HCl}$. In this respect they differ from a class of compounds which has already been mentioned, namely, the acid amides. This class of substances has been regarded (p. 101) as a derivative of ammonia, in which a hydrogen has been substituted by an acidyl group (for example, acetamide, $\left.\mathrm{CH}_{3} \cdot \mathrm{CO} \cdot \mathrm{NH}_{2}\right)$. The existence of this group deprives the substance of its strongly basic character.

The amines, which formed the subject of a series of classical investigations by Hoffmann, to whose labours the principal knowledge of these compounds is due, can be prepared by the action of an alcoholic solution of ammonia on alkyl iodides or bromides. A mixture of all three compounds, together with another compound of the general formula $\mathrm{NR}_{4} \mathrm{I}$ or $\mathrm{NR}_{4} \mathrm{Br}$, known as a tetralkyl ammonium iodide or bromide, is formed.

The reactions involved may, in the case of ethyl iodide and ammonia, be represented by the following equations :-

$$
\begin{array}{ll}
\mathrm{C}_{2} \mathrm{H}_{5} \mathrm{I}+\mathrm{NH}_{3} & =\mathrm{C}_{2} \mathrm{H}_{5} \mathrm{NH} \mathrm{H}_{2} \cdot \mathrm{HI} \\
2 \mathrm{C}_{2} \mathrm{H}_{5} \mathrm{I}+\mathrm{NH}_{3} & =\left(\mathrm{C}_{2} \mathrm{H}_{5}\right)_{2} \mathrm{NHHI}+\mathrm{HI} \\
3 \mathrm{C}_{2} \mathrm{H}_{5} \mathrm{I}+\mathrm{NH}_{3} & =\left(\mathrm{C}_{2} \mathrm{H}_{5}\right)_{3} \mathrm{~N} \cdot \mathrm{HI}+2 \mathrm{HI} \\
\left(\mathrm{C}_{2} \mathrm{H}_{5}\right)_{3} \mathrm{~N}+\mathrm{C}_{2} \mathrm{H}_{6} \mathrm{I}=\mathrm{N}\left(\mathrm{C}_{2} \mathrm{H}_{5}\right)_{4} \mathrm{I}
\end{array}
$$

In this reaction, a mixture of several products is obtained, the separation of which is a matter of some difficulty. There are, however, methods, which are described below, for obtaining the primary amines pure and unmixed with secondary or tertiary derivatives. If such a primary amine is treated with the theoretical quantity of an alkyl iodide and potassium hydroxide, it will yield the secondary derivative-

$$
\left(\mathrm{C}_{2} \mathrm{H}_{5}\right) \mathrm{NH}_{2}+\mathrm{C}_{2} \mathrm{H}_{6} \mathrm{I}+\mathrm{KOH}=\mathrm{KI}+\mathrm{H}_{2} \mathrm{O}+\left(\mathrm{C}_{2} \mathrm{H}_{5}\right) \mathrm{NH}
$$

The secondary amine, in its turn, on heating with the same reagents, will yield the tertiary compound-

$$
\left(\mathrm{C}_{2} \mathrm{H}_{6}\right)_{2} \mathrm{NH}+\mathrm{C}_{2} \mathrm{H}_{5} \mathrm{I}+\mathrm{KOH}=\mathrm{KI}+\mathrm{H}_{2} \mathrm{O}+\left(\mathrm{C}_{2} \mathrm{H}_{6}\right)_{3} \mathrm{~N}
$$


The tertiary compound, on treatment with an alkyl iodide, will yield the "quaternary" base-

$$
\left(\mathrm{C}_{2} \mathrm{H}_{5}\right)_{3} \mathrm{~N}+\mathrm{C}_{2} \mathrm{H}_{5} \mathrm{I}=\mathrm{N}\left(\mathrm{C}_{2} \mathrm{H}_{5}\right)_{4} \mathrm{I}
$$

Even in these reactions, when the theoretical amounts of the various reagents are employed, the pure bases are not obtained, for the diethylamine obtained according to equation (1) will partly undergo the reactions of equation (2), and the trimethylamine will undergo the reaction indicated in equation (3).

If the mixture obtained in these reactions is distilled with steam, the secondary and tertiary amines will distil over and leave the quaternary compound behind. If the residue is then neutralized with hydrochloric acid and evaporated to dryness, the quaternary ammonium chloride thus obtained can be separated from the potassium salt by extraction with alcohol. The secondary and tertiary alcohols can be separated by treatment with nitrous acid by a method to be described below.

Primary Amines.-These substances, of the type $\mathrm{NH}_{2} \mathrm{R}$, can be obtained, in addition to the method above described, by the following reactions:- $(a)$ When an acid amide is treated with bromine and potassium hydroxide it yields an amine with one carbon atom less. The reaction is a somewhat complex one, but the final result can be represented by the following equations (in the case of acetamide) -

$\mathrm{CH}_{3} \cdot \mathrm{CO} \cdot \mathrm{NH}_{2}+\mathrm{Br}_{2}+\mathrm{KOH}=\mathrm{CH}_{3} \cdot \mathrm{CO} \cdot \mathrm{NHBr}+\mathrm{KBr}+\mathrm{H}_{2} \mathrm{O}$

$$
\mathrm{CH}_{3} \cdot \mathrm{CO} \cdot \mathrm{NHBr}+3 \mathrm{KOH}=\mathrm{CH}_{3} \cdot \mathrm{NH}_{2}+\mathrm{KBr}+\mathrm{K}_{2} \mathrm{CO}_{3}+\mathrm{H}_{2} \mathrm{O}
$$

To prepare ethylamine, propionamide (the amide of propionic acid), which has one carbon atom more, is submitted to the same reaction. (b) Primary amines can also be obtained by the treatment of the nitriles with nascent hydrogen-

$\mathrm{R} \cdot \mathrm{CN}+2 \mathrm{H}_{2}=\mathrm{R} \cdot \mathrm{CH}_{2} \cdot \mathrm{NH}_{2}$ 


\section{Structure of Simpler Organic Compounds. I 27}

In this way amines can be synthesized from substances containing a smaller number of carbon atoms, for the nitrile can be prepared from an alkyl halogen derivative.

Primary amines can also be prepared by reduction of oximes $(\mathrm{R}=\mathrm{NOH}$, see p. 82), and nitro paraffins (see p. 96$)$.

The primary amines, of which methylamine and ethylamine are types, behave generally very much like ammonia. They form salts, platinichlorides and aurichlorides, and the analogy of these compounds to the ammonia compounds is indicated in the following formulæ-

\begin{tabular}{|c|c|}
\hline $\begin{array}{l}\mathrm{NH}_{4} \mathrm{Cl} \cdot \cdot \cdot \cdot \cdot \\
\mathrm{C}_{2} \mathrm{H}_{5} \mathrm{NH}_{3} \cdot \mathrm{Cl} \cdot\end{array}$ & $\begin{array}{l}\text { Ammonium chloride. } \\
\text { Ethylamine hydrochloride. }\end{array}$ \\
\hline $\begin{array}{l}\left(\mathrm{NH}_{3}\right)_{2} \mathrm{H}_{2} \mathrm{PtCl}_{4} . \\
\left(\mathrm{N}\left(\mathrm{C}_{2} \mathrm{H}_{5}\right) \mathrm{H}_{2}\right)_{2} \mathrm{H}_{2} \mathrm{PtCl}_{6} .\end{array}$ & $\begin{array}{l}\text { Ammonium platinichloride. } \\
\text { Ethylamine platinichloride. }\end{array}$ \\
\hline $\begin{array}{l}\left(\mathrm{NH}_{3}\right) \mathrm{HAuCl}_{4} \cdot \dot{\mathrm{N}_{2}} \\
\left(\mathrm{~N}\left(\mathrm{C}_{2} \mathrm{H}_{5}\right) \mathrm{H}_{2}\right) \mathrm{HAuCl}{ }_{4}\end{array}$ & $\begin{array}{l}\text { Ammonium aurichloride. } \\
\text { Ethylamine aurichloride. }\end{array}$ \\
\hline
\end{tabular}

Similar compounds are yielded by secondary and tertiary bases.

The hydrochloride forms white crystals, the platinichloride orange, and the aurichloride yellow crystals, the general character of the compounds being similar to the corresponding ammonium compounds.

Primary amines, in addition to acting as bases and forming salts analogous to ammonium salts, have certain other characteristic reactions. On treatment with chloroform and alcoholic potassium hydroxide they yield certain substances known as carbylamines, which are characterized by their pungent disagreeable odour. The reaction is illustrated by the following equation-

$$
\mathrm{C}_{2} \mathrm{H}_{6} \mathrm{NH}_{2}+\mathrm{CHCl}_{3}+3 \mathrm{KOH}=\mathrm{C}_{2} \mathrm{H}_{5} \mathrm{~N}: \mathrm{C}+3 \mathrm{KCl}+3 \mathrm{H}_{2} \mathrm{O}
$$

Ethylcarbylamine is to be distinguished from the isomeric cyanide, as in the former compound the nitrogen 
is directly united to a carbon of the alkyl group (see p. 133).

The primary amines, furthermore, decompose when treated with nitrous acid with evolution of nitrogen and formation of an alcohol-

$$
\mathrm{C}_{2} \mathrm{H}_{5} \cdot \mathrm{NH}_{2}+\mathrm{HO} \cdot \mathrm{NO}=\mathrm{C}_{2} \mathrm{H}_{5} \cdot \mathrm{OH}+\mathrm{N}_{2}+\mathrm{H}_{2} \mathrm{O}
$$

(Compare the action when ammonia and nitrous acid are heated together, $\mathrm{NH}_{4} \mathrm{NO}_{2}=\mathrm{N}_{2}+2 \mathrm{H}_{2} \mathrm{O}$.)

This reaction serves to distinguish primary from secondary and tertiary amines. The last-named will not react with nitrous acid, whereas the second-named form nitroso-compounds, for example-

$$
\left(\mathrm{C}_{2} \mathrm{H}_{5}\right)_{2} \mathrm{NH}+\mathrm{HONO}=\left(\mathrm{C}_{2} \mathrm{H}_{5}\right) \mathrm{N} \cdot \mathrm{NO}+\mathrm{H}_{2} \mathrm{O}
$$

In this reaction no nitrogen is evolved.

This nitrous acid reaction is an important one, not only for distinguishing certain classes of amines, but also as a means of synthesis of alcohols. Thus, it is possible to pass from a lower to a higher alcohol by employing this reaction, as is illustrated in the following formula:-

$$
\left.\left.\stackrel{\mathrm{C}_{2} \mathrm{H}_{5} \mathrm{OH} \longrightarrow \text { (by HBr) } \mathrm{C}_{2} \mathrm{H}_{5} \mathrm{Br} \longrightarrow\left(\text { by } \mathrm{KCN} \text { ) } \mathrm{C}_{2} \mathrm{H}_{5}(\mathrm{CN})\right.}{\longrightarrow} \text { (by } \mathrm{H}_{2}\right) \mathrm{C}_{2} \mathrm{H}_{5} \cdot \mathrm{CH}_{2} \cdot \mathrm{NH}_{2} \longrightarrow \text { (by } \mathrm{HNO}_{2}\right)_{\mathrm{C}_{2} \mathrm{H}_{6} \cdot \mathrm{CH}_{2} \cdot \mathrm{OH}}
$$

The following are examples of primary amines:-

$\begin{array}{llrr}\text { Methylamine, } & \mathrm{CH}_{3} \mathrm{NH}_{2} & \text { boiling point, } & -6^{\circ} \\ \text { Ethylamine, } & \mathrm{C}_{2} \mathrm{H}_{5} \cdot \mathrm{NH}_{2} & " & +19^{\circ} \\ \text { Propylamine, } & \mathrm{C}_{3} \mathrm{H}_{7} \cdot \mathrm{NH}_{2} & " & 49^{\circ} \\ \text { Butylamine, } & \mathrm{C}_{4} \mathrm{H}_{9} \cdot \mathrm{NH}_{2} & " & 76^{\circ}\end{array}$

They are liquids with characteristic ammoniacal smells. They are soluble in organic solvents.

Secondary Amines. - The preparation from primary amines has been already described. In this process, as stated, the substance is obtained mixed with tertiary and quaternary ammonium compounds (and also with small 


\section{Structure of Simpler Organic Compounds. I 29}

amounts of unchanged primary amines). The separation of the volatile products from the quaternary compounds having been accomplished by steam distillation, the primary, secondary, and tertiary derivatives in the distillate are treated with nitrous acid. If the reaction mixture is acidified with hydrochloric acid, the tertiary derivative which is not acted on by nitrous acid forms a hydrochloride. The nitroso derivative formed from the secondary amine does not, however, form a salt, and can be extracted from the solution by ether, in which the salts are insoluble. From the nitroso derivative obtained in this way, the secondary amine can be regenerated by boiling with hydrochloric acid-

$$
\left(\mathrm{C}_{2} \mathrm{H}_{5}\right)_{2} \mathrm{NO}+\mathrm{H}_{2} \mathrm{O}=\left(\mathrm{C}_{2} \mathrm{H}_{5}\right)_{2} \mathrm{NH}+\mathrm{HO} \cdot \mathrm{NO}
$$

The secondary amines resemble generally in properties the primary substances, forming similar salts. Diethylamine has boiling point $56^{\circ}$.

Tertiary Amines. - These again are generally similar to the primary and secondary bases. As in the case of so many organic compounds, the boiling points increase with increasing molecular weights.

Quaternary Ammonium Compounds.-Alkyl halogen compounds unite directly with tertiary amines to form these characteristic compounds, which are generally substances which readily crystallize. They are non-volatile. The reaction can be illustrated by the equations-

$$
\begin{aligned}
& \mathrm{N}\left(\mathrm{C}_{2} \mathrm{H}_{5}\right)_{3}+\mathrm{C}_{2} \mathrm{H}_{5} \mathrm{I}=\mathrm{N}\left(\mathrm{C}_{2} \mathrm{H}_{5}\right)_{4} \mathrm{I} \quad \text { Tetrethyl ammonium iodide. } \\
& \mathrm{N}\left(\mathrm{C}_{2} \mathrm{H}_{5}\right)_{3}+\mathrm{CH}_{3} \mathrm{I}=\mathrm{N}\left(\mathrm{C}_{2} \mathrm{H}_{5}\right)_{3}\left(\mathrm{CH}_{3}\right) \mathrm{I}\left\{\begin{array}{c}
\text { Methyl triethyl ammonium } \\
\text { iodide. }
\end{array}\right.
\end{aligned}
$$

When such iodides are treated with silver hydroxide, the iodine is replaced by the hydroxyl group. Tetrethyl ammonium hydroxide produced in this way is a crystalline deliquescent substance which is non-volatile. Its solution is a strongly alkaline base, and absorbs carbon dioxide from $(1,997)$ 
the air ; the hydroxide is, in fact, a stronger base than ammonia. The hydroxides readily neutralize acids-

$$
\mathrm{N}\left(\mathrm{C}_{2} \mathrm{H}_{5}\right)_{4} \mathrm{OH}+\mathrm{HCl}=\mathrm{N}\left(\mathrm{C}_{2} \mathrm{H}_{5}\right)_{4} \mathrm{Cl}+\mathrm{H}_{3} \mathrm{O}
$$

SUMmary.-The amines may be regarded as alkyl substitution products of ammonia, in which one, two, or three hydrogen atoms may be substituted by an alkyl group to form respectively primary, secondary, or tertiary amines. They can be prepared by the interaction of alkyl iodides and an alcoholic solution of ammonia. The primary amines can also be formed by the action of potassium hydroxide and bromine on acid amides, which yield an amine with one carbon atom less; they can also be obtained by the reduction of nitriles. The three classes can be distinguished from one another by the differences in their behaviour towards nitrous acid, the primary compounds giving alcohols with evolution of nitrogen, the secondary nitroso derivatives, whilst the tertiary do not react. The primary amines also give the characteristic carbylamine reaction. Tertiary amines yield with alkyl iodides (or bromides) the crystalline quaternary ammonium iodides or bromides, from which hydroxides and other derivatives can be obtained.

Similar phosphorus and arsenic compounds are known.

\section{Part XIV. - Nitriles, Isonitriles, and other Allied Nitrogen}

\section{Compounds.}

When nitrogenous refuse, such as horn-shavings, hair, etc., are heated with iron and potassium carbonate to a high temperature, and the fused mass is afterwards extracted with hot water, a solution is obtained which deposits on concentration lemon-yellow hydrated crystals of the composition $\mathrm{K}_{4} \mathrm{Fe}(\mathrm{CN})_{6} 4 \mathrm{H}_{2} \mathrm{O}$. This so-called yellow prussiate of potash, or potassium ferrocyanide, has been 


\section{Structure of Simpler Organic Compounds. I 3 I}

known for a long time. The actual reaction involved in its formation by the above-described process is a complex one and need not be discussed in detail. It was found by Scheele, in 1782 , that this substance on treatment with sulphuric acid yields a volatile intensely poisonous acid, designated prussic acid, which is now represented by the formula HCN. It was afterwards recognized by Gay-Lussac that this acid contains a radicle (CN) or cyanogen, and that it behaves in an analogous manner to the halogens. In the course of his researches, Gay-Lussac succeeded in isolating cyanogen gas $(\mathrm{CN})_{2}$.

Cyanogen $(\mathrm{CN})_{2}$, which forms a classical example of a complex radicle, can now be obtained by a variety of methods. Of particular interest in connection with the structural formulæ is its formation from ammonium oxalate, from which it can be obtained by heating with phosphorus pentoxide (to withdraw water)-

$$
\mathrm{NH}_{4} \cdot \mathrm{OCO} \cdot \mathrm{CO} \cdot \mathrm{ONH}_{4}-4 \mathrm{H}_{2} \mathrm{O}=\mathrm{N} \equiv \mathrm{C} \cdot \mathrm{C} \equiv \mathrm{N}
$$

It can also be obtained by heating mercuric cyanide-

$$
\mathrm{Hg}(\mathrm{CN})_{2}=\mathrm{Hg}+(\mathrm{CN})_{2}
$$

or by the action of potassium cyanide on cupric sulphate-

$$
2 \mathrm{CuSO}_{4}+4 \mathrm{KCN}=(\mathrm{CN})_{2}+2 \mathrm{CuCN}+2 \mathrm{~K}_{2} \mathrm{SO}_{4}
$$

(Compare the reaction-

$$
\left.2 \mathrm{CuSO}_{4}+4 \mathrm{KI}=\mathrm{I}_{2}+2 \mathrm{CuI}+2 \mathrm{~K}_{2} \mathrm{SO}_{4}\right)
$$

Cyanogen is a colourless intensely poisonous gas, which burns with a peach-coloured flame yielding carbon dioxide and nitrogen. It is soluble in water, and the aqueous solution on keeping decomposes, forming a dark precipitate. Of particular interest is its reaction towards potassium hydroxide, with which it forms a mixture of potassium cyanide and cyanate, a reaction which is 
analogous to the formation of chlorides and hypochlorites when chlorine is passed into alkalis-

$$
\begin{aligned}
(\mathrm{CN})_{2}+2 \mathrm{KOH} & =\mathrm{KCN}+\mathrm{KCNO}+\mathrm{H}_{2} \mathrm{O} \\
\mathrm{Cl}_{2}+2 \mathrm{KOH} & =\mathrm{KCl}+\mathrm{KClO}+\mathrm{H}_{2} \mathrm{O}
\end{aligned}
$$

On hydrolysis with acids, the (CN) group undergoes the usual transformation into the carboxyl group, yielding oxalic acid-

$$
(\mathrm{CN})_{2}+4 \mathrm{H}_{2} \mathrm{O}=\mathrm{HOOC} \cdot \mathrm{COOH}+2 \mathrm{NH}_{3}
$$

Hydrocyanic acid, $\mathrm{HCN}$, which bears a similar relationship to cyanogen that chlorine does to hydrochloric acid, can be prepared by the method already mentioned of treating potassium ferrocyanide with sulphuric acid-

$$
2 \mathrm{~K}_{4} \mathrm{Fe}(\mathrm{CN})_{6}+3 \mathrm{H}_{2} \mathrm{SO}_{4}=6 \mathrm{HCN}+\mathrm{K}_{2} \mathrm{FeFe}(\mathrm{CN})_{6}+3 \mathrm{~K}_{2} \mathrm{SO}_{4}
$$

For this reaction dilute sulphuric acid is used. When concentrated sulphuric acid is employed, the following reaction takes place :-

$\mathrm{K}_{4} \mathrm{Fe}(\mathrm{CN})_{6}+6 \mathrm{H}_{2} \mathrm{O}$ (from the water of crystallization of the ferrocyanide) $+6 \mathrm{H}_{2} \mathrm{SO}_{4}=6 \mathrm{CO}+2 \mathrm{~K}_{2} \mathrm{SO}_{4}+\mathrm{FeSO}_{4}+3\left(\mathrm{NH}_{4}\right)_{2} \mathrm{SO}_{4}$

It can also be obtained from potassium cyanide (a salt which is made on a large scale for certain industrial processes, such as extraction of gold from tailings) by treatment with sulphuric acid-

$$
2 \mathrm{KCN}+\mathrm{H}_{2} \mathrm{SO}_{4}=\mathrm{K}_{2} \mathrm{SO}_{4}+2 \mathrm{HCN}
$$

Hydrocyanic acid, when obtained anhydrous, is a colourless intensely poisonous liquid, of boiling point $25^{\circ}$. Two reactions are of interest. Its aqueous solution on keeping undergoes decomposition, forming, amongst other products, ammonium formate-

$$
\mathrm{HCN}+2 \mathrm{H}_{2} \mathrm{O}=\mathrm{COONH}_{4}
$$

and on reduction it yields methylamine-

$$
\mathrm{HCN}+2 \mathrm{H}_{2}=\mathrm{CH}_{3} \cdot \mathrm{NH}_{2}
$$




\section{Structure of Simpler Organic Compounds. I 33}

Both these reactions are examples of general reactions of cyanides, and indicate that the chemical constitution of hydrocyanic acid may be represented by the formula $\mathrm{H} \cdot \mathrm{C}: \mathrm{N}$.

Potassium cyanide, $\mathrm{KCN}$, is made by various processes on a large scale, in which the reactions involved are somewhat complex.

The nitriles or cyanides can be prepared by the action of potassium cyanide on alkyl halogen compounds, for example-

$$
\mathrm{C}_{2} \mathrm{H}_{5} \mathrm{I}+\mathrm{KCN}=\mathrm{KI}+\mathrm{C}_{2} \mathrm{H}_{5} \mathrm{CN}
$$

or by the distillation of ammonium salts with phosphorus pentoxide-

$$
\mathrm{CH}_{3} \cdot \mathrm{COONH}_{4}-2 \mathrm{H}_{2} \mathrm{O}=\mathrm{CH}_{3} \cdot \mathrm{CN}
$$

Methyl cyanide is derived thus from acetic acid, and is also designated acetonitrile.

The two principal reactions are the hydrolysis to carboxylic acid (see p. 88) and the reduction to primary amines.

The nitriles are colourless liquids, the lower members of the series being readily soluble in water.

Cyanates.-When potassium cyanide is heated with lead oxide, the latter is readily reduced. For this reason potassium cyanide is largely used as a reducing agent-

$$
\mathrm{KCN}+\mathrm{PbO}=\mathrm{KCNO}+\mathrm{Pb}
$$

The ammonium cyanate readily undergoes isomeric change into urea. The free acid, $\mathrm{HO} \cdot \mathrm{CN}$, is an unstable substance, which cannot be prepared by a direct method from its salts.

Isocyanides or Isonitriles.-In these substances the nitrogen is directly united to the alkyl radicle. They are prepared by treating amines with chloroform and alcoholic potassium hydroxide (see p. 127)-

$\mathrm{CH}_{3} \mathrm{NH}_{2}+3 \mathrm{KOH}+\mathrm{CHCl}_{3}=\mathrm{CH}_{2} \cdot \mathrm{N}: \mathrm{C}+3 \mathrm{KCl}+3 \mathrm{H}_{2} \mathrm{O}$ 
They are also formed when alkyl iodides are treated with silver cyanide-

$$
\mathrm{C}_{2} \mathrm{H}_{5} \mathrm{I}+\mathrm{AgCN}=\mathrm{AgI}+\mathrm{C}_{2} \mathrm{H}_{5} \cdot \mathrm{N}: \mathrm{C}
$$

They are colourless liquids with a particularly objectionable odour, with somewhat higher boiling points than the isomeric nitriles. Their constitution is indicated by the fact that they yield on hydrolysis an amine and formic acid-

$$
\mathrm{C}_{2} \mathrm{H}_{5} \cdot \mathrm{N}: \mathrm{C}+2 \mathrm{H}_{2} \mathrm{O}=\mathrm{H} \cdot \mathrm{COOH}+\mathrm{C}_{2} \mathrm{H}_{5} \cdot \mathrm{NH}_{2}
$$

Contrast this reaction with that of the isomeric nitrile-

$$
\mathrm{C}_{2} \mathrm{H}_{5} \mathrm{CN}+2 \mathrm{H}_{2} \mathrm{O}=\mathrm{C}_{2} \mathrm{H}_{5} \cdot \mathrm{CO} \cdot \mathrm{OH}+\mathrm{NH}_{3}
$$

\section{Part XV.-The Benzene Derivatives.}

In 1825 Faraday isolated from oil gas a hydrocarbon, benzene, to which the formula $\mathrm{C}_{6} \mathrm{H}_{6}$ is now ascribed, which subsequent investigation has shown to differ markedly in its properties from a hydrocarbon which should, from the formula, be expected to contain three double bonds. Since Faraday's original discovery, benzene has been produced on a large scale as a product of coaltar distillation, and is now known to form a nucleus from which a very important and interesting series of compounds, known as aromatic derivatives, has been derived. The number of these derivatives is very large, and their investigation has occupied the attention of numerous chemists over several decades; many of the benzene derivatives, furthermore, are of great technological importance. It will be possible in this place to deal with only a very limited number. As some of them play an important part in the physiology of the plant and animal, it is necessary to consider in some detail certain of the fundamental conceptions now generally held as to their constitution and structure. 
Structure of Simpler Organic Compounds. I 35

When allyl iodide, $\mathrm{CH}_{2}: \mathrm{CH} \cdot \mathrm{CH}_{2} \mathrm{I}$ (the iodine derivative corresponding to allyl alcohol, see p. 78), is treated with sodium, it yields a hydrocarbon with six carbon atoms containing two double bonds-

$$
\begin{aligned}
\mathrm{CH}_{2}: \mathrm{CH} \cdot \mathrm{CH}_{2} \mathrm{I}+\mathrm{Na}_{2}+\mathrm{CH}_{2}: \mathrm{CH} \cdot \mathrm{CH}_{2} \mathrm{I} & =2 \mathrm{NaI}+\mathrm{CH}_{2}: \mathrm{CH} \cdot \mathrm{CH}_{2} \cdot \mathrm{CH}_{2} \cdot \mathrm{CH}: \mathrm{CH}_{2}
\end{aligned}
$$

By virtue of the two double bonds, the diallyl thus prepared will form with bromine a tetrabrom addition product, $\mathrm{CH}_{2} \mathrm{Br} \cdot \mathrm{CHBr} \cdot \mathrm{CH}_{2} \cdot \mathrm{CH}_{2} \cdot \mathrm{CHBr} \cdot \mathrm{CH}_{2} \mathrm{Br}$, from which, on treatment with alcoholic sodium hydroxide, the bromine can be eliminated to yield a substance isomeric with benzene and known as dipropargyl-

$$
\begin{gathered}
\mathrm{CH}_{2} \mathrm{Br} \cdot \mathrm{CHBr} \cdot \mathrm{CH}_{2} \cdot \mathrm{CH}_{2} \cdot \mathrm{CHBr} \cdot \mathrm{CH}_{2} \mathrm{Br}+4 \mathrm{KOH}=4 \mathrm{KBr}+4 \mathrm{H}_{2} \mathrm{O} \\
+\mathrm{CH}: \mathrm{C} \cdot \mathrm{CH}_{2} \cdot \mathrm{CH}_{2} \cdot \mathrm{C}: \mathrm{CH}
\end{gathered}
$$

This substance, boiling point $85^{\circ}$, behaves as an unsaturated compound should be expected to. It readily forms addition products with bromine, it is readily destroyed by oxidizing agents such as nitric acid, and it forms silver and copper compounds like acetylene (p. 61). In all these respects its behaviour is in marked contrast to the isomeric benzene, boiling point $80.5^{\circ}$, which does not readily form addition products, but substitution products with halogens such as $\mathrm{C}_{6} \mathrm{H}_{5} \mathrm{Br}$, and which, on treatment with nitric acid, is not oxidized into compounds with smaller number of carbon atoms, but gives nitro-substitution products such as $\mathrm{C}_{6} \mathrm{H}_{5}\left(\mathrm{NO}_{2}\right)$. Other hydrocarbon derivatives, furthermore, are known, several of which can be isolated from coal tar, which, as regards behaviour towards bromine and nitric acid, behave in a similar way to benzene, yielding bromo- and nitro-substitution products. These can be obtained synthetically from benzene, and are now known to be alkyl substitution products of benzene 


\section{36 Biological Chemistry.}

of the type $\mathrm{C}_{6} \mathrm{H}_{5} \mathrm{R}, \mathrm{C}_{6} \mathrm{H}_{4} \mathrm{RR}$, etc. On oxidation these substances are converted into carboxylic acids $\mathrm{C}_{6} \mathrm{H}_{5}(\mathrm{CO} \cdot \mathrm{OH})$, $\mathrm{C}_{6} \mathrm{H}_{4}(\mathrm{CO} \cdot \mathrm{OH})_{2}$. From the former of these, $\mathrm{C}_{6} \mathrm{H}_{4} \mathrm{CO} \cdot \mathrm{OH}$ benzene can be obtained when the calcium salt is distilled with lime-

$$
\left(\mathrm{C}_{6} \mathrm{H}_{5} \mathrm{CO} \cdot 0\right)_{2} \mathrm{Ca}+\mathrm{Ca}(\mathrm{OH})_{2}=2 \mathrm{CaCO}_{3}+\mathrm{H}_{2} \mathrm{O}+\mathrm{C}_{6} \mathrm{H}_{6}
$$

Furthermore, when a substitution product such as bromoor nitro-benzene is treated in various ways, the substituting group can be replaced and altered, but throughout all the various series of reactions the six-carbon-atom nucleus of the benzene remains intact. From these facts, therefore, it is obvious that benzene must have a constitution different from that of an ordinary hydrocarbon. It is now generally represented by what is known as a "ring" formula in the following way :-

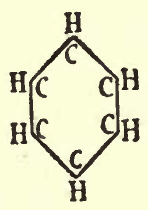

A ring formula (but somewhat different to the above) was first given to benzene by Kekule, to whom the fundamental conceptions of the constitution of the aromatic substances are due.

It will be observed in this formula that the carbon atoms are all represented as being tervalent and not quadrivalent, and as the adoption of the quadrivalency of the carbon atom is one of the basal conceptions upon which the theory of structural formulæ of the organic compounds has been built up, some further explanation of this formulæ is necessary. It has been assumed by Armstrong and Baeyer that the fourth valency of the carbon atom is directed towards the centre of the ring, 


\section{Structure of Simpler Organic Compounds. I 37}

which thus acquires great stability. The formula would be then represented as follows:-

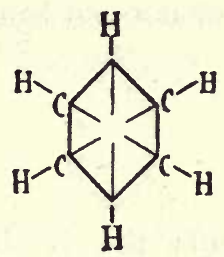

The actual constitution of benzene has been the subject of a large number of controversies, which need not be discussed in this place, and various alternative formulæ have been suggested. With the adoption, however, of the first formula, which, by omitting the symbol for carbon, may be written-

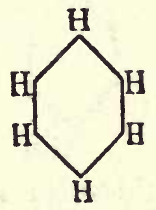

the relationship of the various benzene derivatives to one another may be sufficiently well indicated. For the theory of the constitution and the considerations relating to the dynamics of the formula reference must be made to textbooks on organic chemistry.

It now remains to substantiate the above formula.

It will be observed that it is quite symmetrical, and that every hydrogen atom is of equal value. From this it should follow that not more than one mono-substitution product of benzene is possible when a hydrogen atom is replaced by another group. In actual practice this had been found to be the case ; there is, for example, only one monobrom benzene, $\mathrm{C}_{6} \mathrm{H}_{5} \mathrm{Br}$, known, and only one mononitroderivative, $\mathrm{C}_{6} \mathrm{H}_{5}\left(\mathrm{NO}_{2}\right)$. It is found, thus, that the assumption of the equal value of all hydrogen atoms is correct. 
When the di-substitution products are considered, certain isomerides are possible. Starting from a mono-substitution product (for example, monobrom benzene)-

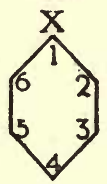

(omitting in the formula the symbol for hydrogen and numbering the carbon atoms in the way indicated), it is conceivable that the following derivatives are possible if a second hydrogen atom is substituted (for example, to form a dibromo benzene, $\mathrm{C}_{6} \mathrm{H}_{4} \mathrm{Br}_{2}$ )-

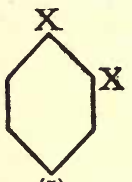

(I)

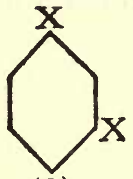

(2)

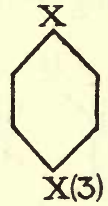

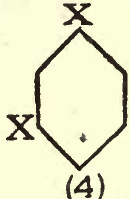

(4)

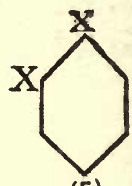

(5)

At first sight it would seem as if five di-substitution products were possible. Suppose, now, that the figure representing No. (4) is constructed from sticks, instead of being drawn, and is then regarded from a certain point. Let the figure then be turned through $180^{\circ}$ about an axis joining carbon atoms 1 and 4 . If looked at again a figure identical with No. (2) will be observed. In other words, with the formulæ as above, the relative arrangements of the atoms in Nos. (2) and (4) are identical. Substances represented by these formulæ should also be identical and not isomerides. From the same considerations, substances denoted by the formulæ (1) and (5) are identical. It therefore follows, if the suggested benzene formula is sufficient, that three, and only three, di-substitution products of benzene are capable of existence. Experience, drawn from the preparation of an immense 
Structure of Simpler Organic Compounds. I 39

number of benzene derivatives, has shown that this is really the case. These are the $(1,2),(1,3)$, and $(1,4)$ derivatives, which are known respectively as the ortho-, meta-, and para-derivatives, or, more shortly, the $o$-, $m$-, and $p$-derivatives-
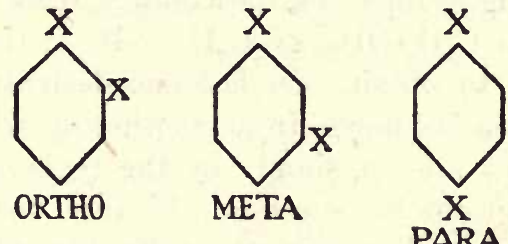

[Example: o-dinitro benzene would be represented by formula No. (1), in which, in place of $\mathrm{X}$, the group $\mathrm{NO}_{2}$ would be given. This substance could also be indicated by the formula $\mathrm{C}_{6} \mathrm{H}_{4}\left(\mathrm{NO}_{2}\right)_{2}(1,2)$.]

Of the tri-substitution products, when the three substituting groups are all the same, three isomerides should be possible, namely-

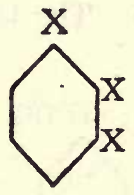

$1,2,3$, or Adjacent derivative.

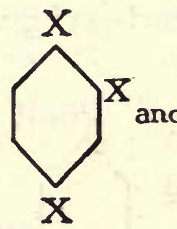

$1,2,4$, or Asymmetrical derivative.

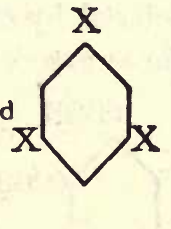

$1,3,5$, or $1,3,5$, or
Symmetrical derivative.

A larger number of isomerides is possible when the three substituting groups are not all the same. All these suppositions, which are based on the acceptance of the hexagonal ring formula for benzene, are borne out by ample experience.

Determination of the Constitution of Benzene Derivatives.-Accepting all these facts as a basis, the question next arises: How is the constitution of any given benzene derivative ascertained? How is it possible, for example, 
to determine whether a given compound, $\mathrm{C}_{6} \mathrm{H}_{4}(\mathrm{X})_{2}$, is an ortho-, meta-, or para-derivative?

It will be seen in the sequel that it is possible to pass from one benzene derivative to another by replacement of the substituting groups - as, for example, from $\mathrm{C}_{6} \mathrm{H}_{5}\left(\mathrm{NO}_{2}\right)$ to $\mathrm{C}_{6} \mathrm{H}_{5}\left(\mathrm{NH}_{2}\right)$, to $\mathrm{C}_{6} \mathrm{H}_{5}(\mathrm{OH})$, or $\mathrm{C}_{6} \mathrm{H}_{6}$. It is, therefore, very often possible to obtain one benzene derivative of which the constitution is known from another of which the constitution is not known, simply by the replacement of one substituting group by another. If this method is used, however, it is still necessary to fix the constitution of certain derivatives by an independent method, for it is obviously of no use to convert a derivative of the type $\mathrm{C}_{6} \mathrm{H}_{4} \mathrm{X}_{2}$ into $\mathrm{C}_{6} \mathrm{H}_{4} \mathrm{XY}$ or $\mathrm{C}_{6} \mathrm{H}_{4} \mathrm{Y}_{2}$, unless the constitution of the two latter derivatives can be fixed.

Certain benzene derivatives can be employed for this purpose, the most important of which are the phthalic acids-that is, benzene derivatives in which two hydrogen atoms are replaced by carboxyl groups. The three possible formulæ of these are-

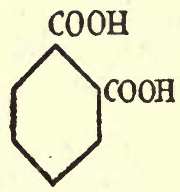

ORTHO

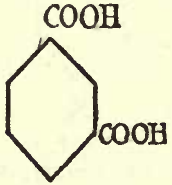

META

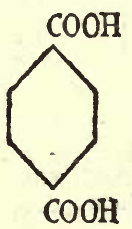

PARA

Of these only one forms an anhydride-

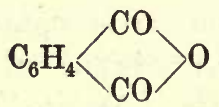

Now acid anhydrides are known to be readily formed from dibasic acids only when the carboxyl groups are near to one another. This happens only in the ortho-derivative. 


\section{Structure of Simpler Organic Compounds. 14I}

Of the three carboxyl acids known, therefore, the orthophthalic acid can be readily distinguished from the other two. One of the other two can, however, be obtained by a synthetic method, which leaves no doubt as to its constitution. When acetone is distilled with concentrated sulphuric acid, it yields a product $\mathrm{C}_{9} \mathrm{H}_{12}$, which behaves like a benzene derivative-

$$
3 \mathrm{CH}_{3} \cdot \mathrm{CO} \cdot \mathrm{CH}_{3}=\mathrm{C}_{6} \mathrm{H}_{2}\left(\mathrm{CH}_{3}\right)_{3}+3 \mathrm{H}_{2} \mathrm{O}
$$

The product is known as mesitylene, and if it is a benzene derivative it would, from its formation from acetone, contain probably three methyl groups which would be in a symmetrical position to one another. If three molecules of acetone are written in such a way as to indicate the method of the withdrawal of water, a picture of the following character is obtained-

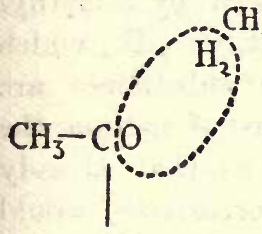

$\mathrm{CH}$
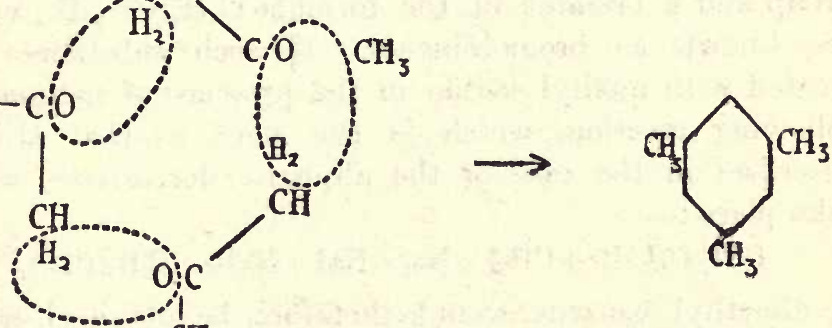

$\mathrm{CH}_{3}$

It is hardly conceivable that any but a symmetrical derivative could be obtained by such a reaction as the above. Furthermore, when alkyl substitution products of benzene are submitted to oxidation, the alkyl group is oxidized to a carboxyl group. Thus, mesitylene can be oxidized to $\mathrm{C}_{6} \mathrm{H}_{3}(\mathrm{COOH})_{3}$. This reaction can be accomplished in stages, and by regulating the process it is possible to isolate first the substance $\mathrm{C}_{6} \mathrm{H}_{3}\left(\mathrm{CH}_{3}\right)_{2} \mathrm{COOH}$, the calcium salt of which on distillation with lime yields 
$\mathrm{C}_{6} \mathrm{H}_{4}\left(\mathrm{CH}_{3}\right)_{2}$. (Compare preparation of benzene on p. 136.) This substance on oxidation yields a phthalic acid, in which the carboxyl groups must be attached to carbons separated by another carbon atom - that is, it must be the meta-derivative-

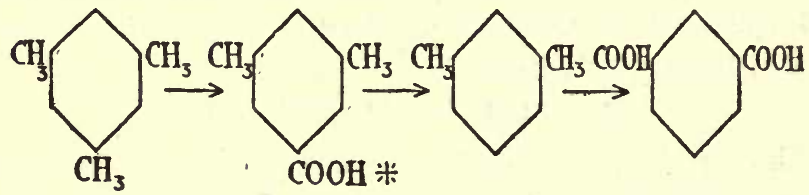

It would follow from the above, that the constitution of any derivative of the type $\left(\mathrm{C}_{6} \mathrm{H}_{4}\right) \mathrm{XY}$, which could be converted into a phthalic acid, could be ascertained. The following may be taken as an example of how such a method can be applied. There are three possible derivatives of benzene in which a hydrogen is replaced by a methyl group and a bromine of the formula $\mathrm{C}_{6} \mathrm{H}_{4}\left(\mathrm{CH}_{3}\right) \mathrm{Br}$, which are known as bromotoluenes. If such substances are treated with methyl iodide in the presence of sodium, the following reaction, which is the same as that already described in the case of the aliphatic derivatives, would take place:

$$
\mathrm{C}_{6} \mathrm{H}_{4}\left(\mathrm{CH}_{3}\right) \mathrm{Br}+\mathrm{CH}_{3} \mathrm{I}+\mathrm{Na}_{2}=\mathrm{NaI}+\mathrm{NaBr}+\mathrm{C}_{6} \mathrm{H}_{4}\left(\mathrm{CH}_{3}\right)_{2}
$$

A dimethyl benzene would, therefore, be obtained, which on oxidation would yield a phthalic acid. As the three phthalic acids differ from one another in melting points and other properties, it would be quite easy to ascertain the constitution of the bromotoluene from which any one of these acids was obtained.

Another method for determining the constitution of di-substitution products of benzene is due to Körner. This depends upon the fact that, if a tri-substitution product is

- Note that it does not matter which $\left(\mathrm{CH}_{3}\right)$ group is indicated as having undergone oxidation, as the positions are all symmetrical. 
Structure of Simpler Organic Compounds. I43

made from it, the number of isomerides obtainable from the ortho-, meta-, and para-compounds differs. Take, for example, an ortho-derivative, $\mathrm{C}_{6} \mathrm{H}_{4} \mathrm{X}_{2}$, and suppose this is treated with nitric acid to yield a nitro-derivative. The following are the possible formulæ:-
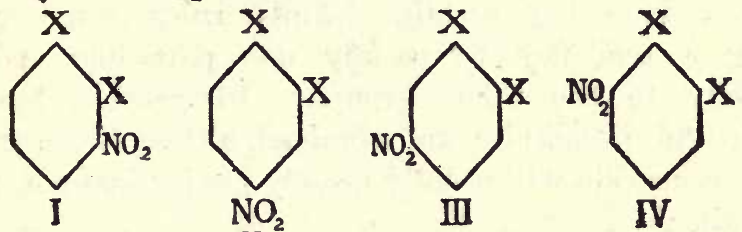

II

It will be observed here that the formulie I. and IV. are identical, as also are II. and III. From the ortho-derivative, therefore, only two nitro-derivatives can be obtained. Take now the case of the meta-compound. The following are the possible formulæ:-

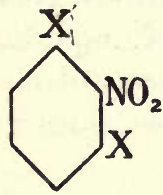

I

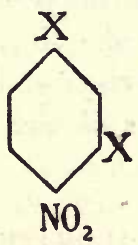

II

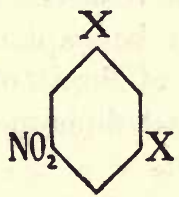

III

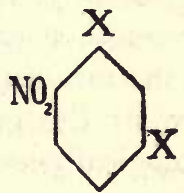

IV

Of these only IV. and II. are identical. The meta-compound can yield, therefore, three isomerides. In the case of the para-compound, the following are the possible formulæ for the nitro-compound :-
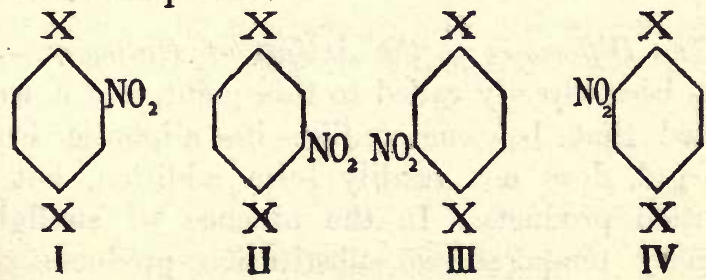
It will be noticed that all these formulæ are identical. The para-derivative can yield, therefore, only one nitroderivative. In introducing another group, such as the nitro group, into the benzene nucleus, the production of one isomeride predominates over another, the positions of substitution following certain definite rules, some groups having a tendency to occupy one particular position relatively to the other groups. In general, however, mixtures of isomerides are obtained, although the amount of one isomeride will usually greatly predominate over that of another.

So far the determination of the constitution of only disubstitution products has been discussed. The constitution of more complex derivatives is often not easy. The above illustrations will serve, however, to emphasize the reasons for adopting the ring formula for benzene, and in showing how, generally, the relationship of the various isomerides to one another can be explained. It is of importance to grasp the meaning of the isomerism of benzene derivatives in view of the great differences of the isomerides in their physiological action.

\section{GENERAL PROPERTIES OF AROMATIC COMPOUNDS.}

The benzene or aromatic derivatives containing the ring nucleus differ from the so-called "chain" or "aliphatic" compounds, as they are sometimes called, in many particulars. The chief of these may be summarized as follows:

I. The Difference in the Action of Halogens.-Attention has been already called to this point, and it was then mentioned that benzene, unlike its aliphatic isomeride dipropargyl, does not readily form addition, but rather substitution products. In the absence of sunlight and at ordinary temperatures, substitution products, such as 


\section{Structure of Simpler Organic Compounds. 145}

$\mathrm{C}_{6} \mathrm{H}_{5} \mathrm{Cl}, \mathrm{C}_{6} \mathrm{H}_{5} \mathrm{Cl}_{2}, \mathrm{C}_{5} \mathrm{H}_{5} \mathrm{Br}$, can be formed. This action is accelerated by the action of the so-called halogen " carriers," such as iodine, aluminium chloride, etc. Benzene is, however, also able to form addition products, the substance $\mathrm{C}_{6} \mathrm{H}_{6} \mathrm{Cl}_{6}$ being formed when benzene is treated with chlorine in direct sunlight. The action of halogens on certain benzene derivatives is mentioned later.

II. The Difference in the Action of Nitric Acid.Nitric acid does not oxidize benzene and its derivatives as it would if it were an unsaturated compound, but forms with it a well-defined series of nitro compounds. The reaction is best carried out with a mixture of nitric and sulphuric acids, the latter acting as a dehydrating agent. At moderate temperatures the mono-nitro derivative is formed-

$$
\mathrm{C}_{6} \mathrm{H}_{6}+\mathrm{H}_{4} \mathrm{NO}_{3}=\mathrm{C}_{6} \mathrm{H}_{5} \mathrm{NO}_{2}+\mathrm{H}_{2} \mathrm{O}
$$

At higher temperatures the dinitro-derivatives are formed, of which the meta-derivative preponderates in quantity. The "nitrating" action of nitric acid is a general one.

III. The action of sulphuric acid on aromatic derivatives is a characteristic one. By means of sulphuric acid, a series of substances known as the sulphonic acids is produced, the formation of which is illustrated by the following equation-

$$
\mathrm{C}_{6} \mathrm{H}_{6}+\mathrm{H}_{2} \mathrm{SO}_{4}=\mathrm{C}_{6} \mathrm{H}_{5} \cdot \mathrm{SO}_{3} \mathrm{H}+\mathrm{H}_{2} \mathrm{O}
$$

The constitution of these sulphonates may be represented by the general formula $\mathrm{SO}_{2}<\mathrm{OH}$ where $\mathrm{R}$ is a benzene radicle. They contain, like carboxylic acids, an acid hydroxyl group, which on treatment with phosphorus pentachloride yields an acid chloride of the type $\mathrm{SO}_{2}\left\langle\begin{array}{l}\mathrm{R} \\ \mathrm{Cl}\end{array}\right.$ The sulphonic acids are strongly acid substances, which are generally soluble in water, and yield well-defined salts. $(1,097)$ 
IV. The hydroxyl derivatives of the aromatic substances differ in many respects from the aliphatic hydroxyl derivatives. Whereas, in the aliphatic derivatives, a halogen is readily replaceable by a hydroxyl group, this is not the case in aromatic derivatives when the halogen is directly united to a carbon of the benzene nucleus. Ethyl bromide, $\mathrm{C}_{2} \mathrm{H}_{5} \mathrm{Br}$, for example, readily yields ethyl alcohol, $\mathrm{C}_{2} \mathrm{H}_{5} \cdot \mathrm{OH}$. Bromobenzene, $\mathrm{C}_{6} \mathrm{H}_{5} \mathrm{Br}$, on the other hand, is only attacked with very great difficulty by alkalis, the bromine appearing to be very strongly combined to the carbon atom. To obtain an aromatic hydroxyl derivative in which the hydroxyl is directly combined with a carbon atom of the ring, or a "phenol" as it is called, other methods must be employed. The two principal are (1) the treatment of the corresponding amino-derivative with nitrous acid (or through the diazo-derivative, see p. 148)-

$$
\mathrm{C}_{6} \mathrm{H}_{6} \mathrm{NH}_{2}+\mathrm{HONO}=\mathrm{C}_{6} \mathrm{H}_{5} \cdot \mathrm{OH}+\mathrm{N}_{2}+\mathrm{H}_{2} \mathrm{O}
$$

(2) A more general method is that of the fusion of the potassium salt of the sulphonic acid with potassium hydroxide-

$$
\mathrm{C}_{6} \mathrm{H}_{5} \cdot \mathrm{SO}_{3} \mathrm{~K}+2 \mathrm{KOH}=\mathrm{K}_{2} \mathrm{SO}_{3}+\mathrm{C}_{6} \mathrm{H}_{5} \mathrm{OK}+\mathrm{H}_{2} \mathrm{O}
$$

The potassium derivative of the phenol is thereby obtained. The phenols are colourless crystalline substances, the lower members of which are soluble in water. The chief of the phenols, $\mathrm{C}_{6} \mathrm{H}_{5} \cdot \mathrm{OH}$, is known generally as "carbolic acid." As the name might indicate, it is a substance of acid character, and in this respect the phenols differ markedly from their aliphatic analogues the alcohols. It may be recalled that the alcohols have a hydrogen replaceable by sodium when they are treated with the metal, but that the sodium derivative thus produced is readily decomposed by water, yielding again alcohol and sodium hydroxide. The phenols, on the other hand, dissolve in sodium hy- 
Structure of Simpler Organic Compounds. I 47

droxide solutions, and give fairly stable salts known as the phenates. The phenols, however, are still weak acids, and their salts are decomposed by carbon dioxide. Potassium phenate is $\mathrm{C}_{6} \mathrm{H}_{5} \cdot \mathrm{OK}$. These particular properties of phenols are not characteristic of hydroxyl derivatives of benzene, unless the hydroxyl group is directly attached to a carbon atom of the benzene nucleus. Thus, for example, a hydroxyl group attached to a carbon atom in a substituting group or "side-chain" can behave like an ordinary alcoholic group; a halogen atom in the same position will also behave like a halogen atom in an aliphatic compound. As an example, the substances known as benzyl alcohol, $\mathrm{C}_{6} \mathrm{H}_{5} \cdot \mathrm{CH}_{2} \mathrm{OH}$, and benzyl bromide, $\mathrm{C}_{6} \mathrm{H}_{5} \mathrm{CH}_{2} \mathrm{Br}$, may be mentioned. Both these substances behave, in their reactions, in the same way as aliphatic derivatives.

V. A characteristic series of derivatives known as diazo compounds can be prepared from aromatic amines. When a nitro-derivative is treated with nascent hydrogen, it is reduced to an amino-derivative of which $\mathrm{C}_{6} \mathrm{H}_{5} \cdot \mathrm{NH}_{2}$, or aniline, is a type. The salts of these compounds, on treatment with nitrous acid, yield unstable compounds, which readily decompose on warming, on a percussion, and are in fact so unstable as to be explosive. To obtain them, therefore, the treatment with nitrous acid must be carried out in cooled solutions. They are known as the diazonium compounds. Their formation is illustrated by the following equation-

$$
\mathrm{C}_{6} \mathrm{H}_{5} \cdot \mathrm{NH}_{2} \cdot \mathrm{HCl}+\mathrm{HO} \cdot \mathrm{NO}=\mathrm{C}_{6} \mathrm{H}_{5} \cdot \mathrm{N}: \mathrm{N} \cdot \mathrm{Cl}+2 \mathrm{H}_{2} \mathrm{O}
$$

The compound thus produced is phenyldiazonium chloride.

The process of preparation of diazo compounds is known as "diazotization." A certain number of aliphatic diazo compounds are also known. The aromatic diazo compounds are made by dissolving the salt of the base, 
such as aniline in excess of an acid, cooling the solution thus obtained, and then adding the theoretical amount of amyl nitrite or sodium nitrite. In the former case alcohol is used as a solvent to dilute the acid, and in the latter case, water. The diazonium salt of the acid then separates in a crystalline form. This is a general reaction when the amino group is directly attached to a carbon atom of the benzene ring.

The diazonium salts undergo certain characteristic reactions :

(a) With alcohol the whole diazonium group is replaced by hydrogen, the alcohol being oxidized to aldehyde-

$$
\mathrm{C}_{6} \mathrm{H}_{5} \cdot \mathrm{N}_{2} \cdot \mathrm{Cl}+\mathrm{C}_{2} \mathrm{H}_{5} \mathrm{OH}=\mathrm{C}_{6} \mathrm{H}_{6}+\mathrm{N}_{2}+\mathrm{HCl}+\mathrm{CH}_{3} \cdot \mathrm{CHO}
$$

(b) On warming with water, the diazonium group is replaced by a hydroxyl group to yield a phenol-

$$
\mathrm{C}_{6} \mathrm{H}_{5} \cdot \mathrm{N}_{2} \cdot \mathrm{Cl}+\mathrm{H}_{2} \mathrm{O}=\mathrm{C}_{6} \mathrm{H}_{5} \mathrm{OH}+\mathrm{N}_{2}+\mathrm{HCl}
$$

If nitrous acid is added to an aromatic amine without cooling, the diazonium compound is not produced, but a phenol is obtained directly. In this case the action is the same as that of a primary aliphatic amine.

(c) They undergo a characteristic reaction when treated with cuprous salts, such as the chloride, bromide, or cyanide, yielding chloro-, bromo-, or cyano-derivatives respectively, the chlorine, bromine, or cyanogen replacing the diazonium group. An addition product with the cuprous salt is formed first, and this then decomposes-

$$
\begin{aligned}
\mathrm{C}_{6} \mathrm{H}_{5} \cdot \mathrm{N}_{2} \mathrm{Cl} 2 \mathrm{CuCl} & =\mathrm{C}_{6} \mathrm{H}_{5} \mathrm{Cl}+\mathrm{N}_{2}+2 \mathrm{CuCl} \\
\mathrm{C}_{6} \mathrm{H}_{5} \cdot \mathrm{N}_{2} \mathrm{Cl} \cdot 2 \mathrm{Cu}(\mathrm{CN}) & =\mathrm{C}_{5} \mathrm{H}_{5}(\mathrm{CN})+\mathrm{N}_{2}+\mathrm{CuCl}+\mathrm{Cu}(\mathrm{CN})
\end{aligned}
$$

This reaction is known as Sandmeyer's reaction, and is commonly employed for preparing halogen and cyanogen compounds. It may be cited as an example of the method 


\section{Structure of Simpler Organic Compounds. 149}

by means of which one group attached to the carbon of a benzene nucleus may be replaced by another group. Thus, for example, nitrobenzene, $\mathrm{C}_{6} \mathrm{H}_{5}\left(\mathrm{NO}_{2}\right)$, may be reduced to aniline, $\mathrm{C}_{6} \mathrm{H}_{5}\left(\mathrm{NH}_{2}\right)$, the latter can be "diazotized" and then treated with cuprous cyanide according to the Sandmeyer reaction, and the cyanide or benzonitrile, $\mathrm{C}_{6} \mathrm{H}_{5}(\mathrm{CN})$, thus produced will yield on hydrolysis $\mathrm{C}_{6} \mathrm{H}_{5} \cdot \mathrm{COOH}$ or benzoic acid. As the diazo compounds are unstable, they are not generally isolated when required for further operations ; the amine salt in presence of excess of acid is treated with the theoretical amount of amyl or sodium nitrite in cold solution, and the solution of the diazonium salt is then treated with the necessary reagent. Operations of the above description are of importance in determining the structure of many aromatic substances, as by such means it is often possible to pass from a substance of unknown to one of known composition.

(d) Diazonium compounds can condense with a large number of aromatic derivatives, and many of the substances thus produced are valuable representatives of classes of aniline dyes. Thus, for example, phenyldiazonium chloride will condense with aniline-

$$
\mathrm{C}_{6} \mathrm{H}_{5} \cdot \mathrm{N}_{2} \cdot \mathrm{Cl}+\mathrm{C}_{6} \mathrm{H}_{5} \cdot \mathrm{NH}_{2}=\mathrm{C}_{6} \mathrm{H}_{5} \cdot \mathrm{N}_{2} \mathrm{NH} \cdot \mathrm{C}_{6} \mathrm{H}_{6}+\mathrm{HCl}
$$

to form diazoamino benzene; on warming this substance with a small amount of aniline hydrochloride to $40^{\circ}$, it undergoes intramolecular change to form aminoazo benzene-

$$
\mathrm{C}_{6} \mathrm{H}_{6} \cdot \mathrm{N}_{2} \cdot \mathrm{NH} \cdot \mathrm{C}_{6} \mathrm{H}_{6}=\mathrm{C}_{6} \mathrm{H}_{6} \cdot \mathrm{N}_{2} \cdot \mathrm{C}_{6} \mathrm{H}_{4} \cdot \mathrm{NH}_{2}
$$

The hydrochloride of this substance was formerly used as a dye for silk under the name of "aniline yellow."

The diazo compounds will also condense with amines in which both the hydrogen groups are replaced by alkyl radicles - for example, with dimethyl aniline-

$$
\mathrm{C}_{6} \mathrm{H}_{5} \cdot \mathrm{N}_{2} \cdot \mathrm{Cl}+\mathrm{C}_{6} \mathrm{H}_{5} \cdot \mathrm{N}\left(\mathrm{CH}_{3}\right)_{2}=\mathrm{C}_{6} \mathrm{H}_{5} \cdot \mathrm{N}_{2} \cdot \mathrm{C}_{6} \mathrm{H}_{4} \cdot \mathrm{N}\left(\mathrm{CH}_{3}\right)_{2} \cdot \mathrm{HCl}
$$


They will also condense with a phenol-

$$
\mathrm{C}_{6} \mathrm{H}_{5} \cdot \mathrm{N}_{2} \cdot \mathrm{Cl}+\mathrm{C}_{6} \mathrm{H}_{5}(\mathrm{OH})=\mathrm{C}_{6} \mathrm{H}_{5} \cdot \mathrm{N}_{2} \cdot \mathrm{C}_{6} \mathrm{H}_{4}(\mathrm{OH})+\mathrm{HCl}
$$

or a polyhydroxy phenol-

$$
\mathrm{C}_{6} \mathrm{H}_{5} \cdot \mathrm{N}_{2} \cdot \mathrm{Cl}+\mathrm{C}_{6} \mathrm{H}_{4}\left(\mathrm{OH}_{2}\right)=\mathrm{C}_{6} \mathrm{H}_{6} \cdot \mathrm{N}_{2} \cdot \mathrm{C}_{6} \mathrm{H}_{3}(\mathrm{OH})_{2}+\mathrm{HCl}
$$

These reactions are very general. Thus, sulphanilic acid, a benzene derivative containing a sulphonic acid and an amino group, both attached to carbons of a benzene nucleus, can be "diazotized," and the diazonium salt will condense with phenols, aromatic amines, and other substances. The dye "helianthin," for example, can be obtained by the condensation of a diazonium derivative of sulphanilic acid and diamethyl aniline-

$$
\begin{aligned}
\mathrm{SO}_{3} \mathrm{H} \cdot \mathrm{C}_{6} \mathrm{H}_{4} \cdot \mathrm{N}_{2} \cdot \mathrm{OH}+\mathrm{C}_{6} \mathrm{H}_{5} \cdot \mathrm{N}\left(\mathrm{CH}_{3}\right)_{2} \\
=\mathrm{SO}_{3} \mathrm{H} \cdot \mathrm{C}_{6} \mathrm{H}_{4} \cdot \mathrm{N}_{2} \cdot \mathrm{C}_{6} \mathrm{H}_{4} \cdot \mathrm{N}\left(\mathrm{CH}_{3}\right)_{2}+\mathrm{H}_{2} \mathrm{O}
\end{aligned}
$$

An enormous variety of coloured substances can be produced in a similar way, all of which belong to the class of azo-dyes, many of which are largely used for tinctorial purposes.

(e) The diazo-derivatives can be reduced. The reduction product of phenyl diazonium chloride is of considerable importance as a chemical reagent, in that it condenses readily with ketones and aldehydes, a reaction to which attention has been already drawn. The substance in question, phenylhydrazine, which is largely used in biochemical work in the investigation of sugars (which contain aldehydic and ketonic groups), can be prepared from phenyldiazonium chloride by reducing it with stannous chloride and hydrochloric acid-

$$
\mathrm{C}_{6} \mathrm{H}_{5} \cdot \mathrm{N} \cdot \mathrm{NCl}+2 \mathrm{H}_{2}=\mathrm{C}_{6} \mathrm{H}_{5} \cdot \mathrm{NH} \cdot \mathrm{NH}_{2} \cdot \mathrm{HCl}
$$

In the foregoing pages the chief reactions of benzene and its derivatives have been summarized very shortly. Reasons have been given for the adoption of the so-called 


\section{Structure of Simpler Organic Compounds. I 5 I}

"ring" formula, and it has been shown how, by means of the formula, the number of possible isomerides of benzene derivatives and their relationship to one another can be explained. It has been further pointed out that benzene differs in many respects from the unsaturated aliphatic substance dipropargyl which is isomeric with it. It is a very stable substance, and the ring nucleus of six carbon atoms is only destroyed with difficulty. When benzene or its derivatives are treated with nitric acid they yield nitro-derivatives, and with sulphuric acid they give rise to sulphonic acids. When a halogen is attached to a carbon of the benzene nucleus it is not readily replaced by hydroxyl. When a hydroxyl group is directly attached to a carbon atom, a "phenol" is obtained which differs in many respects from an aliphatic hydroxyl derivative. When an amino group is attached to a carbon atom of the benzene nucleus, it can, on treatment with nitrous acid, give rise to diazonium compounds, which undergo an interesting series of condensations with other aromatic derivatives, yielding characteristic products, some of which are of considerable commercial value as dyestuffs (aniline dyes).

\section{SOME TYPICAL AROMATIC SUBSTANCES.}

Hydrocarbons.

Benzene.-This hydrocarbon is obtained from the lower boiling fractions produced by the distillation of coal tar. It boils at $80^{\circ}-81^{\circ}$. The ordinary commercial product is contaminated with a substance, thiophene, $\mathrm{C}_{4} \mathrm{H}_{4} \mathrm{~S}$, which can only be removed with some difficulty. The removal is usually effected by shaking with concentrated sulphuric acid, which sulphonates thiophene more readily than it does benzene. The crude benzene obtained from coal tar also contains certain quantities of the homologues 
toluene and xylene (see below), the last traces of which cannot be completely separated by fractional distillation. On freezing the liquid, benzene can be caused to separate as a crystalline mass, melting point $5 \cdot 4^{\circ}$, which is filtered off. By repeated separation in crystalline form the benzene can be obtained pure with boiling point $80.5^{\circ}$. Pure benzene can also be obtained by the distillation of calcium benzoate with lime.

Toluene, $\mathrm{C}_{6} \mathrm{H}_{5}\left(\mathrm{CH}_{3}\right)$, is the next higher homologue of benzene, and is also contained in the lower fractions of coal tar, from which it can be separated in a crude form by fractional distillation. It can also be obtained from balsam of Tolu and other resins by distillation. The pure product boils at $110^{\circ}$. It can also be obtained synthetically from benzene by two methods which are of general application for the preparation of alkyl substitution products of benzene.

(a) By the so-called Friedel and Crafts' reaction, which consists in the treatment of benzene with an alkyl halogen compound in the presence of anhydrous aluminium chloride-

$$
\mathrm{C}_{6} \mathrm{H}_{6}+\mathrm{CH}_{3} \mathrm{Cl}=\mathrm{HCl}+\mathrm{C}_{6} \mathrm{H}_{5} \cdot \mathrm{CH}_{3}
$$

More than one hydrogen of the benzene nucleus can be replaced in this way-

$$
\mathrm{C}_{6} \mathrm{H}_{6}+2 \mathrm{CH}_{3} \mathrm{Cl}=2 \mathrm{HCl}+\mathrm{C}_{6} \mathrm{H}_{4} \cdot\left(\mathrm{CH}_{3}\right)_{2}
$$

The mechanism of this reaction is somewhat complex, and need not be further discussed here.

(b) By the method already referred to (p. 142), by the treatment of a mixture of a benzene halogen derivative and an alkyl halogen derivative with metallic sodium (see p. 55).

Toluene can also be obtained by the distillation of the calcium salt of toluic acid, $\mathrm{C}_{6} \mathrm{H}_{4} \cdot \mathrm{CH}_{2} \cdot \mathrm{COOH}$, with lime. 
Structure of Simpler Organic Compounds. I 53

The reaction is the same as that involved in the preparation of benzene from benzoic acid.

Xylenes, $\mathrm{C}_{6} \mathrm{H}_{4}\left(\mathrm{CH}_{3}\right)_{2}$. - Three isomerides are known, all of which exist in the distillate of coal tar. The $m$-compound predominates in quantity over the other two.

Mesitylene, $\mathrm{C}_{6} \mathrm{H}_{3}\left(\mathrm{CH}_{3}\right)_{3}$.-The $1 \cdot 3 \cdot 5$ (symmetrical) compound has been already mentioned, and is of importance owing to the fact that it can be obtained synthetically from acetone (p. 141).

Other homologues of benzene are known, such as cymene, $\mathrm{C}_{6} \mathrm{H}_{4}\left(\mathrm{CH}_{3}\right)\left(\mathrm{C}_{3} \mathrm{H}_{7}\right)$, p-methyl iso-propyl benzene, some of which are contained in essential oils.

\section{Halogen Derivatives of Benzene and its Homologues.}

The action of chlorine and bromine on benzene itself has been already mentioned (p. 144). Addition products only form in the presence of direct sunlight. The iodine substitution products cannot be obtained directly. They are best obtained by the action of potassium iodide in aqueous solution on a diazonium salt-

$$
\mathrm{C}_{6} \mathrm{H}_{5} \cdot \mathrm{N}_{2} \mathrm{SO} 4 \mathrm{H}+\mathrm{KI}=\mathrm{C}_{6} \mathrm{H}_{5} \mathrm{I}+\mathrm{N}_{2}+\mathrm{KHSO}_{4}
$$

The action of halogens on alkyl derivatives of benzene is of interest. In this case substitution of a hydrogen atom can take place either in the benzene nucleus or the alkyl group or so-called "side-chain." In the absence of direct sunlight or in the presence of a "carrier" (see p. 145), the substitution takes place in the nucleus. By the action of chlorine on toluene, under such conditions, a mixture of $o$ - and $p$-chlor toluenes-

is obtained.

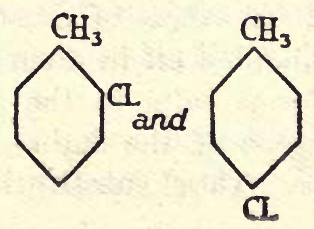


If, however, no carrier is present, and toluene is treated in direct sunlight or at its boiling point with chlorine or bromine, substitution takes place in the "side-chain" and derivatives of the type $\mathrm{C}_{6} \mathrm{H}_{5} \cdot \mathrm{CH}_{2} \mathrm{Cl}$, benzyl chloride, $\mathrm{C}_{6} \mathrm{H}_{5} \cdot \mathrm{CHCl}_{2}$, benzal chloride, and $\mathrm{C}_{6} \mathrm{H}_{5} \cdot \mathrm{CCl}_{3}$, benzotrichloride, are obtained.

The various halogen derivatives are mostly liquids which can be purified by distillation. It may be recalled here (see p. 146) that the halogen when in the "side-chain". is readily replaced by a hydroxyl group, on treatment with caustic alkalis, whereas this is not the case when it is attached to the benzene nucleus.

\section{Nitro Compounds.}

Nitrobenzene.-This compound is made by treating benzene with a mixture of nitric and sulphuric acid, under conditions which do not allow too great a rise in temperature. It is a liquid which boils at $205^{\circ}$. By treating it with a mixture of nitric and sulphuric acid at higher temperatures, the chief product produced is the $m$-dinitro benzene, $\mathrm{C}_{6} \mathrm{H}_{4}\left(\mathrm{NO}_{2}\right)_{2}$, melting point $90^{\circ}$; small quantities of the $o$ - and $p$-compounds are formed at the same time.

\section{Amino Compounds.}

Aniline, $\mathrm{C}_{6} \mathrm{H}_{5} \cdot \mathrm{NH}_{2}$ - This is produced from nitrobenzene by reduction, tin and hydrochloric acid being generally employed for the purpose. With these reagents, the aniline separates in the form of a tin double salt, which is decomposed by excess of caustic alkalis, and the free aniline is then distilled off in a current of steam. It boils at $184^{\circ}$, and forms salts in the same way as other amines. The hydrogens of the amino group are replaceable by alkyl radicles. These substitution products can be 


\section{Structure of Simpler Organic Compounds. I 55}

prepared either by heating aniline with the alkyl halogen compounds (compare preparation of secondary and tertiary amines, p. 124 and seq.) or by heating aniline to $200^{\circ}-250^{\circ}$, with a mixture of the alcohol and hydrochloric acid-

$$
\begin{aligned}
& \mathrm{C}_{6} \mathrm{H}_{5} \cdot \mathrm{NH}_{2} \mathrm{HCl}+\mathrm{CH}_{3} \cdot \mathrm{OH}=\mathrm{C}_{6} \mathrm{H}_{5} \cdot \mathrm{NH}\left(\mathrm{CH}_{3}\right) \mathrm{HCl}+\mathrm{H}_{2} \mathrm{O} \\
& \mathrm{C}_{6} \mathrm{H}_{5} \cdot \mathrm{NH}_{2} \cdot \mathrm{HCl}+2 \mathrm{CH}_{3} \cdot \mathrm{OH}=\mathrm{C}_{6} \mathrm{H}_{5} \mathrm{~N}\left(\mathrm{CH}_{3}\right)_{2} \mathrm{HCl}+\mathrm{H}_{2} \mathrm{O}
\end{aligned}
$$

The general properties of aromatic amines, apart from their ready formation of diazonium salts, are not very different from those of the aliphatic derivatives.

\section{Phenols.}

Phenol or Carbolic Acid, $\mathrm{C}_{6} \mathrm{H}_{5} \cdot \mathrm{OH}$.-This substance can be prepared from benzene by nitrating first to produce nitrobenzene, which substance is then reduced to aniline, which on treatment with nitrous acid yields phenol. It can also be prepared by treating potassium benzene sulphonate with potassium hydroxide. It is obtained on a large scale from that portion of the coal-tar distillate which boils between $170^{\circ}$ and $230^{\circ}$. This fraction also contains another hydrocarbon, naphthalene, which separates in a crystalline form on cooling. The phenol is extracted by alkalis from the oily residue pressed out from these crystals; by virtue of its phenolic character (see p. 146), it dissolves in the alkali forming a salt. From the solution so obtained the free phenol or carbolic acid separates on acidification. Phenol is also found in small quantities in urine. It is a colourless crystalline substance, melting point $42^{\circ}$, boiling point $183^{\circ}$, which is volatile in steam and turns pink on exposure to air. It forms ethers of the type $\mathrm{C}_{6} \mathrm{H}_{5} \cdot \mathrm{OR}$, in a similar way to the aliphatic alcohols.

Cresols $(o-, m-, p-)$ are the next higher homologues of phenol, having the formula $\mathrm{C}_{6} \mathrm{H}_{4} \cdot\left(\mathrm{CH}_{3}\right)(\mathrm{OH})$. They also 


\section{56 Biological Chemistry.}

occur in coal tar, and, like phenol, are valuable antiseptics.

Thymol, $\mathrm{C}_{6} \mathrm{H}_{3}\left(\mathrm{CH}_{3}\right)\left(\mathrm{CH} \cdot\left\langle\begin{array}{l}\mathrm{CH}_{3} \\ \mathrm{CH}_{3}\end{array}\right)(\mathrm{OH}), 1: 4: 3\right.$, occurs in oil of thyme. It is a methyl isopropyl phenol. The 1:4:2 isomer is known as carvacrol, and can be prepared by heating camphor with iodine.

\section{Dihydroxy Phenols.}

The following dihydric phenols are known-

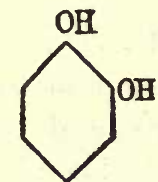

Catechal Resorcind

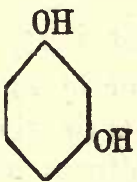

OH

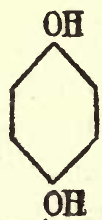

Quinal (Hydro. quinone)

Catechol occurs in catechu, a substance obtained from Acacia catechu, an Indian tree, and hydroquinone occurs combined with dextrose (p. 193) in arbutin, a glucoside obtained from the bear-berry. Resorcinol is obtained synthetically only by the fusion of the potassium salt of the corresponding disulphonate with potassium hydroxide. It readily oxidizes when treated with mild oxidizing agents to yield quinone, which belongs to a characteristic class of benzene derivatives, which needs no further discussion in this place-

$$
\mathrm{C}_{6} \mathrm{H}_{6}(\mathrm{OH})_{2}+\mathrm{O}=\mathrm{C}_{6} \mathrm{H}_{4} \mathrm{O}_{2}+\mathrm{H}_{2} \mathrm{O}
$$




\section{Structure of Simpler Organic Compounds. I 57}

\section{Trihydroxy Phenols.}

The following are known-

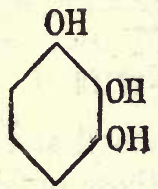

Pyrogallol

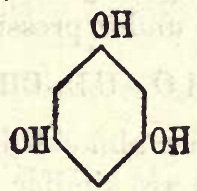

Phloroglucind

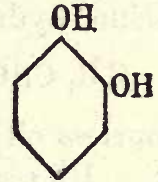

$\mathrm{OH}$

Pyrogallol is generally prepared by heating to about $210^{\circ}$ gallic acid, which has the formula-

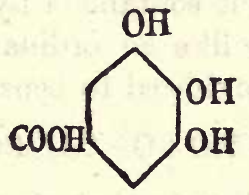

It then decomposes according to the equation-

$$
\mathrm{C}_{6} \mathrm{H}_{2}(\mathrm{OH})_{3} \mathrm{COOH}=\mathrm{CO}_{2}+\mathrm{C}_{6} \mathrm{H}_{3}(\mathrm{OH})_{3}
$$

Gallic acid is obtained from gall-nuts, and is closely related to tannin or tannic acid.

Pyrogallol is largely used in the laboratory and in photography on account of its reducing properties. In alkaline solution it readily absorbs oxygen, and forms a dark-coloured pigment. It is a colourless, crystalline substance, with melting point $115^{\circ}$.

\section{Aldehydes.}

Benzaldehyde, $\mathrm{C}_{6} \mathrm{H}_{5} \cdot \mathrm{CHO}$, is the chief representative of this class. It is sometimes known as "oil of bitter almonds." Bitter almonds contain a glucoside known as amygdalin, which under the influence of ferment "emulsin" decomposes into hydrocyanic acid, glucose, 
and benzaldehyde. The latter can be prepared directly from benzene, but it is best obtained from benzalchloride, $\mathrm{C}_{6} \mathrm{H}_{5} \cdot \mathrm{CHCl}_{2}$ (p. 154), by hydrolysis with dilute sulphuric acid or calcium hydroxide under pressure-

$$
\mathrm{C}_{6} \mathrm{H}_{6} \cdot \mathrm{CHCl}_{2}+2 \mathrm{H}_{2} \mathrm{O}=\mathrm{C}_{6} \mathrm{H}_{5} \cdot \mathrm{CHO}+2 \mathrm{HCl}
$$

It is a colourless oil with an almond-like smell and boiling point $179^{\circ}$. Its reactions are similar to those of aliphatic aldehydes. It can be reduced, for example, to benzyl alcohol-

$$
\mathrm{C}_{6} \mathrm{H}_{5} \mathrm{CHO}+\mathrm{H}_{2}=\mathrm{C}_{6} \mathrm{H}_{5} \cdot \mathrm{CH}_{2} \mathrm{OH}
$$

a substance which, as it contains a hydroxyl group in the "side-chain," behaves like an ordinary alcohol, but not as a phenol. It can be oxidized to benzoic acid-

$$
\mathrm{C}_{6} \mathrm{H}_{8} \mathrm{CHO}+\mathrm{O}=\mathrm{C}_{6} \mathrm{H}_{5} \cdot \mathrm{COOH}
$$

another reaction similar to that of a fatty aldehyde. It also yields bisulphite compounds, an oxime and hydrazone (compare p. 82).

Carboxylic Acids.

Benzoic Acid, $\mathrm{C}_{6} \mathrm{H}_{5} \cdot \mathrm{COOH}$.-This occurs in many resins, and is obtained by sublimation of gum benzoin. Its synthesis from benzyl cyanide (or benzonitrile) has been already mentioned. It is soluble in hot water, from which it separates in crystals on cooling. It has melting point $121.5^{\circ}$, and boiling point $249^{\circ}$, and readily sublimes. It forms esters, an acid chloride, anhydride, and amide like aliphatic acids.

The dicarboxylic acids of benzene are known as the phthalic acids. Their constitution has been already discussed. 
Structure of Simpler Organic Compounds. I 59

\section{Hydroxy Acids.}

Salicylic Acid, $\mathrm{C}_{6} \mathrm{H}_{4}(\mathrm{OH})(\mathrm{COOH}), 1: 2$. - This substance is important as a therapeutic agent and disinfectant, and occurs in the form of its methyl ester in oil of winter green. It is prepared synthetically on a large scale by treating sodium phenate with carbon dioxide under pressure. The substance, $\mathrm{C}_{6} \mathrm{H}_{4} \cdot \mathrm{O} \cdot \mathrm{COONa}$, forms first, and then undergoes intramolecular change. Salicylic acid dissolves in hot water, from which it separates on cooling in colourless crystals, melting point $156^{\circ}$.

Gallic acid, $\mathrm{C}_{6} \mathrm{H}_{2}(\mathrm{OH})_{3}(\mathrm{COOH})$, has been already mentioned (p. 157). 


\section{CHAPTER IV.}

STEREOISOMERISM.

Mention has been already made of the fact that certain substances, such as amyl alcohol (p. 76), lactic (p. 116) and tartaric acids, exist in the form of isomerides, the relationship of which one to another cannot be explained in a satisfactory manner by the ordinary structural formulæ. Certain of these isomerides are also optically active. It is proposed to devote the present chapter to the discussion of isomerides of this character and to the question of optical activity, both of which subjects are matters of considerable biological importance.

Lactic acid was discovered by Scheele in 1780 in sour milk, and a similar acid was isolated in 1807 by Berzelius from extract of muscular tissue. The acids were considered to be identical by Liebig, who reinvestigated them in 1847; but in the following year Engelhardt pointed out that there was a difference in the calcium and the zinc salts of the acids derived from the two sources. The acid from muscular tissue was designated "sarcolactic" acid by Strecker. Between 1863 and 1873 the acids were subjected to a detailed investigation by Wislicenus, who succeeded in synthesizing a third lactic acid in the following way. Ethylene chlorhydrin was obtained by treating ethylene with hypochlorous acid-

$$
\prod_{\mathrm{CH}_{2}}^{\mathrm{CH}_{2}}+\mathrm{HClO}={\stackrel{C}{\mathrm{CH}_{2} \mathrm{Cl}}}_{\mathrm{H}_{2} \mathrm{OH}}^{\mathrm{Cl}}
$$


This on treatment with potassium cyanide yielded-

$$
\mathrm{CH}_{2} \cdot(\mathrm{OH}) \cdot \mathrm{CH}_{2}(\mathrm{CN})
$$

which on hydrolysis yielded-

\section{$\mathrm{CH}_{2}(\mathrm{OH}) \cdot \mathrm{CH}_{2} \cdot \mathrm{COOH}$}

This was identical with neither sarcolactic acid nor with the acid from sour milk, which latter can be synthetically obtained by the action of dilute alkalis or silver hydroxide on a-brompropionic acid-

$$
\mathrm{CH}_{3} \cdot \mathrm{CHBr} \cdot \mathrm{COOH}+\mathrm{H}_{2} \mathrm{O}=\mathrm{CH}_{3} \cdot \mathrm{CH}(\mathrm{OH}) \cdot \mathrm{COOH}
$$

(The alkali is omitted from this equation.) There were therefore three isomeric acids obtained, all of which were found to contain a hydroxyl and a carboxyl group. On the basis of the formulæ already discussed, only two such isomerides are possible, namely, the $\alpha$ and $\beta$ hydroxy propionic acids-
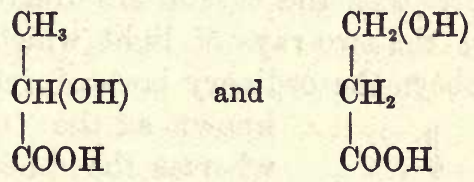

It was further shown that one of the three known acids was optically active. (The explanation of "optical activity" is given below.) These facts indicated to Wislicenus that the structural formulæ hitherto in use were not sufficient to explain all cases of isomerism.

The second classical example which indicated the insufficiency of structural formulæ was that of the tartaric acids.

The aqueous solution of ordinary tartaric acid was known to have the property of rotating the plane of polarized light, but in 1830 Berzelius discovered in the mother liquors from Kastner's tartaric acid manufactory a second acid, very similar in its chemical properties, but differing from ordinary tartaric acid in the fact that it 
was optically inactive. This acid was known as " racemic acid." The first great classical research of Pasteur deals with the relationship between racemic and tartaric acids (1848-54), but before considering these results it will be necessary to diverge for a time to discuss the meaning of the expression "optical activity," to which repeated reference has already been made.

Optical Activity.-If a ray of light is allowed to fall on to a rhomb of Iceland spar (a certain crystalline form of calcium carbonate) part will pass straight through, whereas another part will be refracted and travel through another path. A double image will therefore be seen of any object viewed through a crystal of the spar. This phenomenon is known as double refraction, and is due to the anisotropic properties of the crystal-that is, the physical properties of the crystal are different in different directions. Of the two rays of light which pass through the spar, one obeys the ordinary laws of refraction, and is

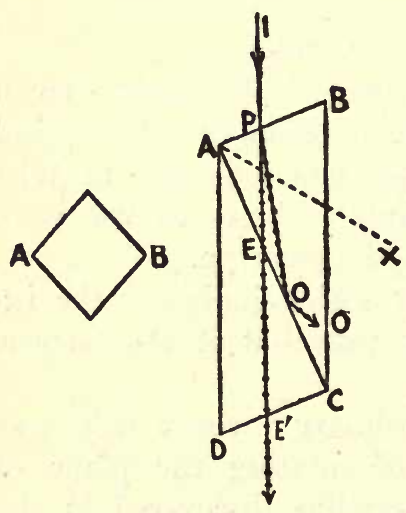

Fig. 18. known as the "ordinary ray"; whereas the other does not, and is called the "extraordinary ray."

By means of a device known as the Nicol prism, it is possible so to arrange the light incidence that only the extraordinary ray passes through. The Nicol prism is constructed in the following manner:-A rhomb of Iceland spar is cut in two by a plane AC perpendicular to the principal plane for the face $A B$ (see Fig. 18). The two cut surfaces are then polished and cemented together by Canada balsam. The refractive index of Canada balsam 
is greater than that of the minimum value for the extraordinary ray in Iceland spar, but less than that of the ordinary ray. If the incidence of the ordinary ray is sufficiently oblique, it is totally reflected. If the plane $\mathrm{AC}$ is inclined at a suitable angle, the ordinary ray $\mathrm{PO}$ will be incident on the surface $\mathrm{AC}$ at an angle greater than the critical angle, and will be totally reflected along $\mathrm{OO}^{\prime}$, whilst the extraordinary ray $\mathrm{PEE}^{\prime}$ will pass through the prism.

Now this emergent ray has certain properties which distinguish it from ordinary light rays. The ether vibrations take place only in one plane, and the light is then said to be "plane polarized."* If this polarized light is allowed to fall on another Nicol prism, it will be found that on rotating the latter, the field of view will appear alternately dark and light, the minimum following the maximum as the second prism is rotated through an angle of $90^{\circ}$. The prism by means of which the light is polarized is called the "polarizer," whereas the second prism is called the "analyzer." Suppose now that the two prisms are so placed that the maximal amount of light in the field is obtained, and suppose a liquid or a solution of a substance is placed between the analyzer and polarizer. In the case of certain substances, no effect will be observed (except a slight diminution of the intensity). In the case of other substances, however, the field will be darkened, and the maximal intensity of light will only be observed again if the analyzer is rotated. In this case the substance, or the solution of the substance, has rotated the plane of polarized light and is said to be optically active, and the degree of its activity can be measured by ascertaining the angle through which the analyzer must be rotated to produce

* For fuller details as to the theory of polarization, reference should be made to a text-book on physics. 
the maximal intensity of the field of illumination. A substance may rotate the plane of polarized light either in one direction or another-that is, it may be necessary to rotate the analyzer either to the right or the left to produce the maximal illumination of the field. According to the direction in which the analyzer must be rotated, a substance is either dextro- or lævo-rotatory. The instrument for determining the rotatory power is known as the "polarimeter."

The apparatus actually employed for the measurement of optical rotation is somewhat more complex than that suggested by the foregoing description. If only an analyzer and polarizer were employed, it would be difficult to determine with accuracy the positions of maximal illumination or darkness. To obviate this difficulty the so-called "half-shadow" instruments are employed (polarimeters of Lippich and Laurent). In these instruments, the monochromatic light from some source, such as a Bunsen burner containing fused sodium chloride (for sodium light), or a mercury lamp (for the mercury light), is focused on to the polarizer (B, Fig. 19) through lens A. These are con-

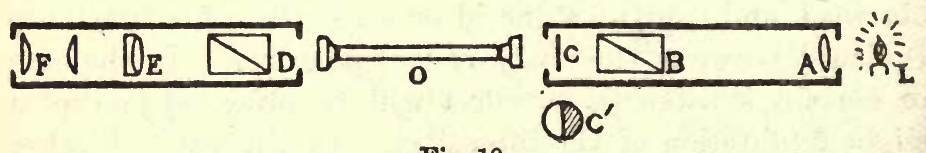

Fig. 19.

tained in one tube of the polarimeter. The analyzer is contained in another tube in which is a telescope EF. The liquid under examination is placed in a tube 0 . The end of the tube containing the polarizer is covered with a half-disc of quartz (Laurent's polarimeter) or a small Nicol prism (Lippich's polarimeter) which is of such thickness that the light passing through the plate is altered in phase a half-length, but still remains plane-polarized. Two 
beams of polarized light thus pass through the polarimeter. On rotating the analyzer, a position will be found in which one beam will be completely, and the other only partially extinguished. On rotating the analyzer further, a second position will be found in which the second beam will be extinguished, and the part of the field which was originally dark will be light, whereas the first beam will be extinguished and the other half of the field will be dark. In the intermediate position, both halves of the field will be equally illuminated. This is the position to

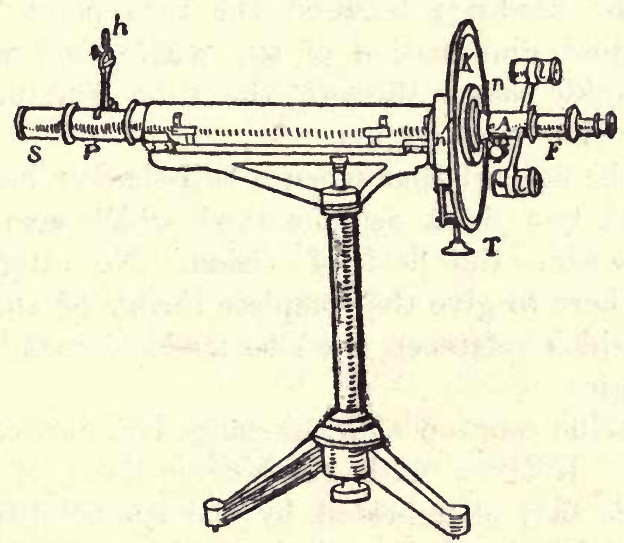

Fig. 20.

which the analyzer must be set before a reading is taken, and it is noted on a scale provided with a vernier with which the instrument is furnished, the actual point being read with a magnifying glass (see $l$ in Fig. 20). The eye-piece of the instrument is provided with a cross-wire which divides the field of vision into two halves. When the zero position has been attained, the substance under investigation is introduced between the tubes containing the analyzer and polarizer (this is covered by a piece of 
metal on hinges, seen only in the illustration of the complete instrument, to keep away light; the instrument is used in a dark room). If the substance is optically active, one side of the field will be rendered darker than the other, and the analyzer is turned until both halves of the field show equal illumination. The point at which equal illumination is attained is then read off on the scale; according to the direction in which the analyzer is turned, the substance under examination is either dextro- or lævo-rotatory, and the magnitude of the rotation is indicated by the differences in the readings between the zero point and the point of equal illumination of the whole field when the polarized light passes through the tube containing the substance under investigation.

It will be noticed that when a half-shadow instrument is employed, two fields are observed which come simultaneously within the field of vision. No attempt has been made here to give the complete theory of the instrument, for which reference must be made to text-books on physical optics.

The specific rotation of a substance is indicated by the symbol [a]. If taken with the sodium line (the so-called $\mathrm{D}$ line), this fact is indicated by the symbol $[\alpha]_{D}$. The temperature is also indicated by writing it above the symbol $[\alpha]$-for example, $[\alpha]_{D}^{20^{\circ}}$ signifies that the specific rotation is measured by sodium light at the temperature $20^{\circ}$.

The rotation is calculated from the following formulæ:-

For a homogeneous liquid-

$$
[a]=\frac{a}{l d}
$$

where $[\alpha]$ is the rotation actually read, $l$ is the length of the column in decimetres, and $d$ is the density of the fluid. 
For a solution-

$$
[a]=\frac{100 \alpha}{l p d}
$$

where $p$ is the number of grammes of active substance in 100 c.c. of solution, and $d$ is the density of the solution.

Pasteur's Researches on the Tartaric Acids.-The discovery of the isomeric tartaric acid (racemic acid) by Berzelius in the mother liquors of the tartaric acid has been already mentioned. The two known tartaric acids were subsequently investigated by Mitscherlich, who found generally a marked similarity between the sodium ammonium salts of the two acids, but showed that whereas the solution of the ordinary tartrate rotated the plane of polarized light to the right, the corresponding salt of the racemic acid was optically indifferent. The investigation of this difference in properties between the two acids forms the starting point of the classical investigations of Pasteur. It is of interest to read the account of Pasteur's endeavours to obtain the racemic acid, as related in his biography by his son-in-law, Vallery-Radot; for it appears that after the first discovery of this acid by Berzelius, its appearance in the mother liquors of the tartaric acid manufacture was rare, and it was only after a somewhat exciting search through factories that sufficient material for investigation was obtained.

In the pursuit of his studies on the two isomerides Pasteur was guided by certain observations of his predecessors. The discovery of polarized light had been made in 1808 by Malus, and his investigations were continued after his early death by his pupils Arago and Biot. The latter had found that there are two kinds of quartz crystals, one of which rotates polarized light in one direction, whereas the other rotates it in the opposite direction. Now, two kinds of quartz crystals had been described by 
the mineralogist Haüy which differed from one another in possessing hemihedral facets on opposite sides of the crystals, the two kinds forming what mineralogists had termed "enantiomorphous" forms, and Sir John Herschel, in 1820, had suggested that there is a link between the optical activities and the crystalline forms of the two descriptions of quartz crystals. Pasteur, accepting this suggestion, paid particular attention to the crystalline forms of the isomeric tartrates (dextro-rotatory tartrate and racemate). The ordinary sodium ammonium tartrate was found to possess hemihedral facets, and was optically

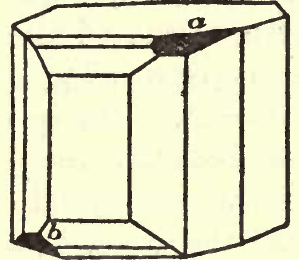

D.

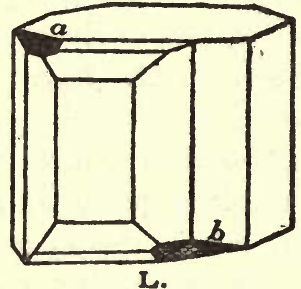

Fig. 21 .

active, and Pasteur expected that such facets would be absent in the racemate. On examining the crystals of the sodium ammonium racemate carefully, he found that this was not the fact, but that a mixture of two kinds of crystals was obtained, one of which had the facets on one side of the crystals and the other on the opposite side. One kind of crystals was, in fact, a mirror image of the other (see Fig. 21). The two classes of crystals were carefully separated by hand ; and on examining the optical properties, it was found that one class was dextro-rotatory, whereas the other was lævo-rotatory, and that the optical activities of the two were equal, but in the opposite direction. These results immediately suggested the reason of the optical inactivity of the racemic acid, namely, that it was 
compounded of two active acids, which rotated polarized light equally in opposite directions, and produced thereby an optically inactive mixture. They further suggested to Pasteur the conception of an asymmetric arrangement of atoms in the molecules in the two sets of crystals, either along the spirals of left-handed or right-handed screws, or at the corners of irregular tetrahedra, or in some other asymmetric forms which could yield non-superposable images. According to this conception, the racemic acid would result from a mixture of two such images.

The Theories of Le Bel and Van't Hoff.-In 1874 theories to explain "optical isomerism" * were promulgated almost simultaneously by the French chemist Le Bel and the Dutchman Van't Hoff, which were nearly identical. The Van't Hoff method of explanation is the one now generally adopted, and will be retained in this place. If the quadrivalency of carbon is accepted, compounds are possible in which this atom is united to four different elements or radicles. Suppose, now, that the carbon atom is represented in the centre of a tetrahedron, and the atoms or radicles to which it is united are represented at the four corners of this figure. It will then be obvious that the atoms or groups to which the carbon is united can be grouped at the corners in such a way that the positions relatively to one another are different. If, for example, a compound of the type (CABCD is considered, where (C) is the carbon atom, and A, B, C, D other elements or radicles, two different figures can be obtained, namely-
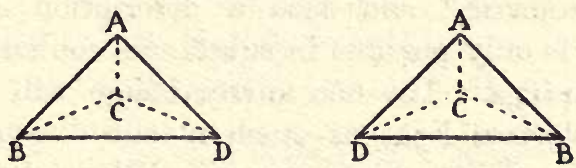

* The meaning of this expression should be clear from the foregoing re. marks on the tartaric acids. 
The carbon atom (which is not indicated in these diagrams) occupies the centre of the tetrahedron. If these two figures are regarded carefully, it will be noticed that they are not super-imposable, but that the one is a mirror image of the other. The reader will find it easy to convince himself, if he actually handles the model of a tetrahedron, and represents the atoms by coloured hollow pyramids which slide over the solid angles at the corners, that the formation of mirror images, as described above, is only possible when the element or radicles A, B, C, D are all different. If any two of them are the same, it is not possible to obtain two mirror images when the tetrahedron is employed. According to the Van't Hoff conception, "optical isomerism" is possible when the compound contains what is known as an "asymmetric carbon atom"that is, a carbon atom united to four different atoms or radicles. In a compound containing only one asymmetric carbon atom, it is possible to obtain two isomerides, which can be represented by means of the tetrahedron formula, of which the one form is the mirror image of the other. Substances containing an asymmetric grouping, such as have been described above, possess the power (if they are liquids, without dilution, or if they are solids, when dissolved in a suitable solvent) of causing plane polarized light to be rotated when passing through them. Substances which differ from one another only in the arrangement of the groups and atoms relatively to one another in space, in the manner described above, are stated to be "stereoisomeric," and such a description of "stereoisomerism " is only possible in substances containing asymmetric groupings. The one mirror image will rotate the plane of polarized light as much in one direction as the other, or so-called "enantiomorph," will rotate it in the other direction. 
The instances already mentioned which exhibit optical activity are those of amyl alcohol, lactic acid, and tartaric acid. The chief isomeride of the amyl alcohols formed as a by-product in the alcoholic fermentation processes has the formula-

$$
\mathrm{CH}_{3} \cdot \mathrm{CH}_{2}>\mathrm{CH} \cdot \mathrm{CH}_{2} \mathrm{OH}
$$

and has been stated to be optically active. It will be noticed that this substance contains an asymmetric carbon atom (the symbol of which is surrounded by a ring).

Lactic acid has the formula-

$$
\mathrm{CH}_{3} \cdot \mathrm{CH}(\mathrm{OH}) \cdot \mathrm{COOH}
$$

Again, the asymmetric carbon atom is in evidence.

If an optically active substance is submitted to such reactions that the asymmetry of the carbon atom disappears, the product obtained will be inactive. Thus, lactic acid on reduction with hydriodic acid yields propionic acid, $\mathrm{CH}_{3} \cdot \mathrm{CH}_{2} \cdot \mathrm{COOH}$, which contains no asymmetric carbon atom; an optically active lactic acid cannot yield, therefore, anything but an optically inactive propionic acid on reduction, as, according to the Le Bel-Van't Hoff hypothesis, propionic acid cannot yield optical isomerides owing to the absence of the asymmetric carbon atom. On the other hand, if one of the groups attached to the asymmetric carbon atom is replaced by a group or element differing from the three groups or elements already attached to it, an asymmetric derivative is possible. Thus, if active amyl alcohol is treated with phosphorus and iodine, so as to replace the hydroxyl group with the latter element, the substance $\mathrm{CH}_{3} \cdot \mathrm{CH}_{2}>\mathrm{CH} \cdot \mathrm{CH}_{2} \mathrm{I}$ is obtained, which is optically active. 
When a substance with an asymmetric carbon atom is obtained synthetically (see synthesis of lactic acid, p. 116, and tartaric acid, p. 119), the product is always inactive. It is produced in what is termed the "racemic" form, and consists of a mixture in equimolecular proportions of the two enantiomorphs. It can, however, be often "resolved" into the two optically active constituents by methods which will be described in detail below. It is of great interest to note that products containing asymmetric carbon atoms produced by living objects, such as the proteins and carbohydrates of plants and animals, are often optically active. This fact will be repeatedly referred to later, as it is one of great biological significance.

Stereoisomerism in Substances containing more than one Asymmetric Carbon Atom.-Tartaric acid has the formula-

\section{(c) $\mathrm{H}(\mathrm{OH}) \cdot \mathrm{COOH}$ \\ C $\mathrm{H}(\mathrm{OH}) \cdot \mathrm{COOH}$}

a fact which can be demonstrated by its synthetical production; the product obtained in this way is, however, optically inactive, and differs in this respect from the natural acid got from argol. Now it will be noticed that in the formula given above, there are two asymmetric carbon atoms, both of which can influence the stereochemical configuration of the molecule. If each of them is represented as the centre of a tetrahedron, the following stereoisomerides can be derived (see Fig. 22). In these figures, the union of two carbon atoms is indicated by the junction of two apices of the tetrahedra. The positive and negative signs, which are chosen arbitrarily, indicate that the particular configurations to which they are attached cause the ray of polarized light to be rotated to the right (dextro-rotatory) or left (lævo-rotatory) re- 
spectively. It will be noticed from these figures that one form of tartaric acid will be dextro-rotatory, another will be lævo-rotatory, whereas in a third form, the configuration of groups round one carbon atom will cause dextro

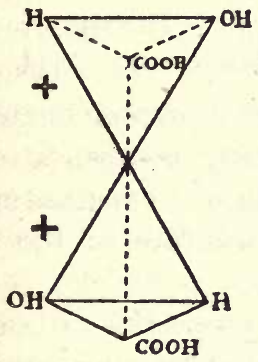

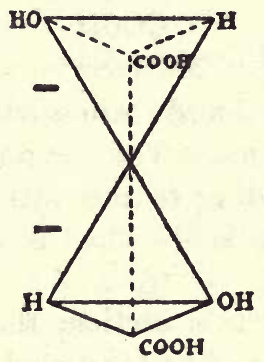

Fig. 22.

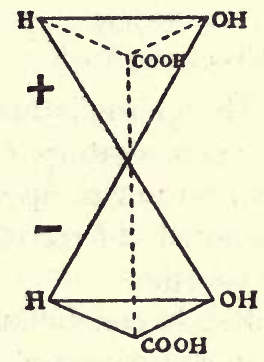

rotation, whilst that round the other carbon atom will cause lævo rotation. In the two first-named forms, the configuration round both carbon atoms is the same. Now, as in tartaric acid the elements or radicles connected with each carbon atom are the same, the dextro rotation due to one set of groups in the third form will be equal to the lævo rotation due to the other set. An optically inactive stereoisomeride of this character is actually known, and is designated meso-tartaric acid, and it is to be distinguished from racemic acid in that the optical inactivity in the latter form is due to a mixture in equimolecular proportions of dextro- and lævo-acids. The racemic form can be resolved, by methods given below, into the dextro- and lævo-components, whereas this is not possible in the case of "internally compensated" compounds such as the mesoacid, where optical inactivity is due to compensation by the two asymmetric halves of the same molecule. The tetrahedron formulø for the tartaric acids given above can be conveniently condensed into the following forms:- 


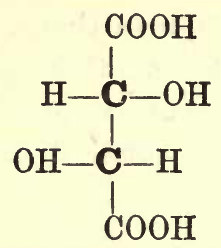

d-Tartaric Acid.

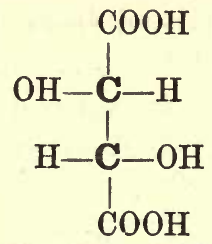

l-Tartaric Acid.
$\mathrm{COOH}$

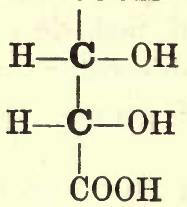

The abbreviations $d$ and $l$ are used to represent dextroand lævo-rotatory forms. The "externally compensated" racemic form is, according to this system of nomenclature, designated $d$-l-tartaric acid-that is, a mixture of the $d$ and $l$-forms.*

Before concluding this section, the properties of some of the stereoisomerides of tartaric acid may be considered.

The ordinary tartaric acid obtained from argol is, as already mentioned, dextro-rotatory, and melts with decomposition at $167^{\circ}$.

The meso-acid, melting point $140^{\circ}$, is obtained together with the $d-l$ - (racemic) acid, melting point $204^{\circ}$, by synthetical processes (see p. 119). Both these acids differ from the natural $(d-)$ and the $l$-acid in their melting points, solubilities, and other physical properties, and they also differ from one another. There are also characteristic differences in their various salts. There is, however, very little difference between the $d$ - and the $l$-acids; the main distinction is that their solutions rotate polarized light (to the same degree) in opposite directions. Both acids, on heating with water to $165^{\circ}$ and by other methods

* The above description will be easier to understand if the student prepares (or obtains from an apparatus manufacturer) tetrahedra with hollow coloured pyramids which fit over the corners. Various other forms of models are made, such as those with black balls to represent carbon atoms, into holes in which rods can be inserted, which carry at the other end coloured balls to represent the various elements of radicles to which the carbon atom is united. No difficulty will be found in grasping, with the aid of such models, the fundamental conceptions of stereoisomerism. 
of treatment, undergo what is known as "racemization"that is, they are converted into the racemic form, and the expression "racemic" is now applied not only to the tartaric acids, as in its original sense, but to all the externally compensated substances which can be resolved into enantiomorphous forms. The methods of accomplishing this process are considered in the next section. The chemical properties of all isomerides are the same, all act as dihydroxysuccinic acid. When substances contain more than two asymmetric carbon atoms, the number of possible stereoisomerides increases. Whereas, as already stated, two isomerides only are possible when one asymmetric carbon atom is in the molecule, four can exist in substances containing two asymmetric carbon atoms, eight when three such atoms are present, and no less than sixteen when four are present. A very important example of the last description of isomerism is afforded by the sugars, the chemistry of which will be discussed in some detail later.

The Resolution of Racemic Forms into their Enantiomorphs.-Various methods exist for the resolution of optically inactive forms. (N.B.-Where the inactivity is due to external compensation only; as already stated, internally compensated forms cannot be resolved.) Only the more important of these need be considered.

A. Resolution by Crystallization.-This method has been already mentioned in the historical introduction to this section, and was employed by Pasteur, who showed that from solutions of the ammonium sodium salt of racemic acid two kinds of crystals were formed, which could be separated from one another mechanically. This is, of course, a very tedious process, and the two kinds of crystals (of the sodium ammonium salts of the $d$ - and $l$ acids) must be carefully sorted and separated from one another by hand. The crystallization, where a separation 
of the enantiomorphs is desired, must take place at a low temperature. If the crystals are allowed to separate above $26.7^{\circ}$ (the "transition temperature"), the two kinds of crystals do not form; the sodium ammonium salt of the racemic acid separates instead, which contains no water of crystallization.

B. Resolution by Biological Methods.-These are also due to Pasteur. Generally speaking, living organisms exert a selective action on enantiomorphs. Pasteur showed, for example, that when the green mould penicillium glaucum was allowed to grow in a solution of a racemic acid containing a little potassium phosphate, it gradually became lævo-rotatory; the mould used only the dextrorotatory form as food, and left the laevo variety for the most part untouched. Innumerable instances of selective action of this character are known, and for this reason alone the study of stereoisomerism is one of great biological importance, for in choosing a substance as a foodstuff, due regard must be paid to its stereochemical configuration. This remark applies not only to the lower organisms, but even to the higher mammalia. There is, furthermore, a marked difference in the pharmacological and therapeutic action of the various stereoisomerides, as might be expected from the differences in their foodvalues.

C. Resolution by Active Substances.-This is a third method due to Pasteur. If an acid, such as racemic acid, is neutralized by an optically active base, two salts can be obtained. Suppose the base laevo-rotatory, like cinchonine. The two salts formed would be the cinchonine $l$-tartrate and the cinchonine $d$-tartrate. These two salts are not enantiomorphs, because two acids of opposite rotations are united to the same optically active base; their rotations, therefore, are not equal but in 
opposite directions. Now it is characteristic of enantiomorphs that they possess almost the same physical properties, such as melting points, solubilities, etc., although they rotate polarized light (to an equal extent) in opposite directions. The two salts formed with an optically active base mentioned above, differ in their solubilities and other physical properties. It is, therefore, possible to separate them by fractional crystallization. By such means as this, racemic forms of acids obtained synthetically have often been separated into their components; and on the same principles optically active bases have been obtained from synthetic racemic forms by combination with optically active acids. The third method has, in fact, been very largely applied for the preparation of optically active substances.

Other more recent methods for obtaining optically active substances have been employed, but the most general are the three classical methods of Pasteur given above.

Summary.-It has been shown that when substances contain an asymmetric carbon atom-that is, a carbon atom united to four different elements or radicles-substances are obtained which can exist in optically active forms-that is, forms which rotate the plane of polarized light. Optical activity is thus conditioned by the presence of the asymmetric carbon atom, and where one such atom exists, the various elements or radicles can be arranged round it in such ways that two forms are possible, one of which is the mirror image of the other. These two images are called "optical antipodes" or "enantiomorphs," and rotate the plane of polarized light to an equal extent, but in opposite directions. Substances related to one another as such enantiomorphs are, are said to be stereoisomeric. Substances containing an asymmetric 
carbon atom, which are obtained synthetically, are optically inactive. The "racemic" form is always obtained-that $i s$, a mixture in equimolecular amounts of the two enantiomorphs. An account of the methods for "resolving" racemic forms into the optically active enantiomorphs has been given. Where more than two asymmetric carbon atoms exist in the molecule, the number of possible stereoisomerides increases. In such cases, in addition to the ordinary racemic form, a meso-form can exist, which is optically inactive, but which cannot be resolved into active enantiomorphs. In this case, the molecule is inactive owing to "internal compensation," whereas in the racemic forms this inactivity is due to "external compensation." The modern conceptions of stereoisomerism are due chiefly to Le Bel and Van't Hoff, and are founded mainly on the work of Pasteur on the tartaric acids, and Wislicenus on lactic acids, of which a short historical account has been given. The various stereoisomerides, although undergoing the same chemical reactions, behave very differently towards living objects. For this reason the study of stereoisomerism is one of considerable importance to biologists. 


\section{CHAPTER V.}

\section{THE CHIEF CHEMICAL CONSTITUENTS OF THE}

ANIMAL BODY.

ThE term biological chemistry is a comprehensive one, and embraces the consideration of all substances which form the constituents of living organisms. The number would naturally be very large, as the constituents of both plants and animals would enter the category of substances to be included in a complete treatise on biological chemistry. It is, therefore, necessary to limit at the outset the number of products of which the chemical reactions can be studied in a detailed manner. There are various reasons for selecting for the more complete study the constituents of the animal body. In the first place, man himself belongs to the animal kingdom, and the chief physiological studies have naturally been those of the human body and the mammalia generally. In the second place, paradoxical as it may at first sight seem, the study of the chemistry of higher organisms is in many respects simpler than that of the lower organisms and of plants. This is due to the fact that, owing to the greater morphological differentiation of the tissues of the higher organisms, the functions of the various organs are more highly specialized. In the higher animals certain chemical changes will be limited to certain definite organs, such as the liver or the pancreas, whereas in the lower organisms, or in plants, where the morphological differentiation is less 
complex than in animals, a far larger number of chemical processes would be expected to take place in one tissue. For this reason it is probable that an organ in mammals with the most diversified chemical activity, such as the liver, probably contains a less complex mixture of substances than, for example, the leaves of plants. Whether this is actually so or not, biochemical knowledge is much more extensive as far as it relates to the higher animals than it is as far as it relates to plants. The latter, it is true, contain a very large variety of chemical substances, the chemistry of which has been studied in detail, such as the alkaloids, the essential oils, tannins, etc., but so far their biological significance is almost unknown.

The chief constituents of the mammalian body fall into three classes-the fats, the carbohydrates, and the proteins. The tissues of plants are also, to a very large extent, made up of substances which fall into one of these three classes. They form, therefore, not only the chief constituents of the body of animals, but also of their food. A knowledge of the chemistry of the substances belonging to these three classes is, therefore, of primary importance to the student of physiology.

\section{Part I.-The Fats.}

A brief mention has been already made of the fats and oils (p. 99). These substances are esters of the trihydroxy alcohol, glycerol, in which all the hydroxyl hydrogens are replaced by an acid radicle. Included in the category of the fats are substances known as oils or fats, * the former name being given to those products which are liquid at ordinary atmospheric temperatures,

*The substances known as "waxes" are generally esters of higher alcohols, such as cetyl alcohol, $\mathrm{C}_{16} \mathrm{H}_{34} \mathrm{O}$, which occurs in the form of cetyl palmitate in spermacetti. 


\section{Chemical Constituents of the Animal Body. I8I}

whereas the latter name is generally applied to substances with relatively high melting points (that is, are solid at room temperature). These terms have, however, no very definite significance; all substances to which they are applied can be included under the designation of "fats," which may be defined chemically as the glyceryl esters of fatty acids. They yield, therefore, on hydrolysis a mixture of glycerol and a fatty acid. This hydrolysis may be accomplished either by water under high pressure and at temperatures above the boiling point (at $200^{\circ}$ ), in which case a mixture of glycerol and free fatty acid is obtained, or by means of alkalis, which produce a mixture of glycerol and the sodium salt of the fatty acid or "soap." As an example of hydrolysis, the scission of the tristearic ester of glycerol or "tristearin" into stearic acid and glycerol may be quoted-

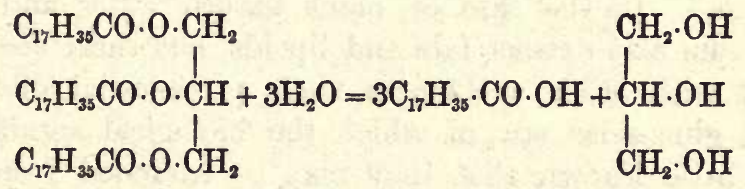

The various fats differ from one another in that they yield different acids on hydrolysis. All yield glycerol, but the fatty acids of fats obtained from different sources are very diverse. A natural fat may be either a mixture of glycerol esters (glycerides) or it may consist of mixed glycerides - that is, the hydrogens of the hydroxyl group in glycerol may be replaced by different acid radicles. Fats from different sources can be characterized by the determination of certain properties of the acids yielded by hydrolysis. The methods adopted for the characterization of fats are of considerable technological importance in that they serve for detection of adulteration (for example, detection of margarine in a butter sample), and they have 
also been extensively employed in biological research for the purpose of tracing out the various processes of synthesis and degradation of fats in living objects. They warrant, therefore, some more detailed description in this place.

Extraction of Fats from Tissues.-The fats are soluble in organic solvents, and can therefore be separated from the other constituents of tissues. In the case of the animal tissues, the substances extracted by solvents such as ether or light petroleum consist chiefly of fats; the latter are, however, almost invariably accompanied by small amounts of other substances, some of which are phosphorus derivatives, such as lecithin, and also a widely distributed complex alcohol known as cholesterol. These substances appear to have a great biological significance. The chemical investigation is as yet far from complete, and they are designated by the somewhat vague name of "lipoids." In the case of plant tissues, ether and light petroleum also extract fats and lipoids, but these are often mixed with other substances such as essential oils, pigments, glucosides, etc., of which the biological significance is so little known that they may be excluded from discussion in this place.

The ordinary animal tissue contains generally about 80 per cent. of water. Direct extraction of the moist tissue by ether or light petroleum is not a satisfactory process ; the tissue must be first dried and powdered before the fat is extracted. Various methods are employed for this purpose, the most satisfactory, perhaps, being the heating of the tissue in vacuo at $100^{\circ}$, as by this procedure the oxidation of the fat can be avoided. Owing to the fact that "lipoids" are extracted at the same time, the quantitative estimation of fat is not very simple.* If

- Not only is the fat extracted by solvents mixed with lipoids, but the quantitative estimation is complicated by the fact that certain of the substances 


\section{Chemical Constituents of the Animal Body. 183}

the extract is weighed, a rough quantitative approximation to the fat content of the tissue can be made. The extraction is carried out generally in a Soxhlet extractor (Fig. 23), which acts continuously. The powder is introduced into a thimble made from fat-free blotting paper which is introduced into a receptacle which fits into a cork, or is ground into a widemouthed flask containing the solvent. The upper part of the receptacle is fitted to a reflux condenser, and it is also provided with two side tubes, one of which is made in the form of a siphon. The solvent is boiled, and passes up the one side tube, is condensed in the condenser, and then flows back into the thimble receptacle, until the latter is filled up to the top of the siphon tube; when the solvent reaches this point, it siphons back into the boiling flask. In this way the substance is repeatedly extracted with fresh solvent, only a limited amount of which is necessary for a complete extraction.

The Methods of characterizing Fats.-Fats from various sources differ from one another, as

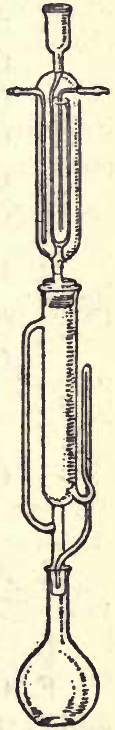

Fig. 23. already stated, in the fact that they yield different acids on hydrolysis. These acids may be subdivided into various classes according to their degree of saturation. The following is a list of the chief acids which have been obtained by the hydrolysis of fats :-

A. The saturated acids of the general formula $\mathrm{C}_{n} \mathrm{H}_{2 n} \mathrm{O}_{2}-$ $\mathrm{C}_{2} \mathrm{H}_{4} \mathrm{O}_{2}$. . . Acetic acid.

$\mathrm{C}_{6} \mathrm{H}_{8} \mathrm{O}_{2}$. . . . Butyric ",

which are soluble in organic solvents are not readily extracted directly owing to the formation of complexes with other constituents of the tissues. Various methods have been suggested by Liebermann, Kumagawa, and Suto and others for the quantitative estimation of fats in tissues; for these reference must be made to larger text-books. 
$\mathrm{C}_{6} \mathrm{H}_{12} \mathrm{O}_{2}$. . . . Caproic acid (isobutyl acetic acid).

$\mathrm{C}_{8} \mathrm{H}_{16} \mathrm{O}_{2}$. . . . Caprylic "

$\mathrm{C}_{10} \mathrm{H}_{20} \mathrm{O}_{2}$. . . . Capric ",

$\mathrm{C}_{12} \mathrm{H}_{24} \mathrm{O}_{2}$. . . Lauric ",

$\mathrm{C}_{18} \mathrm{H}_{28} \mathrm{O}_{2}$. . . Myristic ",

$\mathrm{C}_{16} \mathrm{H}_{32} \mathrm{O}_{2}$. . . Palmitic "

$\mathrm{C}_{18} \mathrm{H}_{36} \mathrm{O}_{2}$. . . Stearic "

$\mathrm{C}_{20} \mathrm{H}_{40} \mathrm{O}_{2}$. . . Arachidic "

$\mathrm{C}_{22} \mathrm{H}_{44} \mathrm{O}_{2}$. . . . Behenic "

B. Unsaturated acids of the oleic or acrylic series, $\mathrm{C}_{n} \mathrm{H}_{2 n-2} \mathrm{O}_{2}$ (with one double bond)-

$$
\begin{aligned}
& \mathrm{C}_{18} \mathrm{H}_{34} \mathrm{O}_{2} \text {. . . Oleic acid. }
\end{aligned}
$$

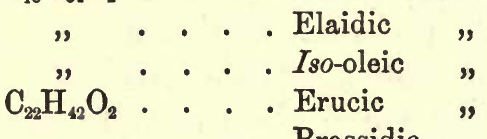

$$
\begin{aligned}
& \text { ". . . Brassidic " }
\end{aligned}
$$

C. Acids of the linolic series, $\mathrm{C}_{n} \mathrm{H}_{2 n-4} \mathrm{O}_{2}$ (with two double bonds). The chief of these is linolic acid, $\mathrm{C}_{18} \mathrm{H}_{32} \mathrm{O}_{2}$.

D. Acids of the linolenic series, $\mathrm{C}_{n} \mathrm{H}_{2 n-6} \mathrm{O}_{2}$.

E. Certain hydroxy acids of the general formula $\mathrm{C}_{n} \mathrm{H}_{2 n-2} \mathrm{O}_{3}$, of which the best known is ricinoleic acid, $\mathrm{C}_{18} \mathrm{H}_{34} \mathrm{O}_{3}$.

Now, as already stated, a natural fat generally yields on hydrolysis a mixture of fatty acids. It might be thought possible that a fat could be characterized by isolating these acids. The obstacle to a method of this kind is the fact that the acids obtained are generally so similar in their properties that no method exists for separating them from one another quantitatively. Indirect methods are, therefore, employed for the analysis of fats, which consist in the determination of certain chemical constants. The chief of these are the following:-

(a)The Saponification Value. - The amount of potassium hydroxide which is necessary to neutralize with the acids set free by hydrolysis will be influenced by the molecular 
weight of these acids. If a fat is boiled with excess of an alcoholic solution of potassium hydroxide, the mixture at the completion of the saponification will consist of glycerol, potassium soap, and excess of potassium hydroxide. Now, if a fat yields on hydrolysis relatively large amounts of an acid of low molecular weight, such as butyric acid, there will be less free potassium hydroxide after the completion of the hydrolysis of one gramme of fat than there would be if the fat yielded only acids of higher molecular weight, such as stearic acid. The "saponification value" denotes the number of milligrams of potassium hydroxide which is required for the saponification of one gramme of a fat. This number is determined by heating a weighed amount of a fat with excess of semi-normal alcoholic solution of alkali, and determining the excess of alkali remaining in the liquid after heating for about half an hour, by titration with standard acid in the presence of phenol-phthalein.

The following are some typical saponification numbers-

Beef suet . . . . . 19322-200

Lard . . . . . . . 19544-200

Mutton fat. . . . . 195

Palm oil . . . . . . 242-250

Linseed oil . . . . . 191-195

Olive oil . . . . . . 185-196

Butter . . . . . . 227

Certain fats and oils contain a small amount of free acid.

This should be determined before estimation is made of the saponification number. The "acid number" is the number of milligrams of potassium hydroxide necessary to neutralize to phenol-phthalein the free acid in $\mathbf{1}$ gramme of fat.

(b) The Iodine Number.-The acids obtained by 
hydrolysis from various fats differ greatly in the degree of saturation-that is, in the number of double bonds. They will differ greatly, therefore, in their capacities to form addition products with halogens. The iodine value is amount of iodine expressed as a percentage of the weight of the fat taken, which will combine with the fat under certain standard conditions of experiment. Even saturated acids will decolorize iodine solutions (with formation of substitution products), but they will not do so as rapidly as acids which are unsaturated. It is therefore necessary to choose certain standard conditions for determination of the iodine value, which, valuable as it is for characterizing fats, must be regarded as a somewhat empirical number. The method of determining this factor was worked out by Von Huibl, but the modified and short method of Wijss is now generally employed. The solution of Wijss is made by dissolving iodine trichloride $(9.4$ grammes) and iodine $(7 \cdot 2$ grammes) in glacial acetic acid ( 1 litre). The amount of iodine in this solution is ascertained by titration with sodium thiosulphate.* To determine the iodine value of a fat, a weighed amount of the latter is dissolved in carbon tetrachloride and allowed to stand in a dark place for one hour with excess of the Wijss reagent. After this interval, the amount of free iodine remaining is estimated by titration with thiosulphate solution. From the difference between the titration number thus obtained, and that of the same amount of the reagent before keeping with the fat, the amount of iodine which has combined under the conditions of experiment can be ascertained.

The "iodine numbers" have been largely used in biological research. Leathes, for example, estimated the iodine numbers of the liver fat after animals had ingested large quantities of various other fats, and found that this

- For methods refer to a text-book on quantitative analysis. 
organ has the tendency to convert the acids of the ingested fats into other acids with a greater degree of unsaturation (that is, with higher iodine number). The influence of the ingestion of large amounts of various foreign fats on the normal fats from other parts of the animal body have also been investigated by means of the iodine numbers. These experiments form interesting examples of the application of chemical methods to biological research. The following are some examples of iodine numbers :-

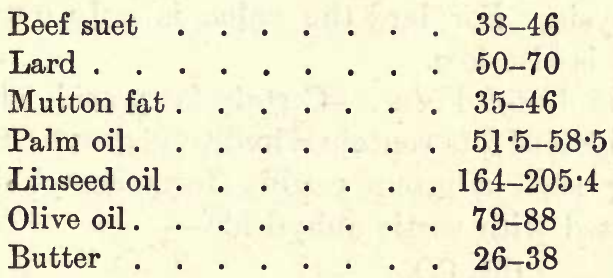

It is interesting to note the high iodine number of a typical "drying" oil, linseed oil, in the above table. The drying properties (utilized by painters) are no doubt due to the high degree of unsaturation of the fatty acid, by virtue of which the oil readily undergoes oxidation in air to yield solid products.

(c) The Reichert-Meissl Value.-Certain fatty acids obtained by the hydrolysis of fats, such as butyric acid, volatilize readily when distilled in steam. The so-called Reichert-Meissl value denotes the number of c.c. of $N / 10$ potassium hydroxide which are necessary to neutralize the fatty acids obtainable from 5 grammes of fat, which can be distilled over in steam under certain standard conditions of experiment. A small amount of acid passes over with steam, even when the higher non-volatile acids are distilled. Hence the necessity of choosing standard conditions. The fat is first saponified with alcoholic potassium hydroxide solution; the alcohol is evaporated off, the 
residue is acidified with sulphuric acid, and the distillation of the fatty acid is then carried out in an apparatus of standard dimensions. The amounts of liquid and the rate of distillation are always kept as nearly as possible uniform. The liquid to be distilled is usually 140 c.c., and 110 c.c. are distilled off in one hour. The ReichertMeissl value is of special service in the examination of butter, for which it is $20 \cdot 6-33 \cdot 1$. This high number is due to the relatively large amount of butyric acid yielded on hydrolysis. For lard the value is only 0.68 , and for beef-fat it is also low.

(d) The Acetyl Value.-Certain fatty acids obtained by the hydrolysis of fats contain a hydroxyl group. Substances containing such a group readily form acetyl derivatives when treated with acetic anhydride-

$$
\left.\mathrm{R} \cdot \mathrm{OH}+\underset{\mathrm{CH}_{3} \cdot \mathrm{CO}}{\mathrm{CH}_{3} \cdot \mathrm{CO}}\right\rangle \mathrm{O}=\mathrm{R} \cdot \mathrm{O} \cdot \mathrm{CO} \cdot \mathrm{CH}_{3}+\mathrm{CH}_{3} \cdot \mathrm{COOH}
$$

If the acetyl derivative thus formed is hydrolyzed, it undergoes scission into the original hydroxyl derivative and acetic acid-

$$
\mathrm{R} \cdot \mathrm{O} \cdot \mathrm{CO} \cdot \mathrm{CH}_{3}+\mathrm{KOH}=\mathrm{R} \cdot \mathrm{OH}+\mathrm{CH}_{3} \cdot \mathrm{COOK}
$$

The number of milligrams of potassium hydroxide necessary to combine with the acetic acid set free by hydrolysis from the acetylated acids from 1 gramme of fat is known as the acetyl value.

The chemistry of the fats may be summarized as follows:-The fats are esters of glycerol in which all three hydroxyl hydrogen atoms are replaced by an acidyl radicle. They are sometimes called triglycerides. They yield on hydrolysis ("saponification") with alkalis the alkali salts of the acids ("soaps") and glycerol. Different acids are yielded by fats from different sources, and the mixtures thus obtained can be characterized by certain 
chemical constants. (a) The saponification value gives an idea of the molecular weight of the acids. (b) The iodine value gives some measure of the degree of unsaturation of the acids. (c) The Reichert-Meissl value indicates roughly the amounts of acid (of low molecular weight) which are readily volatile. (d) The acetyl value gives a measure of the hydroxyl groups in the acids. These values are more or less empirical, and they are determined under certain standard conditions of experiment. The fats are the chief constituent of the animal tissues which can be removed by organic solvents.

\section{ADDENDUM TO PART I.-THE LIPOIDS.}

The term "lipoid," as already stated, is a somewhat indefinite one. It may be held to include those substances which are not glycerides which can be extracted from animal tissues or fluids. Similar substances can also be obtained from plant tissues; the latter yield, however, a number of other products soluble in organic solvents which are neither fats nor lipoids.

Although lipoids play a very important part in the general economy of the cell, little is at present known either of their chemical properties or of their true biological significance. It is not, therefore, possible to deal with them in any detail. In certain tissues, such as in those of the central nervous system, they are found in relatively large quantities. Owing to their physical properties, they are not readily obtained in a pure state. The difficulties of investigation are also complicated by the fact that in the majority of animal tissues and fluids, such as the blood and the liver, they only exist in small amounts.

The chief lipoids are the alcohol cholesterol, which exists in small quantities in most tissues of vertebrate animals, and the chemically allied phytosterols of plant 
tissues, and the group of substances containing phosphorus, known as the phospholipins, of which lecithin and the various brain lipoids, such as cerebrone, are examples.

Cholesterol, $\mathrm{C}_{27} \mathrm{H}_{46} \mathrm{O}$, a monohydroxy alcohol, melting point $148.5^{\circ}-150.8^{\circ}$, is the chief constituent of certain forms of gall-stones. It and its hydroxy derivatives are found in the majority of tissues. Its constitution is complex, and is still unknown. It can best be prepared in quantity from brains. The latter are dried by mixing with plaster of Paris, and the powder thus formed is ground up with sand. On extracting this mixture with cold acetone, and evaporating the extract, almost pure cholesterol separates.

Lecithin was originally prepared from yolk of egg. It yields on hydrolysis fatty acids, glycero-phosphoric acid, and choline. The constitution which has been assigned to it is the following:-

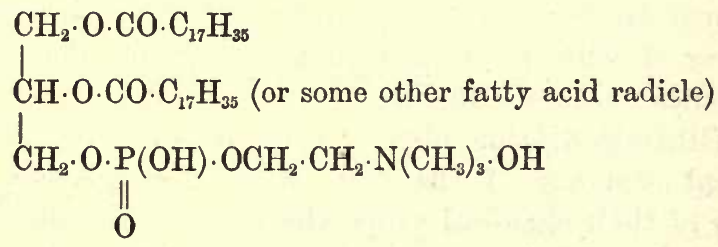

Such a product on complete hydrolysis would yield glycerol, fatty acids, phosphoric acid, and the basic substance choline, - $\mathrm{OH} \cdot \mathrm{CH}_{2} \cdot \mathrm{CH}_{2} \cdot \mathrm{N}\left(\mathrm{CH}_{3}\right)_{3} \mathrm{OH}$, which on heating in aqueous solution decomposes into ethylene glycol (p. 76) and trimethylamine-

$\mathrm{OH} \cdot \mathrm{CH}_{2} \cdot \mathrm{CH}_{2} \cdot \mathrm{N}\left(\mathrm{CH}_{3}\right)_{3} \mathrm{OH}=\mathrm{OH} \cdot \mathrm{CH}_{2} \cdot \mathrm{CH}_{2} \cdot \mathrm{OH}+\mathrm{N}\left(\mathrm{CH}_{3}\right)_{3}$

The chemistry of lecithin is still, however, very indefinite, and it is doubtful whether a pure product has as yet been obtained. It is generally prepared from the alcoholic extract of egg-yolk by precipitation with an 


\section{Chemical Constituents of the Animal Body. I 9 I}

alcoholic solution of cadmium chloride. The cadmium salt is then decomposed in alcohol with ammonium carbonate. After filtration of the precipitated cadmium, the lecithin is deposited from the alcoholic solution on concentration, and is purified by dissolving in chloroform and adding acetone to this solution, which causes the precipitation of the lecithin. Similar products containing nitrogen and phosphorus have been obtained from various tissues, but it is doubtful whether any have yet been obtained in a pure condition. Some of the brain lipoids yield on hydrolysis the carbohydrate galactose, and have been therefore designated galactolipins.

\section{Part II.-The Carbohydrates.}

Several classes of substances are included under the designation of carbohydrates, some of which have the composition represented by the formula $\mathrm{C}_{6} \mathrm{H}_{12} \mathrm{O}_{6}$. This might be written $6 \mathrm{C}+6 \mathrm{H}_{2} \mathrm{O}$, and owing to this fact the name of "carbohydrate" has been given to these substances. Such a formula for a pure substance is, however, in the present stage of the development of chemistry, quite meaningless. The name carbohydrate has, nevertheless, been maintained, and the substances included under the designation form a well-defined class.

Carbohydrates form an important part of the total bulk of the tissues of plants; in animal tissues the amount is relatively much smaller. From the fact, however, that they form an important constituent of the ordinary mixed animal diet, they are substances of considerable importance in the domain of animal physiology.

The classes included under the designation carbohydrate are the following:- $(a)$ the sugars, $(b)$ the starches, (c) the celluloses. 


\section{THE SUGARS.}

The best known representative of this class is canesugar or sucrose, the ordinary sweetening agent prepared usually from the sugar-cane and the beet. This substance has the formula $\mathrm{C}_{12} \mathrm{H}_{22} \mathrm{O}_{11}$, but on hydrolysis (with dilute solutions of mineral acids and certain ferments) it undergoes scission into a mixture of equal parts of two isomeric sugars known as dextrose or glucose and lævulose or fructose-

$$
\mathrm{C}_{12} \mathrm{H}_{22} \mathrm{O}_{11}+\mathrm{H}_{2} \mathrm{O}=\mathrm{C}_{6} \mathrm{H}_{12} \mathrm{O}_{6}+\mathrm{C}_{6} \mathrm{H}_{12} \mathrm{O}_{6}
$$

Dextrose. Lævulose.

Dextrose rotates the plane of polarization to the right and lævulose to the left. As the lævulose has a greater lævo rotation than dextrose has a dextro rotation, the mixture of equimolecular proportions of the two sugars is lævo-rotatory. As the original cane-sugar solution is dextro-rotatory, the direction of rotation changes on hydrolysis. The conversion by hydrolysis of the cane-sugar into dextrose and lævulose is known, therefore, as inversion, and the mixture of sugars is called "invert sugar," and is extensively used for the manufacture of preserves and of alcohol. The simpler sugars, dextrose and lævulose, belong to the sub-class of the monosaccharoses; whilst cane-sugar, which is degraded on hydrolysis into two molecules of monosaccharoses, is known as a disaccharose. Other sugars still more complex than cane-sugar are known, which on hydrolysis undergo scission into three molecules of monosaccharoses. As an example of this class, the sugar melitose or raffinose, which is found in sugar-beet in small quantities, and in Australian manna in relatively large quantities, may be cited. This sugar undergoes scission on hydrolysis into a mixture of the isomeric sugars dextrose, lævulose, and galactose -

$$
\mathrm{C}_{18} \mathrm{H}_{82} \mathrm{O}_{16}+2 \mathrm{H}_{2} \mathrm{O}=\mathrm{C}_{6} \mathrm{H}_{12} \mathrm{O}_{6}+\mathrm{C}_{6} \mathrm{H}_{12} \mathrm{O}_{6}+\mathrm{C}_{6} \mathrm{H}_{12} \mathrm{O}_{6}
$$

Dextrose. Lævvulose. Galactosea 


\section{Chemical Constituents of the Animal Body. I 93}

Glucose or dextrose is found in large quantities in grapes, hence the name "grape-sugar" is sometimes employed. It can be obtained by "inversion" of cane-sugar, and is separated from the løvulose formed at the same time by recrystallization from alcohol in which the latter sugar is much more soluble. Lævulose may also be separated from invert sugar by the addition of slaked lime, with which, in contradistinction to dextrose, it forms a compound which is only slightly soluble in water. Dextrose can also be obtained by the hydrolysis of starch. The knowledge of the constitution of glucose is due chiefly to Kiliani, who showed that it can be represented by the formula-

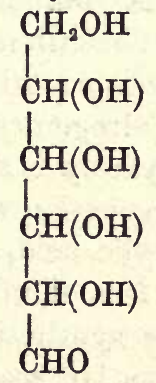

Before the researches of Kiliani, it was known that five alcoholic hydroxyl groups existed, as glucose on treatment with acetyl chloride yielded a pentacetyl derivative. On reduction with nascent hydrogen, furthermore, it was known. to yield a hexahydroxyl alcohol, which on treatment with hydriodic acid yielded the normal hexyl iodide, $\mathrm{CH}_{3} \cdot \mathrm{CH}_{2} \cdot \mathrm{CH}_{2} \cdot \mathrm{CH}_{2} \cdot \mathrm{CH}_{2} \cdot \mathrm{CH}_{2} \mathrm{I}$. Kiliani showed that dextrose, on treatment with hydrogen cyanide, yielded a hydroxy nitrile (like other aldehydes), which on hydrolysis formed a hexahydroxy heptylic acid. This hydroxy acid, on treatment with hydriodic acid, gave rise to normal heptylic acid. These changes can be represented by the formulæ- 


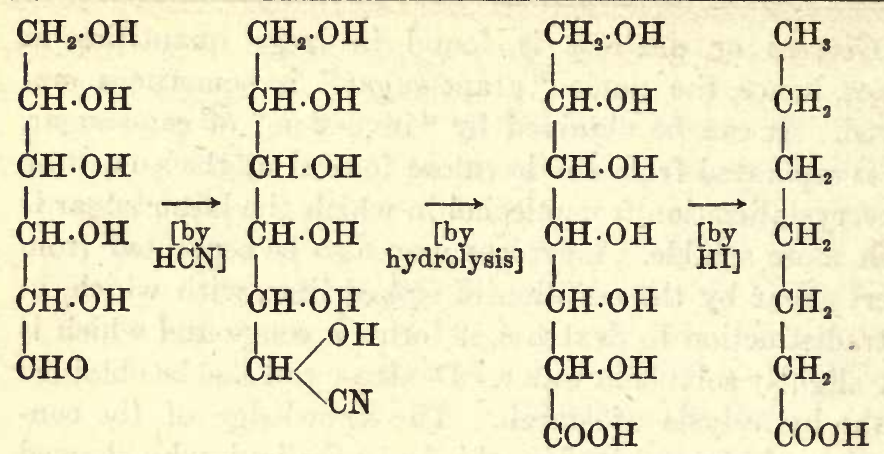

Loevulose or fructose, the other sugar produced by inversion of cane-sugar, is similar in general reactions to dextrose. It is, as already mentioned, lævo-rotatory instead of dextro-rotatory. It also contains five hydroxyl groups, and it also yields with hydrogen cyanide a hydroxy nitrile. The hydroxy nitrile on hydrolysis also yields a hexahydroxy acid; but this latter on reduction with hydriodic acid gives rise, not to normal heptylic acid, as is the case with the corresponding compound from dextrose, but to methyl butyl acetic acid (which can be synthesized from ethyl malonate through the sodium derivative, see p. 109). Lævulose was, therefore, held to be a ketone with five hydroxyl groups, and the formula assigned to it was the following:-

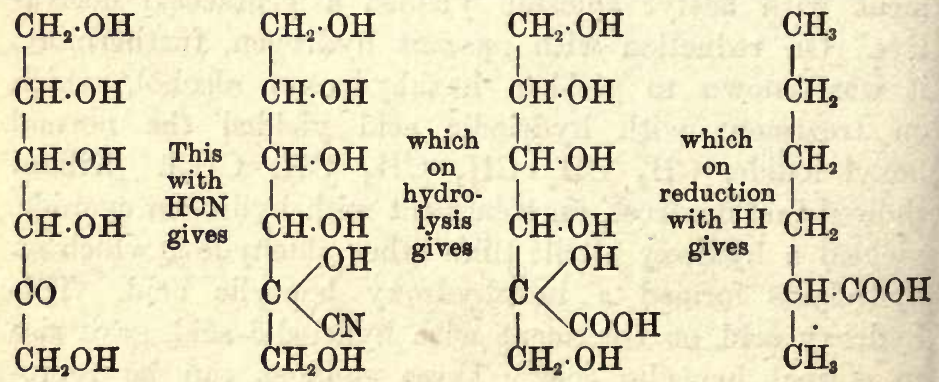

or methyl-butyl acetic acid. 


\section{Chemical Constituents of the Animal Body. I 95}

Reactions of Dextrose and Lovulose.-Both dextrose and lævulose give rise on reduction to an alcohol, sorbitol, of the formula-

\section{$\mathrm{CH}_{2} \mathrm{OH} \cdot \mathrm{CH}(\mathrm{OH}) \cdot \mathrm{CH}(\mathrm{OH}) \mathrm{CH}(\mathrm{OH}) \mathrm{CH}(\mathrm{OH}) \cdot \mathrm{CH}_{2} \cdot \mathrm{OH}$}

In giving rise to an alcohol of such a formula they behave as an aldehyde or ketone may be expected to do. In other respects, also, dextrose and lævulose behave like aldehydes and ketones. They reduce, for example, alkaline solutions of cupric salts. The reagent generally employed is known as Fehling's solution, which is generally prepared in the following manner :- 34.6 grammes of copper sulphate (with water of crystallization) are dissolved in water, and the solution is made up to 500 c.c.; a second solution containing 173 grammes of Rochelle salt (potassium sodium tartrate) and 60 grammes of sodium hydroxide in 500 c.c. is also prepared. Equal volumes of these two solutions are mixed, and then warmed with the solution containing the sugar. The reduction is indicated by the precipitation of red cuprous oxide when the mixture is warmed. This reaction can be employed for the quantitative estimation of sugars in solutions, each individual sugar producing a definite amount of precipitate when warmed with Fehling's solution under certain standard conditions of experiment. The amount of precipitate yielded by each sugar is determined under these standard conditions. The estimations can be carried out either by gravimetric or volumetric methods, of which a large variety have been suggested. The employment of Fehling's solution in one form or another is the most usual one for the quantitative estimation of sugars. In the volumetric methods the sugar solution is added to the Fehling solution until the blue colour disappears; various indicators can also be employed. In the gravimetric method, the weight of cuprous oxide produced by a given amount of solution is determined. Under given 
conditions of experiment dextrose will yield an amount of cuprous oxide different from that yielded by the same amount of lævulose, and this "reducing power" of sugars must be determined separately with each individual member of the class.*

The sugars also react, like other aldehydes and ketones, with hydroxylamine to form oximes, the oxime of dextrose having the formula-

\section{$\mathrm{CH}_{2}(\mathrm{OH}) \cdot \mathrm{CH}(\mathrm{OH}) \cdot \mathrm{CH}(\mathrm{OH}) \mathrm{CH}(\mathrm{OH}) \mathrm{CH}(\mathrm{OH}) \mathrm{CH}: \mathrm{NOH}$}

The Action of Phenylhydrazine on Dextrose and Loevulose.-The action of phenylhydrazine on these sugars is an important one. The first action, both on dextrose and lævulose, is the one which would be expected from the fact that these substances are an aldehyde and ketone respectively. They form products known as hydrazones. $\dagger$

$\mathrm{CH}_{2}(\mathrm{OH}) \cdot(\mathrm{CH}(\mathrm{OH}))_{4} \mathrm{CHO}+\mathrm{NH}_{2} \cdot \mathrm{NH} \cdot \mathrm{C}_{6} \mathrm{H}_{5}$

$$
=\mathrm{H}_{2} \mathrm{O}+\mathrm{CH}_{2}(\mathrm{OH})(\mathrm{CH} \cdot \mathrm{OH})_{4} \mathrm{CH}: \mathrm{N} \cdot \mathrm{NHC}_{6} \mathrm{H}_{6}
$$

$\mathrm{CH}_{2}(\mathrm{OH})(\mathrm{CH}(\mathrm{OH}))_{3} \mathrm{CO} \cdot \mathrm{CH}_{2} \mathrm{OH}+\mathrm{NH}_{2} \cdot \mathrm{NHC}_{6} \mathrm{H}_{5}$

$$
=\mathrm{H}_{2} \mathrm{O}+\mathrm{CH}_{2}(\mathrm{OH})(\mathrm{CH}(\mathrm{OH}))_{3} \mathrm{C}: \mathrm{N} \cdot \mathrm{NHC}_{6} \mathrm{H}_{5}
$$

Now when these hydrazones are heated with excess of phenylhydrazine, a group - $\mathrm{CH}(\mathrm{OH})$ in the case of dextrose, and a $-\mathrm{CH}_{2} \cdot \mathrm{OH}$ group in the case of lævulose, loses hydrogen, which reacts with phenylhydrazine in accordance with the following equation-

$$
\mathrm{C}_{6} \mathrm{H}_{5} \mathrm{NH} \cdot \mathrm{NH}_{2}+\mathrm{H}_{2}=\mathrm{C}_{6} \mathrm{H}_{6} \mathrm{NH}_{2}+\mathrm{NH}_{3}
$$

Products are thereby produced from dextrose and lævulose having the two following formulæ:-

* For full details of the methods reference must be made to text-books on quantitative analysis.

+ These formulæ are written in an abbreviated form. 


\section{Chemical Constituents of the Animal Body. 197}

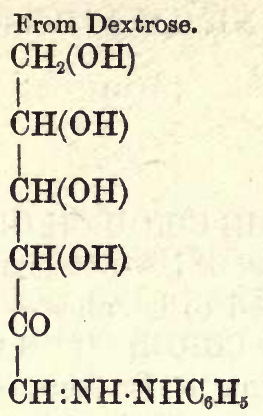

From Lævulose.

$\mathrm{CH}_{2} \cdot \mathrm{OH}$

$\mathrm{CH}(\mathrm{OH})$

${ }_{\mathrm{CH}}(\mathrm{OH})$

' $\mathrm{CH}(\mathrm{OH})$

C: $\mathrm{N} \cdot \mathrm{NHC}_{6} \mathrm{H}_{5}$

CHO

As these contain, in the case of dextrose, an extra ketone group, and in the case of lævulose an extra aldehyde group, they are capable of reacting with another molecule of phenylhydrazine, and they yield thereby characteristic yellow crystalline substances known as the osazones. Both dextrose and lævulose will yield the same osazone, which has the formula-

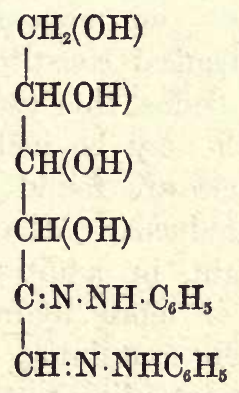

As substances of this class are readily obtained in a crystalline form, and have generally definite melting points and other properties, they serve well for the characterization of dextrose and lævulose and other sugars, the properties of which will be discussed later.

On heating the osazones with hydrochloric acid they undergo scission, yielding phenylhydrazine hydrochloride and a substance known as an "osone"- 


\section{Biological Chemistry.}

$\mathrm{CH}_{2}(\mathrm{OH}) \cdot(\mathrm{CH}(\mathrm{OH}))_{3} \cdot \mathrm{C} \cdot \mathrm{CH}: \mathrm{N} \cdot \mathrm{NH} \cdot \mathrm{C}_{6} \mathrm{H}_{5}+2 \mathrm{HCl}+2 \mathrm{H}_{2} \mathrm{O}$

$\ddot{\mathrm{N}}$

$=2 \mathrm{C}_{6} \mathrm{H}_{5} \mathrm{NH} \cdot \mathrm{NH}_{2} \cdot \mathrm{HCl}$

\section{$\mathrm{NHC}_{6} \mathrm{H}_{8}$}

$+\mathrm{CH}_{2}(\mathrm{OH}) \cdot \mathrm{CH}(\mathrm{OH}) \cdot \mathrm{CH}(\mathrm{OH}) \mathrm{CH}(\mathrm{OH}) \cdot \mathrm{CO} \cdot \mathrm{CHO}$

The osone obtained from dextrose or lævulose, on treatment with nascent hydrogen, is reduced to lævulose$\mathrm{CH}_{2}(\mathrm{OH}) \cdot \mathrm{CH}(\mathrm{OH}) \cdot \mathrm{CH}(\mathrm{OH}) \cdot \mathrm{CH}(\mathrm{OH}) \cdot \mathrm{CO} \cdot \mathrm{CH}_{2} \mathrm{OH}$

By means of a series of reactions it is therefore possible to convert dextrose into lævulose. With phenylhydrazine it yields the osazone (which is identical with the osazone obtained from lævulose). This substance on hydrolysis yields the osone, from which, on reduction with nascent hydrogen, lævulose is obtained.

The General Characters of the Sugars.-In addition to glucose and lævulose, a large number of other substances are included amongst the monosaccharoses. Since the recognition of the chemical constitution of the former, it has been possible to define this class chemically. Under the above designation may be included a series of substances, of which some are found native and others are artificial laboratory products. All are characterized by the fact that they contain, in addition to an aldehyde or ketone radicle, one or more hydroxyl radicles. Monosaccharoses are known containing from two up to nine carbon atoms, and are according to the number classified as bioses, trioses, tetroses, etc. The simplest member of the class of monosaccharoses is glycollic aldehyde-

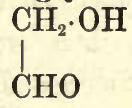

As an example of a triose may be mentioned glyceraldehyde and the isomeric ketone, dihydroxy acetone, of which the formulæ are given below- 


\section{Chemical Constituents of the Animal Body. I 99}
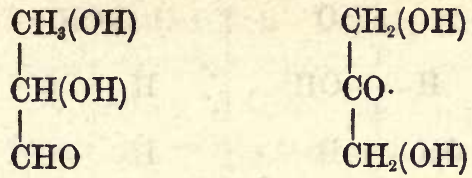

Amongst the tetroses which are found native are erythrose and threose, and amongst the pentoses, arabinose, xylose, ribose. The hexoses include the natural products glucose, mannose, and galactose, all of which are aldehydes (or aldoses), and lævulose and sorbose, which are ketones (ketoses). All the native monosaccharoses are optically active. They are crystalline substances, readily soluble in water, less soluble in alcohol, and practically insoluble in the majority of organic solvents. Nearly all the above sugars may be represented by the general empirical formula $\mathrm{C}_{n} n \mathrm{H}_{2} \mathrm{O}$. A few sugars are also known which cannot be represented by this formula, such as rhamnose, which is a methyl pentose.

Isomerism in the Group of Monosaccharoses. - If the formula representing the structure of glucose is examined, it will be found to contain four asymmetric carbon atoms. No less than sixteen stereoisomerides are capable of existence, composed of eight pairs of enantiomorphically related substances.

These stereoisomerides are the following:-

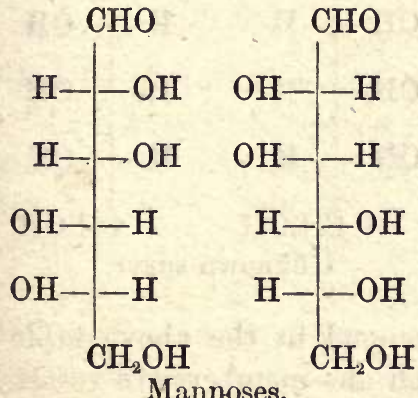

Mannoses.

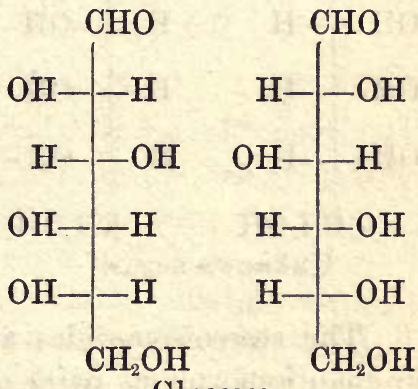

Glucoses. 

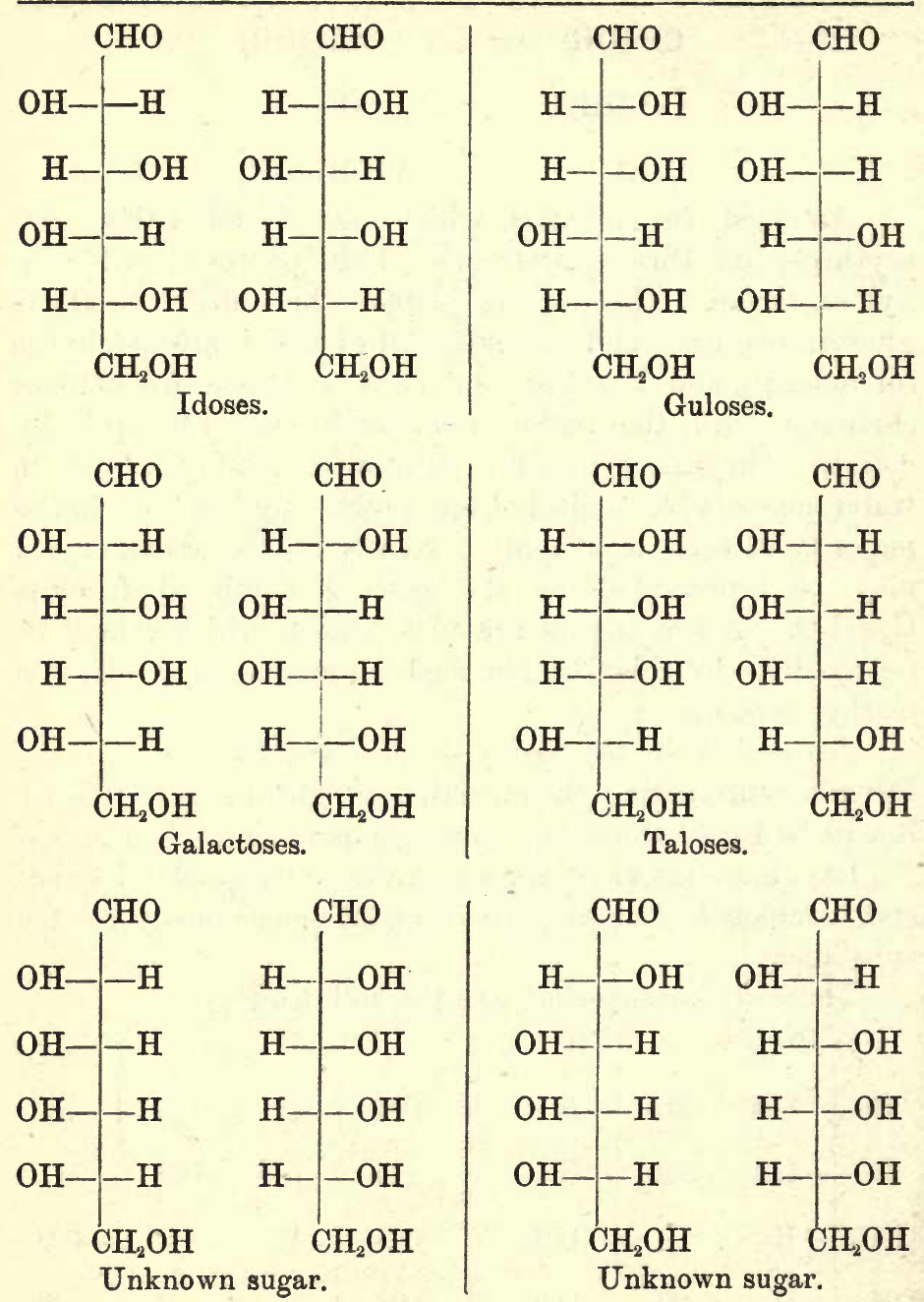

The stereoisomerides are arranged in the above table in enantiomorphous pairs, of which one member will rotate 


\section{Chemical Constituents of the Animal Body. 201}

polarized light in one direction exactly to the same amount that the other member rotates it in the opposite direction. It is not possible in this place to give in detail the methods by means of which the relative positions of the hydroxyl and hydrogen groups in the above isomerides have been ascertained. The present knowledge on this subject is due chiefly to the labours of Emil Fischer and his pupils, whose work is published in a monograph of extensive character. It will suffice to give an account of a few of the reactions which have led to the final results, and which indicate the stereometric relationships of the sugars to one another.

I. It is possible to reverse the positions of the hydrogen and hydroxyl groups attached to the a-carbon atom (the positions of the carbon atoms are reckoned from the aldehyde group) - that is, convert, e.g., a sugar-
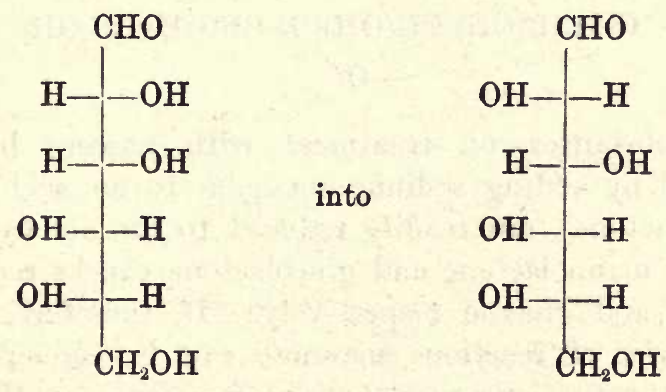

- that is, convert a mannose into a glucose.

These sugars are converted on oxidation by mild oxidizing reagents into acids, the - $\mathrm{CHO}$ group being oxidized to the - $\mathrm{COOH}$ group. From glucose the acid $\mathrm{COOH}(\mathrm{CH}(\mathrm{OH}))_{4} \mathrm{CH}_{2} \mathrm{OH}$ can be obtained. On heating such an acid with water to $150^{\circ}$, made alkaline with pyridine or quinoline, the position of the $-\mathrm{H}$ and $-\mathrm{OH}$ on the $\alpha$-carbon atom is reversed; that is - 

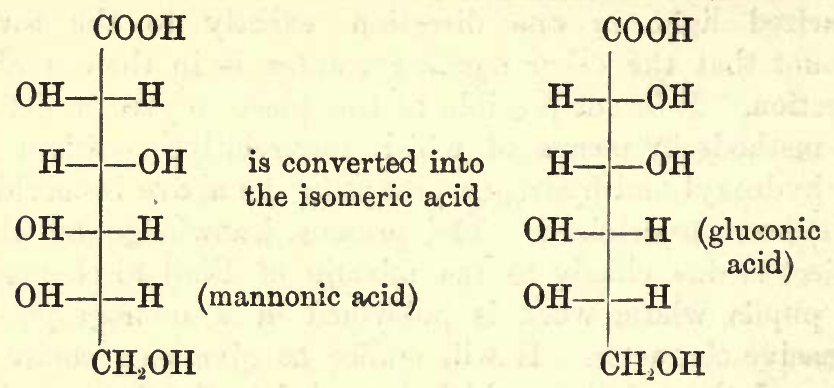

This reaction is comparable to the conversion of an optically active tartaric acid into the racemic form. Acids like mannonic and gluconic acids, which contain a hydroxyl group attached to a carbon atom in the $\gamma$ position to the carboxyl group, readily form anhydrides known as lactones. Mannolactone would have the formula-

\section{$\mathrm{CO} \cdot \mathrm{CH} \cdot(\mathrm{OH}) \cdot \mathrm{CH}(\mathrm{OH}) \mathrm{CH} \cdot \mathrm{CH}(\mathrm{OH}) \cdot \mathrm{CH}_{2} \mathrm{OH}$ $0 /$}

These substances, on treatment with nascent hydrogen (obtained by adding sodium amalgam to an acid solution of the lactone), are readily reduced to the aldehyde. In this way mannolactone and glucolactone can be reduced to mannose and glucose respectively. If, therefore, by the above series of reactions, mannose can be converted into glucose, the two sugars can differ from one another only in the relative space positions of the hydrogen and the hydroxyl group attached to the carbon atom next to the aldehyde group. It is easy to see that sugars so related should yield the same osazone, and this, in the case of mannose and glucose, is indeed the fact.

II. It is possible to convert one sugar into another in which the positions of the $-\mathrm{CHO}$ and $-\mathrm{CH}_{2} \mathrm{OH}$ groups are reversed; that is, to convert- 


\section{Chemical Constituents of the Animal Body. 203}

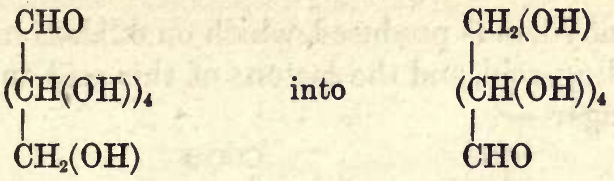

In the preceding section it has been stated that sugars can be converted by oxidation into monobasic acids (for example, gluconic and mannonic acids). This reaction can be brought about by means of bromine water. If a more powerful oxidizing reagent, such as nitric acid, is employed, the sugar can be converted into a dibasic acid. In this way saccharic acid can be formed from glucose. Saccharic, like gluconic acid, also forms a lactone, which on reduction yields an aldehyde acid (glycuronic acid). The latter, on further reduction, yields a new acid by the conversion of the - $\mathrm{CHO}$ group into the $-\mathrm{CH}_{2} \mathrm{OH}$ group. This acid also forms a lactone, which on reduction yields a sugar. This series of reactions is represented by the following formulæ :-

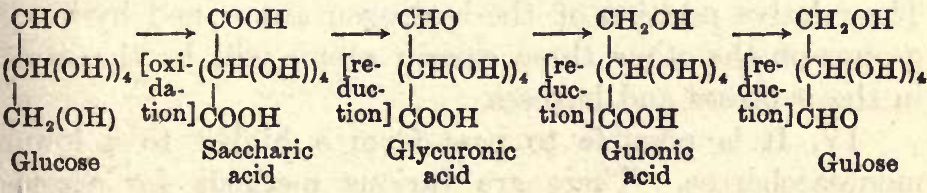

Throughout this series of reactions the relative positions of the hydrogen atoms and hydroxyl groups on the four asymmetric carbon atoms remain unchanged. Sugars related to one another in the way that glucose is related to gulose can only differ in the relative positions of the $-\mathrm{CHO}$ and $-\mathrm{CH}_{2} \mathrm{OH}$ groups. It is easy to see that they will yield the same dibasic acid (in the example cited saccharic acid) on oxidation.

III. It is possible to pass from one sugar to another containing an additional carbon atom-for example, from a pentose to a hexose. On treatment with hydrocyanic 
acid a cyanhydrin is produced, which on oxidation yields the corresponding acid, and the lactone of this acid on reduction yields a sugar-

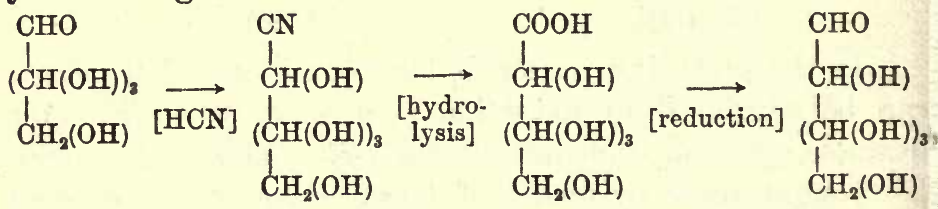

This reaction introduces a new asymmetric carbon atom, and a mixture of sugars is generally produced, the steric relationship to one another of which may be represented by the formulæ-
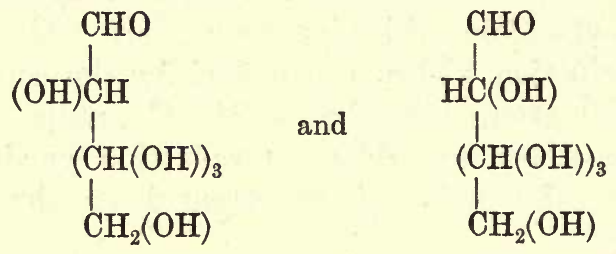

The relative position of the hydrogen atoms and hydroxy: groups on the other three carbon atoms will be the same in the pentoses and hexoses.

IV. It is possible to pass from a higher to a lower monosaccharose. There are various methods for accomplishing this purpose, the simplest being that due to Ruff. The sugar is first oxidized to a monobasic acid, and the latter on oxidation with hydrogen peroxide in the presence of an iron salt (Fenton's reagent) is oxidized to a sugar containing one carbon atom less. In this way the pentose; arabinose, has been produced from glucose. The arrangement of the hydrogen atoms and hydroxyl groups attached to the three asymmetric carbon atoms, in arabinose, must therefore be the same as those attached to three of the asymmetric carbon atoms of glucose. The reactions may, be represented by the following formule:- 
Chemical Constituents of the Animal Body. 205

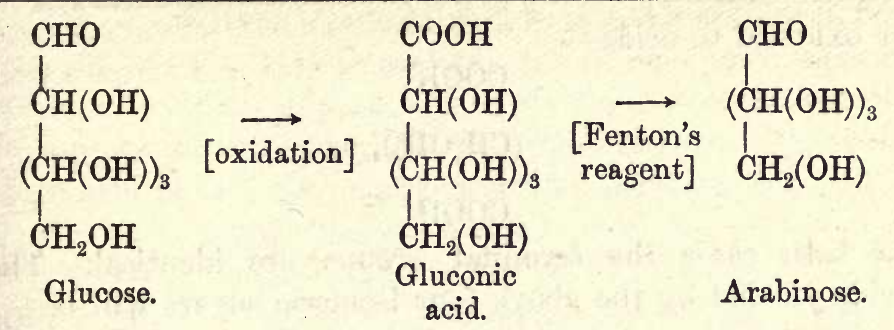

The oxidation by Fenton's reagent may be represented by the equation-

$$
\mathrm{C}_{7} \mathrm{H}_{12} \mathrm{O}_{7} \text { (gluconic acid) }+\mathrm{O}=\mathrm{C}_{5} \mathrm{H}_{10} \mathrm{O}_{5}+\mathrm{CO}_{2}+\mathrm{H}_{2} \mathrm{O} \text {. }
$$

$\mathrm{V}$. Although all the reactions in the preceding four sections show the stereometric relationships of certain sugars one to another, they are insufficient to fix definitely the correct formula for any given sugar. In order to establish this, the positions of the hydrogen atoms and hydroxyl groups in certain derivatives of the sugars must be taken into account. It will facilitate the explanation if the reactions involved are first applied to the simpler sugars. There are four possible isomerides of the sugars containing four carbon atoms (that is, erythrose and its isomerides), namely-

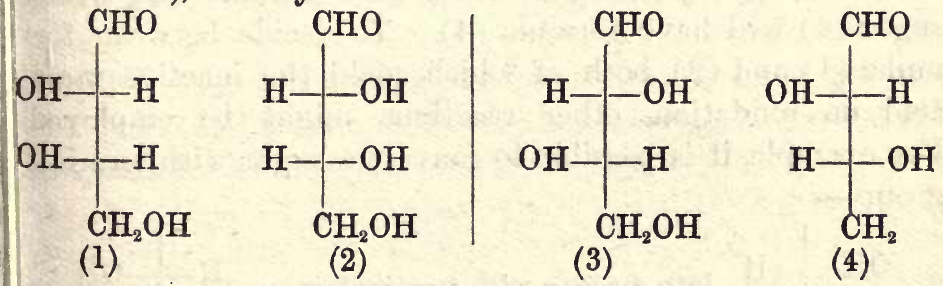

orming two pairs of enantiomorphs.

Now these sugars can be reduced to alcohols$\mathrm{CH}_{2} \mathrm{OH}$

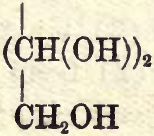




\section{Biological Chemistry.}

or oxidized to acids-

$\mathrm{COOH}$

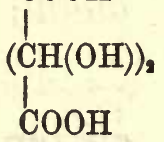

In both cases the terminal groups are identical. The acids yielded by the above four isomeric sugars will be-

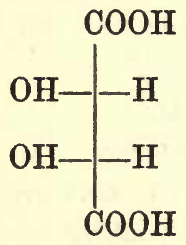

(A)

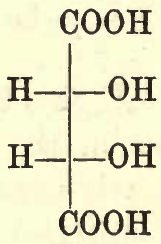

(B)

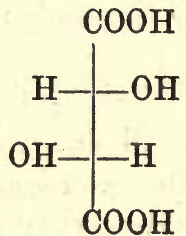

(C)

$\mathrm{COOH}$

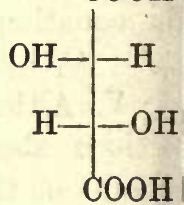

(D)

These acids are all tartaric acids. Now acids (A) and (B) are mesotartaric acid, the internally compensated form (see p. 173), and must therefore be optically inactive. If therefore, a sugar yields on oxidation an inactive tartaric acid, it must have the formula of either (1) or (2). If (C) be taken (conventionally) as the formula of $d$-tartaric acid, the sugar yielding it must have formula (3), whilst sugar (4) will have formula (4). To decide between for mulæ (1) and (2), both of which yield the inactive meso acid on oxidation, other reactions might be employed For example, it is possible to convert a sugar with termina group-

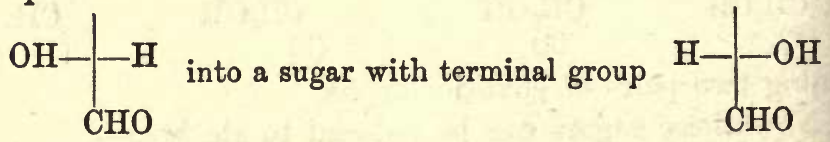

(reaction I. given above). Sugar (1) would by this re action be obtainable from (3), which yields the dextro-acic on oxidation, and sugar (2) from (4). In this way th constitution of the erythroses could be settled. 


\section{Chemical Constituents of the Animal Body. 207}

By methods of reaction III., it is possible to pass from the lower to a higher sugar. A new asymmetric carbon atom will be introduced, and from each tetrose two pentoses can be obtained. It is not necessary to give the formulæ of all the eight possible pentoses; it will be sufficient to consider those derived from any two tetroses, say those of formulæ (1) and (3)-
(1)
CHO

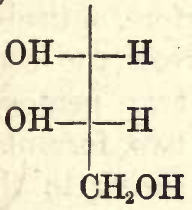
will give
rise to

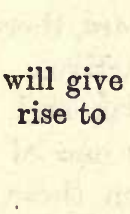

(A) $\mathrm{CHO}$

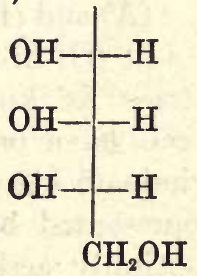

(B) $\quad \mathrm{CHO}$

and

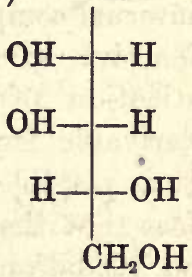

(3)

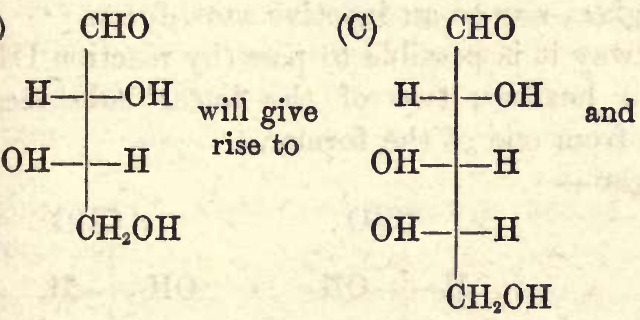

(D)

CHO

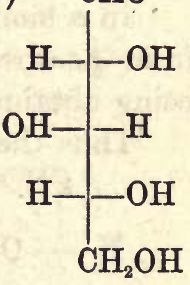

The four synthetically-obtained pentoses will give rise on oxidation to the following dibasic acids (trihydroxy glutaric acids) -
(A) $\mathrm{COOH}$
(B) $\mathrm{COOH}$
(C)
$\mathrm{COOH}$
(D) $\mathrm{COOH}$
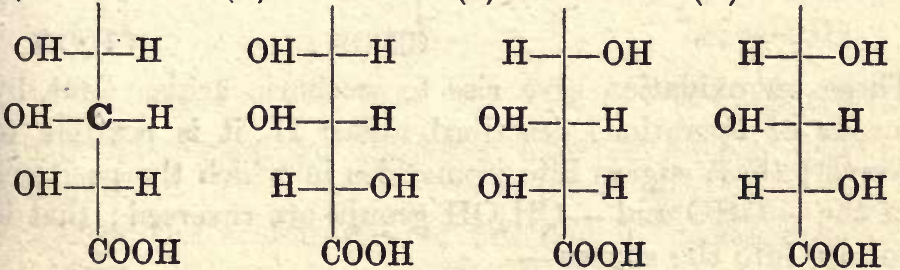
Now it will be noticed that the middle carbon atom (denoted by insertion of the symbol $\mathrm{C}$ in formula (A)) is connected with two structurally similar groups $(-\mathrm{CH}(\mathrm{OH}) \mathrm{COOH})$, and is therefore no longer asymmetric. It will be noticed, furthermore, that in formulæ (A) and (D) the arrangement of the hydrogen atoms and hydroxyl groups around the carbon atoms to which this asymmetric carbon atom is attached is such that they cause internal compensation. (A) and (D) are, therefore, optically inactive, whereas (B) and (C) are active. Now the constitution of each tetrose is known, and two pentoses derivable from each can have only one of two formulæ. It is possible to discriminate between these, owing to the fact that the sugar represented by one formula gives rise on oxidation to an optically active dibasic acid, whereas the other sugar gives rise to an inactive meso-form.

In a similar way it is possible to pass (by reaction III.) from pentoses to hexoses, two of the latter substances being obtainable from one of the former.

Thus the sugar-
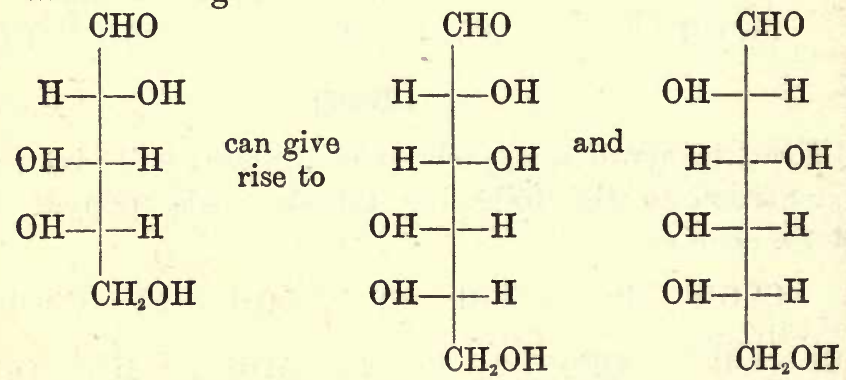

These on oxidation give rise to saccharic acids. But, by means of operations described under II., it is possible to convert these sugars into isomerides in which the positions of the $-\mathrm{CHO}$ and $-\mathrm{CH}_{2} \mathrm{OH}$ groups are reversed; that is to say, into the sugars- 
Chemical Constituents of the Animal Body. 209

(1)

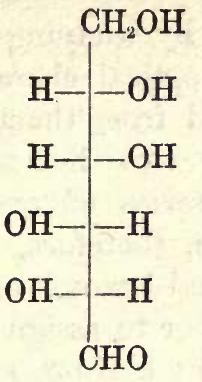

(2)

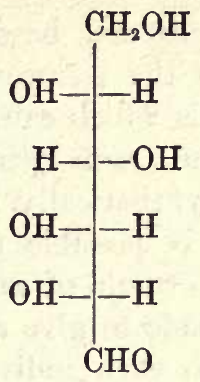

These can be synthesized from pentoses, or they can be degraded into pentoses by reaction IV. (Ruff's reaction).

(1) Will be degraded to the pentose-
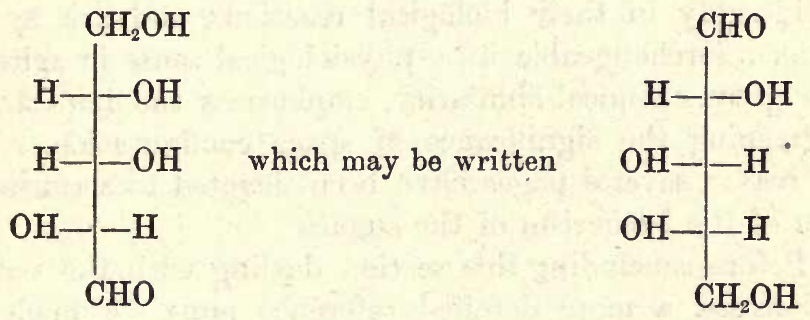

which will yield an optically active dibasic acid on oxidation.

(2) Will be degraded to the pentose$\mathrm{CH}_{2} \mathrm{OH}$
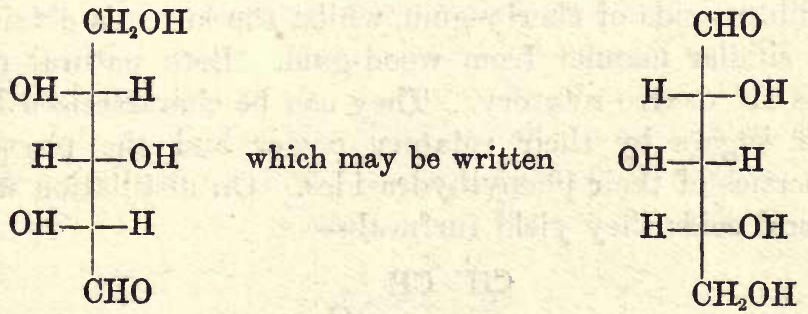

which will yield an optically inactive dibasic acid on oxidation.

Now the constitution of the various pentoses can, as $(1,997)$ 14 
already mentioned, be determined by studying their relationship to the tetroses, and the optical character of the dibasic acids which can be obtained from them by hydrolysis. From each pentose only two hexoses can be obtained synthetically. By the series of reactions just related, it is possible to ascertain, therefore, the correct structural formula of each individual hexose. No attempt has been made to give any details, or to assign the correct structure to each individual sugar; a short summary of the chief reactions only has been given, in order that a general idea of the methods adopted may be acquired. The fact that the isomeric sugars differ from one another considerably in their biological reactions, and are by no means interchangeable in a physiological sense in spite of their great chemical similarity, emphasizes the importance of grasping the significance of space configuration. For this reason several pages have been devoted to a consideration of the isomerism of the sugars.

Before concluding this section dealing with the monosaccharoses, a more detailed reference must be made to a few of the more important members of the class.

Arabinose and xylose are the two best known of the pentoses, the former being obtained by the hydrolysis by dilute acids of cherry-gum, whilst the latter is obtained in a similar manner from wood-gum. Both natural products are dextro-rotatory. They can be characterized like other sugars by their rotatory power and the physical properties of their phenylhydrazides. On distillation with mineral acids they yield furfural-

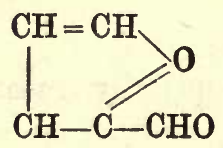

or derivatives of the same. 


\section{Chemical Constituents of the Animal Body. 2 I I}

Mannose is a hexose isomeric with glucose which is obtained by the hydrolysis of a polysaccharose (mannane) which occurs in several plants. The sugar obtained from natural products is dextro-rotatory.

Galactose is also a hexose isomeric with glucose, and like this sugar and mannose also an aldehyde. It is obtained from the disaccharose milk-sugar or lactose (see p. 214) by hydrolysis with acids. The more complex sugar by this treatment undergoes scission into equimolecular amounts of dextrose and galactose. It is also dextro-rotatory.

Synthesis of Sugars.-Attention has been already called to the methods of building up the more complex from the simpler sugars. Particular interest attaches to some other methods of synthesis, which tend to throw light on the processes by means of which these substances are formed in plants, which are the chief agents in nature for their production. In 1861 Butlerov found that trioxymethylene, a solid polymerization product of formaldehyde, on treatment with lime water, yielded a sweet syrupy substance which possessed many of the reactions of a sugar. The observation was extended in 1886 by Loew, who showed that formaldehyde itself, on treatment with lime water, also yielded a sugar-like substance. This observation is an important one, for Baeyer, in 1870, had expressed the view that carbon dioxide, when assimilated by green plants, is first reduced to formaldehyde, $\mathrm{CH}_{2} \mathrm{O}$; this latter substance on polymerization was thought to be capable of yielding a sugar, $\mathrm{C}_{6} \mathrm{H}_{12} \mathrm{O}_{6}$, from which by condensation of several molecules and the withdrawal of water, starch can be produced. The substance obtained by Loew was not isolated in a pure state, and subsequent researches by E. Fischer and his collaborators have shown that Loew's product was in fact a mixture. Later, it was 
shown that sugars could be obtained by a somewhat different synthetical process. It was found that acrolein dibromide, $\mathrm{CH}_{2} \mathrm{Br} \cdot \mathrm{CHBr} \cdot \mathrm{CHO}$, on treatment with baryta water, yields a mixture of two sugars, which were isolated in the form of their osazones. The reaction representing the formation of these sugars may be represented in the following way-

$$
2 \mathrm{C}_{3} \mathrm{H}_{4} \mathrm{OBr}_{2}+2 \mathrm{Ba}(\mathrm{OH})_{2}=\mathrm{C}_{6} \mathrm{H}_{12} \mathrm{O}_{6}+2 \mathrm{BaBr}
$$

The sugars isolated were designated $\alpha$ and $\beta$ acrose, and were, as might be expected from the fact that they were produced synthetically by ordinary laboratory methods, optically inactive. One of these sugars (the $a$-variety) was investigated in some detail. From the osazone the osone (see p. 197) was prepared, which on reduction yielded an optically inactive fructose, which would be expected to be a ketone (loc. cit.). The optical inactivity is due to the fact that the fructose thus obtained is a mixture of enantiomorphically related pairs. On fermenting with yeast only the $d$-form is consumed, and $l$-fructose is left almost untouched by the micro-organism. (Note biological difference between the two stereoisomerides.) From the active fructose, by a somewhat complex series of reactions, several isomeric hexoses were obtained.

Alcoholic Fermentation of the Sugars.-Under the influence of yeast plants, certain sugars undergo a chemical change, which results in the production of alcohol and carbon dioxide. This action, which has long been known as fermentation, is directly due to the presence in the organism of certain substances known as ferments, to the discussion of which part of a later chapter (Chapter VI.) is devoted. The reaction, in the case of dextrose, may be represented by the equation-

$$
\mathrm{C}_{6} \mathrm{H}_{12} \overline{\mathrm{O}}_{6}=2 \mathrm{C}_{2} \mathrm{H}_{6} \mathrm{U}+2 \mathrm{CO}_{2}
$$




\section{Chemical Constituents of the Animal Body. 2 I 3}

In view of the chemical constitution of ethyl alcohol, which contains a methyl group, $\left(\mathrm{CH}_{3} \cdot \mathrm{CH}_{2} \cdot \mathrm{OH}\right)$, and of dextrose, in which this group is absent, the chemical mechanism of this biochemical reaction is obscure, and a large amount of work has been devoted to the elucidation. No completely satisfactory explanation, in spite of the amount of research, can be said, so far, to have been offered. It is of interest to note, however, that not all the sugars can undergo alcoholic fermentation. Only the monosaccharoses with three, six, or nine carbon atoms are fermentable with yeast, and only selected individuals amongst these sugars. Of the hexoses, the four naturally occurring individuals, $d$-galactose, $d$-mannose, $d$-dextrose, and lævulose, are fermentable, and it is of interest to note that all four are closely related as regards their stereometric configuration. It may be recalled that the three last-named all yield the same osazone.

\section{THE DISACCHAROSES.}

Cane-sugar or sucrose, the most widely distributed of these sugars, is prepared chiefly from the beet and sugar-cane. On hydrolysis with mineral acids, it undergoes scission into "invert sugar" (p. 192), a mixture of dextrose and lævulose-

$$
\mathrm{C}_{12} \mathrm{H}_{22} \mathrm{O}_{11}+\mathrm{H}_{2} \mathrm{O}=\mathrm{C}_{6} \mathrm{H}_{12} \mathrm{O}_{6}+\mathrm{C}_{6} \mathrm{H}_{12} \mathrm{O}_{6}
$$

It contains eight hydroxyl groups, since on treatment with acetic anhydride and sodium acetate it yields an octacetyl derivative, $\mathrm{C}_{12} \mathrm{H}_{14} \mathrm{O}_{3}\left(\mathrm{O} \cdot \mathrm{CO} \cdot \mathrm{CH}_{3}\right)_{8}$.

Sucrose also undergoes scission into a mixture of dextrose and lævulose when treated with the ferment "invertase," which occurs in yeast.

Maltose, $\mathrm{C}_{12} \mathrm{H}_{22} \mathrm{O}_{11}$, is produced from starch when the latter is treated with malt which contains a ferment 
"maltase." On hydrolysis maltose undergoes hydrolysis, one molecule yielding two molecules of glucose-

$$
\mathrm{C}_{12} \mathrm{H}_{22} \mathrm{O}_{11}+\mathrm{H}_{2} \mathrm{O}=2 \mathrm{C}_{6} \mathrm{H}_{12} \mathrm{O}_{6} \text { (glucose) }
$$

Lactose or milk-sugar, which occurs in milk, and is readily prepared from the liquid squeezed out from the clot after the milk has been clotted with rennin, is a sugar confined to the animal kingdom. On hydrolysis it yields a mixture of galactose and glucose-

$$
\mathrm{C}_{12} \mathrm{H}_{22} \mathrm{O}_{11}+\mathrm{H}_{2} \mathrm{O}=\underset{\text { (Glucose) (Galactose) }}{\mathrm{C}_{6} \mathrm{H}_{12} \mathrm{O}_{6}}+\mathrm{C}_{6} \mathrm{H}_{12} \mathrm{O}_{6}
$$

All the above disaccharoses yield characteristic osazones.

\section{POLYSACCHAROSES.}

The chief of these are starch and glycogen, both of which yield on hydrolysis glucose. Intermediate complex products, such as dextrin, are also formed.

Starch is widely distributed throughout the animal world, occurring in potatoes, and forming a large proportion of the substance of various grains. On an industrial scale it is prepared chiefly from potatoes. It is a very complex substance, which is insoluble in water. It occurs in the form of granules, with characteristic shapes which vary in the different plants. On heating them with water they swell and burst, separating into an insoluble cell wall which can be filtered off, and a portion soluble in water and known as "soluble starch," which can be precipitated from solution on the addition of alcohol. The molecular weight of starch is very large; its composition is generally represented by the formula $n\left(\mathrm{C}_{6} \mathrm{H}_{12} \mathrm{O}_{6}\right)-(n-1) \mathrm{H}_{2} \mathrm{O}$, and as $n$ is very great the simpler formula $\left(\mathrm{C}_{6} \mathrm{H}_{10} \mathrm{O}_{5}\right)_{n}$ is sufficiently accurate. The more complex formula will explain the hydrolysis by acids of one molecule of starch into $n$ molecules of glucose. 
Hydrolysis can also be brought about by means of the ferment "diastase," which occurs in malt, saliva,* and elsewhere. The degradation in this case does not proceed as far as when acids are used, but other intermediate products of the general formula $n\left(\mathrm{C}_{6} \mathrm{H}_{12} \mathrm{O}_{6}\right)-(n-1) \mathrm{H}_{2} \mathrm{O}$ are produced, where $n$ is a number smaller than the $n$ of the starch formula. In the case of maltose, which can be produced by diastase (see p. 213) $n=2$. Other intermediate products where $n>2$ are also produced, such as the various dextrins. A characteristic reaction for starch is the blue colour which it gives on the addition of iodine (generally added in when dissolved in a solution of potassium iodide). As the starch is degraded by the action of the ferment, the colour produced by the iodine reagent changes from blue to purple and red, and finally disappears. The simplest polysaccharoses, such as the maltose, give no coloration, whereas the dextrins give brownish or reddish colorations.

Glycogen is the animal starch, and is found in greatest quantity in the livers of animals, especially after diets rich in carbohydrates. It can be obtained by warming the organs with strong solutions of potassium hydroxide, which converts the proteins, etc., into soluble products, and then adding alcohol to the mixture. The glycogen is thereby precipitated. It soon disappears from the liver after the death of the animal, as it undergoes hydrolysis into glucose under the influence of the diastase contained in the organs. Glycogen is a white powder, soluble in water, giving an opalescent solution. It gives a red coloration with glucose.

Cellulose is widely distributed throughout the vegetable kingdom, and constitutes the framewerk of most vegetable tissues. It is the chief constituent of linen, cotton, hemp, and flax. The chemical character of the substances included under the name of cellulose is still somewhat

* The ferment in saliva is known as ptyalin. 
uncertain. By the action of acids several derivatives of considerable technical importance can be obtained, such as gun-cotton, celloidin, celluloid, and the various artificial silks.

In addition, a large number of other starch-like substances are found in plants, which give rise on hydrolysis to sugars other than glucose.

Inulin, which is found in certain plants, such as the dahlia, yields on hydrolysis lævulose.

Cherry-gum gives rise to arabinose (p. 210).

Wood-gum gives rise to xylose.

The mannans give rise to mannose.

The vegetable gums and mucilages mostly appear to be complex polysaccharoses, but their chemical constitutions have not yet been definitely decided.

\section{ADDENDUM TO PART II.-THE GLUCOSIDES.}

When dextrose is treated with methyl alcohol and hydrochloric acid, two methyl derivatives known as a and $\beta$ methyl glucosides are obtained, which may be regarded as the simplest types of a large series of sugar derivatives, many of which are found native in plants, which are known as glucosides. The formulæ assigned to these substances are-

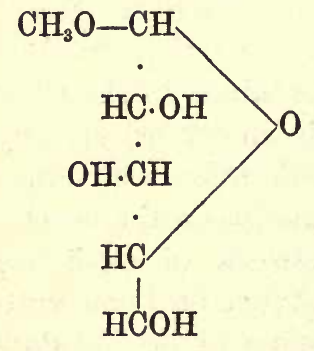

$\mathrm{CH}_{2} \mathrm{OH}$

a-Methyl Glucoside.

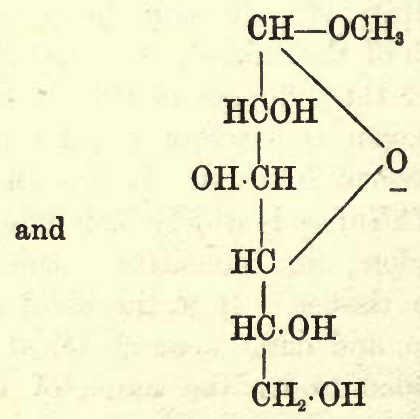

$\beta$-Methyl Glucoside. 


\section{Chemical Constituents of the Animal Body. 2 I 7}

- that is to say, they are stereoisomerides containing a methoxyl group, but that this latter occupies different positions with regard to the terminal carbon atom. Dextrose itself is an aldehyde, but it is assumed that it may form an addition product with water, like so many other aldehydes. Now, as a substance derived in this manner contains a terminal hydroxyl group which is in the $\gamma$ position to another hydroxyl group, it should readily form an anhydride analogous to a lactone (see p. 202). If tetrahedra models are employed to represent the formulæ, it will be easy to see that the two hydroxyl groups in question can be readily brought into close apposition. Two possible stereoisomerides can be produced by this anhydride formation, and the relationship can be expressed in the following formulæ:-
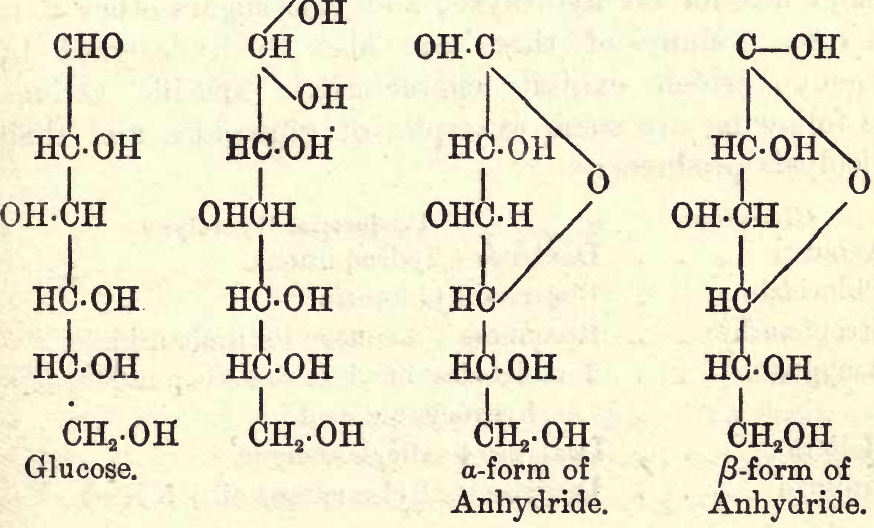

There is evidence of the existence of the two forms of dextrose, for Tanset has shown that by employing different methods of crystallization, dextroses with different rotations, melting points, etc., can be employed. Solutions of these forms change rotation when dissolved in water; dextrose solutions, in fact, do not show as a rule a 
constant rotatory power when freshly prepared, and a definite rotation is only obtained when the solutions have been kept for some time. Dextrose exhibits the phenomenon of "mutarotation," and this can be explained on the hypothesis of the existence of two isomerides of the forms indicated above. When the rotation of the solution becomes constant it contains an equilibrated mixture of the $a$ - and $\beta$-isomerides.

The glucosides undergo hydrolysis yielding methyl alcohol and dextrose when treated with acids or ferments. Some ferments will hydrolyze only the $a$-form, whereas others will hydrolyze only the $\beta$-form, an -important fact which will be considered later when discussing the nature of ferment action.

Glucosides exist which yield products other than methyl alcohol on hydrolysis, and also sugars other than dextrose. Many of these can also be hydrolyzed by ferments, which exhibit characteristic specific actions. The following are some examples of glucosides and their hydrolysis products :-

Glucosides.

Products of Hydrolysis.

Arbutin . . Dextrose + hydroquinone.

Phloridzin . . Dextrose + phloretin.

Strophanthin . . Rhamnose + mannose + strophanthidin.

Amygdalin. . 2 molecules of dextrose + benzaldehyde + hydrocyanic acid.

Helicin . . . Dextrose + salicylaldehyde.

Sinigrin . . Dextrose + allyl mustard oil $+\mathrm{KHSO}_{4}$.

A large number of other glucosides are known.

SumMary. - The carbohydrates may be subdivided into the classes of the monosaccharoses, disaccharoses, and polysaccharoses, the two latter classes being derived from the first-named by condensation of two or more molecules with the withdrawal of the elements of water. Mono- 


\section{Chemical Constituents of the Animal Body. 2 I 9}

saccharoses are known containing two up to nine carbon atoms, and according to the number they are designated bioses, trioses, tetroses, etc. They are either aldoses (aldehydes), or ketoses (ketones), containing hydroxyl groups, and give the ordinary aldehyde and ketone reactions. Of these, the most important are the reducing actions (with Fehling's solution), and the formation with phenylhydrazine of characteristic derivatives known as the osazones. By virtue of the asymmetric carbon atoms, large numbers of stereoisometric forms are known, which in the case of the pentoses and hexoses have been considered in some detail. The methods by means of which the steric relationships of these isomerides to one another can be ascertained have been discussed, and it has been pointed out that differences in the space positions of various groups are of great biological importance. The sugars also form derivatives known as the glucosides, a large number of which are found native. Certain simple glucosides have been obtained synthetically, in which are found characteristic examples of stereoisomerism.

\section{Part III.-The Proteins.}

The chief constituents of animal tissues are nitrogencontaining substances known as the albuminoid substances or proteins. Similar products are also widely distributed in plant tissues. In spite of the fact that they differ very widely from one another in their physical properties, and have in many cases no outward resemblance to one another, these substances belong to a well-defined chemical class. A typical member is the chief protein constituent of the white of egg, albumin, which name was formerly employed to designate all other members of the group. The proteins are chemically characterized by the fact that they yield, on hydrolysis with mineral acids, a mixture of amino-acids. 
The simplest of the amino-acids is known as glycine or aminoacetic acid, the constitution of which is represented by the formula $\mathrm{CH}_{2}\left(\mathrm{NH}_{2}\right) \cdot \mathrm{COOH}$. This substance is therefore acetic acid in which a hydrogen atom is replaced by an amino group. It may be recalled that when acetic acid is treated with chlorine, the hydrogens of the methyl group may be replaced by chlorine, giving rise successively to mono-, di-, and tri-chloracetic acid (see p. 90). When monochloracetic acid is treated with ammonia, the chlorine can be replaced by the amino group-

$\mathrm{CH}_{2} \mathrm{Cl} \cdot \mathrm{COOH}+2 \mathrm{NH}_{3}=\mathrm{CH}_{2}\left(\mathrm{NH}_{2}\right) \cdot \mathrm{COOH}+\mathrm{NH}_{4} \mathrm{Cl}$

Now the group $\left(\mathrm{NH}_{2}\right)$ has basic properties by virtue of which it forms salts such as $\mathrm{CH}_{2} \mathrm{NH}_{2} \cdot \mathrm{COOH}$. Owing to the fact that this amino-radicle is contained in the molecule, glycine only acts as a very weak acid, although it contains a carboxyl group. Nevertheless, it can also form salts of the type $\mathrm{CH}_{2}\left(\mathrm{NH}_{2}\right) \cdot \mathrm{COOM}^{\prime}$ by the replacement of a hydrogen of the carboxyl group by metals. Substances like glycine, containing both acid and basic groups, are known as amphoteric electrolytes (or ampholytes).

In addition to substances like glycine, which contain one amino group and one carboxyl group, proteins yield on hydrolysis amino-acids containing two amino groups and one carboxyl group. In these the basic character predominates over the acid, and they were formerly known as the "hexone bases."

The proteins differ from one another chemically both in the character and the quantity of the various aminoacids which they yield on hydrolysis. The systematic chemical examination and differentiation of the various proteins was only possible after Emil Fischer and his pupils had elaborated a method for separating in an approximately quantitative way the amino-acids derived 


\section{Chemical Constituents of the Animal Body. 22 I}

by the hydrolysis of a given protein. The latter could then be differentiated from other members of the class by the quality and quantity of the amino-acids derived by hydrolysis. In the following list it will be observed that some of the amino-acids are aliphatic derivatives, whereas others are aromatic. Others again contain rings other than the benzene ring, such as the iminazol, the pyrollidine, and the indole rings. It would be extending the limits of this book too far to enter into detail into the chemistry of all the amino-acids. It will be obvious that the substances with the simpler formulæ are just aminoderivatives of the fatty acids, with the amino group in the a position. All the substances in the undermentioned list have been obtained synthetically, and there is no doubt as to their chemical constitution. In addition to those given, other amino-acids have been recently described which have been obtained in small quantities by the hydrolysis of certain proteins. Their production as hydrolysis products has not, however, been in all cases definitely established, and they are omitted from the following list :

HYDROLYSIS PRODUCTS OF PROTEINS.

A. Monoamino-monocarboxylic Acids.

1. Glycine, $a$-aminoacetic acid, $\left(\mathrm{NH}_{2}\right) \mathrm{CH}_{2} \cdot \mathrm{COOH}$

2. Alanine, $a$-aminopropionic acid, $\mathrm{CH}_{3} \cdot \mathrm{CH}\left(\mathrm{NH}_{2}\right) \cdot \mathrm{COOH}$

3. Valine, $a$-aminoisovaleric acid-

$\underset{\mathrm{CH}_{3}}{\mathrm{CH}_{3}}>\mathrm{CH} \cdot \mathrm{CH}\left(\mathrm{NH}_{2}\right) \cdot \mathrm{COOH}$

4. Leucine, a-aminoisocaproic acid-

$\underset{\mathrm{CH}_{3}}{\mathrm{CH}_{3}}>\mathrm{CH} \cdot \mathrm{CH}_{2} \cdot \mathrm{CH}\left(\mathrm{NH}_{2}\right) \cdot \mathrm{COOH}$ 
5. Isoleucine, $\alpha$-amino- $\beta$-methyl- $\beta$-ethylpropionic acid$\mathrm{CH}_{3}>$ $\mathrm{C}_{2} \mathrm{H}_{6}$ $\mathrm{CH} \cdot \mathrm{CH}\left(\mathrm{NH}_{2}\right) \cdot \mathrm{COOH}$

6. Phenylalanine, $\beta$-phenyl-a-aminopropionic acid$\mathrm{C}_{6} \mathrm{H}_{5} \cdot \mathrm{CH}_{2} \cdot \mathrm{CH}\left(\mathrm{NH}_{2}\right) \cdot \mathrm{COOH}$

7. Tyrosine, $\beta-p$ hydroxyphenyl- $\alpha$-aminopropionic acid$\mathrm{OH} \cdot \mathrm{C}_{6} \mathrm{H}_{4} \cdot \mathrm{CH}_{2} \cdot \mathrm{CH}\left(\mathrm{NH}_{2}\right) \cdot \mathrm{COOH}$

8. Serine, $\beta$-hydroxy- $\alpha$-aminopropionic acid$\mathrm{OH} \cdot \mathrm{CH}_{2} \cdot \mathrm{CH}\left(\mathrm{NH}_{2}\right) \cdot \mathrm{COOH}$

9. Cystine, a sulphur derivative of $a$-aminopropionic acid, of the formula-

$\mathrm{HOOC} \cdot \mathrm{CH}\left(\mathrm{NH}_{2}\right) \cdot \mathrm{CH}_{2} \cdot \mathrm{S}-\mathrm{S} \cdot \mathrm{CH}_{2} \cdot \mathrm{CH}\left(\mathrm{NH}_{2}\right) \cdot \mathrm{COOH}$

B. Monoamino-dicarboxylic Acids.

10. Aspartic, or aminosuccinic acid$\mathrm{CH}_{2} \cdot \mathrm{COOH}$ $\mathrm{CH}\left(\mathrm{NH}_{2}\right) \cdot \mathrm{COOH}$

11. Glutamic, or a-aminoglutaric acid$\mathrm{HOOC} \cdot \mathrm{CH}_{2} \cdot \mathrm{CH}_{2} \cdot \mathrm{CH}\left(\mathrm{NH}_{2}\right) \cdot \mathrm{COOH}$

C. Diamino-monocarboxylic Acids.

12. Arginine-

$$
\mathrm{HN}=\mathrm{C}_{\mathrm{NH} \cdot \mathrm{CH}_{2} \cdot \mathrm{CH}_{2} \cdot \mathrm{CH}_{2} \cdot \mathrm{CH}_{2} \cdot \mathrm{CH}\left(\mathrm{NH}_{2}\right) \mathrm{COOH}}^{\mathrm{NH}_{2}}
$$

13. Lysine- $\mathrm{H}_{2} \mathrm{~N} \cdot \mathrm{CH}_{2} \cdot \mathrm{CH}_{2} \cdot \mathrm{CH}_{2} \cdot \mathrm{CH}_{2} \cdot \mathrm{CH}\left(\mathrm{NH}_{2}\right) \cdot \mathrm{COOH}$

D. Heterocyclic Compounds (compounds containing rings other than that of benzene).

14. Histidine, $\beta$-iminazole- $\alpha$-aminopropionic acid- 
Chemical Constituents of the Animal Body. 223

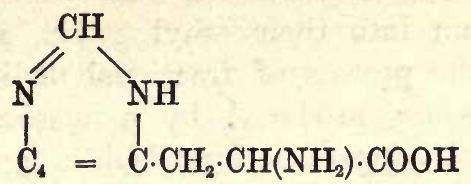

15. Proline, a-pyrollidinecarboxylic acid-

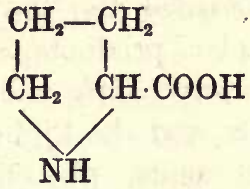

16. Hydroxyproline, a hydroxyl derivative of the above.

17. Tryptophan or $\beta$-indole- $\alpha$-aminopropionic acid-

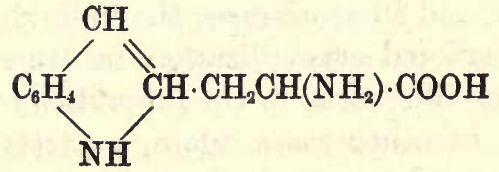

HYDROLYSIS OF PROTEINS AND SEPARATION OF THE AMINO-ACIDS PRODUCED IN THIS OPERATION.

The hydrolysis is generally carried out by means of 25 per cent. sulphuric or hydrochloric acid. The protein is first warmed with about three times its weight of the acid on a water bath, and the reaction is completed over a free flame, the flask in which the operation is carried out being provided with a reflux condenser. When sulphuric is employed, it is removed quantitatively at the completion of the hydrolysis (which usually takes about sixteen hours) by the addition of a theoretically requisite quantity of barium hydroxide. After filtration of the barium sulphate thus precipitated, and concentration of the liquid, the greater part of the tyrosine and cystine separate when these substances are present in sufficient quantity. The separation of the monoamino-acids can be effected by the method due to Emil Fischer. The principle consists in 
converting them into their ethyl esters, and submitting the latter to the process of fractional distillation under a very low pressure produced by a mechanically driven Fleuss pump (the apparatus for which is figured on p. 19), or by means of charcoal soaked in liquid air. A series of fractions is thereby obtained, the lower of which contain the esters of the simpler products, such as glycine and alanine, whereas the intermediate ones contain chiefly the valine and leucine esters, and the highest ones the esters of glutamic and aspartic acids, phenylalanine and serine. The processes for the separation of the mixtures in the various fractions are somewhat complex; the esters are first hydrolyzed, and in some cases the individual acids are separated by fractional crystallization, in others by taking advantage of the differences in the properties of the copper and lead salts; in other cases, again, a partial separation of the esters themselves can be brought about by making use of the differences of their solubilities in organic solvents. For the complete methods and the various modifications proposed of Fischer's original method, reference must be made to more complete text-books. The esters themselves are prepared directly from the crude hydrolysis products. When hydrochloric acid has been employed the hydrolysis mixture is evaporated to a small bulk in vacuo, the syrupy mixture thus obtained is dissolved in alcohol, and the solution thereby produced is saturated with dry hydrochloric acid gas. The alcohol is then evaporated off in vacuo, the residue is redissolved in alcohol, and again saturated with hydrochloric acid. This process is generally repeated twice more. When sulphuric acid has been employed for hydrolysis, the same method of esterification is used after the separation of the sulphuric acid by baryta. By this means the amino-acids are converted into the hydrochlorides of the esters. Glycine 


\section{Chemical Constituents of the Animal Body. 225}

would yield, for example, glycine ethyl ester hydrochloride of the formula $\mathrm{CH}_{2}\left(\mathrm{NH}_{2}\right) \cdot \mathrm{HCl} \cdot \mathrm{COOC}_{2} \mathrm{H}_{5}$. This substance, when glycine is yielded in relatively large quantity by the hydrolysis, usually separates in a crystalline form when the concentrated solution of the ester hydrochlorides in alcohol (obtained after the third or fourth saturation of the alcoholic solution with hydrochloric acid and subsequent concentration) is cooled.* The free esters are then generated from the hydrochlorides by the addition, first of strong caustic soda solutions to the cooled syrup until the excess of hydrochloric acid is neutralized, and then of so much potassium carbonate till a pasty mass is obtained. These operations are carried out in the presence of large quantities of ether and with careful cooling by ice. The hydrochloride is thus decomposed according, in the case of glycine, to the equation-

$2 \mathrm{CH}_{2} \cdot\left(\mathrm{NH}_{2}\right)_{2} \cdot \mathrm{COOC}_{2} \mathrm{H}_{5} \mathrm{HCl}+\mathrm{K}_{2} \mathrm{CO}_{3}$

$$
=\mathrm{CO}_{2}+2 \mathrm{KCl}+2 \mathrm{CH}_{2}\left(\mathrm{NH}_{2}\right) \cdot \mathrm{COOC}_{2} \mathrm{H}_{5}
$$

The free ester as it is formed passes into ethereal solution. The latter is then dried, first by potassium carbonate and then fused sodium sulphate, the ether is distilled off, and the residue is then submitted to fractional distillation under low pressure $(0.5 \mathrm{~mm}$.).

The whole process of the separation of the monoamino-acids requires considerable care and experience, and even then the separation of the various acids is by no means completely quantitative. To obtain satisfactory results, relatively large amounts of the protein under investigation must be available.

* When glutamic acid is present in quantity it separates in the form of its hydrochloride when the hydrolysis mixture (produced by hydrochloric acid) is concentrated for the purpose of esterification. The syrupy liquid is kept for some time in a cold place, and the glutamic acid hydrochloride separates, and is filtered off. The filtrate is then esterified with alcohol and hydrochloric acid in the way described.

$(1,997)$ 
For the estimation of the diamino-acids, arginine, histidine, and lysine, the protein is hydrolyzed with sulphuric acid, which is afterwards quantitatively precipitated with barium hydroxide. The liquid is then acidified with sulphuric acid, and phosphotungstic acid is added. This latter substance possesses the property of precipitating various basic substances, such as alkaloids, which are carried down in the form of phosphotungstates. The precipitate is then decomposed by shaking with barium hydroxide in excess, with the formation of barium phosphotungstate, which is insoluble, and can be filtered off. The excess of baryta in the solution is then removed by carbon dioxide or sulphuric acid added in the exact amount required, and the filtrate from the barium salt, which contains the free diamino-acids, is then concentrated. These are then separated from one another by taking advantage of the facts that arginine can be precipitated as a silver salt in a solution made strongly alkaline with barium hydroxide, histidine can be precipitated as a silver salt in a nearly neutral solution, whereas lysine cannot be precipitated as a silver salt, but is obtained from the mother liquors after the separation of the two other substances, first in the form of its phosphotungstate, which latter is afterwards converted into the picrate. The process, which has been devised by Kossel and his pupils, is a somewhat elaborate one, and has only been outlined above, and gives, with careful work, satisfactory results.

The substance tryptophan, which, from a biological point of view, is very important, is destroyed by hydrolysis with acids. In order to obtain it the protein must be hydrolyzed by a ferment; to estimate the amount set free colorimetric and other methods have been suggested.

In the following table the percentages of the various 
Chemical Constituents of the Animal Body. 227

amino-acids derived from the hydrolysis of certain typical proteins are given :-

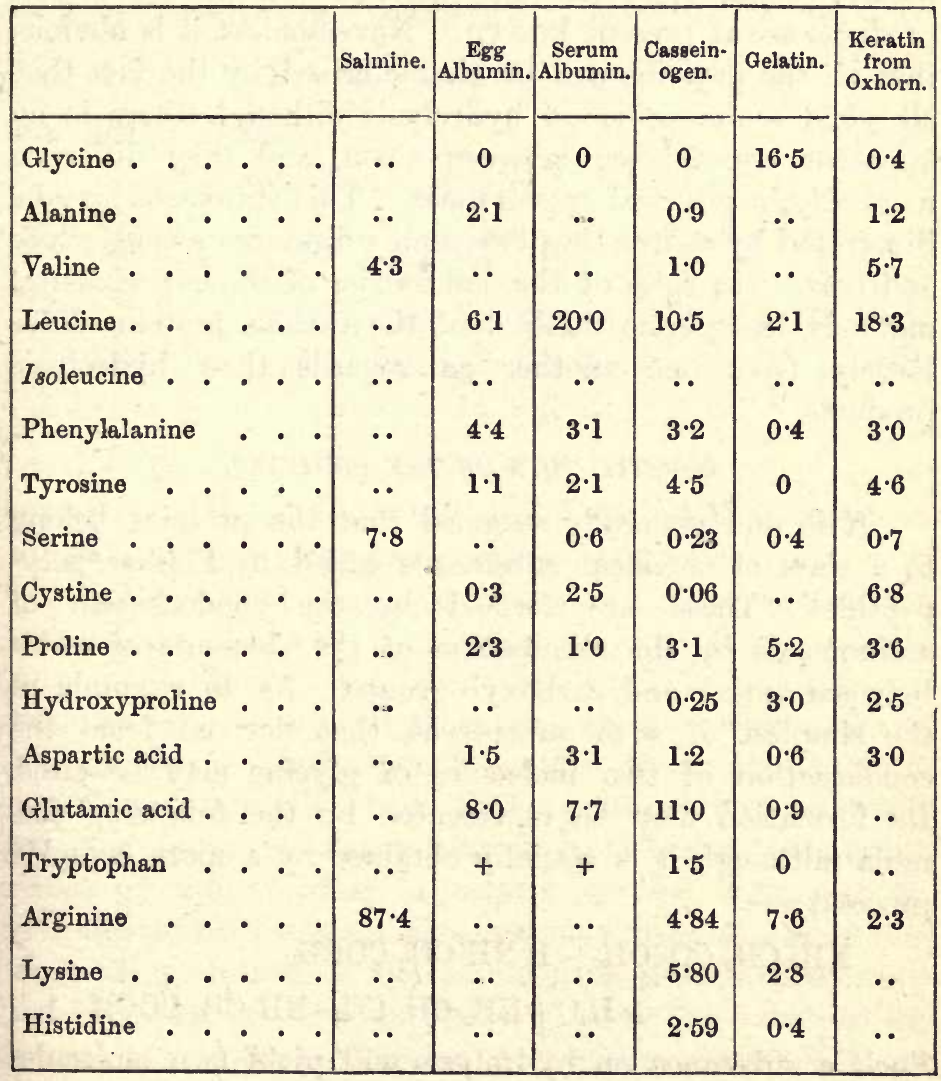

In the above table the complete hydrolysis has not in all cases been carried out. Even, however, where all the known hydrolysis products have been determined, the total often falls far short of 100 per cent. This is due partly to the inherent defects of the quantitative methods, such as 
the necessary losses due to secondary decompositions and the difficulties of separating the individual acids, and partly, probably, to the fact that not all the hydrolysis products are at present known. Nevertheless, it is obvious that all the proteins can be characterized by the fact that all yield amino-acids on hydrolysis, although there is no apparent resemblance between them, and they differ so markedly in physical appearances. This statement may be illustrated by contrasting two such substances as egg-white and horn. In spite of the deficiencies of the experimental methods, there is no doubt that the various proteins differ largely from one another as regards their hydrolysis products.

\section{CONSTITUTION OF THE PROTEINS.}

It is now generally assumed that the proteins belong to a class of chemical substances called by Fischer polypeptides. These are formed by the condensation of amino-acids by the elimination of the elements of water between amino and carboxyl groups. As an example of the simplest of such substances, that derived from the condensation of two molecules of glycine may be cited. Its formation may be represented by the following formula (although it is actually obtained by a more complex process) :

$$
\begin{array}{rl}
\mathrm{NH}_{2} \cdot \mathrm{CH}_{2} \cdot \mathrm{CO} \cdot \mathrm{OH} \quad \mathrm{H} & \mathrm{NH} \cdot \mathrm{CH}_{2} \cdot \mathrm{COOH} \\
=\mathrm{H}_{2} \mathrm{O}+\mathrm{NH}_{2} \cdot \mathrm{CH}_{2} \cdot \mathrm{CO}-\mathrm{NH} \cdot \mathrm{CH}_{2} \cdot \mathrm{COOH}
\end{array}
$$

Such a substance on hydrolysis will yield two molecules of glycine-

$$
\mathrm{NH}_{2} \cdot \mathrm{CH}_{2} \cdot \mathrm{CO} \cdot \mathrm{NH} \cdot \mathrm{CH}_{2} \cdot \mathrm{COOH} \cdot+\mathrm{H}_{2} \mathrm{O}=2 \mathrm{NH}_{2} \cdot \mathrm{CH}_{2} \cdot \mathrm{COOH}
$$

This contains the so-called "peptide" linkage $-\mathrm{NH}-\mathrm{CO}-$. A polypeptide formed by the condensation of two aminoacids is a dipeptide. Glycyl glycine is formed by the 
Chemical Constituents of the Animal Body. 229

condensation of two similar amino-acids, but a dipeptide can also be formed from two different acids. Thus, by the condensation of glycine and alanine, two dipeptides can be formed, namely, glycyl alanine-

\section{$\mathrm{NH}_{2} \cdot \mathrm{CH}_{2} \cdot \mathrm{CO} \cdot \mathrm{NH} \cdot \mathrm{CH}\left(\mathrm{CH}_{3}\right) \cdot \mathrm{COOH}$}

and alanyl glycine-

\section{$\mathrm{NH}_{2} \cdot \mathrm{CH}\left(\mathrm{CH}_{3}\right) \cdot \mathrm{CO} \cdot \mathrm{NH} \cdot \mathrm{CH}_{2} \cdot \mathrm{COOH}$}

Both these products will yield on hydrolysis a mixture of equimolecular proportions of glycine and alanine. By a similar scheme of condensation tri- and poly-peptides can be formed by the condensation of three or more amino-acids. As examples of tripeptides the following may be cited:

Glycyl glycyl glycine-

\section{$\mathrm{NH}_{2} \cdot \mathrm{CH}_{2} \cdot \mathrm{CO} \cdot \mathrm{NH} \cdot \mathrm{CH}_{2} \cdot \mathrm{CO} \cdot \mathrm{NH} \cdot \mathrm{CH}_{2} \cdot \mathrm{COOH}$}

which yields on hydrolysis only glycine.

Leucyl alanyl glycine-

\section{$\mathrm{NH}_{2} \cdot \mathrm{CH}\left(\mathrm{C}_{4} \mathrm{H}_{9}\right) \cdot \mathrm{CO} \cdot \mathrm{NH} \cdot \mathrm{CH}\left(\mathrm{CH}_{3}\right) \cdot \mathrm{CO} \cdot \mathrm{NH} \cdot \mathrm{CH}_{2} \cdot \mathrm{COOH}$}

which yields on hydrolysis a mixture of leucine, alanine, and glycine.* Many complex polypeptides have been prepared synthetically, and those with higher molecular weights have, in many respects, properties not unlike those of the proteins, or certain of the more complex derivatives of the latter, obtained therefrom by the scission of only a portion of the amino-acids from the molecule. Such derivatives are known as proteoses (albumoses) and peptones, and are produced from proteins by partial hydrolysis under the influence of certain ferments. These will be considered in greater detail later. In general, a protein

* The methods of synthesizing polypeptides have been elaborated by Emil Fischer and his pupils. They are described in detail in his monograph on the subject, and also by R. H. A. Plimmer in one of a series of biochemical monographs. (Longmans.) 
is essentially a polypeptide, which may be represented by the formula-

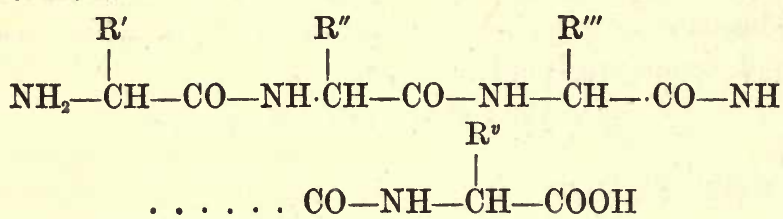

A substance of this character would yield on hydrolysis a mixture of amino-acids. Whether groups other than amino-acids are essential to the constitution of proteins cannot yet be definitely decided, as in most cases the total amount of these acids obtainable by hydrolysis will only account for a fraction (though generally a large fraction) of the whole molecule.

\section{CLASSIFICATION OF THE PROTEINS.}

No exact classification of proteins based on essential chemical differences is yet possible. The provisional system adopted is based partly on physical differences, partly on the biological origins, and, to a small extent only, on the chemical characters. The proteins are divided into the following classes:-

\section{The Simple Proteins.}

(a) The Protamines.-This group of proteins has a very limited distribution, and is found only in the spermatozoa of certain fish. The members of the class are interesting from a chemical standpoint, in that they yield on hydrolysis chiefly diamino-acids. They are therefore strongly basic in character, containing a large number of amino groups, and as much as 32 per cent. of nitrogen.

(b) The Histones. - These are somewhat similar to the protamines, but they yield a smaller percentage of diamino- 


\section{Chemical Constituents of the Animal Body. $23^{1}$}

acids on hydrolysis and contain less nitrogen (18-19 per cent.). They also have a somewhat limited distribution, and are found in certain fish-roes and globin, the protein derived from hæmoglobin; the red pigment of blood is also generally considered as a protein (see below).

(c) The Albumins.-These are proteins soluble in water and less basic than the histones, yielding a smaller percentage of diamino-acids on hydrolysis and containing only about 15 per cent. of nitrogen. They are found largely in animal tissues, the albumins of egg-white and blood-serum being typical examples. They are not precipitated from solution by magnesium sulphate, but are precipitated by saturating their aqueous solutions with ammonium sulphate.

(d) The Globulins.-Proteins of this class are widely distributed in both the animal and the vegetable world. They are insoluble in water, but soluble in salt solutions of somewhat low dilutions, from which they can be precipitated by saturation with magnesium sulphate or halfsaturation with ammonium sulphate. As examples of globulins may be cited the globulins from blood-serum and edestin, a vegetable protein from hemp seed. These two examples may, perhaps, illustrate the artificial character of the classification of the proteins adopted, as, apart from their solubility in salt solutions and insolubility in pure water, the two substances have little in common.

(e) The Alcohol Soluble Proteins or Prolamines.Only a very few members of this class are known, but gliadin, the chief constituent of wheat gluten, is an important protein. This substance is insoluble in water and absolute alcohol, but is readily soluble in a mixture of the two fluids. The best solvent is $70-80$ per cent. alcohol. It is characterized by the large amount of ammonia it yields on hydrolysis (or amide nitrogen, see 
p. 242), and on the relatively large amounts of proline and glutamic acid.

( $f$ ) The Glutenins.-Only two proteins of this class have been described; they are glutenin from wheat and oryzenin from rice. They are insoluble in water, dilute alcohol, and salt solutions, but soluble in dilute alkalis, from which solution they can be precipitated by acids.

(g) The Sclero-proteins.-This group includes a miscellaneous class of substances, which are derived chiefly from the supporting and connective tissues of animals (whence the name). The chief examples of the group are hair, horn, gelatin, and keratin. Certain of them, such as hair and horn, are characterized by the large amount of cystine which they yield on hydrolysis, and, therefore, also by the relatively large amount of sulphur which they contain.

\section{The Conjugated Proteins.}

(a) The Nucleo-proteins.-These proteins are widely distributed in nature. They were originally discovered in fish spermatozoa, which consist chiefly of nuclei, and for this reason they have been supposed to form an important constituent of nuclei generally. They are also found in the plant world, and the so-called tritico-nucleic acid, from the wheat nucleo-protein, has been carefully investigated. The nucleo-proteins contain the protein group in some form of combination with nucleic acid.

(b) The Glyco-proteins.-This class, which includes animal mucins and mucoid substances, has not been fully investigated. The glyco-proteins are said to yield on hydrolysis carbohydrate-like substances, amongst which glucosamine, an amino-derivative of dextrose, has been described. Cartilage is included amongst the glyco-proteins, and yields on treatment with acids a peculiar substance known as chondroitin-sulphuric acid. 
Chemical Constituents of the Animal Body. 233

(c) The Phospho-proteins. - The two chief members of this class are caseinogen, the protein of milk and vitellin from eggs. These are characterized by the fact that on treatment with 1 per cent. sodium hydroxide at $37^{\circ}$ they undergo partial hydrolysis with scission from the molecule of phosphoric acid. They are possibly protein derivatives of this acid.

(d) The hcemoglobins, which undergo scission on treatment with dilute acids into a chromatogenic group (hæmin) and a protein (globin).

\section{Derived Proteins.}

(a) The Meta-proteins.-On treating proteins with dilute acid or alkali, they undergo change into acid albumin or alkali albumin, which are soluble in excess of alkali or acid. The protein undergoes relatively little chemical change when converted into acid or alkali albumin, both of which substances are included amongst the metaproteins.

(b) The Proteoses.

(c) The Peptones. - When proteins are partially hydrolyzed with ferments, or submitted to gentle hydrolysis with acids, products can be obtained in which complete scission of all the peptide linkages has not taken place. Substances which are still polypeptides, but which are not so complex as the original proteins (that is, do not yield so many amino-acids on hydrolysis and have a smaller molecular weight), can be obtained. The proteoses (formerly called albumoses) and peptones are substances of this description; the former can be precipitated from aqueous solutions when they are saturated with zinc or ammonium sulphate, whereas the latter cannot. The aminoacids, peptones, proteoses, and proteins bear more or less the same kind of relationship to one another as do glucose, 
the dextrins, and starch. In the former case the aminoacids represent the final stages of hydrolysis as in the latter dextrose does; proteoses, peptones, and the dextrins are intermediary degradation products. (Compare p. 215.)

\section{PREPARATION OF THE SIMPLE PROTEINS.}

As the proteins possess such varied physical properties, the methods of isolating them from their natural sources are very diverse.

Some, such as the albumins, are soluble in water, and exist in aqueous solution in various body tissues and fluids. They are substances of large molecular weight, and belong to the class called by Graham colloids, which are incapable of passing the pores of vegetable parchment owing to the large size of their molecules. By submitting the solutions to dialysis - that is, putting them in a membrane of parchment or collodion or other suitable membrane, and surrounding the membrane with pure waterthey can be freed from the presence of "crystalloids," or simpler substances, which will pass the membrane. The simpler substances pass the membrane into the distilled water, and distribute themselves nearly equally between the outside liquid and the liquid contained in the dialysor. The water outside the latter is repeatedly renewed until practically all the crystalloids have been dialyzed away. Albumins and globulins can be precipitated from aqueous solutions by the addition of various inorganic salts; those principally employed for this purpose are ammonium sulphate, magnesium sulphate, and zinc sulphate. The exact mechanism of the precipitation of complex colloidal substances from aqueous solutions by salts has not yet been satisfactorily explained. It is probably due to an alteration in the distribution of the water between the colloidal particles and the salts. When the proteins have been 


\section{Chemical Constituents of the Animal Body. 235}

precipitated by salts, they are washed with salt solution of the same concentration as that of the solution in which they have been precipitated, and then freed from the salt by dialysis. From the aqueous solution thus obtained, they can be prepared either by evaporating off the water at a temperature not exceeding $40^{\circ}$ or by the addition of alcohol or acetone, in which liquids they are insoluble. They are then washed with aqueous alcohol, then with more concentrated aqueous alcohol, then with absolute alcohol and ether, and finally dried in vacuo. They should not be allowed to remain too long in presence of alcohol, as they are apt to undergo change which renders them insoluble in water.

The globulins are found in some animal fluids, such as blood-serum, and are held in solution owing to the presence of the salts which these fluids contain. When the solutions are submitted to dialysis, or diluted sufficiently, these globulins are precipitated. When dilution is used as a means of precipitation, the process is facilitated by slight acidification of the liquid with weak acids (such as acetic or carbonic acids).

In the case of the vegetable globulins, which occur in many seeds, such as hemp seed, various beans, etc., the finely ground dry material is first extracted with ether or light petroleum to separate the fats. The fat-free powder is then treated with saline solution. In the case of hemp seed, the protein, known as edestin, can be obtained in a crystalline form. To prepare the protein in this state, the fat-free powder is extracted with saline solution (usually 6 per cent.) warmed to $60^{\circ}$; the warm solution is then diluted with water, also warmed to $60^{\circ}$, and the mixture allowed to cool. Other plant products yield crystalline proteins, which are prepared in a similar manner. The chief prolamine, the gliadin of 
wheat, is obtained by extraction of wheat gluten-that is, wheat flour freed from starch by lixiviation with water with 70 per cent. alcohol. From the solution in this solvent, the protein can be precipitated by addition of absolute alcohol. It separates as a thick glutinous mass, which solidifies on repeated trituration with absolute alcohol; the powder is then rapidly washed with absolute alcohol and ether and dried in vacuo. After the separation of the gliadin from wheat gluten a residue remains, from which the glutenin can be extracted by very weak solutions of caustic alkalis; from this solution it can be precipitated by neutralization with acids; too much acid must not be added, as the protein is soluble in excess.

The sclero-proteins, such as hair, horn, silk, etc., are, as a rule, insoluble in any solvents. They are usually prepared by separating all the other constituents of the tissues. Thus the fats can be extracted by organic solvents. Gelatin and collagen are usually included amongst the sclero-proteins. These are extracted from bones. The conjugated and derived proteins will be considered later. -

\section{GENERAL PROPERTIES OF THE PROTEINS.}

Owing to the fact that they are very complex chemical substances which cannot, except in very few cases, be obtained in crystalline form, and do not melt or boil without decomposition, the criteria of purity which are available in the case of the simpler organic compounds are wanting in the case of the proteins. It is consequently often difficult to determine always whether a given product is a pure chemical entity. As a class, however, they can be recognized with tolerable facility. The following are some of the chief reactions:-

(1) As they contain nitrogen, the proteins evolve ammonia when heated with soda-lime. They also contain 


\section{Chemical Constituents of the Animal Body. 237}

sulphur, which may be detected by boiling the substance with a strong solution of sodium hydroxide and then adding a few drops of lead acetate solution, when a black precipitate is produced.

(2) Nearly all the proteins are lævo-rotatory.

(3) The solutions of most (but not all) proteins when heated in solutions made faintly acid with weak acids (acetic or butyric) undergo a change-the protein separates out in an insoluble form known as a "coagulum," and the protein is said to be coagulated. The best known example is the coagulation of white of egg. The protein, on coagulation, is now known to undergo a definite chemical change, the exact nature of which has not yet been elucidated. The degradation products of proteins such as the albumoses and peptones (see p. 258) do not undergo this change. By means of coagulation it is possible to separate the proteins (although in a changed form) from other substances in solution. The coagulation of proteins is an irreversible process - that is, the coagulum does not redissolve when the heated solution is cooled. The coagulative change does not readily take place in the absence of water-that is, when the dry protein is heated alone. On account of the coagulative change it is inadvisable to heat protein solutions above $40^{\circ}$ when the "natural" protein is required. A protein changed by heat is stated to be "denaturated."

(4) Proteins are precipitated from solutions by strong acids. If strong nitric acid is allowed to flow into a testtube containing a protein solution, a white ring forms at the junction of the liquids. (Heller's test.)

(5) Proteins are nearly all precipitated by the following reagents-ferrocyanic acid (potassium ferrocyanide and acetic acid), trichloracetic acid, sulphonyl salicylic acid, and uranyl acetate. They are also precipitated by 
the salts of heavy metals. The composition of the precipitate will, in the last-named case, vary with the relative amounts of heavy metal and protein in solution, and the phenomenon is a somewhat complex one, which need not be discussed in detail here.

(6) Proteins are precipitated by the reagents which are used for precipitation of the more complex basic substances, known as the alkaloids (p. 226). The chief are phosphotungstic and phosphomolybdic acid, potassium. mercuric iodide and potassium-bismuth iodide, tannic acid and picric acid. The last-named is often used in a solution containing 1 per cent. picric and 1 per cent. citric acids, known generally as Esbach's reagent.

(7) A very important property of the proteins is that they can be precipitated, as already mentioned, from aqueous solutions by certain salts other than those of the heavy metals. This precipitation is, unlike coagulation, a reversible process-that is, the precipitate produced will redissolve in salt-free water, or, in the case of globulins, in water containing a relatively small amount of salt. The salts generally employed for protein precipitation are sodium chloride, and the sulphates of ammonium, magnesium, and zinc. The degrees of saturation by a given salt, in which precipitation for any given protein (and certain derivatives of proteins such as proteoses) begins and is completed, is characteristic for each individual member of the class. As already stated, a globulin, such as serum globulin, can be precipitated from solution when the latter is saturated with magnesium sulphate. If an albumin is present at the same time, this, for the most part, remains in solution, and a partial separation of the two proteins can be accomplished.*

* It cannot be pretended that a complete separation of proteins, when they exist together in solution, can be accomplished in this way. The globulin precipitate would carry down with it a certain amount of the albumin. 
Again, a globulin is precipitated from its aqueous solution when sufficient ammonium sulphate is present to half-saturate it, whereas an albumin is precipitated only from the completely saturated solution. The degrees of saturation in which precipitation begins and ends will vary slightly with the concentration of the protein. By taking a standard concentration-for example, 1 or 2 per cent.-it is possible to compare the precipitation limits of two proteins; such limits serve to characterize the protein. This determination may be carried out in the following manner:-Into a series of test-tubes 2 c.c. of a protein solution are diluted to 10 c.c. with varying amounts of saturated salt solution and water. The filtrates from the precipitate are then tested with one or two drops of the saturated salt solution. The lowest dilution of salt to cause precipitation, and the lowest dilution the filtrate from which gives no precipitate on further addition of salt, are noted. These two dilutions give the precipitation limits for any given salt. The salt precipitation of proteins has been discussed in some detail, as this process, imperfect as it is, affords the only means of separating two proteins which exist together in one solution, as fractional crystallization or distillation is in this case quite inapplicable.

\section{COLOUR REACTIONS OF THE PROTEINS.}

The various colour reactions are not yielded by all proteins. They are due to certain groups contained in the molecule.

(1) Nitric acid (sp. gr. 1·2-1.25) imparts a bright yellow colour to solid proteins; the same colour is produced when solutions of proteins are boiled for some time with strong acids. The reaction, known as the "xanthoproteic" reaction, is probably due to the presence of a 
benzene nucleus in the protein molecule. With gelatin, the xanthoproteic acid is either absent or very faint. This protein yields very small amounts of aromatic derivatives on hydrolysis.

(2) "Millon's reagent" gives with proteins a white precipitate which turns red on boiling, and produces a coloration in the supernatant fluid. This reaction is also said to be due to the presence of an aromatic group in the molecule. The reagent is prepared by dissolving mercury in an equal weight of nitric acid (sp. gr. 1.4) by the aid of gentle heat, and then diluting the solution with twice the volume of cold water. The liquid thus obtained contains mercurous nitrate and nitrous acid.

(3) An important reaction is that produced when a few drops of very dilute copper sulphate solution are added to protein solutions. A precipitate is produced which dissolves on the addition of excess of potassium or sodium hydroxide. If the mixture is then warmed, a fine violet coloration is generally produced. Certain derivatives of proteins, such as the proteoses, produce under similar circumstances a rose-red colour. This reaction is known as the "biuret reaction." It is probably connected with the presence of peptide linkages in the molecule, and is also yielded by substances other than proteins.

(4) Certain colour reactions are ascribed to the presence of tryptophan in the molecule, and are only yielded by such proteins from which this substance can be obtained by hydrolysis with ferments. The chief tryptophan reaction is due to Adankiewicz, and called by his name. It was originally carried out in the following manner:The solution of a protein (which yields tryptophan on hydrolysis) is treated with an equal volume of concentrated sulphuric acid, and twice the volume of glacial acetic acid; a reddish-violet colour is thereby produced. It was sub- 


\section{Chemical Constituents of the Animal Body. 24I}

sequently shown by Hopkins and Cole that a positive result is only obtained when the acetic acid contains glyoxylic acid, which it does if the former acid has been exposed to air in the presence of sunlight. The latter acid is now substituted for the former when carrying out the test. A solution of this is prepared by treating 250 c.c. of a concentrated solution of oxalic acid with 10 grammes of magnesium powder. The solution is then filtered, slightly acidified with acetic acid, and then diluted to 1 litre. A few drops of this are added to the protein solution, and then concentrated sulphuric acid is carefully poured in; if tryptophan is present a violet colour develops. There are, in addition, various other reactions for tryptophan.

(5) A substance, discovered by Ruhemann, known as triketohydrindene hydrate, yields, on boiling with neutral solutions of proteins and amino-acids, a blue colour. This is known now as the "ninhydrin" reaction, and has been largely used in recent years for certain clinical tests. Various other colour reactions for proteins have been described, but these mentioned are, perbaps, more often employed than any of the others.

\section{METHODS FOR THE IDENTIFICATION OF INDIVIDUAL}

\section{PROTEINS.}

As already stated, the proteins differ from one another in the quality and quantity of their hydrolysis products. The complete quantitative estimation of the monoaminoacids is a complicated process requiring relatively large amounts of material, and even when carried out with great care and expenditure of time, it yields only approximately correct results. The estimation of the diamino-acids by the method indicated (p. 226) is simpler and more satisfactory; even this, however, is too cumbersome as a routine 
process to be employed for characterization of proteins obtained in the course of biological research. Of the physical constants for the identification of individual proteins, the solubilities in various solvents, the precipitability by salts from aqueous solution, which has been already discussed in detail (p. 238), and the optical rotation and refractive index of the solutions, may also be employed. Far more certain than the physical are certain chemical constants which can be determined with relatively little trouble. These are the following:-

(1) The Empirical Composition and the Sulphur Content.-With the exception of the basic protamines, which yield large amounts of diamino-acids on hydrolysis, and the histones, which also contain relatively large amounts of nitrogen, and are also somewhat basic, though less so than the protamines, there is not, as a rule, much difference between the proteins as regards their carbon, hydrogen, nitrogen, and oxygen content. The determination of the composition of a protein by means of the ordinary combustion methods is, therefore, of little value for their characterization, and for distinguishing between proteins of different origins. - Proteins yield, however, as one of their hydrolysis products, cystine, which contains sulphur; and as the amount of this element in a given substance is determined very easily, and as there are wide variations in the quantity of cystine which is yielded by the hydrolysis of the different proteins, the sulphur estimation affords a valuable method for characterization. The amount of sulphur varies from less than 0.5 up to 5 per cent. in the different proteins, the higher value being found in the case of hair, which yields a large amount of cystine on hydrolysis.

(2) The Nitrogen Distribution in the Hydrolysis Products. The "Haussmann Numbers."-The hydrolysis 


\section{Chemical Constituents of the Animal Body. 243}

products of the proteins consist chiefly of mono- and diamino-acids. As already stated, the latter, by virtue of the fact that they contain two amino groups, have a basic character, and can therefore be precipitated by certain reagents generally employed for separation of alkaloids from solution. It is, therefore, possible to separate the monoamino from the diamino hydrolysis products. Most proteins also yield when hydrolyzed, in addition to these acids, a certain amount of ammonia. This is supposed to be derived from acid amide groups existing in the molecule. Some of the plant proteins, such as gliadin, yield on hydrolysis a large amount of glutamic acid. This contains only one amino group, but two carboxyl groups. Its characters are, therefore, predominatingly acid. Nevertheless, gliadin itself is not markedly acid in character, although it yields so much glutamic acid when hydrolyzed. It is noteworthy, however, that it also yields relatively large amounts of ammonia. It is not unreasonable to assume, then, that the carboxyl groups of glutamic acid which are not condensed in the peptide linkings with an amino group exist condensed with ammonia in the form of acid amide. On hydrolysis the acid amide group would undergo scission to yield ammonia.

Furthermore, when proteins are hydrolyzed with acids there is nearly always formed a small amount of darkcoloured insoluble residue, generally known as "humin" substance. The nitrogen of the hydrolysis products can be distributed, therefore, amongst four groups namely, the humin substances, the ammonia, the monoamino-acids, and the diamino-acids. The nitrogen in these groups is known respectively as " humin nitrogen," " amide nitrogen," "monoamino nitrogen," and "diamino nitrogen." The percentages of the total protein nitrogen contained in these four groups are known as the "Haussmann numbers." 
They are very easily determined. A weighed amount of a protein is hydrolyzed with acid. On completion of hydrolysis the humin substance is filtered off. The mother liquor, after evaporation to a small bulk, is made alkaline with magnesium oxide, and the ammonia set free is then distilled off in vacuo into an excess of standard acid, and estimated by titration. The residue in the distillation flask is then acidified, and phosphotungstic acid is then added; this precipitates the diamino-acids. The nitrogen is determined in the humin and phosphotungstic acid precipitate, the nitrogen of the ammonia is determined, as already mentioned, by titration, whereas the monoamino nitrogen is ascertained by difference, by determining the total nitrogen in the protein, and subtracting the amount of "humin," "amide," and "diamino " nitrogen. All nitrogen estimations are made by Kjeldahl's method.

The following are some examples of the Haussmann numbers :

\begin{tabular}{|c|c|c|c|c|c|}
\hline Protein. & Total N. & $\underset{\mathrm{N} .}{\text { Amide }}$ & $\begin{array}{l}\text { Mono- } \\
\text { amino N. }\end{array}$ & $\begin{array}{c}\text { Diamino } \\
\text { N. }\end{array}$ & $\underset{N .}{H u m i n}$ \\
\hline Egg-albumin & $\begin{array}{c}\text { Per cent. } \\
15.51\end{array}$ & $\begin{array}{c}\text { Per cent. } \\
8.64\end{array}$ & $\begin{array}{l}\text { Per cent. } \\
68 \cdot 13\end{array}$ & $\begin{array}{c}\text { Per cent. } \\
21.27\end{array}$ & $\begin{array}{c}\text { Per cent. } \\
1.87\end{array}$ \\
\hline Caseinogen . & $15 \cdot 62$ & $10 \cdot 36$ & $66 \cdot 00$ & $22 \cdot 34$ & 1.34 \\
\hline Salmine. & & 0 & & $87 \cdot 8$ & \\
\hline Edestin & $18 \cdot 64$ & $10 \cdot 08$ & $57 \cdot 83$ & $31 \cdot 70$ & 0.64 \\
\hline Glutenin. & $17 \cdot 49$ & 18 & $68 \cdot 31$ & $11 \cdot 72$ & $1 \cdot 08$ \\
\hline Gliadin . & $17 \cdot 66$ & $23 \cdot 78$ & $70 \cdot 27$ & $5 \cdot 54$ & 0.79 \\
\hline Gelatin . & .... & $1 \cdot 61$ & $62 \cdot 56$ & & \\
\hline
\end{tabular}

By carrying out the determination of the Haussmann numbers on two proteins of different origin it is possible to gain some idea as to whether they are identical or not. 


\section{Chemical Constituents of the Animal Body. 245}

(3) The Distribution of the Diamino Nitrogen between Arginine, Histidine, and Lysine, and the Indirect Determination of these Hydrolysis Products. - It has recently been shown that the amount of the three diamino-acids present in the phosphotungstic acid precipitate can be determined. It may be recalled that when a substance containing an amino group is treated with nitrous acid nitrogen is evolved, and the amino group is replaced by the hydroxyl group. Glycine, for example, will react with nitrous acid according to the equation-

$\mathrm{NH}_{2} \cdot \mathrm{CH}_{2} \cdot \mathrm{CO} \cdot \mathrm{OH}+\mathrm{HO} \cdot \mathrm{NO}=\mathrm{N}_{2}+2 \mathrm{H}_{2} \mathrm{O}+\mathrm{OH} \cdot \mathrm{CH}_{2} \cdot \mathrm{CO} \cdot \mathrm{OH}$

One-half the nitrogen evolved will come from the amino group, and the other half from the nitrous acid. This reaction is characteristic of the amino group only. Now, if reference is made to the formulæ of the diamino-acids (p. 222), it will be seen that all the lysine nitrogen is in the form of amino-nitrogen, whereas only one-third is in histidine. In arginine only one-fourth of the nitrogen is evolved on treatment of this substance with nitrous acid. If, now, the percentage of the total nitrogen contained in the phosphotungstic acid precipitate is ascertained, and the amount of this evolved when the diamino-acids therefrom are treated with nitrous acid, then, if $D=$ the amount of nitrogen which does not act as amino-nitrogen (that is, difference between the total and amino-nitrogen), and if $\operatorname{Arg}=$ arginine nitrogen, then the histidine nitrogen = $\frac{3}{2}$ (D- $\left.\frac{3}{4} \mathrm{Arg}\right)$. Now the arginine nitrogen can be determined directly, for arginine is the only one of the three diamino-acids from which ammonia is evolved when the substance is treated with potassium hydroxide. Under this treatment arginine decomposes into a base called ornithine and ammonia, according to the following equation:-

$$
\mathrm{C}_{6} \mathrm{H}_{14} \mathrm{O}_{2} \mathrm{~N}_{4}+2 \mathrm{H}_{2} \mathrm{O}=\mathrm{C}_{6} \mathrm{H}_{12} \mathrm{O}_{2} \mathrm{~N}_{2} \text { (ornithine) }+2 \mathrm{NH}_{3}+\mathrm{CO}_{8}
$$


In estimating the relative amounts of the three diaminoacids they are separated as phosphotungstates, nearly in the same way as in the process for the determination of the Haussmann numbers. In fact, the latter are determined by employment of the same sample of material used for the estimation of the individual diamino-acids. The diamino-acids are set free from the phosphotungstates by means of baryta. In an aliquot portion of the liquid the total nitrogen is datermined (diamino-acid nitrogen), in another portion the auino-nitrogen which reacts with nitrous acid, and in a third portion the arginine is estimated by determining the amount of ammonia evolved when the liquid is treated with potassium hydroxide under certain standard conditions. The relative amounts of arginine, histidine, and lysine can then be readily calculated from the data given above. The crux of this valuable method, which is due to Donald van Slyke, lies in the invention of an apparatus for the estimation of the nitrogen evolved when the solutions of the substances containing an amino group are treated with nitrous acid. This is devised in such a way that nitrous acid is first generated in a vessel by treatment of sodium nitrate with glacial acetic acid, which is shaken until all the air is driven out. A solution of the substance under examination is then run in, and the mixture is well shaken with the excess of nitrous acid in the flask. Nitrogen, mixed with nitric oxide, is evolved, and is collected in a gas burette. The mixture of gases is then passed through "Hempel" bulbs containing an alkaline solution of potassium permanganate, which absorbs the nitric oxide, and the gas is then withdrawn back again into the burette, and the volume of the nitrogen is noted.*

* This apparatus has been largely employed lately in investigations on proteins and their digestion products. It is described in the Berichte der deutschen chemischen Gesellschaft, 1910, 43, 3170, and also in (in English) Allen's 
(4) The Estimation of Some Individual Hydrolysis Products.-Tyrosine and tryptophan are readily split off from certain proteins under the influence of digestive ferments, such as trypsin. Methods have been proposed for the estimation of the amounts of these substances set free in this manner, the amount of tyrosine being determined by titration with bromine, with which it forms a definite compound, whilst the amount of tryptophan can be estimated by colorimetric methods.

(5) The Biological Differentiation of Proteins.-If a protein is repeatedly injected into an animal, such as a rabbit or a dog, the serum of that animal acquires the property of forming a precipitate with the injected protein. The latter is called the "antigen," whilst the precipitate is designated a "precipitin," and the serum of the treated animal an "anti-serum." The anti-serum produced by injecting an antigen from one species will produce, as a rule, a precipitate with all proteins from that species, but not with proteins from other species, unless they are very closely allied. Thus, by injecting a protein from the human body into a rabbit an anti-serum will be produced which will form a precipitin with human but not with ox-serum. It will, however, produce a slight precipitate with the serum of an anthropoid ape. Other analogous biological reactions are known, but no satisfactory explanation of their chemical or physical mechanism has as yet been offered.

\section{THE BIOLOGICAL IMPORTANCE OF THE CHEMICAL}

\section{INVESTIGATION OF PROTEINS.}

In view of the fact that the proteins form the main constituent of animal tissues, and are essential constituents "Commercial Organic Analysis," fourth edition, vol. vii., p. 263, and vol. viii., p. 487. The apparatus has been much improved in various details (such as mechanical methods for shaking), and is supplied in the newest forms by various manufacturers of apparatus. 
of diet, the chemical examination of proteins forms a subject of supreme biological importance, to which much attention has been devoted in recent years. A few examples will suffice to illustrate this statement. It has been long known that when gelatin is the sole protein administered to an animal as food, "nitrogenous equilibrium" cannot be maintained. This means that the nitrogenous food supplied will not maintain the body weight of the animal, which has consequently to draw upon the protein of its tissues to maintain its condition. Under these circumstances, more nitrogen is excreted by the animal than is ingested. Now it is known that the hydrolysis products of gelatin are deficient in certain aromatic constituents, and it is probable that the protein should yield these on hydrolysis in order that it may serve as completely satisfactory nitrogenous foodstuff. Again, it has also been shown that mice cannot be maintained in nitrogenous equilibrium when the sole source of nitrogenous food is zein, the protein derived from maize. It is known that tryptophan is not yielded by this protein on hydrolysis, and this result indicates that a protein to form a completely satisfactory foodstuff should yield some of this amino-acid on hydrolysis. Furthermore, proteins differ very markedly in their behaviour towards the various proteoclastic ferments. The significance of this statement will be made more obvious in the subsequent discussion on ferment action.

\section{Part III. (A). - The Conjugated Proteins.}

\section{THE NUCLEO-PROTEINS.}

These substances are widely distributed in the cells of the nucleus, of which they are said to form an important constituent. The amount of nucleo-protein present in any 


\section{Chemical Constituents of the Animal Body. 249}

given tissue is, however, small. The tissues which have been chiefly employed for their preparation are the ripe spermatozoa of fish, the thymus gland, testicular substance, and yeast cells.

Nucleo-proteins were first investigated in some detail by Miescher, who isolated them from the spermatozoa of fish. As these cells consist to a large extent of nucleus, and as, furthermore, they yield a large amount of nucleoprotein, the conclusion was drawn that nucleo-proteins are the chief constituent of the nucleus. It was found that the matured testicle of salmon and other fish contained a very basic protein, belonging to the class of protamines, combined with a moderately strong acid which contains phosphorus as an essential constituent, which was called nucleic acid. On extracting the disintegrated spermatozoa with solutions of mineral acids, the protamine is separated from the nucleic acid and converted into a salt of the mineral acid, which can be precipitated from the aqueous solution by the addition of alcohol.

The general method of preparing nucleo-proteins consists in extracting the tissues with either water or dilute alkali and precipitating the nucleo-protein by very dilute acid. The tissue, before extraction, is generally treated with alcohol which withdraws the water and extracts the fats. A product is thereby obtained which can be ground into a powder.

The nucleo-proteins from fish spermatozoa contain, as already stated, the basic protein prolamine combined with nucleic acid. Other nucleo-proteins are formed by the combination of nucleic acid with less basic proteins. On treatment with pepsin the protein part of the molecule is partially hydrolyzed, and a residue, known as a nuclein, is obtained, which contains the nucleic acid in combination with the degraded protein residue.

Nucleic Acid.-The most essential part of the nucleo- 
protein molecule is nucleic acid. This product can, as a rule, be isolated in a purer condition than the nucleoprotein from which it is derived. The substance itself is relatively stable towards alkalis, although it is readily decomposed by acids. It is a product of great biological significance, and as it is found invariably combined with proteins its chemical nature is best discussed in this place.

Various methods for the preparation of nucleic acid have been employed. The method originally suggested by Neumann is that generally adopted, and consists in extracting tissues with hot solutions of sodium hydroxide which contains sodium acetate. The extract is then neutralized with acetic acid and thrown into a large amount of alcohol, when the nucleic acid is precipitated in the form of its sodium salt.*

Nucleic acid is readily hydrolyzed by acids, and yields the following products: (1) The alloxuric bases, guanine, adenine, xanthine, and hypoxanthine; $(2)$ the pyrimidine substances, cytosine, uracil, and thymine; (3) carbohydrates, or derivatives produced from those substances by the action of acids, such as formic and lævulinic acids; (4) phosphoric acid.

According to the more recent investigations of Levene, Jacobs, and their collaborators, nucleic acid is built up by the condensation of a number of complexes called "nucleotides," which are formed by the condensation of phosphoric acid with a carbohydrate and a base such as guanine. Nucleic acid is, accordingly, a "polynucleotide." From the nucleotides, furthermore, phosphoric acid can be split off, leaving a residue consisting of a sugar combined with an alloxuric or pyrimidine group, and known as a nucleo-

* The plant nucleic acids appear to be much less stable towards alkalis and more stable towards acids than do the animal nucleic acids. A method for their preparation has been recently elaborater by Clarke and Schryver. 


\section{Chemical Constituents of the Animal Body. 251}

side. According to Levene and Jacobs the nucleic acid from thymus gland is a tetranucleotide produced by the condensation of four nucleotides, each of which is a complex of a sugar group, phosphoric acid, and a nitrogenous substance (either an alloxuric or pyrimidine base). The following seemingly complex formula has been assigned to it :-

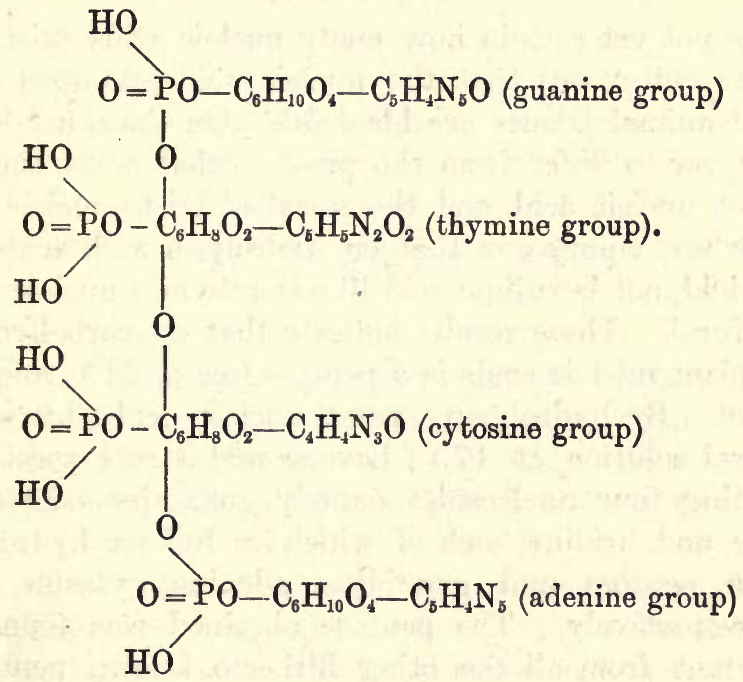

It is easy to see that by drastic hydrolysis such a substance can be converted into phosphoric acid, $\mathrm{H}_{3} \mathrm{PO}_{4}$, a hexose, $\mathrm{C}_{6} \mathrm{H}_{12} \mathrm{O}_{6}$, and four different nitrogenous substances, namely, guanine, thymine, cytosine, and adenine. By less drastic methods of hydrolysis nucleotides can be obtained - the thymine nucleotide, for example, which has been actually isolated in a pure state, and has the formula-

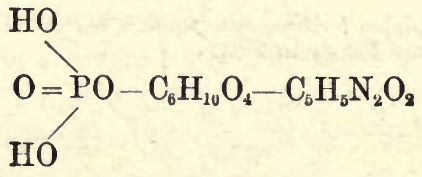


On complete hydrolysis this nucleotide undergoes scission into phosphoric acid, thymine, and lævulinic acid, $\mathrm{CH}_{3} \cdot \mathrm{CO} \cdot \mathrm{CH}_{2} \cdot \mathrm{CH}_{2} \cdot \mathrm{CO} \cdot \mathrm{OH}$, a substance which is formed along with formic acid when a hexose is treated with mineral acids-

$$
\mathrm{C}_{6} \mathrm{H}_{12} \mathrm{O}_{6}=\mathrm{C}_{5} \mathrm{H}_{8} \mathrm{O}_{3}+\mathrm{CH}_{2} \mathrm{O}_{2}^{\prime}+\mathrm{H}_{2} \mathrm{O}
$$

It is not yet certain how many nucleic acids exist, but there are indications that the nucleic acids obtained from different animal tissues are identical. On the other hand, they appear to differ from the plant nucleic acids, such as the yeast nucleic acid, and the so-called triticonucleic acid of the wheat embryo, in that on hydrolysis with acids the latter yield, not lævulinic acid like the thymus nucleic acid, but furfurol. These results indicate that the carbohydrate in the plant nucleic acids is a pentose (see p. 210), and not a hexose. By hydrolyzing yeast nucleic acid with water in neutral solution at $175^{\circ}$, Levene and Jacobs succeeded in isolating four nucleosides, namely, guanosine, adenosine, cytidine, and uridine, each of which on further hydrolysis yields a pentose and guanidine, adenine, cytosine, and uracil respectively. The pentose obtained was found to be different from all the other hitherto known pentoses, and to have the stereochemical configuration of a sugar, to which the name $d$-ribose ${ }^{*}$ had been assigned. Now the above nucleosides, on condensation with phosphoric acid, should yield the corresponding nucleotides. It has been assumed that yeast nucleic acid is formed by the condensation of four such nucleotides, and has the formula -

* The enantiomorphous $l$-ribose was known before this time, and had been prepared by Fischer and Piloty in 1891. 


\section{Chemical Constituents of the Animal Body. 253}

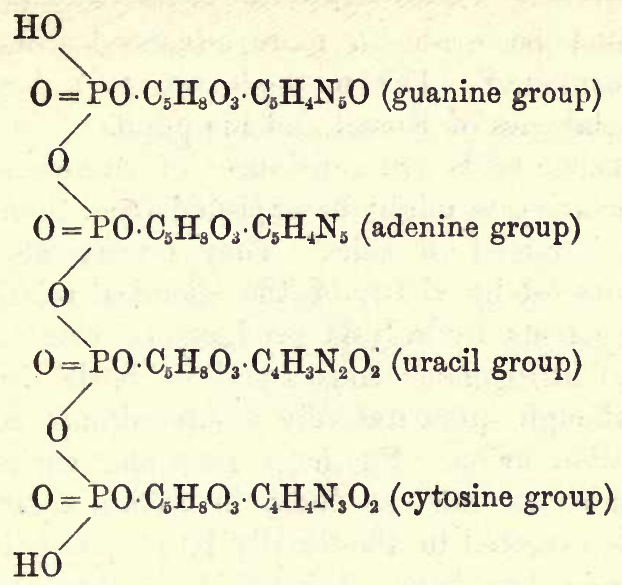

From the above it will appear that the main differences between the animal (thymus) and plant (yeast) nucleic acids are that the former yields thymine instead of uracil on hydrolysis, and contains a hexose instead of a pentose group.

It is of interest to note that certain nucleotides have been found which are not derived directly by the hydrolysis of nucleic acid. Thus, inosinic acid, discovered by Liebig in 1847 in meat extract, yields on partial hydrolysis the nucleoside inosine and phosphoric, and on complete hydrolysis, hypoxanthine, d-ribose, and phosphoric acid. Guanylic acid, which has been isolated from the pancreas, yields, on partial hydrolysis, the nucleoside guanosine (which is identical with the guanosine obtained by Levene and Jacobs from yeast nucleic acid), and on complete hydrolysis, phosphoric acid, guanine, and $d$-ribose.

In the above summary of the results of the chemical investigations of nucleic acid, no attempt has been made to describe the methods by means of which the various hydrolysis products have been isolated. For these re- 


\section{Biological Chemistry.}

ference must be made to more advanced works and to original memoirs.* The methods are to a large extent due to the labours of Kossel and his pupils.

The nucleic acids are substances of considerable biological importance, as might be expected from their relationship to the nuclei of cells. They possess also another point of interest by virtue of the chemical relationship of their nitrogenous hydrolysis products to uric acid, which is the chief nitrogenous constituent of birds' urine, and a constant, though quantitatively a subordinate constituent of mammalian urine. Furthermore, under various pathological conditions, such as those in certain cases of gout, uric acid is excreted in abnormally large quantities.

Uric acid has been obtained by several synthetical methods. To it the following formula has been assigned:-

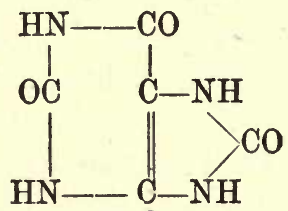

This is derived from a parent substance, designated by Emil Fischer, to whom the chief knowledge of the constitution of the alloxuric bases is due, purine, which also contains two rings. This has the formula-

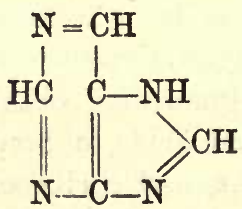

All the alloxuric bases have this ground structure, and are consequently known also as the purine bases.

*For complete literature, see Jones: "Nucleic Acids." (Longmans, Green, \& Co. 1914.) 


\section{Chemical Constituents of the Animal Body. 255}

The following are the formulæ of the purine bases which have been obtained by the hydrolysis of nucleic acids :-

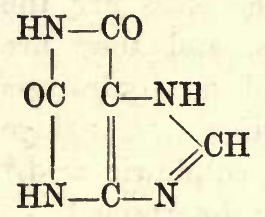

Xanthine.

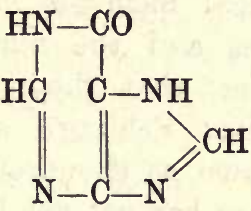

Hypoxanthenine.

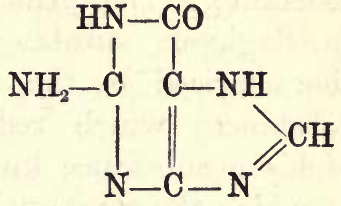

Guanine.

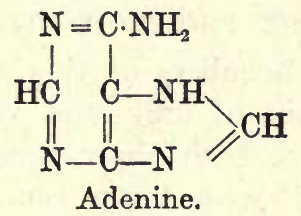

The pyrimidine bases contain only one ring, which has the same relative arrangement of the carbon and nitrogen atoms as exists in the six-membered ring of purine. These have been synthesized chiefly by E. Fischer and his collaborators, and by Wheeler and Johnson. The formulæ assigned to them by reason of these syntheses are the following:-

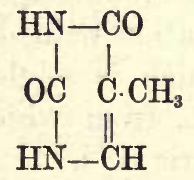

Thymine.

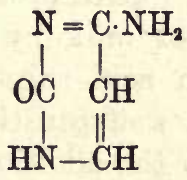

Cytosine.

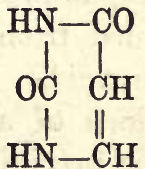

Uracil.

The relationship of the alloxuric bases to uric acid will be evident from the above formulæ, and has given rise to a large number of researches bearing on the metabolism of nucleic acid and the pathology of gout. 


\section{Biological Chemistry.}

\section{THE GLYCO-PROTEINS.}

The chemistry of this group of substances is still very indefinite. The principal members of the class are the cartilaginous substances and the mucins, and they are characterized by the fact that they yield on hydrolysis substances which reduce Fehling's solution. Cartilage yields a substance known as chondroitin sulphuric acid,* of which the constitution has not yet been determined.

\section{THE PHOSPHO-PROTEINS.}

The two chief members of this group are caseinogen, the principal protein of milk, and vitellin, the protein of egg-yolk. They are both characterized by the fact that on treatment at $37^{\circ}$ with 1 per cent. sodium hydroxide a scission of phosphoric acid takes place. This is in marked contrast to the other conjugated proteins which contain phosphorus, namely, the nucleo-proteins. It may be recalled that the part of the molecule containing the phosphorus, namely, the nucleic acid, is stable towards alkalis, but is readily decomposed by acids. By investigating the action of alkalis, it is possible, therefore, to distinguish between a phospho-protein and nucleo-protein. Caseinogen may be obtained from skimmed milk by precipitation with dilute acetic acid. It is an acid substance which is soluble in solutions of ammonia and caustic alkalis, from which it can be precipitated by the addition of acetic acid.

THE HEMOGLOBINS.

These are proteins (globins) which are supposed to be of a histone-like character, in combination with a chromatogenic group. They form the chief constituent of the red blood corpuscles. They are capable of forming com-

* Since the text of this book was prepared, a considerable amount of work on this substance has been carried out by Levene 


\section{Chemical Constituents of the Animal Body. 257}

pounds with oxygen (oxyhæmoglobin) and carbon-monoxide, and by reason of their capacity to form the first-named compound, they perform an important function in effecting the oxygen supply to the tissues in the organism.

Oxyhæmoglobin can be obtained in a crystalline form by treating the corpuscles with water containing ether, which causes them to "lake "- that is, the cells are broken up, and the contents escape. From the solution thus obtained the oxyhæmoglobin separates in a crystalline form on treatment with alcohol and cooling to between $-5^{\circ}$ and $-10^{\circ}$. On treatment with alcohol, ether, and sulphuric acid, the oxyhæmoglobin can be decomposed, the globin being precipitated, whilst the pigment remains dissolved in the mixture of alcohol, ether, and water.

The pigment can be separated in a crystalline form by treatment of oxyhæmoglobin with hot glacial acetic acid, which contains some sodium chloride. A product known as hæmin is thereby obtained, the composition of which, according to the latest researches, can be represented by the formula $\mathrm{C}_{33} \mathrm{H}_{32} \mathrm{O}_{4} \mathrm{~N}_{4} \mathrm{FeCl}$. This is a derivative of a substance aetioporphyrin, $\mathrm{C}_{31} \mathrm{H}_{36} \mathrm{O}_{4} \mathrm{~N}_{4}$, from which chlorophyll, the green pigments of plants, is also derived. This interesting biological fact has been recently demonstrated by Willstätter and his collaborators, who have described their investigations in a monograph ("Untersuchungen über Chlorophyll." Berlin, 1913). Aetioporphyrin is a somewhat complex substance, containing four pyrrol rings, of which the constitution has not yet been definitely established: Allied chemically to the blood pigment are the bile pigments, bilirubin and biliverdin. All these substances have been the subjects of numerous researches in recent years, but the knowledge of them is not yet sufficiently complete for a co-relationship to be established between their chemical constitution and biological functions.

$(1,99$ ) 


\section{Part III. (B)-The Derived Proteins.}

It has been already stated that the proteins on complete hydrolysis yield a mixture of amino-acids. If less drastic methods are adopted, intermediary products can be obtained which contain several amino groups coupled together in the form of polypeptides (see p. 228); the latter on complete hydrolysis undergo scission and yield a mixture of amino-acids. The production of such intermediary products of hydrolysis may be compared with the production of substances like the dextrins and maltose from starch. The last-named substance on complete hydrolysis yields only dextrose, but if treated with certain ferments, such as diastase, the hydrolysis is incomplete; a scission of only a certain number of the dextrose groups coupled together in the original starch molecule takes place, and a residue can be obtained which is less complex than the parent substance, but which still contains in the molecule two or more dextrose groups. (Compare p. 215.)

If proteins are treated with certain ferments or with acids at lower temperatures (for example, at $37^{\circ}$ and not boiled with the acids, as is usual when complete hydro. lysis is desired) the scission of amino-acids is not completed; by variation of conditions of hydrolysis, substances of greater or lesser complexity can be obtained according to the method employed. All such substances, on more drastic hydrolysis, can be degraded into their constituent amino-acids by a method similar to that by means of which dextrin or maltose, the intermediary hydrolysis products of starch, can be degraded into dextrose. The intermediary hydrolysis products from proteins are, like the parent substance, essentially polypeptides, although of smaller complexity. Of the intermediary hydrolysis products very few have been obtained in a crystalline form. 


\section{Chemical Constituents of the Animal Body. 259}

These are for the most part quite simple products, which yield on hydrolysis only two amino-acids. As examples, glycyl tyrosine and alanyl glycine, which have been obtained from silk, may be mentioned.

By treatment with weak solutions of acids $(0.4 \mathrm{per}$ cent. sulphuric acid) or alkalis $(0.1$ per cent. sodium hydroxide) at $40^{\circ}$, proteins undergo a slight change and yield the so-called acid or alkali albumins. These are insoluble in water, but soluble in excess of alkalis and acids. A scission of only a small number of amino-acid groups takes place in the formation of these products, which are sometimes known as the metaproteins. By hydrolysis of certain proteins with 12 per cent. hydrochloric acid at $40^{\circ}$, a series of apparently pure products known as "kyrines" have been obtained, which were purified by precipitation as phosphotungstates.

The most interesting intermediary hydrolysis products of the proteins are, however, those obtained by the action of ferments. The gastric juice contains such a substance which readily degrades most (but not by any means all) proteins at $37^{\circ}$ in the presence of acids $(\mathrm{N} / 20$ hydrochloric acid). The pancreas also secretes a liquid containing a ferment,* which digests proteins in alkaline solutions $(0.5$ per cent. sodium carbonate). If the general formula of the protein is referred to-
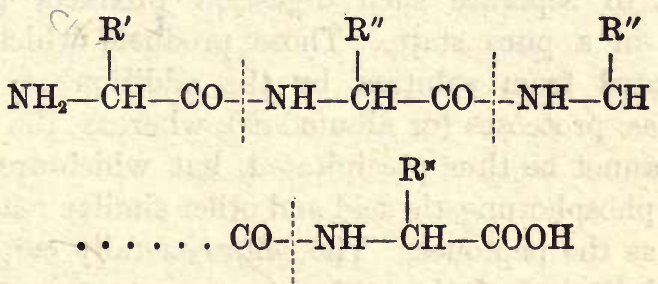

* Or rather, a ferment-yielding substance (proferment) from which a ferment is generated when the secretion comes in contact with the mucous membrane of the small intestine, which contains the so-called entero kinase. 
it will be obvious that several peptide linkages exist (in. dicated in the above formula by dotted lines), at which positions hydrolysis can take place-

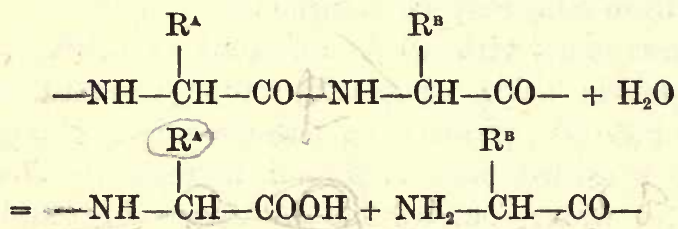

Theoretically it is conceivable that hydrolysis can occur at any one or more places. A peptide linkage can be broken either at the end of the chain or at any intermediate point. By incomplete hydrolysis it is possible, therefore, that a very large number of products can be obtained from a complex protein made up by the conjugation of a large number of amino-acids. Several polypeptides are, therefore, derivable by the incomplete hydrolysis of a protein in addition to simple amino-acids. In practice it is found that when a protein is digested with gastric juice in acid solution at $37^{\circ}$, many products are obtained, varying in complexity from simple amino-acids to highly complex substances, which, like the original proteins, are incapable of passing a parchment membrane (see p. 234). Up to the present it has been found impossible to separate such digestion products from one another in a pure state. Those products which can be precipitated from solution by the addition of salts are known as proteoses (or albumoses), whereas the products which cannot be thus precipitated, but which are precipitable by phosphotungstic acid and other similar reagents, are known as the peptones. The salts generally employed for the precipitation of the proteoses are ammonium sulphate and zinc sulphate (which is employed in solutions made acid with sulphuric acid). Some of the albumoses are 


\section{Chemical Constituents of the Animal Body. 26r}

precipitated by comparatively low dilutions of the salts (for example, when the liquid is one-third saturated), whereas others are only precipitated when their solutions are completely saturated with the salt. By taking advantage of these facts, it is possible to accomplish a partial (but only partial) separation of the proteoses from one another. The salt is added to the digest to a known degree of saturation (for example, one-third or one-half); the precipitate of albumoses is filtered off, more salt is then added to the filtrate (for example, to the degree of two-thirds saturation), a second fraction of albumoses is then produced, whilst from the filtrate, by a similar procedure of gradual increase in the degree of saturation, further fractions can be produced. It will be seen that the process of separation of products produced by the partial hydrolysis of proteins by means of ferments is an empirical one, which does not lead to the separation of pure chemical entities."

There are two chemical methods which may be employed for determining the degree of degradation of a protein, both of them due to the fact that the scission of a peptide linkage sets free an amino and a carboxyl group. This is illustrated by the equation representing the hydrolysis of glycyl glycine-

$\mathrm{CH}_{2}\left(\mathrm{NH}_{2}\right) \cdot \mathrm{CO} \cdot \mathrm{NH} \cdot \mathrm{CH}_{2} \cdot \mathrm{COOH}+\mathrm{H}_{2} \mathrm{O}=2 \mathrm{CH}_{2}\left(\mathrm{NH}_{2}\right) \cdot \mathrm{COOH}$

for whereas glycyl glycine contains only one amino group and one carboxyl group, the two molecules of glycine obtained by the hydrolysis contain two such groups.

Now when a molecular equivalent of glycyl glycine is treated with nitrous acid, only two atoms of nitrogen are evolved-

$\mathrm{CH}_{2}\left(\mathrm{NH}_{2}\right) \cdot \mathrm{CO} \cdot \mathrm{NH} \cdot \mathrm{CH}_{2} \cdot \mathrm{COOH}+\mathrm{HO} \cdot \mathrm{NO}$

$$
=\mathrm{N}_{2}+\mathrm{CH}_{2}(\mathrm{OH}) \cdot \mathrm{CO} \cdot \mathrm{NH} \cdot \mathrm{CH}_{2} \cdot \mathrm{COOH}
$$

* A more detailed reference to the action of fernents is given later. 
whereas two molecules of glycine obtained by the hydrolysis of the polypeptide yield four atoms of nitrogen when treated with this reagent-

\section{$2 \mathrm{CH}_{2}\left(\mathrm{NH}_{2}\right) \cdot \mathrm{COOH}+2 \mathrm{HO} \cdot \mathrm{NO}=2 \mathrm{~N}_{2}+2 \mathrm{CH}_{2}(\mathrm{OH}) \cdot \mathrm{COOH}$}

A complex protein will contain only a relatively small number of free amino groups capable of reacting with nitrous acid. On hydrolysis, however, amino groups will be set free, the more complete the hydrolysis the larger the number. By measurement of the amount of nitrogen set free during the course of hydrolysis (or digestion as it is called) by a ferment, when an aliquot part of the mixture is treated with excess nitrous acid, the amount of change undergone by the protein can be ascertained. The reaction with nitrous acid can be best carried out with the apparatus devised by Van Slyke (see p. 246).

The relative number of carboxyl groups set free by hydrolysis can also be estimated. This cannot, however, be accomplished by direct titration with a standard solution of an alkali and the use of an indicator in the ordinary way, as an amino-acid contains a basic (amino) as well as an acidic group, and acts as an ampholyte (compare p. 220). If, however, the action of the basic group can be eliminated, then a hydrolysis mixture should become more and more acid as the hydrolysis proceeds. The elimination of the basic action of the amino group can be effected by treatment with a large excess of formaldehyde. Glycine, for example, reacts with formaldehyde according to the equation-

$$
\mathrm{CH}_{2}\left(\mathrm{NH}_{2}\right) \cdot \mathrm{COOH}+\mathrm{HCHO}=\mathrm{H}_{2} \mathrm{O}+\mathrm{CH}_{2}(\mathrm{~N}: \mathrm{CH}) \cdot \mathrm{COOH}
$$

The methyleneimino-derivative thus obtained reacts as an acid, and can be titrated with a standard solution of alkali when phenolphthalein is used as an indicator. The employment of this method can be illustrated by consider- 


\section{Chemical Constituents of the Animal Body. 263}

ing again the reactions of glycyl glycine. This substance reacts with formaldehyde according to the equation-

\section{$\mathrm{CH}\left(\mathrm{NH}_{2}\right) \cdot \mathrm{CO} \cdot \mathrm{NH} \cdot \mathrm{CH}_{2} \cdot \mathrm{COOH}+\mathrm{HCHO}$}

$$
=\mathrm{CH}(\mathrm{N}: \mathrm{CH}) \cdot \mathrm{CO} \cdot \mathrm{NH} \cdot \mathrm{CH}_{2} \cdot \mathrm{COOH}
$$

It yields on hydrolysis two molecules of glycine, which react with formaldehyde to give two molecules of the methyleneimino-derivative, $\mathrm{CH}(\mathrm{N}: \mathrm{CH}) \cdot \mathrm{COOH}$, which contain twice as many carboxyl groups as the glycyl glycine from which it has been derived. They will require, therefore, twice as much standard alkali to neutralize. If now a protein is submitted to hydrolysis, and aliquot parts of the hydrolysis mixture are removed from time to time, treated with formaldehyde in excess (half the volume of 40 per cent. aldehyde solution) and titrated with standard alkali solution in the presence of phenolphthalein, it will be found that the mixture becomes more and more acid as hydrolysis proceeds and the peptide linkages undergo scission. This method, which is due to Sörensen, is a convenient one for following the course of the digestion of a protein, and is largely employed in the study of the action of the so-called proteoclastic ferments, to which more detailed reference will be made later.

It will be seen from the above description that it is possible to obtain hydrolysis products from the proteins varying in complexity from simple amino-acids up to products of relatively high molecular weights, which still possess many properties in common with the original proteins, such as the non-diffusibility through parchment membranes. These latter substances have been derived from the original protein by the scission of a comparatively small number of amino-acid groups, and yield on complete hydrolysis a relatively large number of amino-acids. Complex polypeptides have been obtained synthetically containing as many as sixteen amino-acids conjugated together, which 
have many properties in common with proteoses and peptones obtained by the digestion of natural proteins.

The general properties of the proteins may be summarized in the following way:-Although they are substances which vary very greatly in physical properties, they all yield on hydrolysis mixtures of amino-acids and belong to a group of products which have been designated "polypeptides." The individual proteins differ from one another in the number and character of the amino-acids which they yield on hydrolysis. Methods have been elaborated for the quantitative estimation of such products, which have been briefly described. A complete quantitative estimation requires large amounts of material, but it is possible, when working with relatively small amounts, to determine the amount of ammonia, monoamino-acids, and diamino-acids yielded by any given protein. A method has also been described by means of which the amounts of arginine, histidine, and lysine (the diaminoacids) yielded by hydrolysis of a protein can be ascertained with a fair degree of accuracy when only a small amount of substance is available for investigation. By analytical methods of this description, it is possible to distinguish between proteins of various origin. It must be remembered, however, that there are various difficulties in determining whether a protein is a pure chemical entity. It possesses no definite melting point, and other ordinary criteria of purity are also wanting. The methods of investigation are, therefore, more uncertain than those usually applied to crystalline organic substances, and the results obtained are in many cases only approximately correct.

Proteins occur naturally in combination with other groups which are not of polypeptide character. The most important of such combinations are the nucleo-proteins, which are proteins combined with nucleic acid. There 


\section{Chemical Constituents of the Animal Body. 265}

is evidence that these compounds form the chief constituents of the nuclei of cells. Nucleic acid itself is a polynucleotide, a substance formed by the conjugation of several nucleotide groups. The latter are formed by the conjugation of phosphoric acid, a sugar, and a base, which is either an alloxuric or a pyrimidine substance. Both classes are chemically related to uric acid, and for this reason the nucleic acids have been extensively investigated on account of their pathological interest. It is supposed that the plant nucleic acids differ from the nucleic acids of animal origin, in that the former contain a pentose sugar group whereas the latter contain a hexose.

Another interesting group of conjugated proteins is that of the homoglobins, in which the protein is combined with a pigment. The latter contains iron, and is a derivative of aetioporphyrin, from which the green chlorophyll pigments of plants are also derived.

By means of gentle treatment with acids or with certain ferments, intermediary hydrolysis products of proteins can be obtained, which are polypeptides, less complex than the original proteins. These on complete hydrolysis undergo scission into mixtures of amino-acids. The more complex of these hydrolysis products can be precipitated from solutions by salts (that is, can be "salted out"), such as ammonium sulphate or zinc sulphate, and are known as proteoses or albumoses. The less complex products which cannot be precipitated in this way, but which are precipitable by phosphotungstic acid, are known as peptones.

As a protein undergoes progressive hydrolysis, the number of free amino and carboxyl groups increases. The former may be estimated by treatment with nitrous acid and measurement of the nitrogen evolved, and the latter by titration with standard alkali in the presence of formaldehyde. 


\section{CHAPTER VI.}

THE METHODS EMPLOYED FOR INVESTIGATION OF CHEMICAL CHANGES WITHIN THE ANIMAL ORGANISM.

\section{Introduction.}

In the foregoing pages attention has been directed almost entirely to the consideration of the structure of organic compounds. An intimate acquaintance with this structure is essential before any progress can be made in the study of the various anabolic and catabolic processes which take place within the living organism (see p. 10). It is not surprising, therefore, that the state of knowledge of the chemical changes which take place in the living organism falls far below that of the transformations which can be accomplished in the apparatus of the laboratory, as a systematic investigation of the biological aspects of chemistry, or what is commonly known as physiological chemistry, can only commence when the study of the structure of the constituents of living objects is comparatively far advanced.

It must be admitted that, up to the present time, the advances made in the study of chemical transformations taking place within the bodies of living objects have been comparatively slow, in spite of the large number of workers who have been attracted to the investigations ; and in connection with this statement it is of interest to note that one journal alone dealing with biological chemistry pub- 


\section{Chemical Changes in Animal Organism. 267}

lished more than ten volumes during the course of the year 1913.

Within the scope of this book it is only possible to deal with certain typical methods which have been employed in research; the results are discussed in detail more suitably in works treating specially certain defined aspects of physiology and pathology.

In the present chapter it is proposed to deal with the methods employed for the investigation of the chemical changes of substances which take place within the mammalian body, and various reasons can be advanced for choosing this subject first for special treatment. The chief of these is the fact that the higher animals employ as the chief sources of their food supply complex substances included in three classes-namely, the fats, the carbohydrates, and the proteins. These substances undergo degradation and oxidation in the organism, supplying thereby the energy needs for muscular work and the heat requisite for maintaining the body temperature above that of the surroundings. They supply, in addition, the material necessary to replace the tissue waste, and in the case of the young growing organism, the substances necessary for the manufacture of new tissues. The changes to be investigated in the mammalian body are mainly of a degradative character, as far more material is employed for energy needs than is utilized for tissue growth and repair. Now a degradation of a substance into simpler products is as a rule easier to follow by experimental methods than is the reverse process of a synthesis. It is, therefore, not surprising that far more is known of the methods by means of which foodstuffs are broken down and utilized than is known of the methods by means of which new tissues are built up. The mammalian organism, in which the degradative chemical changes far surpass in quantity those of a 
synthetical character, affords, therefore, the most suitable subject for the first investigations in biochemistry.

In contradistinction to the animal body, the plant can, as a rule, utilize as foods simple substances like the carbon dioxide of the air, and nitrogen from inorganic salts such as nitrates. From suitable simple chemical compounds it can build up complex products such as starch and the proteins. As it moves but little, and its temperature is not necessarily above that of its surroundings, its energy needs are small. The synthetical processes tend, therefore, to predominate over the degradative processes, although the latter are by no means negligible. Furthermore, there is not in the plant the morphological differentiation which exists in the higher animal and which is associated with a differentiation of function. More distinct chemical processes probably take place within a given plant organ than occur within a single animal organ, and this fact alone renders the study of biochemical changes in plants excessively difficult. For the reasons stated above, it is not illogical to choose the higher animal in the first instance for the study of biochemical changes in spite of its great morphological complexity.

\section{Part I.-The Total Metabolism and the Balance-Sheet of the Organism.}

As already stated, the greater part of the food ingested by the animal undergoes oxidation within the organism, providing thereby a source of energy by means of which the temperature of the body is maintained and muscular work can be performed. A relatively small part of the ingested material is required, however, for the replacement of tissue wasted, and in the case of the young animal, for the growth of new tissue. No diet can, therefore, be considered satisfactory which does not fulfil the twofold func- 


\section{Chemical Changes in Animal Organism. 269}

tion of providing for the energy needs of the organism and for the repair of bodily waste. By far the greater part of the food is employed for the first-named of these two functions, only relatively small parts being required, at any rate in the case of the adult, for the formation of tissue. By far the largest amount of food ingested undergoes oxidative destruction, and the foremost problem for the biological chemist is to elucidate the chemical mechanism of the oxidative processes. With regard to the chemical mechanism of tissue formation practically nothing is known, but within recent years much work has been done in determining the food materials which are necessary for tissue repair and growth.

The first stages in the investigation of metabolism consist in the examination of the initial and the end products of the metabolic processes-in drawing up what, at the heading of this section, has been designated the balance-sheet of the organism.

When food is ingested it passes into the alimentary tract, in which it undergoes various degradative processes, some of which will be considered later; the degraded products are absorbed into the blood stream, which is kept circulating by means of the heart pump, and are conveyed to the various organs of the body, where they undergo other changes. The oxygen supply for the combustion is carried also in the blood in combination with the hæmoglobin (oxyhæmoglobin), the oxygenation taking place during inspiration by the lungs. The blood also carries away the products of catabolism of the organs, of which the carbon dioxide, one end product of oxidation, is excreted by the lungs during expiration, whereas the nitrogenous products of catabolism are eliminated by the kidneys in the urine. There are in addition certain other waste products which are not absorbed but which pass out through the 
lowest part of the alimentary tract in the form of the frees. A small part of the waste products is eliminated in the perspiration through the pores of the skin, but this is almost negligible. It is not proposed to deal in this place with the mechanisms of the various parts of the body, such as with the circulation, the mode of action of the heart pump, and the lungs; for the essential details reference must be made to a manual of physiology. From the more purely chemical standpoint the following factors are of chief interest:-I. The intake of the organism, which includes the food ingested and the oxygen inspired. II. The output of the organism, which includes the carbon dioxide expired by the lungs, the nitrogenous and other substances excreted by the kidneys in the urine, and the materials unabsorbed from (or excreted into) the alimentary tract, which are eliminated in the form of the frees. In the investigations of the total metabolism of the organ the intake is balanced against the output, and the initial and end products only are investigated.

Now the chief organic constituents of the food are the fats, the carbohydrates, and the proteins. The final products of the two first-named groups are carbon dioxide and water when combustion is complete; these are also the final products of combustion of these substances in the animal body. Proteins, on the other hand, contain nitrogen, sulphur, and in certain cases (the nucleo-proteins and phospho-proteins) phosphorus. The end products which would be produced by the complete combustion of proteins in excess of oxygen (as in a combustion furnace), are carbon dioxide, water, nitrogen (or oxides of nitrogen), sulphuric acid, and phosphoric acid. These are actually end products produced by the combustion of protein in the animal body in all cases except that of nitrogen. This latter element is eliminated from the body in the urine 


\section{Chemical Changes in Animal Organism. 27 I}

chiefly in the form of urea and uric acid. (For the formulæ of these two substances see pp. 102 and 254.) The former predominates in the case of mammals, whereas the latter is present in the larger amount in the case of birds. In addition, certain smaller amounts of nitrogen are eliminated in the urine in the form of ammonia, creatinine, and amino-acids, and small amounts of other substances. Sulphates and phosphates are also eliminated in the urine. The combustion of the proteins is, therefore, never complete. Finally, the fæces contain the undigested, or partially digested, materials consisting of more or less complex organic substances, such as vegetable fibres, proteins (mucous), undigested fats, and other products which have escaped absorption in the alimentary tract. The chief factors to be dealt with in the consideration of the initial and final products of metabolism may be summarized in the following scheme:-

Inttial Products.

The food (ingested through the mouth)-

Fats (with the elements $C \cdot H \cdot 0$ ). Carbohydrates (with elements C. H. O).

Proteins (with elements

C. $\mathrm{H} \cdot \mathrm{O} \cdot \mathrm{N} \cdot$ S and sometimes $\mathrm{P}$ ). Water.

The oxygen (inspired by the lungs).
Final Products.

Carbon dioxide expired by lungs.

Nitrogenous excreta-

$$
\text { Urea }
$$

Uric acid

Ammonia

$\left.\begin{array}{l}\text { Ammonia } \\ \text { Amino - acids and }\end{array}\right\} \begin{aligned} & \text { excreted by } \\ & \text { the kidneys }\end{aligned}$ other nitrogenous in the urine.

Water substances

Wholly or partially digested material excreted in unabsorbed from $\{$ the faces. alimentary tract

Water and almost neg-) excreted by ligible amounts of the skin in nitrogenous and the form of other matter perspiration.

* Sulphates, phosphates, sodium chloride, and other products are also excreted in the urine.

This scheme deals with the utilization of foodstuffs, taking 
into account only the metabolism of matter. The utilization can also be dealt with from the point of view of energetics. If a substance is burnt in oxygen so as to yield the end products, a certain amount of heat is evolved which can be measured by carrying out the combustion in a calorimetric bomb. This is a closed platinum-lined apparatus into which a weighed amount of the substance under investigation is introduced together with an excess of oxygen under pressure of several atmospheres. The whole is then sunk in the water of a calorimeter, and the combustion is initiated by heating electrically a small piece of iron wire placed in contact with the solid. separate measurement should be made of the heat evolved by the combustion of the wire.) The heat-value of a foodstuff is usually measured in large "calories," one such unit being the amount of heat necessary to raise 1 kilogram of water from $0-1^{\circ} \mathrm{C}$. By measuring, therefore, the rise of temperature of the water in the calorimeter produced by the combustion of the weighed amount of foodstuff, its caloric value can be calculated. The following represent the caloric values of the chief classes of foods:-

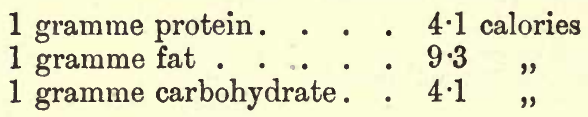

These numbers assume that complete combustion has taken place. In the animal body this is not the case, as the nitrogen is eliminated in the form of urea and other organic compounds and not as nitrogen. Furthermore, certain of the carbohydrates, such as cellulose, undergo only very incomplete combustion, and are eliminated almost unchanged in the fæces. Some nitrogenous matter and fat also pass out in the fæces. Hence a measurement of the utilization of the foodstuff can be made by determining the caloric value of the solids of the excreta (urine and fæces) and 
comparing these with the heat-values of the foods ingested. The larger the relative heat value of the excreta as compared with that of the foods, the smaller the utilization of the latter. The energy-yielding value of any given diet can be ascertained in this way by a direct method. It is also possible to measure directly the heat given out by an animal by placing it in a specially constructed calorimeter. Experiments of this description have been carried out by means of a large scale apparatus. If the subject of the experiment is allowed to do some measurable amount of work, such as the riding of a stationary bicycle connected with an ergometer which measures the amount of work, his efficiency as a machine can be measured when the caloric value of the food and excreta are also measured.

From the point of view of the chemist, however, the metabolism of matter is of greater interest, although the determination of the caloric values of the foods and excreta forms a parallel method of investigation.

In order to investigate the total metabolism of an animal, it is essential to be able to measure accurately the amounts of the various constituents of the ingesta and egesta. The following series of determinations must be made:-(1) The analysis of the amounts of the gaseous products of metabolism-namely, the intake product, oxygen, which is inspired, and the output product, carbon dioxide, which is expired by the lungs. (2) The analysis of the foods ingested. (3) The analysis of the urine and frces. (4) In addition to the determination of these factors, the weight of the subject of the experiment must be carefully ascertained both at the beginning and the end of the experiment, for when the food ingested is insufficient for the supply of the needs of the organism, the latter possesses the capacity of making up the deficiency from its own body material. In such a case it loses weight 


\section{Biological Chemistry.}

\section{(1) THE GASEOUS SUBSTANCES.}

Various methods have been devised for the measurement of the gaseous products of metabolism. One of the earliest employed, and the simplest in principle, is that due to Pettenkofer. The animal is placed in a chamber which is adapted to its size, and a constant current of air is drawn through, the amount passing being measured by a meter. Continuous analyses are made of samples of the air passing in and that passing out. The outgoing air will contain a smaller amount of oxygen and a larger amount of carbon dioxide than the ingoing air, corresponding with the amounts of oxygen consumed and carbon dioxide expired by the animal. Other methods in which the same principle is employed are due to Zuntz and Geppert, and can be readily applied to the human subject for clinical investigation. The nostrils of the subject of the experiment are clamped, and he breathes into a mouthpiece in which the inspired and expired airs are separated by passing through valves of aluminium or animal membrane, and the outgoing current passes a delicate meter. By a special contrivance an aliquot part of the outgoing air is made to pass to a gas-analysis apparatus in which its composition is determined. This will represent the average composition of the expired air. The composition of the inspired air is that of the atmosphere at the time of experiment. In the method of Regnault and Reiset, the subject of the experiment is kept in a closed chamber containing a given volume of air. The carbon dioxide produced by the animal is absorbed by caustic alkali, which is titrated at the beginning and the end of the experiment. The amount of carbon dioxide produced by the animal during the time of the experiment is thereby ascertained. The absorption causes a diminution of the 


\section{Chemical Changes in Animal Organism. 275}

volume of the air in the closed circuit, and this is made good by the supply of fresh oxygen. This principle has been adopted in an apparatus devised by Benedict which can be employed for clinical purposes, the construction of which is indicated in the accompanying diagram (Fig. 24).

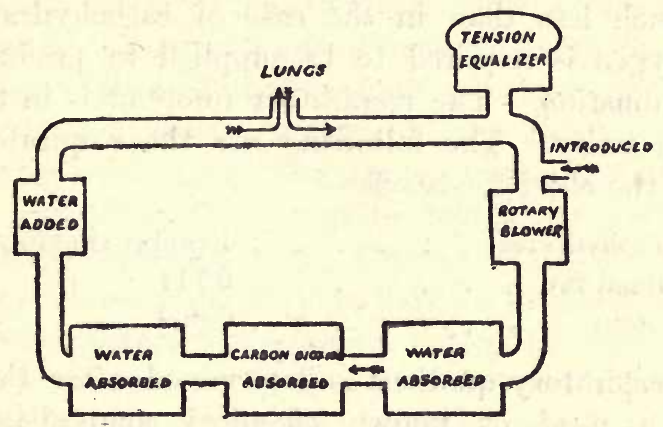

Fig. 24.

A tension equalizer is placed in the circuit which serves to keep the volume of the air constant. The amount of oxygen consumed is ascertained by weighing the cylinder of the gas in which it is contained at the beginning and the end of the experiment. The subject of the experiment breathes through a nose-piece into a wide metal tube which forms part of the closed circuit, the mouth being kept closed.

The apparatus employed for the determination of the gaseous exchanges is usually somewhat complex, and only an indication of the principles employed has here been attempted. A few words are necessary to indicate the value of the results obtained by such determinations. If the equation representing the complete combustion of dextrose is given-

$$
\mathrm{C}_{6} \mathrm{H}_{12} \mathrm{O}_{6}+6 \mathrm{O}_{2}=6 \mathrm{H}_{2} \mathrm{O}+6 \mathrm{CO}_{2}
$$

it will be observed that the volume of oxygen consumed is 


\section{Biological Chemistry.}

the same as that of the carbon dioxide produced. The ratio $\frac{\mathrm{CO}_{2} \text { expired }}{\mathrm{O}_{2} \text { inspired }}$ is known as the "respiratory quotient,"

and in the case of carbohydrates is $=1$. In fats, on the other hand, the amount of oxygen in the molecule is relatively much less than in the case of carbohydrates, and more oxygen is required to be supplied to produce complete combustion. The respiratory quotient is in this case less than unity. The following are the respiratory quotients of the chief foodstuffs-

Carbohydrates . . . . 1 (approximately).

Animal fat . . . . . 0711

Protein . . . . . . 0 0899

If the respiratory quotient is determined after the ingestion of a meal of known chemical composition, it is possible to determine at any given moment the nature of the substances undergoing oxidation in the body. Large numbers of determinations of respiratory quotients have been made in the course of physiological and pathological researches. It is, for example, of interest to ascertain the respiratory quotient during severe muscular work with the object of ascertaining which constituent of a diet forms the chief source of muscular energy. Again, in such a disease as diabetes, where the organism is not able normally to utilize the sugar, which is excreted in the urine in abnormally large quantity, it is of interest to ascertain the methods of utilization of the constituents of various experimental diets.

\section{(2) THE ANALYSIS OF THE FOODS.}

The constituents generally estimated are the fats, carbohydrates, and proteins. The fats may be roughly estimated by determining the percentage of the material 


\section{Chemical Changes in Animal Organism. 277}

which can be extracted in a Soxhlet apparatus (see p. 183) by ether or light petroleum. The so-called lipoids are extracted at the same time. The substance is generally dried before extraction. The amount of protein can be ascertained by the determination of nitrogen by Kjeldahl's method (see p. 35). The number thus obtained multiplied by the factor 6.45 gives approximately the amount of protein. The carbohydrates are generally estimated by difference. The above process gives a rough approximation of the amounts of the three chief constituents in a given foodstuff, and is generally sufficiently accurate for most metabolic experiments. The majority of the standard foods have been repeatedly submitted to analysis, but in many cases different samples show a varying compositionthus, the amount of fat in meat is a very variable quantity. The following are the constituents of some of the chief articles of diet:

Milk, which is the standard food of the young, contains protein, fat, and carbohydrate. The chief protein is caseinogen, which is readily precipitated from the diluted skimmed milk on acidification with acetic acid. A certain amount of fat-not separated in the skimming process-is carried down with the precipitate, and can be extracted by means of graded strengths of alcohol and then with ether. The greater part of the fat from milk can be separated by centrifugalization, and forms the chief constituent of butter. After separation of the fat and caseinogen a residue is obtained which contains the milk-sugar, which can be separated in a crystalline form after concentration, and also a small amount of a water soluble protein (lactalbumin). On treatment of milk with extract of the mucous membrane of the calf's stomach, which contains a ferment known as rennin (or rennet), a clot is produced (junket) as the result of a change the nature of which is not accu- 
rately known. From this clot, by certain somewhat complex changes, cheese can be produced.

Flour consists chiefly of carbohydrate in the form of starch, mixed with a certain amount of proteins. If it is kneaded in a stream of running water the starch can be washed away, and a pasty residue is left known as gluten. This contains two principal proteins-namely, gliadin, which can be dissolved out with 70 per cent. alcohol, and glutenin, which can be obtained from the residue after separation of the gliadin, by extraction with very weak solutions of caustic alkali, from which it is precipitated on neutralization with an acid. Other cereals also consist of carbohydrates mixed with proteins. The amount of fat in flour and other cereals is generally very small.

Vegetables possess a very varied composition. Potatoes consist chiefly of carbohydrates (starch and cellulose), with only small amounts of proteins and fats. The legumes (peas, beans, etc.) contain appreciable amounts of proteins together with starch. The chief constituent of green vegetables is cellulose, but they also contain chlorophyll and other products, the nature of which has not yet been fully determined.

Meat contains chiefly proteins, with interstitial fat and certain soluble nitrogenous substances (" extractives"), such as creatine and other meat bases. Meat also contains nucleo-proteins.

Eggs consist both of white and yolk. The former is essentially a solution of various proteins, whereas the latter is a mixture of fats and lipoids (lecithin), and a phospho-protein known as vitellin. If the dried yolks are extracted with ether the fats, together with the pigment, are separated, and a colourless residue remains from which the vitellin can be extracted by treatment with 10 per cent. sodium chloride solution. From this solution it is 


\section{Chemical Changes in Animal Organism. 279}

precipitated by dilution with water. It is of interest to note that the two chief phospho-proteins, caseinogen and vitellin, are constituents of the foods of young animals or developing embryos.

\section{(3) THE URINE AND FACES.}

The urine contains a large variety of salts and organic substances, but the most interesting constituents are the nitrogenous substances. The chief of these is urea, or carbamide, $\mathrm{OC}<\mathrm{NH}_{2} \mathrm{NH}_{2}$. Small amounts of ammonia are almost invariably found in urine. The quantity can be estimated by making a known amount of urine alkaline with sodium carbonate, and drawing a current of air through the liquid warmed to about $40^{\circ}$. After passing the urine, the air is bubbled through a flask containing a measured quantity of standard acid solution, which is titrated with standard alkali at the end of the experiment. From the result of this titration the amount of ammonia (or ammonium salts) in the urine can be calculated. The urea can be estimated in the urine by drawing air through a measured amount of the liquid, heated to $40^{\circ}$, to which some powdered Soya bean has been added. This contains a ferment capable of decomposing urea into ammonia and carbon dioxide-

$$
\mathrm{CO}\left(\mathrm{NH}_{2}\right)_{2}+\mathrm{H}_{2} \mathrm{O}=\mathrm{H}_{2} \mathrm{CO}_{3}+2 \mathrm{NH}_{3}
$$

The ammonia is drawn by the air through standard acid. After a time sodium carbonate is added, and the air current is continued till all the ammonia is driven off. From the amount of ammonia absorbed by the standard acid the quantity of urea present can be calculated, after allowance has been made for the ammonia pre-existing as such, and determined by the method already mentioned. Uric acid 
can be estimated by precipitating it as the ammonium salt by the addition of ammonium chloride or ammonium sulphate. Different methods for precipitation, and estimation of the uric acid in the precipitate, have been proposed. The principle of the method usually employed for the estimation is that of dissolving the precipitated urate in sulphuric acid, and titration with standard potassium permanganate solution. Creatinine gives a brown coloration with potassium hydroxide and picric acid (Jaffe's reagent). The amount present in urine can be ascertained colorimetrically by comparing the tint produced with Jaffe's reagent with a standard solution of potassium bichromate, or with the depth of colour produced with known amounts of creatinine. A colorimeter is generally used for the purpose. The total nitrogen is also usually determined in the urine by Kjeldahl's method. The difference between this amount and the amounts of nitrogen in the urea, uric acid, creatinine, and ammonia, gives the amount of nitrogen excreted in other forms, such as in the amino-acids and the other nitrogenous constituents which are only present in small quantities.

In the fæces the substances most usually estimated are the nitrogen and the fat-the former by Kjeldahl's method, and the latter by extraction in a Soxhlet apparatus.

THE RESULTS TO BE OBTAINED IN THE INVESTIGATIONS OF THE TOTAL METABOLISM.

Many important results have been obtained of both physiological and pathological interest in investigations of the character outlined above. Only a few examples can be given in this place to indicate their utility.

Some instances of their employment in researches on the physiology of nutrition may be given first. Of the 


\section{Chemical Changes in Animal Organism. 28 I}

ordinary constituents of foods the proteins are the most expensive, and consequently the diet with the smallest proportion of these substances which will fully supply the bodily needs of the organism will be the most economical. It must be remembered that proteins are necessary in the adult individual to make good the bodily waste which is continually taking place. If the protein supplied does not fulfil the purpose, then, even if the caloric value of the diet is more than sufficient for the energy needs, the organism will continually lose some of its own protein material. In other words, more nitrogen will be excreted in the urine and the fæces than was ingested in the food. When the output of nitrogen balances exactly the intake, the body is in "nitrogenous equilibrium." By administration to an individual of a mixed diet of fats, carbohydrates, and protein, the caloric value of which is sufficient, and by determining the nitrogen balance by the estimation of the total nitrogen in the food and excreta, it is possible to ascertain whether the amount of protein is sufficient. If this is the case, there will not be an excess of nitrogen excreted over that ingested. With any given protein or mixture of proteins it is possible to determine the minimum which will maintain the body in nitrogenous equilibrium. The diet necessary for different individuals will vary greatly with circumstances, such as the weight of the subject, the amount of muscular work to be performed, and other factors. It has been estimated that an ordinary workman, working for 8-9 hours per day, will require a diet of caloric value of about 3,000 , containing about 118 grammes of protein, which will correspond to an output of somewhere about 16.5 grammes of nitrogen in the urine. Recent experiments indicate, however, that the bodily needs can be sufficiently supplied with very much smaller amounts (less than half), and ex- 
periments bearing upon this subject have been carried out by the determination of the nitrogen balance with varied diets over prolonged periods of time. The results obtained have been, however, the subject of much controversy.

It is possible, also, to determine the utilization value of any given protein. The more completely a protein has been digested, the greater the proportion of the nitrogen excreted in the urine, and the smaller the amount appearing in the fæces. Again, proteins may be well digested, and yet they may be by themselves inefficient in supplying the bodily needs of an organism even when administered in relatively large quantities. Reference has been already made to the fact that when gelatin is the only protein ingested, the body will not remain in nitrogenous equilibrium. Zein, when administered to adult rats, is also inefficient, as the animals will constantly excrete more nitrogen than they have received in the foods, and lose in body weight. These proteins are deficient in aromatic groups, yielding no tryptophan on hydrolysis. It is supposed that certain definite groups must be contained in the proteins in order that they may efficiently supply the nitrogenous needs of the organism. The results obtained by the chemical investigation of the proteins, combined with those got from metabolism experiments on animals, have in recent years added largely to the knowledge of the physiology of nutrition.

Another interesting example of a diet which lacks some constituent essential for the normal well-being of an animal, although the deficiency is not due apparently to the quality or quantity of the protein, is that of polished rice. When pigeons are fed exclusively on such a diet they develop polyneuritis, which is stated to be cured by the injection of certain constituents of the rice-polishings. 


\section{Chemical Changes in Animal Organism. 283}

The diseases of beri-beri and scurvy are also stated to be due to some deficiency in the diet.

Closely connected with the experiments on insufficient diets are those dealing with the foods essential to growing animals. A diet which may suffice for the bodily needs of the adult is not necessarily adequate for those of the adolescent individual, which requires, apparently, certain specific materials for tissue growth. It has been found, for example, that young rats will die long before they reach maturity if their sole diet is composed of a pure fat such as lard, with a carbohydrate such as starch, and a pure protein such as caseinogen, together with the necessary inorganic salts. Hopkins has shown that something contained' in the milk, after separation of the proteins and the greater part of the fat, when added to the above diet will make good the deficiency, even when added in very small quantity. Osborne and Mendel have quite recently shown that an essential substance soluble in ether can be obtained from butter, and that cod-liver oil also contains the same or a similar substance which must be added to a pure fat-carbohydrate-protein diet to maintain normal growth. The actual nature of the substance has not yet been ascertained.

These experiments have been mentioned in this place, although they do not entail necessarily the complete investigation of the total metabolism of an animal. The determinations of the rate of growth alone on varied diets yield sufficiently striking results.

Examples have been already given of the value of the determinations of the gaseous products (the "respiratory exchanges "). (See p. 276.)

A few words are now necessary as to the value of urine examinations. In the cruder metabolism experiments, it is sufficient to determine the total intake and 
output of nitrogen. It may be recalled that although the greater part of the nitrogen is excreted in the urine in the form of urea, not inappreciable quantities appear in other compounds such as ammonia, uric acid, creatinine, etc. The variation of the distribution of the nitrogen amongst these different constituents has also been the subject of many investigations. Attempts have been made to ascertain how the distribution may be altered with varied diets, and under pathological conditions, when metabolism is abnormal. Amongst the most interesting of these investigations are the ones dealing with the variation of the uric acid output. It may be recalled that there is a chemical relationship between uric acid and certain of the hydrolysis products of nucleic acid, which is contained in varying quantities in food (see p. 254), and as uric acid plays an important part in the pathology of gout, such researches have an immediate bearing on the suitability of different diets for patients suffering from this disease, for it is conceivable that part of the uric acid, at any rate, may be derived from the diet. The literature is too extensive, and the interpretation of the results obtained too controversial, for it to be possible to give more than a passing reference to the subject of uric acid excretion in this place; it affords, however, one more interesting example of the utility of the investigations on the end products of metabolism.

So far no mention has been made of the chemical mechanism by means of which the end products are produced from the initial products; the discussion of this subject is reserved for a later part of this chapter. It may be stated here, however, that nitrogen apparently undergoes scission from the proteins in the form of ammonia, which is converted into urea by some method in the liver. When the liver ceases to perform its normal 


\section{Chemical Changes in Animal Organism. 285}

functions, a relatively large proportion of ammonia is excreted in the urine (as ammonium salt). Thus in certain cases of cirrhosis of the liver the amount of ammonia in the urine is abnormally high ; in such a case the determination of the distribution of the nitrogen amongst the urinary constituents is of importance for the purposes of clinical diagnosis.

In cases involving inflammation of the kidneys, Bright's disease, etc., part of the urinary nitrogen is excreted in the form of protein, which is in negligibly small amounts in normal urine. Hence the value of estimation of proteins in the urine when diseases of this character are suspected.

Finally, only very small amounts of dextrose are excreted in the urine of healthy individuals; diabetic patients on the other hand, who are unable to utilize their carbohydrates normally, can excrete quite large amounts of this sugar, together with $\beta$-hydroxybutyric acid, aceto-acetic acid, and acetone in certain cases. The examination of the urine for these substances can throw much light on the course of the disease.

It has only been possible within the scope of these pages to treat in a very casual manner the subject of the initial and final products of mammalian metabolism, of which only a certain number have been taken into consideration. The few examples, chosen in a somewhat haphazard manner, will illustrate the importance of the subject, and show the intimate bearing of chemical knowledge on certain problems connected with health and disease.

\section{Part II.-Intermediary Metabolism in the Animal Body.}

So far attention has been directed towards the consideration only of the initial and final products of metabolism, and only a few references have been made as to 
the chemical mechanism by means of which the decomposition of the complex ingestion products is brought about in the body. If the case of a simple carbohydrate such as dextrose is considered, it will be found that its final metabolism products consist of carbon dioxide and water. It is not to be supposed that the oxidation of this substance can be represented by the simple equation-

$$
\mathrm{C}_{6} \mathrm{H}_{12} \mathrm{O}_{6}+6 \mathrm{O}_{2}=3 \mathrm{CO}_{2}+6 \mathrm{H}_{2} \mathrm{O}
$$

without the formation of some intermediary products; in fact, if certain substances foreign to the body, such as camphor, chloralhydrate, and certain aromatic substances, are ingested, they are excreted conjugated with glycuronic acid,* $\mathrm{CHO}(\mathrm{CH} \cdot(\mathrm{OH}))_{4} \cdot \mathrm{COOH}$, which is one of the first oxidation products of dextrose. It is not unreasonable to suppose that this acid is formed in the body as a normal oxidation product, and that in the presence of foreign substances with which it can enter into chemical reaction it forms compounds which will not undergo further oxidation, but are eliminated from the organism in the urine. Intermediary oxidation products can even be isolated from such simple substances as methane when the combustion is carried out under suitable conditions. Thus Bone has shown that formaldehyde can be identified at an early stage in the decomposition of methane, the complete combustion of which can be represented in the following way:-

$$
\begin{gathered}
\mathrm{CH}_{4} \rightarrow \mathrm{CH}_{3}(\mathrm{OH}) \rightarrow \mathrm{CH}_{2}(\mathrm{OH})_{2} \rightarrow \mathrm{CH}_{2} \mathrm{O} \rightarrow \mathrm{H}_{2} \\
+\mathrm{CO} \longrightarrow \mathrm{H}_{2} \mathrm{O}+\mathrm{CO}_{2}
\end{gathered}
$$

In the following pages a short account will be given of some of the methods which have been employed for investigating the stages through which the ingesta pass in the course of their degradation through the various organs,

* That is, as compounds formed from glycuronic acid by the elimination of the elements of water from glycuronic acid and the substance. 


\section{Chemical Changes in Animal Organism. 287}

and of the attempts made to localize the chemical reactions in different parts of the body, and thus to determine some of their chemical functions.

\section{(A) THE METHOD OF DIRECT IN VITRO EXPERIMENT.} THE NATURE OF ENZYME ACTION.

The most direct method is the investigation of the chemical changes which take place when any given substance is brought into direct contact with an organ or a body fluid in ordinary laboratory vessels. Examples of this simple method have been already given. Thus it has been stated that when a protein, such as coagulated egg-white, is warmed to $40^{\circ}$ with juice excreted by the mucous membrane of the stomach, or with an extract of such a membrane in the presence of acid $(\mathrm{N} / 20$ hydrochloric acid), it undergoes degradation into polypeptides (proteoses and peptones) and amino-acids; in the case of coagulated egg-white, solution gradually takes place. This action will not take place when the egg-white is warmed with the acid alone.* Something is present in the gastric juice, or is extracted with the mucous membrane, which brings about the "digestion" of the protein. Again, if starch is treated with saliva, it rapidly undergoes degradation with the production of dextrins and the simpler carbohydrates. A very large number of chemical changes can be produced when various chemical substances are treated with animal secretions, or disintegrated animal tissues or their extracts.

Now one of the most obvious facts in connection with the chemical changes brought about by the animal organism is that these all take place in the case of a mammal within

* A small change will take place in this case, but degradation will not go so far. This fact can be confirmed by following the changes by means of the formaldehyde or nitrous acid methods (see pp. 261 and 262). 
a narrow range of temperature (at about $37.5^{\circ} \mathrm{C}$. in man). Degradative changes of the extent to which they occur in the body can often be brought about in the laboratory, when no extracts of organs or secretions are used, only when powerful chemical reagents such as strong solutions of acids or alkalis or high temperatures are employed. Thus, for example, it is not easy to break down starch or proteins to the extent to which they are degraded by saliva or gastric juice at a temperature of $37^{\circ}$, unless powerful hydrolytic reagents, such as strong solutions of mineral acids, are used. The action of the saliva or gastric juice is due to the presence of certain substances known as "enzymes" or "ferments," to the general action of which some attention must now be directed.

The Nature of Enzyme or Ferment Action.-The word fermentation has for ages been associated with the phenomenon of the formation of alcohol from sugar and carbon dioxide, although it is only within comparatively recent times that the nature of the process which takes place has been understood. Lavoisier, towards the end of the eighteenth century, obtained an approximately correct idea as to the nature of the chemical process involved, and the results obtained were amplified and corrected by later investigators when the fundamental principles governing the changes of organic substances came to be more fully understood. For a long time, however, the character of the agency producing the change was a matter of considerable controversy; the nature of the yeast cells and other bodies which produced fermentative action was the subject of various theories, none of which received universal acceptance. About the year 1838, three observers, almost simultaneously and independently of one another, claimed that the fermentation was the result of the activity of a living organism. These investigators, 
Cagniard-Latour, Theodor Schwann, and Kützing, published memoirs in which they brought forward certain evidence indicating the fact that yeast was a living organism. A very important observation is due to Schwann, who showed that if matter which normally undergoes putrefaction on exposure to air is treated in such a way that all living organisms are destroyed, it will remain intact, and can be preserved for an indefinite period without undergoing putrefactive changes. Thus, if animal or vegetable matter is heated in a vessel, and the air which subsequently comes into contact with it is filtered or passed through concentrated sulphuric acid, it will not undergo putrefaction. The conception appeared to be established that both fermentation and putrefaction were due to the agency of living organisms. The conclusions of Cagniard-Latour and of Kiitzing were based chiefly on the microscopical evidence. Other investigators, who worked before the three above-mentioned, had also obtained indications as to the nature of fermentative and putrefactive processes, but the evidence obtained by them was scarcely so definite. Nevertheless, the views as to the vital agency were for a long time controverted, especially by Liebig and Berzelius, who at the time were regarded as the leaders of chemical thought, and it was not till about 1857, when Pasteur published his classical researches, that the correct views as to the nature of yeast and other micro-organisms commenced to be almost universally accepted. To Pasteur is due the greater part of the modern technique for the culture of the pure organisms, of which a great variety exists always in the air, and for the methods of investigation of the chemical changes produced by them. To-day there is practically no question of the fact that fermentation, putrefaction, and certain pathological conditions in both animals and plants are due 
to the presence of living organisms, many of which can be rendered visible only by the highest powers of the microscope. Where matter capable of undergoing fermentative or putrefactive changes exists under such conditions that those organisms have been first destroyed and have no subsequent access, it will remain "sterile," and be "preserved" against putrefaction for an indefinite period.

The next questions which arose were-Was it possible to produce fermentative or putrefactive changes without the presence of the living agent? Was it possible to kill the living yeast cell, for example, and then to extract some substance from it which could cause the conversion of sugar into alcohol and carbon dioxide? Reasons existed for supposing that the above questions could be answered in the affirmative. It had been shown earlier, by Dubrunfaut, that germinating barley possessed the power of converting starch into sugar, and in 1833 Payen and Persoz found that the aqueous extract of the plants yields on the addition of alcohol a white powder which also possessed a capacity for vigorously degrading starch. Many other analogous products were discovered subsequently, such as the starch-digesting substance from the saliva, and the protein-digesting substance from the gastric juice. In all cases the reaction was brought about by the addition of relatively very small amounts of the active substance. In the case of yeast, it suffices to inoculate the sugar solution with a few yeast cells to produce action; sterile vegetable or animal matter will putrefy after coming into contact with air which has not been purified, and which contains only a very minute amount of foreign substance; the addition of a very small amount of the active powder obtained from germinating barley will convert a relatively very large amount of starch into 


\section{Chemical Changes in Animal Organism. 29I}

sugar, and a drop or two of gastric juice will render soluble very appreciable quantities of coagulated eggwhite.

Facts of this character led Moritz Traube to enunciate in $\mathbf{1 8 5 8}$ his theory that the chemical changes produced by living organisms are brought about by certain definite chemical substances contained within them, which are now designated ferments or enzymes (Greek $\epsilon \nu, i n ; \xi v \mu \eta$, yeast). Nevertheless, for a long time all attempts to obtain a product from yeast which could exert the fermentative power of the living organism were without result, and for a period bodies capable of producing chemical change when present in only relatively very small quantities were divided into two classes, namely, organized and unorganized ferments. Yeast, which was found to be able to ferment sugar only when in a living condition, was assigned to the latter class, whereas the starch-digesting product obtained by the extraction by water of germinating barley, or diastase as it is called, was assigned to the former. In 1897, however, Eduard Buchner showed that if yeast cells were thoroughly disintegrated by grinding with kieselguhr and sand, and the disintegrated mass was then exposed to. a high pressure, a juice could be obtained perfectly free from yeast cells which was able to convert sugar into alcohol and carbon dioxide. From this time onwards the distinction between organized and unorganized ferments has gradually dropped, and although certain fermentative processes can still only be brought about by the intact cell, this is probably due to the fact, not that the cell is living, but that the action is due to two or more substances contained in it, which are immiscible; in other words, the action takes place in a heterogeneous system, in which the conditions of aggregation are disturbed when the cell is destroyed. 
The study of the action of tissues or tissue extracts on chemical substances virtually resolves itself to-day into the study of the enzymes contained within the tissue.

The Nature of Ferment Action.-If a solution of sucrose (cane-sugar) is treated with an extract of yeast under suitable conditions it undergoes the change known as "inversion" (see p. 192), and yields a mixture of dextrose and lævulose in equal proportions-

$$
\begin{aligned}
& \mathrm{C}_{12} \mathrm{H}_{22} \mathrm{O}_{11}+\mathrm{H}_{2} \mathrm{O}=\mathrm{C}_{6} \mathrm{H}_{12} \mathrm{O}_{6}+\mathrm{C}_{6} \mathrm{H}_{12} \mathrm{O}_{6} \\
& \text { Dextrose. Lævilose. }
\end{aligned}
$$

In the above equation no account is taken of the ferment "invertase," to the agency of which the reaction is due. A very small amount of the ferment, furthermore, is able to produce a relatively very large amount of chemical change. An action of this description is described as "catalytic," and the agent which brings it about is known as a "catalyst," which has been defined by Ostwald as "a substance which alters the velocity of a reaction but does not appear in the end products." It may be claimed that this definition does not accurately correspond with the facts, for cane-sugar, for example, if left in contact with water, does not undergo change; the reaction only proceeds after the addition of the invertase. There are reasons to suppose, however, that a small amount of inversion of the cane-sugar does actually take place in the absence of the enzyme, but that the amount is so small that it cannot be detected by chemical methods even after a prolonged interval. Instances of catalytic action are not confined to products derived from living organisms. Hydrogen and oxygen will not combine together to form water vapour at ordinary temperatures except in the presence of finely-divided platinum; hydrogen peroxide will not oxidize various organic substances except in the 


\section{Chemical Changes in Animal Organism. 293}

presence of minute quantities of an iron salt-in these cases the platinum and the iron salt peroxide act as the catalysts.

An enzyme may be regarded as a catalyst produced by a living organism. A very large variety of such substances exist, of which examples will be given below. Some will act on starches, others on fats, others on proteins, whereas another class is concerned in various oxidative processes. A convenient terminology has been suggested to indicate the character of the action. The substance which undergoes change under the influence of the enzyme is known as the "substrate," and the termination ase added to a name of the substrate, or an abbreviation of the same, to designate the ferment. Thus, a ferment which degrades starch (otherwise called diastase) may be designated an "amylase," a fat-digesting enzyme is a "lipase," and a protein-digesting ferment a "protease," and the digesting actions themselves are designated as amyloclastic, lipoclastic, or proteoclastic.

Very little is known of the chemical character of the various enzymes, and none have been prepared in a pure condition, nor is much known of the mechanism of their action. There is a certain amount of evidence that they enter into combination with their substrate, but it would be necessary to extend the discussion beyond the scope of this book in order to enter into detail as to the mode of action. There are, however, certain characteristics of enzymes which are well established. They are complex substances, which for the most part are incapable of passing a parchment membrane, and their properties are destroyed when they are heated above a certain temperature. If a solution of an enzyme is boiled, the fermentative properties are destroyed. An enzyme will act furthermore only under certain specified conditions. It will act, for example, only 
within a comparatively narrow range of temperature. The investigation of the enzymes from the mammalian body are usually carried out at the temperature of $37.5^{\circ}$ or thereabouts, and for this purpose special chambers, which can be maintained accurately at a constant temperature ("incubators"), have been designed. At the temperature of melting ice the action of the ferments of the mammalian body are so intensely slow that they are almost negligible, and the enzyme action can be almost stopped if the fermenting mixture is kept surrounded with ice.

There are also well-defined limits of the reaction of the medium within which a ferment will act. Thus pepsin will digest proteins best in a medium which is fairly strongly acid (N/20 hydrochloric acid), whereas the proteoclastic ferment of the pancreas will react in an alkaline medium. Pepsin is inactive in an alkaline medium, whereas trypsin, the pancreatic ferment, fails to act in an acid medium. Invertase reacts best in a medium very little removed from complete neutrality. A very slight shifting of the reaction of the medium either to the acid or the alkaline side from the point of optimal activity will often appreciably affect its rate of action. The question of the optimal conditions of reaction of the various ferments has been the subject of repeated investigations in recent years, and very fine physical methods must be employed in order to obtain correct results.

Finally, the action of the enzymes is often of an intensely specific character. An excellent illustration of this fact is afforded by the study of the enzymes which bring about the hydrolysis of the two methyl glucosides. It may be recalled that by the action of methyl alcohol on glucose in the presence of hydrochloric acid two glucosides have been obtained, to which the two following formulø have been assigned: 


\section{Chemical Changes in Animal Organism. 295}

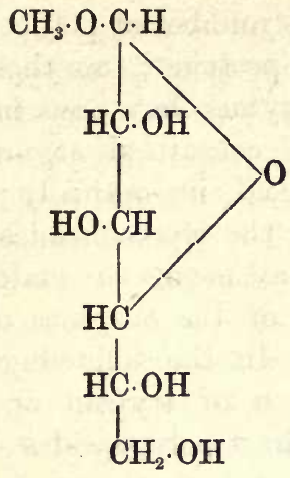

a-Methyl Glucoside.

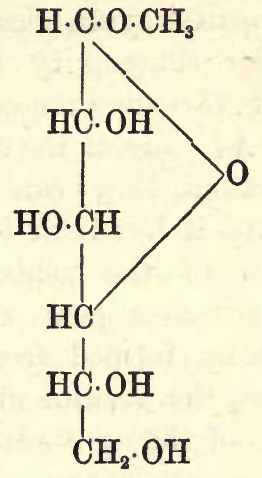

$\beta$-Methyl Glucoside.

The former of these ( $\alpha$-glucoside) can be hydrolyzed into methyl alcohol and dextrose by the presence of the enzyme maltase, which is found in malt extract, and causes the hydrolysis maltose into its monosaccharide (see p. 213), whereas the latter ( $\beta$-compound) is not hydrolyzed by the action of maltase, but is hydrolyzed by that of emulsin, an enzyme present in bitter almonds and other plants. Although these two glucosides differ only slightly in their stereochemical configuration, they are acted upon by two different enzymes; the enzyme which will bring about the hydrolysis of one form will not cause that of the latter. The stereochemical configuration is an important factor to be taken into account when studying the action of the various ferments, and for this reason it has been discussed somewhat fully in this book.

Other interesting examples of the specificity of ferment action are afforded by the study of the action of the proteoclastic ferments on the polypeptides which have been obtained synthetically. It may be recalled that proteins are essentially polypeptides formed by the conjugation of various amino-acids. E. Fischer and his pupils 
have prepared synthetically a large number of polypeptides of smaller complexity than the proteins; on these the action of various proteoclastic enzymes has been investigated. As some of the amino-acids contain an asymmetric carbon atom, they can be obtained in optically active forms, and it has been found that the stereochemical configuration of the acids is by no means a matter of indifference as regards the action of the enzymes on the polypeptides formed from them. In the following table are given the results of the action of trypsin on some examples of the synthetically-obtained polypeptides:-

Those Hydrolyzed.

Alanyl-glycine.

Alanyl-leucine.

(Racemic) Alanyl-leucine A.

Glycyl-l-tyrorine.

$d$-Alanyl-d-alanine.

$l$-Leucyl-l-leucine.
Those Not Hydrolyzed.

Glycyl-alanine.

Glycyl-glycine.

(Racemic) Alanyl-leucine B.

Leucyl-glycine.

$d$-Alanyl-l-alanine.

$l$-Leucyl-d-leucine.

$d$-Leucyl-l-leucine.

It will be seen from the above table that some substances, which are chemically very similar, behave in different manner as regards the action of trypsin. Glycyl-alanine, $\mathrm{NH}_{2} \cdot \mathrm{CH}_{2} \cdot \mathrm{CO}-\mathrm{NH} \cdot \mathrm{CH}\left(\mathrm{CH}_{3}\right) \cdot \mathrm{COOH}$, for example, is not hydrolyzed, whereas the isomeric form alanyl-glycine, $\mathrm{NH}_{2} \cdot \mathrm{CH}\left(\mathrm{CH}_{3}\right) \cdot \mathrm{CO}-\mathrm{NH} \cdot \mathrm{CH}_{2} \cdot \mathrm{COOH}$, is. Two racemic forms of alanyl-leucine are known. These are-

$$
\left.\begin{array}{l}
d \text {-alanyl- } l \text {-leucine } \\
l \text {-alanyl- } d \text {-leucine }
\end{array}\right\} \quad \text { and } \quad\left\{\begin{array}{l}
l \text {-alanyl-l-leucine } \\
d \text {-alanyl- } d \text {-leucine }
\end{array}\right.
$$

both of which should be inactive by external compensation. It is noteworthy that these two substances behave differently towards trypsin. The effect of the trypsin is in all cases where it acts to hydrolyze the polypeptide into the mixture of amino-acids; thus glycyl-rlanine and alanyl- 


\section{Chemical Changes in Animal Organism. 297}

glycine will both yield a mixture of glycine and alanine in equimolecular proportions.

Various tissue extracts contain proteoclastic ferments capable of hydrolyzing polypeptides, and it is obvious that the investigations. of the action of the enzymes obtained from these sources on the different polypeptides will throw considerable light on the protein metabolism of the organism. Numerous researches bearing on this subject have been published in recent years. No rules can yet be formulated as to the substances which are attacked by given enzymes; it will be observed, however, that a very small difference even in the stereochemical configuration will have an influence on the vulnerability of substances. The specificity of action is, in fact, one of the most striking characteristics of enzymes.

It might be supposed, from the fact that the enzyme appears in neither the initial nor final products of the reaction, that a small amount will bring about the change of an infinitively large amount of the substrate and appear unchanged at the end. In practice this is not the case, as usually the enzyme itself gets destroyed during the course of the reaction. A large amount of work has been carried out bearing on the chemical dynamics of ferment action, which cannot be discussed in detail in this place. One important point, however, which is of considerable biological interest deserves a passing mention. Certain hydrolytic processes are reversible, such as ester formation (see p. 95), and it is of importance to ascertain whether the reverse reaction can be brought about by the ferment-that is, whether synthesis as well as degradation can be brought about. A limited number of instances of synthesis by ferments has been discovered. When maltose is treated with maltase it undergoes hydrolysis into two molecules of glucose- 


$$
\mathrm{C}_{22} \mathrm{H}_{22} \mathrm{O}_{11}+\mathrm{H}_{2} \mathrm{O}=2 \mathrm{C}_{6} \mathrm{H}_{12} \mathrm{O}_{6}
$$

It has been found by Croft Hill that when a concentrated aqueous solution of glucose is treated with this enzyme, the reverse reaction takes place, namely-

$$
\mathrm{C}_{6} \mathrm{H}_{12} \mathrm{O}_{6}+\mathrm{C}_{6} \mathrm{H}_{12} \mathrm{O}_{6}=\mathrm{H}_{2} \mathrm{O}+\mathrm{C}_{12} \mathrm{H}_{22} \mathrm{O}_{11}
$$

The actual disaccharide isolated in this case was found to be a mixture of the isomerides maltose and isomaltose, and this fact gave rise to the discussion as to whether the enzyme which produces synthesis is identical with that causing hydrolysis. The bulk of the evidence seems to indicate, however, that the synthetic and hydrolytic actions are due to the same enzyme, and the seemingly anomalous result obtained by Croft Hill is explained by the fact that maltase sometimes contains the two enzymes, namely, true maltase and emulsin (compare p. 295).

Another well-established synthetical reaction of enzymes is that of the lipase, which can be prepared from castor-oil seeds and chelidonium seeds. Under certain conditions these enzymes can produce the synthesis of fats from a mixture of glycerol and the higher fatty acids, and an equilibrium point can be attained with a relatively large amount of fat. The reaction may be shortly represented by the equation-

$\mathrm{CH}_{2} \cdot 0 \cdot \mathrm{OCR}$

CH. $0.0 \mathrm{CR}^{\prime}+3 \mathrm{H}_{2} \mathrm{O}$ $\mathrm{CH}_{2} \cdot 0 \cdot 0 \mathrm{OR}^{\prime \prime}$

\section{$\mathrm{CH}_{2} \cdot \mathrm{OH}$}

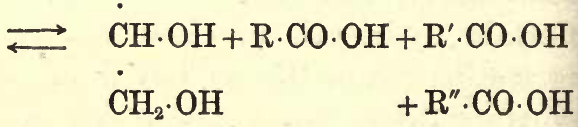

It has recently been shown that whether the reaction is started with a mixture of a fat and water, or of fatty acids and glycerol, the same final equilibrium point is attained.

The general characters of the enzymes may be summarized in the following manner:- 


\section{Chemical Changes in Animal Organism. 299}

Enzymes are catalysts derived from living objects of unknown but complex chemical character; they are readily destroyed by heat, and act only within comparatively narrow limits of temperature and of acidity or alkalinity of the medium. They are highly specific in their reactions, attacking only substances of certain definite constitutions and stereochemical configurations. A limited number of cases is known in which enzymes which bring about hydrolysis can also cause the reverse process of synthesis.

Some Examples of Enzyme Action in the Animal Body.-It is of interest to trace out the various degradative processes which food undergoes during its passage through the alimentary tract. In the mouth it comes into contact with the saliva which is secreted by the salivary glands and contains a ferment known as ptyalin, which is a diastase and degrades starch into dextrins and simpler carbohydrate. In the stomach it comes into contact with the secretion poured out as the result of the stimulus of the food ingestion, which contains hydrochloric acid and the proteoclastic enzyme pepsin which hydrolyzes the proteins into amino-acids and comparatively complex proteoses and peptones. The gastric juice also contains a small amount of lipase. As the partially digested food passes through the pyloric valve of the stomach into the small intestine, mixed with the secretion from the stomach, it enters the small intestine. The acid of the gastric juice then acts upon the mucous membrane of the intestine, and produces a substance called secretin which is absorbed and carried in the blood-stream. This acts on the pancreas, and causes it to secrete through the pancreatic duct a juice which comes into contact with the mucous membrane of the small intestine. It contains a lipase, and also trypsinogen, a "pro-ferment" from which, 
by the action of a substance contained in the mucous membrane of the intestine known as enterokinase, the proteoclastic enzyme trypsin is set free. This is capable of degrading into simpler products the proteoses and peptones produced in gastric digestion. Finally, the small intestine and other organs contain an enzyme known as erepsin which can hydrolyze the peptones, producing therefrom a mixture of amino-acids. The fats also undergo hydrolysis in the small intestines. The undigested food, and the partially digested food which is not absorbed, pass farther down the intestine, where they are acted upon by the bacterial flora which exist normally in the gut. Here they undergo further changes, being acted upon by the bacterial enzymes. All the reactions described above can be studied in vitro. It is easy to study the digestive action of saliva on starch; pepsin can be prepared from extracts of the mucous membrane of the stomach; pancreatic juice can be obtained by the insertion of a cannula into the pancreatic duct of an animal, and commences to flow after injection into the veins of an extract made with dilute hydrochloric acid of the mucous membrane of the small intestine (which extract must be neutralized before injection). The pancreatic juice, if obtained without contaminating the small intestine, possesses no tryptic activity; this is only exhibited after the juice has been treated with extract of the small intestine which contains the enterokinase, which is also supposed to be an enzyme. The mechanism of the conversion of trypsinogen into trypsin is not completely understood. The proteoclastic action of the various ferments can be investigated by the chemical methods already described (p. 259 and seq.). The mucous membrane of the small intestine of young animals, the chief diet of which is milk, contains an enzyme lactase, which converts the milk sugar into a mixture of glucose 


\section{Chemical Changes in Animal Organism. 30I}

and galactose. This ferment is absent, or present only in small quantities, in the intestines of adult animals, which draw their carbohydrate supply from sources other than that of the milk.

A large number of ferments exist in the liver, and have been the subjects of numerous investigations.

So far the enzymes affecting the hydrolysis of fats, carbohydrates, and proteins have been discussed. There exist in the organs, however, another very important class, namely, those to which the oxidative processes in these organs are due. These are known as the oxydases, and a very large number probably exist. Much remains to be learnt about these ferments; as examples, the investigations dealing with the degradation products of nucleic acid may be cited. As already stated, much attention has been directed towards the study of the metabolism of this acid, in view of the important part it appears to play in certain pathological conditions (p. 284). It may be recalled that it yields on hydrolysis certain purine bases which are closely related chemically to uric acid. This is evident from the formulæ given below-

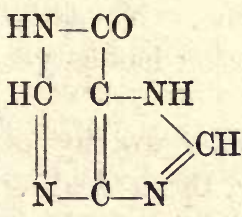

Hypoxanthine.

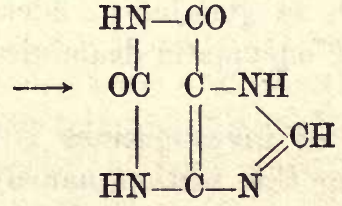

Xanthine.

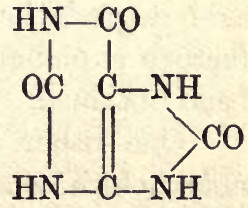

Uric Acid.

It will be noticed that it is possible to pass from hypoxanthine through xanthine to uric acid. Numerous investigations have been carried out with the object of ascertaining which organs of the body produce these oxidative changes, and which organs also cause the oxidative destruction of uric acid itself. It has been found 
that the organs of different animals vary very considerably as regards their content in the oxidases bringing about the oxidation of the various purine substances. Thus the following organs contain an oxidase capable of converting (in the presence of air) xanthine into uric acid: human liver, ox liver, ox spleen, adult pig's liver. In the following organs the xanthine oxidase is absent: human organs other than the liver, ox-thymus, pig's spleen, embryo pig's liver, all the organs of the rat. It is not easy to generalize the results obtained on the oxidation of the purine substances; they are quoted as examples of detailed work, in which attempts have been made to follow out the intermediary metabolism of nucleic acid in vitro. In all cases the experiments have been carried out by the incubation of the pure intermediary products with the minced organ in the presence of air.

Numerous experiments have been also performed with the object of ascertaining the mechanism by means of which deaminization (scission of the amino group) takes place in such substances as the amino-acids and substances containing amino groups derived from products of nucleic acid degradation, such as guanine or adenine. No satisfactory explanation of enzymatic deaminization has as yet been obtained.

One other series of investigations is also worthy of note before concluding this section, namely, those dealing with the conversion of ammonium salts into urea. It is known that this process takes place in the liver; it is of interest to recall the fact that the reverse process is readily brought about by an enzyme in the soya-bean (p. 279). 


\section{Chemical Changes in Animal Organism. 303}

(B) THE INVESTIGATION OF INTERMEDIARY METABOLISM BY PERFUSION OF THE SURVIVING ORGAN.

Another method of investigating chemical changes taking place within an organism approximates more closely to the conditions existing in the living animal. This method consists in the perfusion through an isolated organ of the substances the chemical changes of which are to be investigated dissolved in blood, or in a solution of inorganic salts (for mammals usually 0.85 per cent. sodium chloride, with small amounts of calcium chloride, potassium chloride, and sodium hydrogen carbonate, a solution known as Ringer's fluid). Many chemical changes take place during perfusion which do not occur when substances are simply incubated with minced tissue or tissue extracts. This may be due to various circumstances. Some chemical changes are brought about only by the intact cell. Others appear to require the presence of the blood and efficient oxygenation, the blood acting as oxygen carrier. Others, again, will not occur in the presence of some of the accumulated reaction products, which in the perfusion method are either carried away or destroyed.

The organ under investigation can be perfused either in situ in the body of the animal, or it can be completely removed from the body and placed in a chamber which is constantly maintained at body temperature, either in air or immersed in a saline solution $(0.85$ per cent. sodium chloride). The perfusing liquid is led into the organ through the main artery, and finds its exit through the principal vein. The apparatus employed is so constructed that the same fluid is automatically kept in continual circulation through the organ, and at the end of the experiment it is examined in order to determine the products of the chemical change of the substance under investiga- 
tion. The experiment should be commenced as rapidly as possible after the animal has been killed, so as to avoid all complications due to post-mortem changes. Various forms of perfusion apparatus have been suggested. A comparatively simple one, due to Brodie, is described in this place. The essential details are shown in the accompanying illustration. It consists of a pump $\mathrm{D}$ which drives the blood

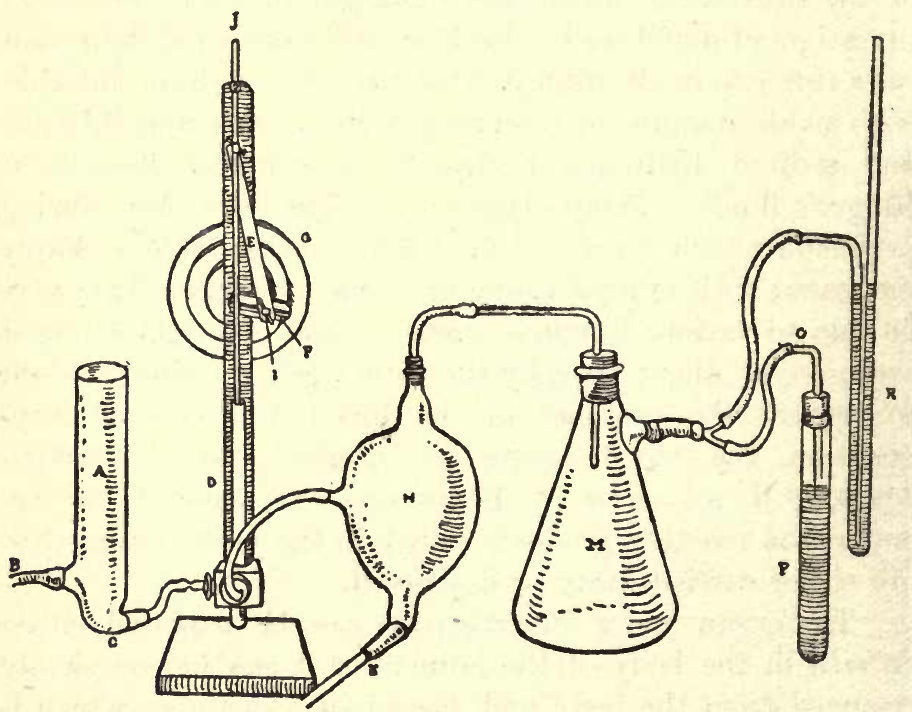

Fig. 25.

into a glass receiver $\mathrm{H}$. The tube $\mathrm{K}$ at the bottom of this is connected by rubber or glass with a cannula tied into the artery of the organ to be perfused. The cannula connected with the vein, through which the fluid flows after perfusion through the organ, is connected by rubber tubing with the lateral inlet of the vessel A. This has also another lateral tube $\mathrm{C}$, which is connected with the inlet tube of the pump D, the outlet tube of which is con- 


\section{Chemical Changes in Animal Organism. 305}

nected with the vessel $\mathrm{H}$. The pump consists of a piston and cylinder, the piston rod $J$ being moved by a crank and a connecting bar $\mathrm{E}$. The pump is provided with cylinders and pistons of varying diameters, so that it can be used for organs of different sizes and varied rates of flow of the blood. The volume of the blood delivered at each stroke can also be varied by fixing the connecting bar $\mathrm{E}$ to different points of the coned pulley G. The connecting valves of the pump are rendered both gas and fluid tight by inserting a double-convex lens into a piece of indiarubber tubing which is thereby stretched, and allows gas and fluid to pass in one direction, but not in the other. The vessel $\mathrm{H}$ is connected with a large flask $\mathrm{M}$, which in its turn is connected with a mercury valve $\mathrm{P}$ and a manometer R. The whipped blood of the animal is introduced into the receiver $\mathrm{A}$, and pumped into the main receiver $\mathrm{H}$. The mercury valve $\mathrm{P}$ is set at the required pressure, and pumping is continued until air escapes through the valve, so that blood in the receiver $\mathrm{H}$ is at the initial pressure required for the perfusion. It is then passed through the tube $\mathrm{K}$ to the arterial cannula through the organ, and thence through the venous cannula to the vessel A. From this it is pumped again into $\mathrm{H}$, and this circulation can be kept up continuously by means of a motor driving the pump. The thrust of the pump and its rate are regulated, so that enough air is pumped with the blood to aërate it sufficiently. The air in excess of that required to maintain the pressure at constant height passes through the vessel $M$, and escapes through the mercury valve $P$. The vessel M serves to collect the froth from the blood.

The organs which have been chiefly employed for perfusion experiments are the heart and the liver. A large variety of forms of apparatus for perfusion experiments have been described, some of which are far more complex 
than the one just described. This, however, illustrates in a satisfactory manner the principles of the diffusion method. The blood and the organ perfused are usually kept at body temperature. The parts of the apparatus necessary for this purpose have been omitted from the illustration.

As an illustration of the employment of the perfusion method, Embden's researches on the formation of the acetone substances may be cited. These include, in addition to acetone, $\beta$-hydroxy butyric acid, and acetoacetic acid, and are excreted by diabetic subjects, and also by normal individuals when on a diet containing small amounts of carbohydrates and large amounts of fats. The acetone substances are supposed to be intermediary products of the catabolism of fatty acids, the end products being carbon dioxide and water. Embden and his pupils have shown that when fatty acids (in the form of salts) are added to the blood perfused through a liver, there is a marked increase in the amount of acetone substances formed, when the fatty acid contains an even number of carbon atoms. When the number of carbon atoms is an uneven one (valeric, heptylic, nonoic acids), no appreciable increase in the acetone substances is observed after the blood has perfused the liver. Certain conclusions as to the method of oxidation of the fatty acids have been drawn from the results. As they have been the subject of a certain amount of controversy they will not be discussed in detail in this place.

Another interesting observation made by means of the perfusion method is also due to Embden. He has shown that when the ammonium salt of lactic acid is perfused with blood through the liver, a certain amount of alanine is formed-

$\mathrm{CH}_{3} \cdot \mathrm{CHOH} \cdot \mathrm{COONH}=\mathrm{CH}_{3} \cdot \mathrm{CH}\left(\mathrm{NH}_{2}\right) \cdot \mathrm{COOH}+2 \mathrm{H}_{2} \mathrm{O}$

Now lactic acid can be derived from dextrose; on treat- 


\section{Chemical Changes in Animal Organism. 307}

ment of this sugar with weak solutions of caustic alkali, this acid is produced in appreciable quantities. The exact mechanism of the formation is unknown, but it is highly probable that it is also an intermediary degradation product produced from dextrose in certain biological processes. The interest of Embden's observation lies in the fact that an amino-acid can be synthesized from ammonia and a degradation product of a sugar. By the conjugation of amino-acids protein-like substances can be produced. The production of alanine from ammonium lactate may be regarded, therefore, as a stage in the synthesis of a protein from carbohydrates. This observation of the formation of alanine from ammonium lactate is, however, of too isolated a character to permit of any useful speculations as to the mode of synthesis of proteins in the animal body.

The number of experiments by the perfusion method is somewhat limited. The complexity of the apparatus, which is not available in all laboratories, and the chemical difficulties of separating small amounts of the reaction products from large quantities of blood, probably account for this fact.

\section{(c) METHOD BY ADMINISTRATION TO ANIMALS OF INTER-}

MEDIARY PRODUCTS OF METABOLISM.

Some intermediary products of metabolism are known. Thus, for example, it is an established fact that peptones and amino-acids are produced from proteins by the action of proteoclastic ferments in the alimentary tract. It is conceivable that information as to the subsequent fate of such intermediary products could be obtained by the direct administration of these to animals, and by attempting to isolate the end products of their metabolism from the urine. Such a direct method of experiment does not 
usually, however, lead to any results of value, as the same end products are formed as when the primary substance is ingested. Thus, both proteins and their degradation products, such as peptones and amino-acids, when administered to animals, give rise to the same nitrogenous end products in the urine, the chief of which is urea. To overcome difficulties of the character just described various devices have been suggested. Thus, intermediary products have been administered to animals in quantities larger than those which can be completely broken down into the final end products. In this case it might be expected either that the substance administered would be excreted unchanged, or that some product intermediate between it and its final degradation products would be eliminated in the urine. When this method of investigation is adopted, the intermediary product under investigation is often administered by intravenous, intraperitoneal, or subcutaneous injection instead of by the mouth. Two examples of this method of experiment may be cited. When dextrose is given to rabbits in large quantities, appreciable amounts of oxalic acid are excreted in the urine. This acid appears, therefore, to be an oxidation product of the sugar which is produced in the organism, but which, under normal circumstances, is oxidized further to carbon dioxide and water. Again, when xanthine is administered to dogs it gives rise to allantoin, which is excreted in the urine. If, however, xanthine is given in large quantities, certain amounts of uric acid are also eliminated. It would appear, therefore, as if uric acid is a product intermediate between the xanthine and the allantoin, which is produced normally by the oxidation of the base in the organism of the dog. The relationship of these substances to one another is illustrated in the following formulæ:- 


\section{Chemical Changes in Animal Organism. 309}

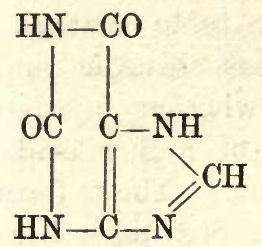

Xanthine.

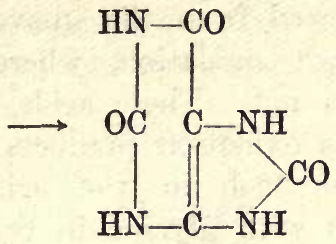

Uric Acid.

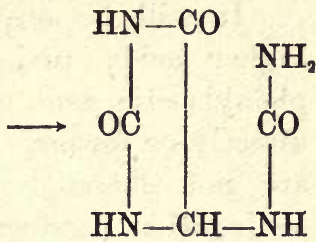

Allantoin.

Results obtained by this method must be accepted with some reserve, for it is possible that the administration of substances in amounts larger than those which can be completely metabolized may lead to a derangement of certain functions of the organs, and the intermediary products isolated nay not be the normal ones.

Another method for investigating the fate of intermediary products is due to Knoop, who conceived the idea of introducing into the substance under investigation a resistant radicle which would therefore be excreted in combination with some part of the original substance. He studied the fate in the organism of certain fatty acids, into which a phenyl group had been introduced, in a position furthest removed from the carboxyl group. Some of his chief results are summarized in the following table:-

\begin{tabular}{|c|c|c|}
\hline Acid Fed. & $\begin{array}{l}\text { Oxidation Pro- } \\
\text { duct. }\end{array}$ & Excreted as \\
\hline $\begin{array}{l}\text { Benzoic acid- }- \\
\mathrm{C}_{6} \mathrm{H}_{3} \cdot \mathrm{COOH}\end{array}$ & Not oxidized. & Hippuric acid. \\
\hline $\begin{array}{l}\text { Phenyllacetic acid- } \\
\mathrm{C}_{6} \mathrm{H}_{5} \cdot \mathrm{CH}_{2} \cdot \mathrm{COOH}\end{array}$ & $" \quad "$ & $\begin{array}{l}\text { Phenylaceturic } \\
\text { acid. }\end{array}$ \\
\hline $\begin{array}{l}\text { Phenylpropionic acid- } \\
\mathrm{C}_{6} \mathrm{H}_{5} \cdot \mathrm{CH}_{2} \cdot \mathrm{CH}_{2} \cdot \mathrm{COOH}\end{array}$ & $\begin{array}{l}\mathrm{C}_{6} \mathrm{H}_{8} \mathrm{COOH} \\
\text { (Benzoic acid). }\end{array}$ & Hippuric acid. \\
\hline $\begin{array}{l}\text { Phenylbutyric acid- } \\
\mathrm{C}_{6} \mathrm{H}_{5} \cdot \mathrm{CH}_{2} \cdot \mathrm{CH}_{2} \cdot \mathrm{CH}_{2} \cdot \mathrm{COOH}\end{array}$ & $\begin{array}{l}\mathrm{C}_{6} \mathrm{H}_{5} \cdot \mathrm{CH}_{2} \cdot \mathrm{COOH} \\
\text { (Phenylacetic }\end{array}$ & $\begin{array}{l}\text { Phenaceturic } \\
\text { acid. }\end{array}$ \\
\hline $\begin{array}{l}\text { Phenylvaleric acid- } \\
\qquad \mathrm{C}_{6} \mathrm{H}_{5} \cdot \mathrm{CH}_{2} \cdot \mathrm{CH}_{2} \cdot \mathrm{CH}_{2} \cdot \mathrm{CH}_{2} \cdot \mathrm{COOH}\end{array}$ & $\mathrm{C}_{6} \mathrm{H}_{5} \cdot \mathrm{COOH}$ & Hippuric acid. \\
\hline
\end{tabular}


It will be observed from the above table that the higher acids undergo oxidation, whereas benzoic and phenylacetic acid do not. These acids, whether injected directly or formed as oxidation products of higher acids, are not excreted as such in the urine. They form conjugation products with glycine in the organism, benzoic acid being excreted in the form of hippuric acid, $\mathrm{C}_{6} \mathrm{H}_{5} \cdot \mathrm{CO} \cdot \mathrm{NH} \cdot \mathrm{CH}_{2} \cdot \mathrm{COOH}$, and phenylacetic acid as phenylaceturic acid, $\mathrm{C}_{6} \mathrm{H}_{5} \cdot \mathrm{CH}_{2} \cdot \mathrm{CO} \cdot \mathrm{NH} \cdot \mathrm{CH}_{2} \cdot \mathrm{COOH}$. Similar cases of conjugation taking place in the animal organism have already been referred to, notably those of the glycuronates (p. 286), when conjugation takes place with an oxidation product of sugars. In this case, conjugation takes place with glycine, derived apparently from the proteins by hydrolysis.

The results obtained by Knoop have led him to propound his $\beta$-oxidation theory. According to this, the carbon atom in the $\beta$-position in a fatty acid is selected for oxidation. The degradation of phenylvaleric acid would be represented, therefore, by the following stages:-

\section{$\mathrm{C}_{6} \mathrm{H}_{5} \cdot \mathrm{CH}_{2} \cdot \mathrm{CH}_{2} \cdot \mathrm{CH}_{2} \cdot \mathrm{COOH} \rightarrow \mathrm{C}_{6} \mathrm{H}_{5} \cdot \mathrm{CH}_{2} \cdot \mathrm{CH}_{2} \cdot \mathrm{COOH} \rightarrow \mathrm{C}_{6} \mathrm{H}_{5} \cdot \mathrm{COOH}$ Phenylvaleric Acid. \\ Phenylpropionic Acid. Benzoic Acid.}

In the cases of benzoic and phenylacetic acid no $\beta$-carbon atom exists, and they are excreted unchanged. This theory of $\beta$-oxidation has not been universally accepted; but Dakin has shown that fatty acids can be degraded by similar stages in vitro, when they are submitted to oxidation by hydrogen peroxide at $37^{\circ}$. It is also noteworthy that the fatty acids derived from milk-fat and other animal fats always contain an even number of carbon atoms. Whatever may be the ultimate conclusions as to the mechanism of the destruction of acids in the organism, Knoop's investigations form an interesting 


\section{Chemical Changes in Animal Organism. 3 I I}

example of a method devised for the study of the intermediary metabolism in the animal body.

(D) METHOD BY ADMINISTRATION OF INTERMEDIARY PRODUCTS TO SUBJECTS IN WHICH THE METABOLISM IS PATHOLOGICALLY IMPERFECT.

Certain pathological abnormalities are known, due to the inability of the individual to catabolize completely definite groups. The diabetic subject, for example, is not able completely to utilize the carbohydrates, and excretes dextrose in abnormally large amounts in the urine. In this case the results of this pathological condition are severe, as a large amount of energy derivable from carbohydrate combustion is lost, and a general derangement of functions ensues. There are known, however, cases of abnormality in metabolism in which groups of far smaller significance than the carbohydrates are concerned. Amongst such abnormalities may be included the rare conditions of alkaptonuria and cystinuria. In the former case the abnormality (for, as generally it does not lead to serious results to the general health, it can hardly be regarded as a disease) is due to the incomplete metabolism of some of the aromatic products derived from the proteins by hydrolysis. In the case of cystinuria the metabolism of the cystine derivable from the proteins is incomplete, and this substance is excreted in the urine, and is apt to give rise to concretions in various parts of the body.

The state of alkaptonuria has been the subject of several exhaustive researches, for although it occurs but very rarely, the conditions existing afford one of the few examples of incomplete metabolism of a very limited number of chemical groups.

The alkaptonuric condition is characterized by the fact that the urine yields a black coloration when treated with 
iron salts. This is due to the presence of homogentisic acid, the amount of which can be readily determined. It has been found that the amount excreted can be increased by the addition of phenylalanine or tyrosine to the diet. These substances appear, therefore, to be the products to which homogentisic acid owes its origin. The chemical relationships of these three substances are indicated in the following formulæ:-

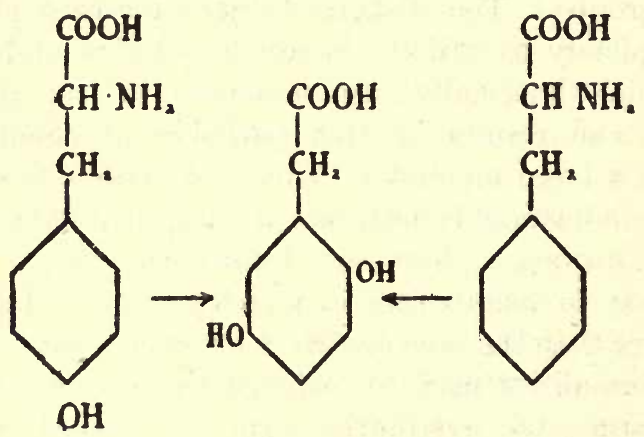

Tomogentisic Phenylalanine.
Acid.

It will be noticed that homogentisic acid contains two hydroxyl groups in the $c-$ and $m$-positions to the $-\mathrm{CH}_{2} \cdot \mathrm{COOH}$ group. There is no difficulty in conceiving the origin of this group from the groups $-\mathrm{CH}_{2} \cdot \mathrm{CH}\left(\mathrm{NH}_{2}\right) \cdot \mathrm{COOH}$ of alanine or tyrosine, but in the latter substance the hydroxyl group is in the $p$-position. Homogentisic acid can only be derived from the latter by a change in the position of the hydroxyl group in the benzene ring. There are reasons for supposing that tyrosine passes through the following stages before conversion into homogentisic acid:- 


\section{Chemical Changes in Animal Organism. 3 I 3}

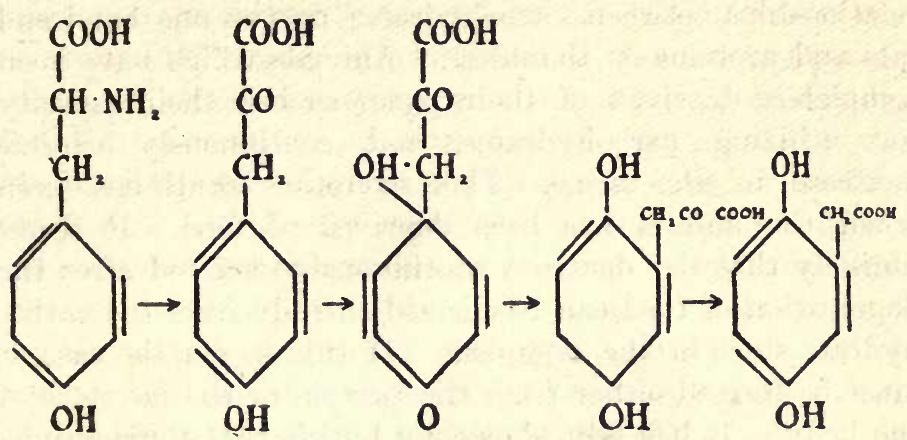

It is not possible in this place to give the chemical reasons for assuming that these stages are passed through in the transition from tyrosine to homogentisic acid. Most of the intermediate products have, however, been prepared, and it has been found that these, when superadded to a given diet of an alkaptonuric subject, cause an increased excretion of homogentisic acid in the urine. On the other hand, substances like 0 - or $m$-tyrosine (that is, substances with the hydroxyl group in the $o$ - and $m$-position to the $-\mathrm{CH}_{2} \cdot \mathrm{CH}\left(\mathrm{NH}_{2}\right) \cdot \mathrm{COOH}$ group instead of the $p$-position) do not lead to an increased homogentisic acid output. It has been supposed by Garrod and others that homogentisic acid is a normal intermediary product of phenylalanine and tyrosine catabolism, which in most individuals is further oxidized in the body; in the case of alkaptonuric subjects, on the other hand, the capacity of degrading homogentisic acid any further is wanting. If this is the case, it can be readily understood that the alkaptonuric individual affords a valuable subject for studying the intermediary metabolism of aromatic substances derived from proteins by hydrolysis.

Experiments have been carried out on diabetic subjects with the object of ascertaining the metabolic 
relationships between carbohydrates on the one hand and fats and proteins on the other. Animals which have been completely deprived of their pancreas lose their capacity for utilizing carbohydrates, and continuously excrete dextrose in the urine. This excretion continues even when the animal has been deprived of food. It seems unlikely that the dextrose continuously excreted after the deprivation of food can be derived entirely from the carbohydrate store in the organism. If this is not the case, it must be formed either from the protein or the fat store of the body. It has been shown by Luithje that the administration of proteins to the starving diabetic animal is immediately followed by a largely increased output of dextrose in the urine. Amino-acids can also produce a similar effect. Experiments of this character appear to indicate the possibility of the formation in the body of carbohydrates from proteins and their degradation products. Probably the first action is that of deaminization; alanine, for example, would give rise to $\mathrm{CH}_{3} \cdot \mathrm{CH}(\mathrm{OH}) \cdot \mathrm{COOH}$, lactic acid. It is possible to conceive the formation of dextrose from such a substance by a series of reactions, but many of the stages in the change are at the present moment so problematical that a further discussion of the possible reactions would be unprofitable. The results are quoted in this place chiefly as an example of a method for the investigation of the intermediary metabolic changes.

(E) METHOD BY CHEMICAL EXamination OF THE BODY, OR ORGANS OF THE BODY, OF AN ANIMAL AFTER ADMINISTRATION OF CERTAIN FOODS.

A classical example of this method is afforded by the experiments of Gilbert and Lawes on the formation of fats from carbohydrates. Two young pigs, ten weeks old, from the same litter, and of approximately equal weight, were 


\section{Chemical Changes in Animal Organism. 3 I 5}

taken. One was killed, and the nitrogen and the fat of the body were estimated. The second was fed for four months on barley, which was carefully weighed and analyzed, and the fat and nitrogen which passed undigested through the body in the fæces were also estimated. At the end of four months the second pig was killed, and its body analyzed. It was found that the animal contained 1.56 kilos more protein and 8.6 more kilos of fat than the control animal which was killed at the age of ten weeks. It had taken up with the food during the time of feeding 7.49 kilos of protein and 0.66 kilo of fat. If the protein added to the body is subtracted from that ingested as food, there is a remainder of 5.93 kilos, which might have given rise to the fat. This, however, is less than the fat actually put on by the animal. The only conclusion from this experiment possible is that the fat was formed from the other chief constituent of the diet. namely, the carbohydrates. Again, it is not possible to ascertain the chemical changes which the carbohydrates must undergo before they are converted into substances with such a different chemical structure as the fats.

Another example of a method of investigating intermediary metabolism, which falls under the above heading, has been already cited. Leathes and Miss Meyer Wedell have shown that on feeding animals with fats and oils, fats accumulate in the liver, the fatty acids of which, judged by their iodine values, are more unsaturated than those contained in the food. As unsaturated acids are generally more readily oxidized than the corresponding saturated derivatives, it would appear as if the removal of hydrogen atoms is one of the first stages in the degradation of the complex fatty acids. 


\section{Biological Chemistry.}

(F) METHOd OF ANALOGY FROM THE BIOCHEMICAL CHANGES PRODUCED BY MICRO-ORGANISMS.

Certain chemical transformations can be readily brought about by micro-organisms which can be accomplished only with difficulty by the ordinary in vitro chemical methods; and it is highly probable that changes similar to those due to micro-organisms take place within the bodies of higher animals. A study of the intermediary metabolism of micro-organisms is likely therefore to throw considerable light on the intermediary metabolism of the higher animals. The change which has perhaps been the subject of the largest amount of study is the formation of alcohol and carbon dioxide from dextrose by the action of yeast. If the formulæ are written-

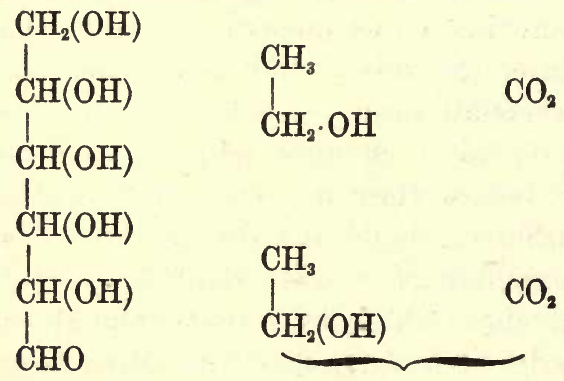

it is not easy to conceive how two molecules of alcohol and two of carbon dioxide can be derived from one molecule of dextrose without the formation of a number of intermediary products.

Various complex changes of dextrose can also be brought about in vitro which cannot be explained without assuming the formation of a series of intermediary products; thus, on treatment of dextrose with dilute alkalis at $37^{\circ}$, lactic acid in a yield up to 50 per cent. can be obtained. There is evidence that this change can also be 
brought about in the animal body. It has been shown, for example, that a liver rich in glycogen gives rise on perfusion to appreciable quantities of lactic acid. In this reaction the glycogen is first hydrolyzed so as to yield dextrose. Conversely, also, lactic acid, when administered to a normal animal, gives rise to glycogen, and when given to a diabetic subject causes an increased output of dextrose in the urine. It has been suggested that the conversion of dextrose into lactic acid takes place through the following stages:-

(1) $\mathrm{CH}_{2}(\mathrm{OH}) \cdot(\mathrm{CH}(\mathrm{OH}))_{4}^{\prime} \cdot \mathrm{CHO} \longrightarrow 2 \mathrm{CH}_{2}(\mathrm{OH}) \cdot \mathrm{CH} \cdot(\mathrm{OH}) \cdot \mathrm{CHO}$

Glyceric Aldehyde.

(2) $\mathrm{CH}_{2}(\mathrm{OH}) \cdot \mathrm{CH}(\mathrm{OH}) \cdot \mathrm{CHO}$

(3) $\mathrm{CH}_{3} \cdot \mathrm{CO} \cdot \mathrm{CHO}$

$\longrightarrow \mathrm{CH}_{3} \cdot \mathrm{CO} \cdot \mathrm{CHO}$

Pyruvic Aldehyde.

$\mathrm{CH}_{3} \cdot \mathrm{CH}(\mathrm{OH}) \cdot \mathrm{COOH}$

Lactic Acid.

It is also possible that the isomeride of glyceric aldehyde, namely, dihydroxy acetone, $\mathrm{CH}_{2}(\mathrm{OH}) \cdot \mathrm{CO} \cdot \mathrm{CH}_{2} \cdot(\mathrm{OH})$, is formed in the first stage of the reaction. The question arises then as to which of these possible intermediary products (if any) is formed when dextrose is converted by yeast into ethyl alcohol. Lactic acid is a possible intermediary product, for on treatment with sulphuric acid it can be converted into a mixture of formic acid and acetaldehyde-

$$
\mathrm{CH}_{3} \cdot \mathrm{CH}(\mathrm{OH}) \cdot \mathrm{COOH}=\mathrm{CH}_{8} \cdot \mathrm{CHO}+\mathrm{H} \cdot \mathrm{COOH} \text {; }
$$

and acetaldehyde on reduction yields ethyl alcohol. Acetaldehyde can also be derived from pyruvic aldehyde, which on oxidation yields pyruvic acid, $\mathrm{CH}_{3} \cdot \mathrm{CO} \cdot \mathrm{COOH}$, from which by scission of carbon dioxide acetaldehyde is formed, and Neuberg has actually shown that this reaction takes place in the presence of yeast. Numerous investigations have been carried out on the action of yeast on almost all the possible intermediary products, with the object of ascertaining whether they give rise on fermentation to ethyl alcohol. The results obtained so far by this method 
do not definitely decide the question of the stages through which dextrose passes when it undergoes the ordinary process of yeast fermentation. Enough has been said, however, to indicate the value of researches of this description, for it is not at all improbable that dextrose undergoes in the body of higher animals changes similar to those produced in yeast fermentation. One investigator, in fact, claims to have isolated ethyl alcohol from mammalian blood and tissue, although this statement has not been confirmed by later investigators.

Another interesting observation on yeast fermentation may be quoted here. Felix Ehrlich has shown that the amyl alcohols of fusel oil formed as by-products in alcoholic fermentation owe their origin, not to the sugar, but to the leucine and isoleucine derived from the hydrolysis of the proteins present in the fermenting liquor. The reactions can be represented by the following equations :-

$$
\begin{aligned}
& \text { (1) }\left(\mathrm{CH}_{3} \cdot\right)_{2} \mathrm{CH} \cdot \mathrm{CH}_{2} \cdot \mathrm{CH}\left(\mathrm{NH}_{2}\right) \cdot \mathrm{COOH}+\mathrm{H}_{2} \mathrm{O} \\
& \text { Leucine. } \\
& =\left(\mathrm{CH}_{3}\right)_{2} \cdot \mathrm{CH} \cdot \mathrm{CH}_{2} \cdot \mathrm{CH}_{2}(\mathrm{OH})+\mathrm{CO}_{2}+\mathrm{NH}_{3} \\
& \text { Isoamyl Alcohol. } \\
& \text { (2) } \mathrm{CH}_{3} \cdot \mathrm{CH}\left(\mathrm{C}_{2} \mathrm{H}_{5}\right) \cdot \mathrm{CH}\left(\mathrm{NH}_{2}\right) \cdot \mathrm{COOH}+\mathrm{H}_{2} \mathrm{O} \\
& \text { Isoleucine. }
\end{aligned}
$$

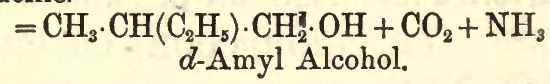

Other amino-acids can be degraded in the same way. The method of experiment consisted in the addition of various amino-acids to sterile sugar solutions and fermentation under aseptic conditions with pure cultures of yeast. The higher alcohols produced under these conditions were isolated, identified, and estimated. The amounts of higher alcohols obtained corresponded closely with the amount and character of the amino-acid present. It is not unlikely that amino-acids undergo a similar deaminization in the bodies of higher animals. 


\section{CHAPTER VII.}

THE CHEMICAL PROCESSES TAKING PLACE IN PLANTS.

A LARGE variety of chemical products has been isolated from plants which include, in addition to fats, carbohydrates, and proteins, such substances as the tannins, essential oils (such as turpentine oil, to which camphor and certain resins are chemically allied), basic substances (alkaioids), and the various pigments. Although many of these products have been investigated in detail, and their constitution has been determined, practically nothing is known with regard to their method of formation in the plant and to their function. In fact, the study of the biochemistry of plants is still in a very rudimentary stage. Nevertheless, there are certain fundamental facts which have been discovered which throw considerable light on the part played by plants in the general economy of nature.

It has already been stated that the chief foodstuffs of animals are the fats, carbohydrates, and proteins, substances of considerable chemical complexity, which in the organism undergo processes of degradation and oxidation, yielding thereby a source of energy for the maintenance of animal heat and for locomotion. The necessary foodstuffs are elaborated by the plants, or at any rate by the higher phanerogamous plants, from comparatively simple materials. Plants, therefore, act as the synthetic agents which manufacture 
the food supply of the higher animals. The materials from which these foods (fats, carbohydrates, and proteins) are built up are supplied by the atmosphere and the soil. The carbohydrates are formed by the plant from carbon dioxide and water vapour, whilst the nitrogen necessary for the protein formation can be obtained from inorganic substances such as the nitrates. It is probable that the fats are formed by some kind of transformation of the carbohydrates, from which the proteins are also formed by the inter-reaction of a nitrogenous substance with some derivative. The methods by means of which transformations of this character are produced are at the present moment simply matters of speculation, and practically nothing is known of the intermediary stages of the synthesis of fats and proteins in the plants. The two main facts which are known with certainty are-(1) that plants can synthesize carbohydrates from the carbon dioxide of the air and water vapour, and (2) that they can utilize inorganic nitrogen compounds and, indirectly under certain conditions, the nitrogen of the air for building up complex organic nitrogenous compounds. To a brief discussion of these two facts the major portion of this chapter will be devoted.

\section{SYNTHESIS OF CARBOHYDRATES IN PLANTS.}

The first important observation on the gaseous metabolism of plants was made by Priestley in 1772. He showed that if plants are grown under a bell-jar in air which has been rendered unfit for respiration and for the support of combustion by keeping an animal for a long time within the space enclosed, this air, after a certain period, could be altered by a plant in such a way as to be fit again both for respiration and combustion. The experiments of Priestley did not, however, yield constant 
results, and the reasons for this variability were discovered somewhat later by Ingenhouss, who showed that improvements in the properties of vitiated air were due entirely to the green parts of plants, and that the action took place only in sunlight. The exact reasons for the improvement of vitiated air by plants were not clear to either of the above-mentioned investigators. The subsequent researches of Senebier, de Saussure, and Boussingault have demonstrated, however, that plants take up the carbon dioxide of the air and evolve oxygen. It was found that the ratio of the carbon dioxide absorbed to the oxygen evolved $\left(\frac{\mathrm{CO}_{2}}{\mathrm{O}_{2}}\right)$ was approximately 1 (it is actually a little less). In other words, the carbon dioxide appears to undergo some reduction process in the green part of plants in the presence of sunlight.

The evolution of oxygen by a green plant can be readily demonstrated in the following manner. A water plant, such as Elodoea, is allowed to grow in water and is covered by a filtering funnel, over the tube of which is inserted a test-tube filled with water. On exposure to light, bubbles will be observed to be evolved, which will pass up the funnel and collect in the test-tube. This gas will be found to consist of oxygen.

The fact that carbon dioxide is taken up from the air can be demonstrated by passing air over a leaf exposed to sunlight in a chamber and analyzing it before and after its passage.

Two other important observations in connection with the carbon dioxide assimilation by plants must be recorded; firstly, as shown by Saussure, the absorption of carbon dioxide is accompanied by the formation of starch, and secondly, as demonstrated by Engelmann, the presence of chlorophyll is necessary. 
The demonstration of the starch formation can be made by partly covering a leaf with tinfoil and exposing it to the light; it is then decolorized by treatment with alcohol and placed in a solution of iodine in caustic potash solution. The parts of the leaf which were covered with the tinfoil will be coloured brown, whereas the parts exposed to light will assume a blue colour due to the presence of the starch.

A series of experiments was carried out by Timiriazev with the object of determining which rays were the most active in causing the assimilation of carbon dioxide by the plant. It was found, when leaves were exposed to different parts of the spectrum, that the greatest amount of activity took place in the red region, between the Fraunhofer lines $\mathrm{B}$ and $\mathrm{C}$, with a second region of maximal activity in the blue region at $F$. These are precisely the kinds of light absorbed by chlorophyll solutions, which show absorption bands in these parts of the spectrum. The chlorophyll appears therefore to absorb the light, which forms the source of energy for the building up of the complex substances in the plant. The absorption of light for the purposes of synthesis is probably not the only function of the chlorophyll. Recent researches of Willstätter and his pupils have shown that no less than four pigments are contained in the crude chlorophyll solutions which are held in certain rounded bodies in the leaf known as chloroplasts. These are carotin, $\mathrm{C}_{40} \mathrm{H}_{56}$; xanthophyll, $\mathrm{C}_{40} \mathrm{H}_{56} \mathrm{O}_{2}$; chlorophyll $a, \mathrm{C}_{55} \mathrm{H}_{72} \mathrm{O}_{5} \mathrm{~N}_{4} \mathrm{Mg}$; and chlorophyll $b$, $\mathrm{C}_{55} \mathrm{H}_{70} \mathrm{O}_{6} \mathrm{~N}_{4} \mathrm{Mg}$. The exact functions of these four pigments have not yet been determined.

The method of the formation of starch from carbon dioxide and water vapour may be formulated in the following way :-

$$
n\left(6 \mathrm{CO}_{2}+5 \mathrm{H}_{2} \mathrm{O}\right)=\left(\mathrm{C}_{6} \mathrm{H}_{10} \mathrm{O}_{5}\right)_{n}+6 n \mathrm{H}_{2} \mathrm{O}
$$


and dextrose is probably formed as an intermediary product-

$$
6 \mathrm{CO}_{2}+6 \mathrm{H}_{2} \mathrm{O}=\mathrm{C}_{6} \mathrm{H}_{12} \mathrm{O}_{6}+6 \mathrm{O}_{2}
$$

The gaseous exchange in the leaf takes place through openings on the surface (which in most plants are chiefly on the under-surface), which are known as the stomata. Starch formation takes place with great rapidity after exposure to light, and can be detected within a few minutes. The exact mechanism of starch production is unknown.* It has been suggested by Bayer that the first assimilation product of the carbon dioxide is formaldehyde. It is known that this substance in the presence of alkalis readily polymerizes to form hexoses-

$$
6 \mathrm{CH}_{2} \mathrm{O}=\mathrm{C}_{6} \mathrm{H}_{12} \mathrm{O}_{6}
$$

It has been shown by Fenton that carbon dioxide can be reduced to formaldehyde by amalgamated magnesium, and other methods of reducing it to the aldehyde have also been described. Formaldehyde, furthermore, can be detected in the growing plant. It has not been proved, however, that this arises from the reduction of carbon dioxide, for thin films of chlorophyll, when exposed to sunlight, even in the absence of this gas, also give rise to the aldehyde, which is a product of photochemical decomposition of a large number of organic substances. Nevertheless, the formation of formaldehyde from carbon dioxide as an intermediary product of assimilation to starch is not at all improbable; in fact, it has been shown that plants can produce starch when grown in very weak solutions of formaldehyde (which in stronger solutions is highly toxic) or in solutions of the less toxic bisulphite compound.

* A recent monograph by Willstätter and Stoll on carbon assimilation has appeared which was not available to the author at the time of this book going to press.

$(1,097)$ 
THE UTILIZATION OF NITROGEN OF INORGANIC COMPOUNDS.

It is easy to demonstrate that plants can grow when the only source of nitrogen at their disposal is that present in inorganic salts. If a seedling is supported in a vessel with the roots immersed in a solution containing the necessary elements, and the upper part of the plant free in the air, it will grow normally, provided that the nutrient solution employed is one adapted to the plant under investigation. This method of investigating plant growth is known as that of water-culture. The elements which appear to be necessary for the normal growth of the higher plants are the following:-Nitrogen, sulphur, phosphorus, potassium, calcium, magnesium, and iron, and sometimes chlorine. It is not proposed to consider in detail the function of all these elements. Nitrogen, sulphur, and phosphorus form part of the various organic constituents of the plants, such as the proteins, nucleo-proteins and lipoids; and magnesium, as has already been stated, enters into the molecule of the two chlorophylls. For the purpose of making water-cultures, the composition of the nutrient medium can be varied for different plants. One solution, which is very largely employed, contains the following salts in the proportions given:

Potassium nitrate

Potassium hydrogen phosphate $\left(\mathrm{KH}_{2} \mathrm{PO}_{4}\right)$.

Magnesium sulphate

Calcium nitrate

1 part.

$.1 \%$

$.1 \%$

. 4 parts.

with a trace of iron salts.

A solution containing salts in these proportions is generally known as Knoop's fluid, and is employed in concentrations of 0.1 per cent. of solids for young plants, 
which may be increased to 0.5 per cent. for those in more advanced stage of growth. If any of the necessary elements is omitted from this solution, the growth of the plant will be stunted if not entirely arrested. From solutions containing nitrogen, sulphur, and phosphorus in the simple forms given above, the plant can elaborate complex organic products containing these elements. Practically nothing is known of the chemical mechanisms by means of which this result is accomplished.

In the normal method of cultivating plants, the roots are embedded in the soil, in which the greater part of the nitrogen is contained in the form of complex organic substances, which are often added to it in such forms as that of farmyard manure, when it has been impoverished by the growth of crops. From the soil the growing plant, with the exception of some of the lupines, which will be discussed later, draws the whole of its nitrogen supply. The majority of plants are quite incapable of utilizing in any way the nitrogen of the air for the building up of complex nitrogenous substances.

The question next arises-In what form is the nitrogen withdrawn from the soil by the plant? Is it possible for the plant to utilize directly the complex organic nitrogenous compounds of the soil, or must these undergo some transformation in the soil before utilization by the plant?

The soil, as has been already stated, generally contains the greater part of its nitrogen in the form of organic compounds, but these are also accompanied by smaller amounts of nitrogen in the form of ammonium salts and nitrates. Now it was shown by Boussingault in 1871 that nitrates can be formed from the organic nitrogenous compounds of the soil. Some soil, in which the organic nitrogen and nitrates had been estimated, was allowed to remain for twelve years in very large closed glass bottles. 


\section{Biological Chemistry.}

At the expiration of this period it was again analyzed, and it was found that the amount of organic nitrogen had diminished, whereas the quantity of nitrates had increased. In 1877 Schlösing and Müntz carried out some experiments which indicated that the nitrification (nitrate formation) of the organic nitrogen compounds was probably due to the presence of bacteria. They allowed ammoniacal sewage water to pass slowly through a filter of sand and chalk, and found that part of the ammonium salts was converted into nitrates. If, however, the filter bed had been treated with chloroform, nitrate formation did not take place. The actual isolation of nitrifying organism in the soil is due to Winogradsky (1890). This observer succeeded in isolating three classes of bacteria which take part in the nitrification process. Of these, two classes, namely nitrosomonas and nitrosococcus, of which the latter is found on the American continent, can, under suitable conditions of cultivation, convert ammonium salts into nitrites. A third class of bacteria, nitrobacter, converts nitrites into nitrates. These bacteria by themselves will not, however, convert organic nitrogen compounds into nitrates; ammonium derivatives must first be formed before the above nitrifying bacieria can carry out the process of nitrification. There is a large number of organisms, however, which can bring about the formation of ammonia from complex organic compounds; in fact, ammonia is a common product of putrefaction, and is produced in appreciable quantities when proteins are allowed to undergo putrefactive decay. Omeliansky has shown that when the source of nitrogen contains only complex organic compounds it can serve as a source of nitrates when submitted to the action of three species of bacteria. Using a substrate, of which the nitrogen source was a meat bouillon, he obtained nitrates, when the following three bacteria were 
cultivated thereon:-Bac. ramosas, nitrosomonas, and nitrobacter. With the first-named alone, only ammonium salts were produced from the bouillon; and with the two last-named alone, the bouillon remained unchanged. With the first two the nitrification was carried only to the nitrite stage. To produce nitrates from the bouillon the co-operation of all three classes of bacteria was necessary, and the nitrification took place in three stages. The various other experiments indicate that plants make use of their nitrogen when it is offered in the form of simpler inorganic compounds, and Chili saltpetre (sodium nitrate) has for a long time been regarded as the source par excellence of the nitrogen for crops. Water-culture experiments show, at any rate, that nitrates can be used as the sole source of nitrogen for the building up of complex organic nitrogen compounds in plants, which in this respect act in marked contrast to animals which utilize the complex proteins as their chief source of nitrogenous food.

Certain lupines can, furthermore, indirectly utilize the nitrogen of the air for building up complex proteins. It was first observed by Lawes and Gilbert that leguminosæ (such as peas and beans) could grow continually in a soil to which no nitrogenous manure had been added without producing exhaustion of nitrogen. In fact, more nitrogen could be taken from the soil than had been added. The results of these experiments were in direct contradiction to those obtained by Boussingault, who found that leguminosæ would not grow in a soil which had not been supplied with nitrogenous material, and who drew from his results the conclusion that plants were unable to utilize the nitrogen of the air. The discrepancy between the observations of Lawes and Gilbert on the one hand, and of Boussingault on the other hand, was finally explained by Hellriegel and Wilfarth. The capacity of producing nitrogenous 
substances without the addition of nitrogenous manures is characteristic of the leguminosæ; other crops, such as the cereals, require the addition of nitrogenous manures, otherwise the soil becomes rapidly exhausted by the removal of its nitrogen. These crops, in fact, remove from the soil approximately the amount of nitrogen added to it. To Hellriegel and Wilfarth is due the credit of explaining the difference of the action of the leguminosæ and other plants. At the time of these investigations it was known that certain bacteria possessed the capacity of utilizing the nitrogen of the air. It was also known that leguminosæ usually formed certain small swellings on the roots, which are known as nodules. It was found by Hellriegel and Wilfarth that if leguminosæ are grown on sterilized soil the nodules do not develop. On the other hand, if the sterilized soil is treated with an extract of ordinary soil on which leguminosæ are grown, nodules will be formed. A heated extract of the soil was found, however, to be ineffective as regards the production of the nodules. These results explain the discrepancy between the observations of Lawes and Gilbert and of Boussingault, for the lastnamed had carried out his experiments on the nitrogen assimilation on plants growing in sterilized soil, whereas the first-named investigators had used ordinary untreated soil. The experiments also indicated the fact that the production of root-nodules was due to the intervention of bacteria-that is, to a "symbiosis" between the higher plant and a lower organism. Beyerinck and Prazmovski succeeded subsequently in isolating the nodule bacteria in the form of pure cultures, and in indicating the morphological relationship between the development of the nodules and the bacterial growth. Subsequent researches revealed later the existence of other bacteria capable of "fixing" the nitrogen of the air, notably of Clostridium pas- 
teurianum (Winogradsky) and of Azobacter chroococcum (Beyerinck); the former is anærobic (that is, grows in the absence of oxygen), whereas the latter is ærobic. These results are remarkable, as it is difficult to produce complex organic nitrogenous compounds directly from the nitrogen of the air by any simple chemical laboratory process.

\section{THE RÔLE OF THE GREEN PLANTS IN THE GENERAL}

\section{ECONOMY OF NATURE.}

From the foregoing remarks it will be evident that the plants play an important part in the synthesis of the more complex organic substances which are necessary for the nutrition of animals. The plants by means of the energy derived from the sun's rays utilize the carbon dioxide of the air and the nitrogen of the nitrates, and build up the carbohydrates, fats, and proteins. The animals, on the other hand, degrade these complex substances, oxidizing them and utilizing the energy thus obtainable for the maintenance of a body temperature higher than the surrounding space, and for the performance of muscular work. The chief end products of animal metabolism are carbon dioxide and urea, and the undigested or partially digested substances voided in the frces. These end products can serve as the chief sources of food for the plants. The carbon dioxide is reduced by them, and oxygen is a product of this action, and serves to regenerate an atmosphere vitiated by the products of animal expiration. The nitrogenous excretory products from the animal, furthermore, can be converted into nitrates by the action of various species of bacteria, and which serve directly as the nitrogenous food of plants. There is, therefore, a continuous cycle, the animals supplying the food of plants from their excreta, the plants building up therefrom the complex materials which by oxidation form the source of energy. 
for animal heat and locomotion. Synthetic processes also occur in the animal body during the formation of new tissues in the adolescent individual and in the repair of mature tissues in the adult, but such processes are quantitatively of subordinate character when compared with the amount of degradative action necessary for the maintenance of bodily heat and of locomotion.

If the products derivable from excreta and the dead bodies of animals were returned to the atmosphere and the soil they could be utilized for plant growth, and thus supply fresh material for animal nutrition. The same matter would thus pass alternately from animal to plant, and it would at first sight appear that, as regards carbon and nitrogen at any rate (the other materials such as phosphorus and sulphur having been omitted from the discussion), there need never be a dearth of animal foodstuff so long as the rays of the sun were available for the supply of the necessary energy for synthesis. In actual practice it is found, however, that the passage of matter from plant to animal and back again is not accomplished without considerable loss, especially as regards nitrogenous material. This nitrogenous loss can be accounted for in various ways. As already stated, ammonia is one of the chief products of the bacterial action on organic nitrogenous substances, and considerable quantities of this substance escape into the air, and are thus lost to the soil. Furthermore, nitrates are readily washed out of the soil by the rain and rendered unavailable as plant food. Small amounts of nitrogen are also set free from complex nitrogenous compounds by the action of bacteria. The general cycle of nitrogenous changes has been represented by Dr. E. J. Russell ("Fertility of the Soil," Cambridge, 1913, p. 25) by the following diagram:- 


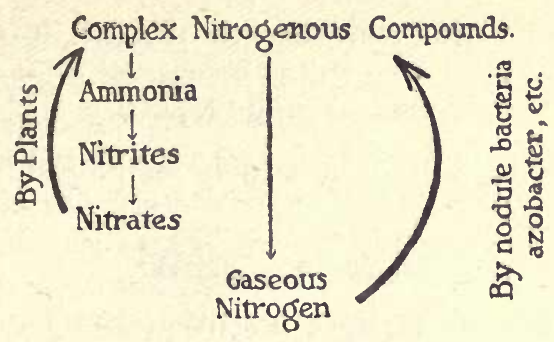

The loss of nitrogen either in gaseous form or as ammonia or nitrates is far from being compensated for by the action of the nodule bacteria, azobacter, etc., so that without artificial manures, the soil would be ultimately depleted of the nitrogen necessary for the growth of crops. This loss has, up to the present, been very largely replaced by the addition to the soil of Chili saltpetre, of which big natural deposits have been discovered. The supply of nitrogen from this source is, however, by no means inexhaustible, and many investigations have been carried out with the object of finding methods for obtaining the nitrogen of the air in such a form that it can be available as a source of food supply to plants.

The loss of nitrogen in a form suitable for plant nutrition, and the prospective exhaustion of natural nitrate stores, such as the Chili saltpetre, have stimulated investigation within recent years on the economical preparation of nitrates and other compounds in which the nitrogen derived from the air can be rendered available as a plant food. Nictric acid has been obtained by the oxidation of atmospheric nitrogen by an electrical discharge. Nitrogen has also been made to combine with hydrogen at high temperatures in the presence of a catalyst to form ammonia from which nitrate can be obtained by oxidation. Another method by means of which atmospheric nitrogen can be rendered available depends on the fact that when the 
gas is passed over calcium carbide it forms calcium cyanamide-

$$
\mathrm{CaC}_{2}+\mathrm{N}_{2}=\mathrm{CaCN}_{2}+\mathrm{C}
$$

which substance has been largely employed as a nitrogenous manure.

\section{Concluding Remarks.}

In the foregoing pages attention has been drawn to the methods of determining the structure of organic compounds, and examples have been given of some of the experimental processes which have been employed for ascertaining the changes they undergo within the living organism. It must be emphasized, however, that reference has been made only to a limited number of aspects of the branch of science included in the term biological chemistry. There are many other problems which have received, at the outside, the merest passing mention in this book, which entail a knowledge of that branch of chemical science which is generally known as physical chemistry. A few examples will suffice to illustrate this statement.

The animal cell contains as a rule, in addition to other substances, a mixture of fats, proteins, and carbohydrates, together with relatively large amounts of water. Such a collection cannot form a simple solution, but constitutes a complex heterogeneous system. Now it is an experimental fact that a cell can carry out all its functions in a normal manner only when its various chemical constituents exist together in a certain definite state of aggregation; certain oxidative processes, for example, will only take place when the cell is more or less intact. A study of the state of aggregation in the complex heterogeneous system existing in a cell entails some knowledge of the physics of surface action, of viscosity, of osmosis, and other factors.

Again, in the higher animals, the metabolites are 
carried to the various organs by the blood-stream, and undergo chemical changes within the cells, the products of these changes being afterwards removed and transported away by the blood. Actions of this description involve a knowledge of the conditions which render the cells permeable or otherwise to the substances with which the organs come into contact; again the investigator is faced with problems dealing with the state of aggregation in a heterogeneous system-this time of the materials forming the cell membranes.

As examples of other problems which involve a knowledge of physical chemistry may be mentioned those concerned with the processes of secretion, immunity, and the pharmacological action of drugs.

Nevertheless, as a preliminary to all such studies, it is absolutely essential that acquaintance should be made with the characters of the chief substances of which a living organism is made up, and a review of these characters constitutes a fitting "Introduction to the Study of Biological Chemistry." 


\section{N D E X}

Acetaldehyde, 79, 80.

Acetamide, 102.

Acetates, 88.

Acetic acid, 87, 89, 92, 183.

- "glacial," 92.

Acetic anhydride, 101.

Acetoacetic ether, synthetical reactions of, 114.

Acetone, 83, 84, 85.

Acetyl chloride, 100.

value of fatty acids, 188 .

Acetylene, 135.

hydrocarbons, 59. isomerism in, 61.

Acid amides, 101, 125.

anhydrides, 100.

chlorides, 100.

Acids, acetic, 87, 89, 92, 183.

acrylic, 121. amino, from hydrolysis of proteins, 223.

aminoacetic, 220.

arachidic, 184.

aspartic, 222, 227.

- behenic, 184.

brassidic, 184.

butyric, 183.

capric, 184.

caproic, 184.

caprylic, 184.

carboxylic, 87, 94, 105.

diamino-monocarboxylic, 222.

dibasic, 105.

dicarboxylic, 105, 115.

elaidic, 184.

erucic, 184.

fatty, 183 et seq. See Fatty

Acids.

formic, $87,89,91$.

gallic, $157,159$.

gluconic, 203, 204, 205.
Acids, glutamic, 222, 227.

- glutaric, 107.

- glycollic, 115, 116.

- glycuronic, 203.

- hydrocyanic, 132.

- hydroxy, 115.

161. in relation to polarized light, inosinic, 253.

isobutyl acetic, 184 .

iso-oleic, 184.

lactic, 116, 160.

lauric, 184.

- malic, 117.

- malonic, 106, 108.

mannonic, 202.

- methyl-butyl acetic, 194.

- monoamino-dicarboxylic, 222.

221. monoamino-monocar boxylic,

- myristic, 184.

301.

nucleic, $250,252,253,265,284$,

- oleic, 122, 184.

- optical activity of, 160, 162.

— oxalic, 105, 108.

- palmitic, 184.

- phosphoric, 250.

- phthalic, 158.

- propionic, 90, 93, 111.

- saccharic, 203.

- - sarcolactic, 160.

- stearic, 184.

— succinic, 107, 114, 118, 119.

—- sulphonic, 145.

- - sulphuric, 145.

- tartaric, 118, 161, 167, 206.

trihydroxy glutaric, 207.

unsaturated, 121.

uric, 254, 301, 308, 309.

- valeric, $91,93$. 
Adankiewicz reaction with tryptophan, 240.

Adenine, 250, 255.

Adenosine, 252.

Adipic acid, 107, 114, 115.

Aetioporphyrin, 257, 265.

Alanine, 221, 227, 306.

Albumin, 231, 234.

egg, 244.

in proteins, 227. serum in proteins, 227.

Albuminoid substances. See Proteins.

Albumoses, 260.

Alcohols, 64, 65 .

- allyl, 78, 79 .

— amyl, 76, 113, 318.

— butyl; 68 .

ethyl, 65, 75 .

isopropyl, 68.

methyl, 65, 75 .

oxidation of, 83.

polyhydroxy, 76.

primary, secondary, and ter-

tiary, 68, 69.

- propyl, 68, 75.

- synthesis of, 71, 72.

Aldehydes, 79 et seq.

- addition products of, 81.

- derivatives of benzene, 157 .

formic, 79 .

- glycollic, 198.

— oxidation of, 81 .

reactions of, 82.

substituted, 86.

Aliphatic compounds, 144.

Aliphatic-diazo compounds, 147.

Alkaptonuria, 311.

Alkyls, 64, 67.

Allantoin, 309.

Allyl alcohol, 78, 79.

- iodide, 135.

Amides, acid, 101.

Amines, 124.

- derivatives from aromatic, 147. primary, secondary, and tertiary, 126-129.

Amino-acids, 258.

Ammonia, production by bacterial action on organic substances, 330 . Ammonium compounds, 125, 129.

Amygdalin, 157, 218.

Amyl alcohols, 76 .
Amyl alcohols as by-products in alcoholic fermentation, 318 . - derived from leucine, 113.

Amyl nitrite, 97.

Anabolism, 10.

Anhydrides, acid, 100.

- of glucose, 217.

Aniline dyes, 149, 154.

Animal body, action of enzymes in, 299.

- chemical constituents of, 179 .

"Antigen," 247.

"Anti-serum," 247.

Arabinose, 205, 210.

Arbutin, 218.

Arginine, 222, 227, 245.

Argol, 118.

Aromatic amines, derivatives from, 147.

- compounds, 144.

—— hydroxyl derivatives, 146.

Bacteria, nitrification by, 326. 328.

Benzaldehyde, 157.

Benzene, 151.

- compounds, 149, 154.

— derivatives, 134.

tion of, 139.

_- halogen derivatives of, 153.

- nitro compounds of, 154 .

- substitution products of, 135,

136.

Benzoic acid, 158.

Biochemistry, scope of, 7 et seq.

Biuret reaction with proteins, 240 .

Boiling point, of dissolved substances, 39.

- of liquids, 16, 25.

Bromides, 64.

Butyl alcohols, 68.

Butyric acid, 91, 93, 111.

Calcium cyanamide, 332 .

- propionate, 85.

Caloric values of foodstuffs, 272.

Cane-sugar, 213.

Carbohydrates in foodstuffs, 270, 272.

- of animal body, 191 et seq.

—_ summary, 218. 
Carbohydrates, synthesis in plants, 320.

Carbolic acid, 146, 155.

Carbon, estimation of, 28.

- identification of, 22 .

Carbon dioxide, assimilation by plants, 321.

Carboxylic acids, 87, 94, 105.

Caseinogen, 244, 256.

- - in proteins, 227.

Catechol, 156.

Cellulose, 215.

Cherry-gum, 216.

Chloral, 86.

Chlorhydrins, 78.

Chlorides, 64 .

- acid, 100.

Chloroform, 64.

Chlorophyll, 257, 265, 322.

Cholesterol, 190.

Citric acid, 120.

"Coagulum," 237.

Colloids, 234.

Copper acetates, 93.

Cresols, 155.

Crystallization, 13.

resolution of racemic acid forms by, 175.

"Crystalloids," 234.

Cuprous oxide, 81 .

Cyanates, 133.

Cyanides, 88, 133.

Cyanogen, 131.

Cymene, 153.

Cystine, 222, 227.

Cystinuria, 311.

Cytidine, 252.

Cytiosine, 250, 251, 255.

Dextrose, 193, 216, 217. complex changes undergone in animal body, 316 .

- reactions of, 195.

Diabetes, experimental investigations in, $311,314$.

Diazo compounds, 147.

Diazonium compounds, 147.

Diazotization, 147.

Dibasic acids, 105.

Dicarboxylic acids, 105, 115.

Diethyl sulphate, 97.

Dipropargyl, 135.
Disaccharoses, 213.

Distillation, 17.

Dulcite, 78.

Edestin, 244.

Eggs, 278.

Enantio-morphs, 170.

- - resolution of racemic acid forms into, 177.

Enzymes, 75, 299.

- examples of action on animal body, 299.

- nature of action, 287, 288.

Erythritol, 78.

Esbach's reagent for proteins, 238.

Esters, 94-99, 122.

Ethyl acetate, 97, 98.

- - acetoacetate, 114.

- alcohol, 65, 75.

ether, 122.

- hydrogen sulphate, 97.

- malonate, synthesis by, 109.

- nitrate, 96.

- nitrite, 96.

Ethylene glycol, 76.

- hydrocarbons, 56.

Fæces, analysis of, 279.

Fats, 180 et seq.

- analysis of, 276.

- extraction of, from tissues, 182.

- methods of characterizing, 183.

- summary of chemistry of, 188.

Fatty acids, 81, 87, 183.

— in organism, 309. derivatives of, 100.

Fehling's solution, 81, 195.

Fenton's reagent, 204.

Fermentation, alcoholic, 75.

- - of sugars, 212.

Ferments, nature of action of, 288, 292.

- products of proteins obtained by, 259.

Flour, 278.

Foodstuffs, analysis of, 273, 276.

caloric values of, 272 .

- organic constituents of, 270.

Formaldehyde, in plants, 323.

- - reaction with glycine, 262.

Formalin, 79.

Formates, 88. 
Formic aldehyde, 79.

Freezing-point of dissolved substances, 39.

Fructose. See Lævulose.

Furfural, 210, 252.

Galactoses, 200, 211.

Gaseous metabolism of plants, 320.

Gaseous products of metabolism, 273,274 et seq.

Gases, molecular weight of, 37.

Gelatin, 236, 244. in proteins, 227.

Gliadin, 244.

Globulins, 231, 234, 235.

—— tests for, 238, 239.

Glucose. See Dextrose.

Glucoses, 199.

Glucosides, 216.

Glutenins, 232, 244.

Glycerine, 77.

Glycerol, 77.

- esters derived from, 98.

Glycine, 220, 221, 227.

- alanyl, 229.

- glycyl, 261.

- glycyl glycyl, 229.

- leucyl alanyl, 229.

Glyco-proteins, 256.

Glycogen, 215.

Glycollic aldehyde, 198.

Glycols, 76, 77.

- esters derived from, 98.

Grignard's method, 72.

Guanine, 250, 251, 255.

Guanosine, 252.

Guloses, 200, 203.

Hæmin, 257.

Hæmoglobins, 233, 256, 265.

Halogen derivatives of hydrocarbons, 62.

Halogens, 56.

- differences in action on aromatic compounds, 144.

- identification of, 23.

Haussmann numbers of proteins, 242.

Helicin, 218.

Heller's test for proteins, 237.

Hexone bases, 220.

Hexoses, 208, 211.
Histidine, 222, 227, 245.

Histones, 230.

Hydrazone, 82.

Hydrocarbons, 151.

- acetylene series, 59.

- chemistry of, 48-53.

— ethylene, 56.

- halogen derivatives of, 62 paraffin, 5l, 53.

Hydrogen, estimation of, 28.

- identification of, 22.

Hydrolysis by enzymes, 294.

- of fats, 181.

— of nucleic acids, 250.

- of proteins, 221, 223.

- reversible, 297.

Hydroquinone, 156.

Hydroxy acids, 115.

Hydroxylamine, 82.

Hydroxyls, 62, 64 .

- derivatives of aromatic com. pounds, 146.

Hydroxyproline, 223, 227.

Hydroxyquinol, 157.

Hypoxanthine, 250, 255, 301.

Idoses, 200.

Inulin, 216.

Iodides, 64 .

"Iodine Number" of fatty acids, 185.

Iodoform, 65 .

Isocyanides, 133.

Isoleucine, 222, 227.

Isomerides, 51, 160.

Isomerism, 51 .

- in acetylene series of hydro. carbons, 61 .

- in sugars, 199.

Isonitriles, 130, 133.

Isopropyl alcohol, 68.

Katabolism, 10.

Keratin, in proteins, 227.

Ketones, 83.

- substituted, 86.

Knoop's investigations on intermediary products, 309.

Kyrines, 259.

Lactic acid, 116.

- as intermediary product, 37 . - isomerism of, 160 . 
Lactones, 202.

- mono-, 202.

Lactose, 214.

Lævulose, 194.

- reactions of, 195 .

Lead acetate, 93 .

Le Bel's theory, 169.

Lecithin, 190.

Leucine, 221, 227. 113.

Light, polarization of, 161 .

Lipase reaction by enzymes, 298.

Lipoids, 277.

- of animal body, 189.

Liquid substances, analysis of, 16$21,25$.

Lupines, 325, 327.

Lysine, 222, 227, 245.

Maltose, 213.

Mannans, 216.

Mannite, 78.

Mannose, 199, 202, 211.

Meat, 278.

Melting point of solids, 15, 25.

Mesitylene, 141, 153.

Meso-tartaric acid, 173.

Metabolism, 10.

- abnormalities in pathological conditions, 311.

analogy with biochemical changes by micro-organisms, 316. - chemical examination after experimental feeding, 314 .

- gaseous products of, 273.

— intermediary, 285.

311.

in pathological subjects,

— investigation by administration to animals of intermediary products, 307.

303.

- total, of the organism, 268.

vestigations of, 280 .

Metals, identification of, 24.

Methane, 48.

Methyl alcohol, 65, 75.

- chloride, 64 .

- glucosides, 216.
Methyl glucosides, hydrolysis by enzymes of, 294.

Micro-organisms, biochemical changes analogous to metabolic processes produced by, 316 .

Milk, 277.

Milk-sugar, 214.

Millon's reagent for proteins, 240.

Molecular weight of compounds, 37.

Monosaccharoses, isomerism in, 199.

Nicol prism, 162.

Ninhydrin reaction with proteins, 241.

Nitrification by bacteria, 326 .

Nitriles, 130, 133.

Nitrobenzene, 154.

Nitrogen, alkyl derivatives of, 124 .

- compounds, 130.

- diamino in proteins, 245.

- distribution in protein derivatives, 242.

- estimation of, 31. identification of, 22 .

utilization by plants of inorganic compounds of, 324.

Nodules in plant roots, formation of, 328.

Nucleo-proteins, 248.

Nucleotides, 250.

Nutrition of organisin, 280.

Oils of animal body, 180 .

Olefines, 56.

Optical activity of acids, 160, 162.

Organic compounds, estimation of, 28 et seq.

- identification of, 12 et seq. molecular weight of, 37.et seq.

- qualitative analysis of, 22-24.

"Osone," 197.

Oximes, 82, 196.

Oxygen, compounds with hæmoglobin, 257.

_ evolution by plants, 321 .

- identification of, 22.

Oxygenation of blood, 269.

Oxyhæmoglobin, 257.

Paraffin hydrocarbons, 51, 53-56.

Paraformaldehyde, 80.

Penicillium glaucum, 176. 
Pentoses, 207, 208, 209, 210.

"Peptide" linkage, 228, 260.

Peptones, 233, 260.

Peraldehyde, 80.

Perfusion, method of investigating intermediary metabolism, 303.

Phenols, 146, 155.

—- dihydroxy, 156.

- trihydroxy, 157.

Phenylalanine, 222, 227.

Phenyldiazonium chloride, 147, 149.

Phenylhydrazine, 150.

- action on sugars, 196.

Phenylhydrazones, 82.

Phloridzin, 218.

Phloroglucinol, 157.

Phosphoric acid, 250.

Phosphorus, estimation of, 36.

- identification of, 23.

in plants, 324 .

Plants, chemical processes in, 319332.

metabolism of, 268.

nucleic acids of, 265 .

organic constituents of, 324 .

rôle in general economy of nature, 329.

Polarization of light and acids, 161.

Polypeptides, 228, 258, 264, 265.

Potassium cyanide, 131, 133.

- ferrocyanide, 130.

"Precipitin," 247.

Prolamines, 231.

Proline, 223, 227.

Protamines, 230.

Proteins, 219 et seq., 270.

- acid or alkali albumins yielded by, 259.

__ alcohol soluble, 231.

247.

biological differentiation of,

- biological importance of chemi-

cal investigation, 247.

_- classification of, 230.

colour reactions of, 239 .

conjugated, 232, 248.

derived, 233, 258-265.

general properties of, 236 .

glyco-, $232,256$.

hæmoglobin, 256.

hydrolysis of, 223.

- hydrolysis products of, 221, 259.
Proteins, meta-, 233.

methods for identification of individual, 241.

—— nucleo-, 232, 248.

- phospho-, 233, 256.

- preparation of simple, 234.

sclero-, 232, 236.

simple, 230.

sulphur content of, 242.

utilization value of, 281 .

Proteoses, 233, 260.

Prussic acid, 131.

Purine, 254.

Pyrogallol, 157.

Qualitative analysis, 22.

Quantitative organic analysis, 24 et seq.

Quantitative separation by solvents, 14, 24 et seq.

Racemic acid, 162, 167.

Racemic acid forms, resolution of, 175.

Reichert-Meissl value of fatty acids, 187.

Resorcinol, 156.

Root-nodules, production of, 328 .

Ruff's reaction, 204.

Salicylic acid, 159.

Salmine, 227, 244.

Sandmeyer's reaction, 148.

Saponification, 91, 98, 99.

- value of fatty acids, 184.

Sarcolactic acid, 160.

Semicarbazide, 82.

Serine, 222, 227.

Sinigrin, 218.

Sodium acetate, 93.

Sodium compounds obtained from malonic esters, 109.

Solid substances, analysis of, 13 .

Solvents, determination of differences in temperature of, 39 .

- elimination of, 25.

- use of, 14.

Sorbite, 78.

Soya-bean, enzymes in, 279,302 .

Starch, 214. 
Starch formation by plants, 321, 322.

Stereoisomerism, 160-178.

Strophanthin, 218.

Sublimation, 20.

Substitution products, 89 . of benzene, 135.

Sucrose, 213.

Sugars, 192.

- alcoholic fermentation of, 212. conversion of, 201 et seq.

- general characters of, 198.

_ stereoisomerism of, 199 et seq.

synthesis of, 211.

Sulphanates, 145.

Sulphonic acids, 145.

Sulphur, in plants, 324. content of proteins, 242. identification of, 23.

Sulphuric acid, action on aromatic compounds, 145.

Synthesis of sugars, 211.

Taloses, 200.

Tartar emetic, 120.

Tartaric acid, 118, 206.

- isomerism of, 161.

- Pasteur's researches on, 167.

Temperatures of dissolved substances, 39.

Thymine, 250, 251, 255.

Thymol, 156.

Thymus gland, nucleo-proteins from, 249.
Thymus gland, nucleic acid from, $252,253$.

Toluene, 152.

Trioxymethylamine, 80 .

"Tristearine," 181.

Tryptophan, 223, 226, 227, 240, 247.

Tyrosine, 222, 227, 247.

Uracil, 250, 255.

Urea, 8, 102.

Uric acid, relationship of, 254, 301, $308,309$.

Uridine, 252.

Urine, analysis of, 279, 283.

Valine, 221, 227.

Van 't Hoff's theory, 169.

Vegetables, 278.

Vinegars, 92.

Volatile substances, molecular weight of, 37.

Weight, molecular, 37.

Wijss, solution of, 186.

Wood-gum, 216.

Xanthine, 250, 255, 301, 308, 309.

Xylenes, 153.

Xylose, 210.

Yeast, 290, 291. action of, 316. nucleic acid from, 252. nucleo-proteins from, 249.

THE END. 



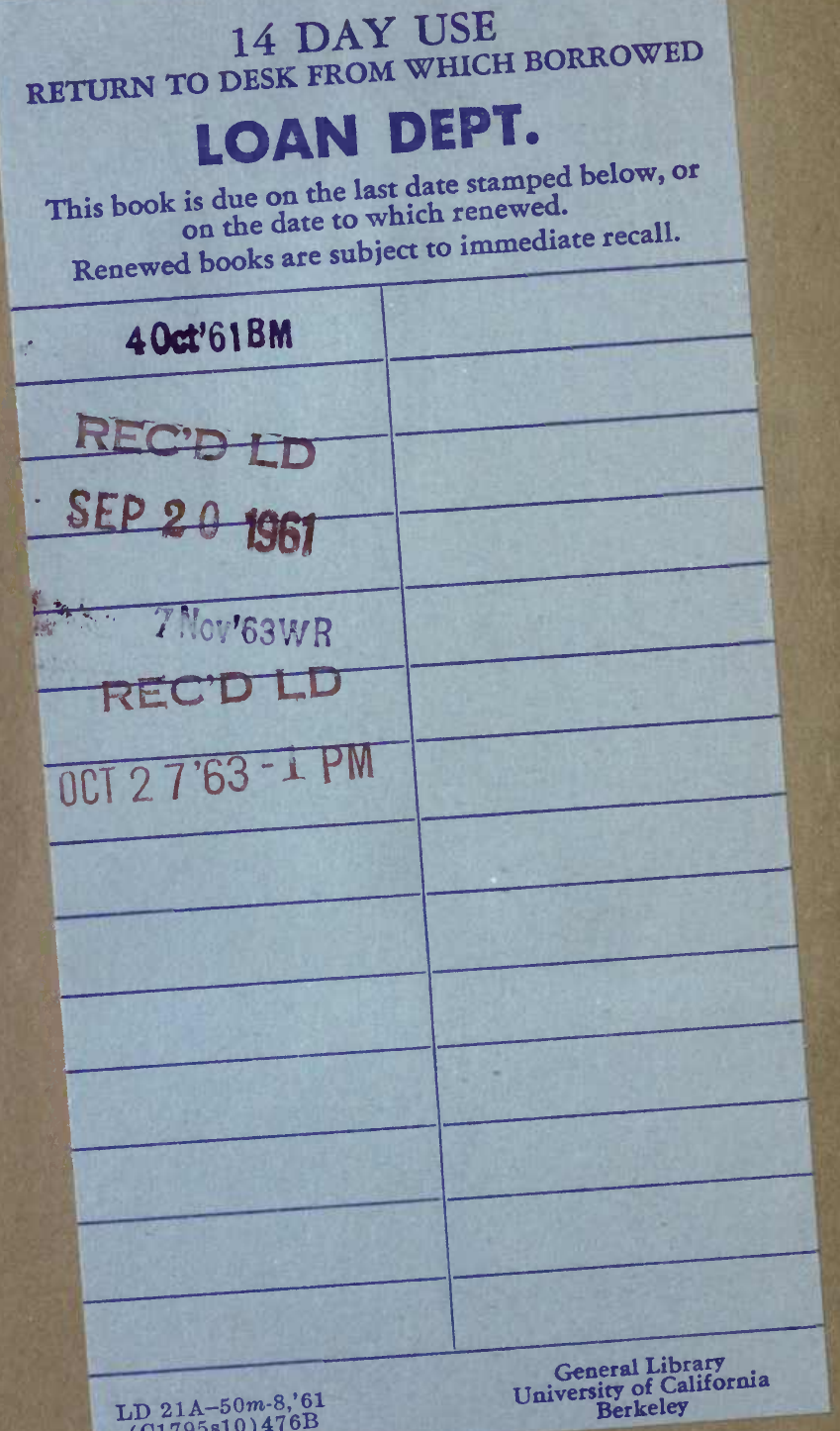


$x^{2}+2 x$

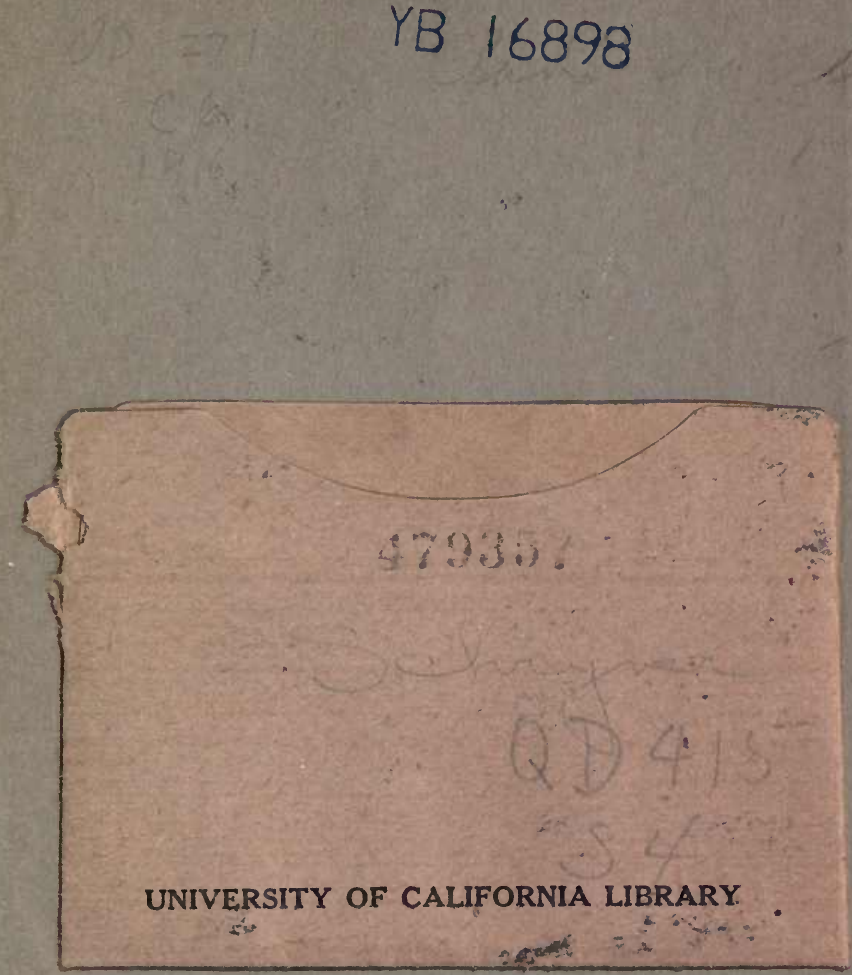


